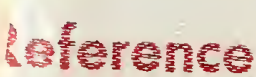

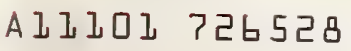

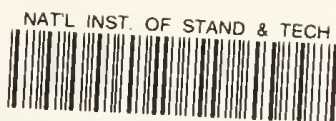

Allidob 97908?

NBSIR 78-1438

\title{
Back-Up Report for the Proposed Standard for the Flammability (Cigarette Ignition Resistance) of Upholstered Furniture, PFF 6-76
}

Joseph J. Loftus

Center for Fire Research National Engineering Laboratory National Bureau of Standards

Washington, D.C. 20234

June 1978

Final Report

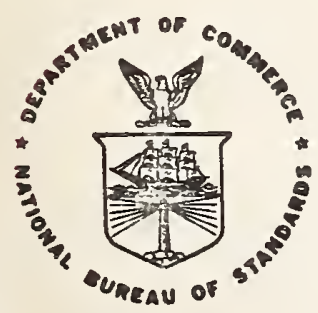


NBSIR 78-1438

BACK-UP REPORT FOR THE PROPOSED STANDARD FOR THE FLAMMABILITY (CIGARETTE IGNITION RESISTANCE) OF UPHOLSTERED FURNITURE, PFF 6-76

Joseph J. Loftus

Center for Fire Research

National Engineering Laboratory

National Bureau of Standards

Washington, D.C. 20234

June 1978

Final Report

U.S. DEPARTMENT OF COMMERCE, Juanita M. Kreps, Secretary

Dr. Sidney Harman, Under Secretary

Jordan J. Baruch. Assistant Secretary for Scionce and Technology

NATIONAL BUREAU OF STANDARDS, Emest Ambler, Director 
CONTENTS

Page

LIST OF FIGURES . . . . . . . . . . . . . . . . . v1

LIST OF TABLES . . . . . . . . . . . . . . . . vi

Abstract .......................... . . . 1

1. INTRODUCTION . . . . . . . . . . . . . . . . 1

2. OBJECTIVE . . . . . . . . . . . . . . . . 2

2.1. The National Household Fire Survey . . . . . . . . 2

2.2. The Flammable Fabrics Accident Case and

Testing System (FFACTS) . . . . . . . . . 3

2.3. Analysis of Fire Accident Scenarios by the Fire

Incidence Data Organization (FIDO) Maintained by

the National Fire Protection Association (NFPA) . . . 4

2.4. Notice of Finding -- Federal Register,

November 29, 1972 . . . . . . . . . . . . 5

2.5. Development of the Proposed Standard . . . . . . 5

3. SWRI RESEARCH (IDENTIFICATION OF THE HAZARDS) . . . . . . 6

4. CFR - EXAMINATION OF THE PROBLEM . . . . . . . . . . 6

5. TESTING PHASE I . . . . . . . . . . . . . . 7

6. TESTING PHASE II . . . . . . . . . . . . . . 7

7. TESTING PHASE III . . . . . . . . . . . . . 9

8. TESTING PHASE IV . . . . . . . . . . . . . 9

9. PLANT VISITS . . . . . . . . . . . . . . . . . 9

10. TEST APPARATUS FOR MOCK-UP UPHOLSTERED FURNITURE TEST • . . 9

11. TESTING PHASE $V$ - SEVEN-LAB EVALUATION OF THE MOCK-UP

UPHOLSTERED FURNITURE TEST METHOD . . . . . . . . . 10

12. TESTING PHASE VI - DEVELOPMENT OF A FABRIC CLASSIFICATION

TEST METHOD . . . . . . . . . . . . . . 11

13. TESTING PHASE VII - SIX-LAB EVALUATION OF FCT TEST METHOD - 12

14. TESTING PHASE VIII - FIFTY-FIVE-LAB EVALUATION OF THE MOCK-UP UPHOLSTERED FURNITURE AND FABRIC CLASSIFICATION TEST METHODS . . . . . . . . . . . . . . . 
CONTENTS (cont'd)

Page

15. TESTING PHASE IX - STANDARD FABRICS ........ 15

16. OTHER TESTS AND REPORTS . . . . . . . . . 16

17. DISCUSSION . . . . . . . . . . . 17

17.1. The Standard ............. . 17

17.2. The Standard's Reasonableness ......... . 17

17.3. The Standard's Appropriateness . . . . . . . . 19

17.4. The Standard's Technological Feasibility ..... 20

17.5. The Standard's Cost ............ 21

17.6. Toxicity of Combustion Products from Materials

Treated with Fire Retardants . . . . . . . . 22

18. CONCLUSIONS . . . . . . . . . . . 22

19. REFERENCES ...................... 23

APPENDIX A. PROPOSED RULE MAKING. . . . . . . . . . A-1

APPENDIX B. FIRE DEATH SCENARIOS AND FIRESAFETY PLANNING. . . B B-1

APPENDIX C. PART 1633 -- PROPOSED STANDARD FOR THE FLAMMABILITY

(CIGARETTE IGNITION RESISTANCE) OF UPHOLSTERED

FURNITURE (PFF 6-76)............... C-1

APPENDIX D. AN INTERLABORATORY EVALUATION OF A CIGARETTE

IGNITION TEST FOR UPHOLSTERED FURNITURE . . . . . . D-1

APPENDIX E. TEST METHOD FOR CLASSIFYING CIGARETTE IGNITJON

CHARACTERISTICS OF UPHOLSTERY FABRICS . . . . . . E-1

APPENDIX F. INTERLABORATORY PROGRAM FOR THE EVALUATION OF A

PROPOSED FLAMMABILITY (CIGARETTE IGNITION

RESISTANCE) TEST FOR UPHOLSTERED FURNITURE. . . . . . F-1

APPENDIX G. EVALUATION OF STANDARD CLASS B AND C FABRICS FOR

THE PROPOSED STANDARD FOR THE FLAMMABILITY

(CIGARETTE IGNITION RESISTANCE) OF UPHOLSTERED

FURNITURE . . . . . . . . . . . . . . G-1 


$$
\text { CONTENTS (cont'd) }
$$

Page

APPENDIX H. RESULTS OF TEMPERATURE MEASUREMENTS MADE ON BURNING CIGARETTES AND THEIR USE AS A STANDARD IGNITION SOURCE FOR MATTRESS TESTING . . . . . . . . . . G-1

APPENDIX I. CIGARETTE IGNITION RESISTANCE TESTS OF TWENTYTHREE POLYURETHANE FOAMS. . . . . . . . . . . . I-1

APPENDIX J. MEMORANDUM ON RATIONALE BEHIND SOME DECISIONS ON WHAT TO SPECIFY IN THE "PROPOSED STANDARD FOR THE FLAMMABILITY OF UPHOLSTERED FURNITURE . . . . . . . . J J-1

APPENDIX K. MEMORANDUM ON COMMENTS ON THE BUREAU OF DOMESTIC COMMERCE'S ECONOMIC IMPACT OF THE PROPOSED STANDARD FOR UPHOLSTERED FURNITURE . . . . . . . . . . . . K-1 


\section{LIST OF FIGURES}

Page

Figure 1. Mock-Up Frame: Upholstered Furniture Test . . . . . . 25

Figure 2. Mock-Up Panels: Upholstered Furniture Test . . . . . 26

Figure 3. Mock-Up Upholstered Furniture Test . . . . . . . . . 27

Figure 4. Fabric Classification Test: Fabric/Glass

Fiberboard Sample . . . . . . . . . . . 28

Figure 5. Fabric Classification Test: Fabric/Cotton

Batting Sample... . . . . . . . . . . . 29

Figure 6. Fabric Classification Test: Sample Holder . . . . . 30

Figure 7. Upholstery Fabric Classification Test . . . . . . . 31

\section{LIST OF TABLES}

Page

Table 1. Covered and Uncovered Cigarette Ignition Test Results on Sma11-Scale Seat Cushion and Chair Arm Furniture Constructions and Flammability Tests on Upholstery

Fabric Materials . . . . . . . . . . . 8

Table 2. Upholstery Test Materials . . . . . . . . . 12

Table 3. Interlaboratory Fabric Test Results . . . . . . . . 13

Table 4. Production Furniture Testing . . . . . . . . . . 19

Table 5. Estimated Cost of Testing to the Furniture Industry . . . 21 


\title{
BACK-UP REPORT FOR THE PROPOSED STANDARD FOR THE FLAMMABILITY (CIGARETTE IGNITION RESISTANCE) OF UPHOLSTERED FURNITURE, PFF 6-76

\author{
Joseph J. Loftus
}

\begin{abstract}
This report brings together data, information, and reports generated by the Center for Fire Research (CFR) at the National Bureau of Standards (NBS) and by others during four years of work on the development of the test method. All of this information was used in the preparation of a recommended Proposed Standard for the Flammability (Cigarette Ignition Resistance) of Upholstered Furniture, PFF 6-76.
\end{abstract}

Key words: Cigarette ignition; fabric classification; mock-up furniture samples; smoldering; upholstered furniture; upholstery fabrics.

\section{INTRODUCTION}

In recent years, the National Bureau of Standards (NBS) has been asked by various government agencies to assist in the development of standards and/or standard methods of test for the measurement of the properties or characteristics of different materials. With increasing frequency, these requests have been directed toward standards for public safety and/or products or materials used by the consumer.

More specifically, one such agency, the Consumer Product Safety Commission (CPSC) had requested that the Center for Fire Research (CFR) at NBS develop and provide CPSC with a viable, repeatable, and reproducible method of test for measuring the flammability (resistance to cigarette ignition and smoldering) of upholstered furniture.

The intent of the Commission was to issue the test method as a flammability standard for upholstered furniture to fulfill the "Finding of Need" [1] ${ }^{1}$ published in the Federal Register in 1972 by the Department of Commerce (see Appendix A). This notice stated that a flammability standard or other regulation may be needed for upholstered furniture to protect the public against unreasonable risk of the occurrence of fire leading to death, personal injury, or significant property damage.

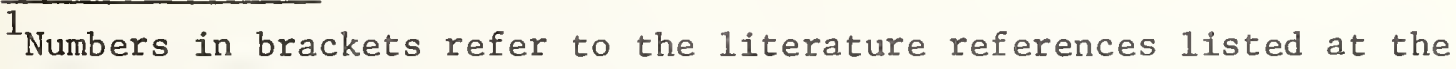
end of this paper.
} 
The Finding's request for a test method was based on fire accident case data obtained from various sources, e.g., the National Bureau of Standards' Flammable Fabrics Accident Case and Testing System (FFACTS); a public safety organization, the National Fire Protection Association (NFPA); and state and local fire departments (New York, Oregon, etc.) which indicated that the majority of fire incidents involving upholstered furniture and bedding were caused by cigarettes and/or smoking related materials.

A more recent report (see Appendix B) published in 1976 added supportive evidence for a need for a test standard by showing that for fire death scenarios occurring annually in the United States $27 \%$ of residential fire deaths resulted from smoking materials igniting bedding and upholstered furniture.

The purpose of this back-up report then, is to bring together some of the data and information and reports generated by CFR (and others) during four years of work on the development of the test method. This information was used in the preparation of a recommended Proposed Standard for the Flammability (Cigarette Ignition Resistance) of Upholstered Furniture, PFF 6-76 (see Appendix C).

\section{OBJECTIVE}

The objective of the proposed standard is to reduce the number of upholstered furniture fire incidents which occur every year in the United States as a result of careless smoking. It proposes to do this by establishing test methods and procedures designed to measure the ignition resistance of upholstered furniture to cigarettes.

Such a standard would obviously serve to protect the consumer from the many hazards associated with furniture fires: e.g., continuous slow burning or smoldering and resultant production of smoke and toxic atmospheres which may lead to death, injury, or significant property loss.

In order to establish priorities for work within CFR, the available fire data sources were studied. As expected, it was found that the most common of all fire death scenarios was cigarette ignition of upholstered furniture resulting in smoldering combustion and causing death by toxic combustion products.

For information purposes, a brief summary of these fire data are presented here.

\subsection{The National Household Fire Survey}

In 1974, the Bureau of the Census, under the sponsorship of NBS and CPSC, conducted "The National Household Fire Survey." The following outlines the findings on upholstered furniture from this survey: 
1. 33856 households were surveyed. (There were approximately 70 million households in the U.S.)

2. Of these households, 2333 reported having had 2463 fires during the previous 12 months. Projected to National totals, this would represent an estimated 5.6 million fires annually. of these, it is estimated that 4.6 million occurred in residences.

3. Of the 4.6 million residential fires, fabric items were identified as first to ignite in an estimated 469000.

4. In 93000 cases, approximately 20\% of the 469000 , upholstered furniture was the first item ignited.

5. In $88 \%$ ( 82 000) of the upholstered furniture fire incidents, the probable cause (or ignition source) was estimated to be cigarettes, cigars, and other smoking related materials.

\subsection{The Flammable Fabrics Accident Case and Testing System (FFACTS)}

FFACTS was developed by NBS in response to the Department of Commerce's responsibility for determining the need for standards under the Flammable Fabrics Act and to characterize accident scenarios. The following information on upholstered furniture fires was obtained from the FFACTS file:

1. There are 3347 cases in the data base.

2. There are 298 cases in which upholstered furniture (upholstery/ sofa bed) was ignited, with a total of 343 pieces (327 upho1stered furniture and 16 sofa beds) ignited.

3. Of the 298 cases in which upholstered furniture was ignited, 182 had personal injury reported, and 115 involved no personal injury (1 personal injury data element was unknown).

4. Of the 182 cases involving personal injury, fatality information is available for 164 cases. Of these 164 cases, there were 90 fatal injuries and 74 nonfatal injuries.

5. Of the 298 cases, in which upholstered furniture was ignited, in 209 cases upholstered furniture was the first item ignited. In 47 cases, the ignition order is unknown, and in 42 cases the upholstered furniture is not the first ignited item. The 209 cases include 8 sofa beds.

6. Of the 209 cases in which upholstered furniture was first to ignite, the distribution of ignition sources is as follows: 
Smoking Materials

Cigarette Cigar, Pipe

Smoking Material (Unspecifled)

Total Smoking Materials

Matches and Lighters

$\left.\begin{array}{r}140 \\ 3 \\ 23\end{array}\right\}$

166

Other

Unknown

Smoking materials, primarily cigarettes, are the ignition source indicated for $84 \%$ of the 198 "first-to-ignite" furniture cases for which the ignition source is known.

7. The injury disposition for the 209 cases in which upholstered furniture was first to ignite is as follows:

\begin{tabular}{lr} 
Died & 49 \\
Hospitalized & 31 \\
Treated and Released & 21 \\
First Aid & 7 \\
No Treatment & 2 \\
Unknown & -3 \\
\multicolumn{1}{l}{ Total Injured } & 113
\end{tabular}

In 95 cases, there were no injuries. In one case this information is not available.

2.3. Analysis of Fire Accident Scenarios by the Fire Incidence Data Organization (FIDO) Maintained by the National Fire Protection Association (NFPA)

The FIDO study made by Clarke and Ottoson (see Appendix B) used a quantitative approach to survey avallable data and to identify and rank what appear to be the most frequent scenarios for fire death in the United States. The 14 top scenarios are listed, and it is shown that almost two-thirds of the Nation's fire deaths are accounted for by this listing. Heading the list with $27 \%$ of the fire deaths is the residential fire where furnishings are the first item to ignite, and the ignition source is smoking. The furnishing category includes both bedding and upholstered furniture.

The next highest 11sting ( $5 \%$ of fire deaths) was furnishings ignited by open flames. 
This report concluded that the residential fire fatality record and the role contributed by furnishings need to be recognized as crucial points for action if fire losses are to be substantially reduced. The National goal [2] of reducing fire losses by $50 \%$ cannot be accomplished unless this aspect of residential fire is addressed.

\subsection{Notice of Finding -- Federal Register, November 29, 1972}

A notice of finding was published in the Federal Register (see Appendix A) in 1972 by the Department of Commerce which informed the public that a flammability standard or other regulation may be needed for upholstered furniture to protect the public against the unreasonable risk of the occurrence of fire leading to death or personal injury or significant property damage.

The basis of possible need for a standard (at that time) was set forth in the proceedings where injury data collected from a number of different sources were presented: e.g., the Flammable Fabrics Accident Case and Testing System (FFACTS), the National Fire Protection Association (NFPA), the States of Oregon and New York, and other public safety organizations and local fire departments. Also cited in the document were research data supplied by the Southwest Research Institute (SwRI) under contract to NBS.

\subsection{Development of the Proposed Standard}

CFR began work on the development of the proposed flammability standard for upholstered furniture soon after the notice of finding was published in the Federal Register in 1972.

The Department of Commerce (DoC) originally had responsibility for the work until the authority to administer the Flammable Fabrics Act was transferred to CPSC as a result of the 1972 Consumer Product Safety Act and formation of the Commission on May 14, 1973. Since that time, the work has been sponsored by CPSC.

By 1974, CFR had developed a "cigarette test" for measuring the ignition resistance of upholstered furniture and had presented a draft of a proposed test standard to CPSC.

The next two years ("74 to '76) were devoted to a full-scale interlaboratory evaluation (50 to 60 laboratories) testing program designed to determine the feasibility of the proposed test.

The American Society for Testing and Materials (ASTM) and the Upholstered Furniture Action Council (UFAC), a group of furniture executives joined together to look after the interests of the furniture industry, helped CFR carry out the feasibility studies. 
Based on the information gained in these interlaboratory studies and other studies, CFR made some revisions to the 1974 draft of the proposed standard and submitted a new draft to CPSC on May 21, 1976.

The following is a summary report of the information generated by CFR and others in the development of the proposed flammability standard.

\section{SWRI RESEARCH (IDENTIFICATION OF THE HAZARDS)}

The Southwest Research Institute report, "Characterization of Bedding and Upholstery Fires" by Hafer and Yuil1 [3], described a series of 30 exploratory tests on beds and on upholstered chairs using various combinations of materials and ignition sources. Eight of the 30 tests were on upholstered chairs made with different combinations of upholstery fabric and cushioning. Both smoldering ignition (cigarettes) and flaming ignition (matches or methenamine pills) tests were conducted.

Conclusions drawn from this work were: (1) that upholstered chairs were easily ignited by lighted cigarettes and open flames and (2) that conditions hazardous to life could be obtained within a short time after ignition was established. Measurements of temperature, light obscuration, oxygen depletion, $\mathrm{CO}, \mathrm{CO}_{2}$, and other noxious gases showed that hazardous (to life) levels were reached within 30 minutes for cigarette ignitions and within 6 minutes for open flame tests. It was reported that choking, irritating, and lachrymating elements of the combustion products rendered the atmosphere intolerable for even an alert, mature, healthy adult before lethal conditions were recorded. But CO could incapacitate a sleeping person.

\section{CFR - EXAMINATION OF THE PROBLEM}

In designing the flammability (cigarette ignition resistance) tests for upholstered furniture, it was decided from the discussion below that the test methods and procedures should follow those already developed for mattresses in the Standard for the Flammability of Mattresses, FF 4-72.

Two elements entered into this decision: (1) the filling or stuffing and cushioning materials used in upholstered furniture were similar to those used in mattresses, e.g., cotton batting, foam rubber, foam urethane, and polyester fiberfill and (2) the primary hazard pattern for furniture fires was the same as identified for mattresses (careless smoking).

A comparison of mattresses and upholstered furniture showed that the two differed by (1) the type of fabric used as cover material, (2) the weight of the fabric cover, and (3) the presence of vertical members (sides and backs) in furniture (not found in mattresses). 
Generally, mattress covers or tickings are made of cotton, rayon, or blends of cotton and rayon, weigh in the range of 136 to $254 \mathrm{~g} / \mathrm{m}^{2}$ ( 4 to $7.5 \mathrm{oz} / \mathrm{yd}^{2}$ ), and provide little fuel for ignition of filling or stuffing materials in a mattress. By comparison, upholstery fabrics are made from a wide range of cellulosic and synthetic fiber materials or blends, weigh from 203 to $881 \mathrm{~g} / \mathrm{m}^{2}$ (6 to $26 \mathrm{oz} / \mathrm{yd}^{2}$ ) (average 339 to $508 \mathrm{~g} / \mathrm{m}^{2}$ (10 to $\left.15 \mathrm{oz} / \mathrm{yd}^{2} \mathrm{j}\right)$, and can strongly influence the ignition of substrate filling materials.

\section{TESTING PHASE I}

CFR began its test development work by evaluating the flammability performance (cigarette ignition resistance) of over 40 different upholstery fabrics on three types of filling materials: e.g., cotton batting, foam rubber, and foam urethane.

Initially, tests involved the burning of cigarettes on the surfaces of $15 \times 15 \mathrm{~cm}$ ( $6 \times 6$ in) mock-up seat cushions and in the crevices of the seat cushions abutting $15 \times 15 \mathrm{~cm}$ ( $6 \times 6$ in) vertical test panels. Both covered and uncovered cigarette tests were conducted. For the covered tests, a paper tissue was used as the covering material.

Table 1 lists the results of cigarette and open flaming tests conducted on each of the fabric materials. The flaming ignition tests included ease of ignition, rate of burning, and methenamine pill tests on small-scale foam urethane seat cushions.

The knowledge gained from these cigarette tests showed that: (1) cellulosic fabrics ignite easily and in turn will ignite cotton batting and foam rubber cushioning in covered cigarette tests, (2) most synthetic fabrics (nylon, olefin, and PVC plastics) on cotton batting and foam rubber cushioning will resist ignition, and (3) foam urethane cushioning in combination with each of the fabrics tested was not ignited.

Observations made for crevice (cigarette) tests showed that 41 of the 47 fabrics tested permitted ignition of cotton filled vertical panels while a combination of $1.3 \mathrm{~cm}$ (1/2 in) foam urethane over cotton allowed only 12 ignitions for the same 47 fabrics. No significant differences were noted between vertical or vertical curved (oval) panel configurations.

\section{TESTING PHASE II}

The next phase of testing involved a study of the ignition resistance of cellulosic and synthetic fabrics on a total of 12 fullsize urethane foam filled seat cushions. Information gained from this study showed that the cellulosic fabrics permitted ignition of the cushions in the welt edges and the synthetics did not. From these data, 


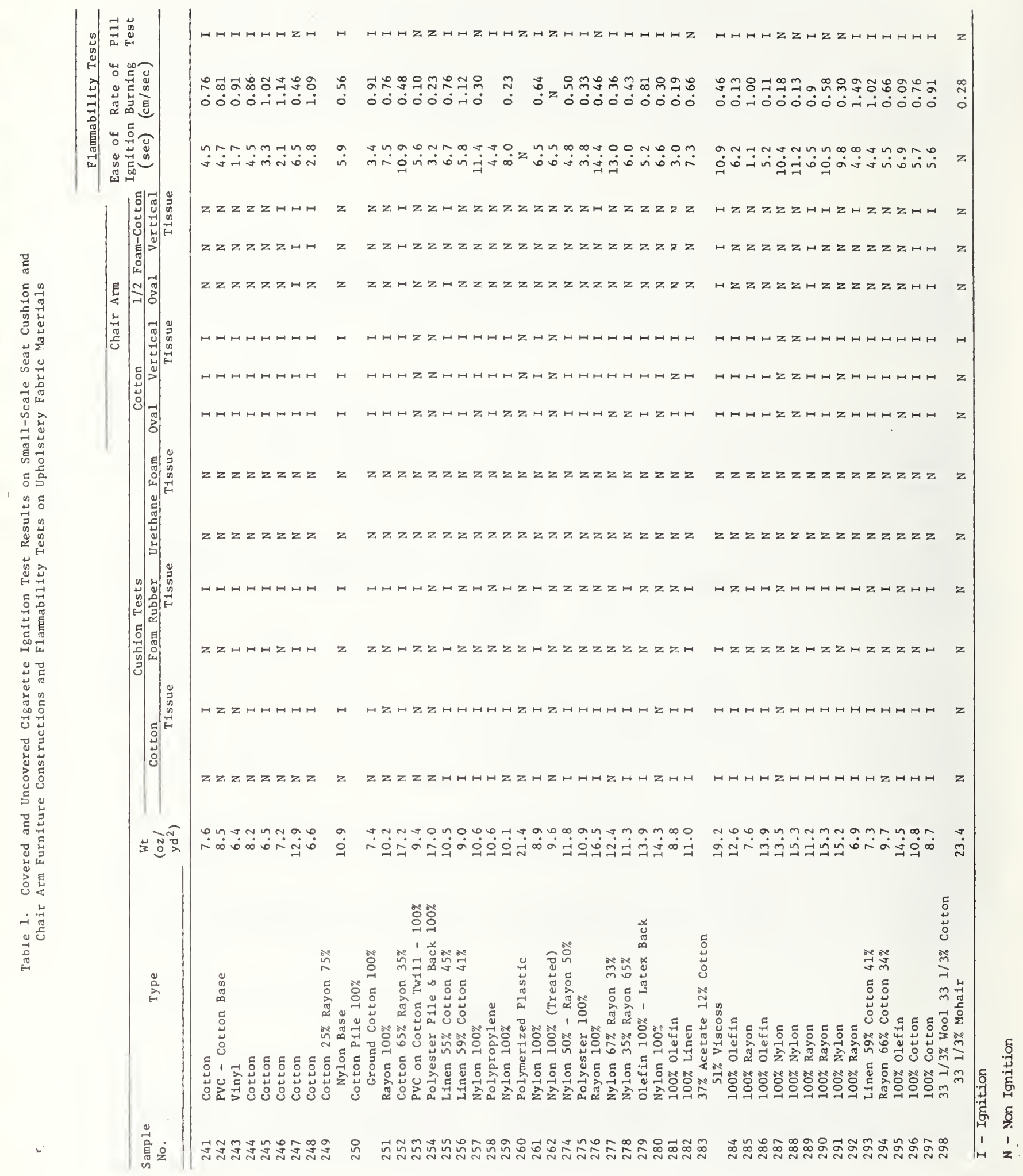


a criterion for test fallure was established as (1) an obvious ignition or (2) a $7.5 \mathrm{~cm}$ (3 $\mathrm{ln}$ ) char or smolder in any direction from a test cigarette. If the char exceeds $7.5 \mathrm{~cm}$ (3 in), experience has shown that the char w1ll generally progress to destruction of the test sample.

\section{TESTING PHASE III}

A total of 47 silk and silk blended fabrics supplied for test by the Decorative Fabrics Assoclation were subjected to the "sma11-scale" testing program.

Information obtained from these experiments showed that (1) silks permit Ignition of vertical cotton panels, (2) silks do not permit ignition of protected cotton panels $1.3 \mathrm{~cm}(1 / 2 \mathrm{in})$ foam urethane layer over cotton, and (3) silks resist ignition from pill tests (open flame) on foam urethane cushioning.

\section{TESTING PHASE IV}

By mid-1973, CFR was investigating (1) aluminized fabrics as a heat dissipating medium under upholstery fabric materials, (2) the possible use of a Standard Fabric for qualification tests of furniture mock-up constructions, (3) glass fiberboard as a standard substrate for fabric evaluations, and (4) the ignition performance of various types of filled and unfilled foam urethane cushioning materials.

\section{PLANT VISITS}

In early 1974, the upholstered furniture industry, working through the Upholstered Furniture Action Counc11 (UFAC), sponsored a tour of seven different furniture factories in the Hickory, North Carolina, area to acquaint government personnel with the methods of furniture manufacture. These plant visits made one lasting Impression: $1 . e$, that the burden of testing had to be lightened if flammability requirements were to be established for furniture under a proposed standard. In view of the vast selection of cover fabrics available to the consumer (in some large plants, this selection may be 500 to 5000 fabrics), it was apparent that a strong effort would have to be made to develop a fabric classification test so that every fabric in a plant would not have to be tested on every furniture construction.

\section{TEST APPARATUS FOR MOCK-UP UPHOLSTERED FURNITURE TEST}

By mid-1974, CFR and UFAC had jointly dectded on a mock-up test apparatus (figures 1-3) for testing upholstered furniture constructions. Briefly, this apparatus was designed to accommodate full-size seat cushions and vertical test panels fabricated with the same filling materials and upholstery fabric intended for use on full-size furniture 
items. This apparatus was to become the accepted means for conducting the Mock-Up Upholstered Furniture Test described in the draft of the proposed standard prepared for CPSC by CFR.

\section{TESTING PHASE V - SEVEN-LAB EVALUATION OF THE MOCK-UP UPHOLSTERED FURNITURE TEST METHOD}

Preparations were made to subject the Mock-Up Upholstered Furniture Test method to an interlaboratory evaluation study and to compare the results of this study with cigarette ignition tests on full-size upholstered chairs.

ASTM and UFAC cooperated with CFR in setting up a seven-lab evaluation of the test method. Each laboratory was instructed to determine the cigarette ignition resistance of six different upholstery fabrics by the Mock-Up Upholstered Furniture Test, and for comparison, to also conduct cigarette tests on three full-size chairs. Foam urethane was used as the cushioning material for the mock-up and chair seat cushions, and cotton batting was supplied as the filling material for vertical mock-up panels and the chair arms and backs.

Instructions called for making uncovered and covered cigarette tests (cover-piece of bed sheeting material) on the smooth surfaces of the seat cushions, on the welt or border edges of cushions, and in the crevices of abutting seat cushions and vertical mock-up panels and sides and backs (chair tests). Horizontal surfaces of chair arms and tops of backs were also tested.

All laboratories submitted their data to CFR for analysis and review; and a report of test results for this study [4] was submitted to CPSC by mid-1975 (see Appendix D).

Briefly, the interlab provided the following information:

1. Cigarette tests on mock-up upholstered furniture constructions were found equable to those obtained for similar tests on ful1-size upholstered chairs.

2. Covered cigarette tests (see note) were more severe (than uncovered) and provided more reproducible results.

3. Ignitions in upholstered furniture constructions were clearly related to the type and kind of cover fabric used on a construction.

4. Synthetic fabrics produced fewer ignitions than did cellulosic fabrics in both the mock-up upholstered furniture and chair test assemblies. 
5. NBS statisticians analyzed test results in terms of percent failure and measured the consistency of results between laboratories. In a memo report to CFR staff, it was reported that with few exceptions, results of the Mock-Up Upholstered Furniture Tests were satisfactory in terms of lab-to-lab variability.

NOTE: Covering the cigarette duplicates what is likely to occur in an actual accident scenario. The cigarette is very likely to come to rest in the crevice underneath some material such as clothing. In this situation, the heat is maintained in the area of the cigarette and presents a more hazardous situation.

\section{TESTING PHASE VI - DEVELOPMENT OF A FABRIC CLASSIFICATION TEST METHOD}

The intent of CFR in developing the Fabric Classification Test Method was to reduce the testing burden on the furniture manufacturer (not every fabric would be required to be tested on every furniture construction).

Briefly, the concept of the test was to use a small-scale test apparatus (figures 4-6) to support fabric-covered, noncombustible glass fiberboard and/or cotton batting/glass fiberboard substrates and to burn cigarettes (covered by a piece of sheeting material) in the crevice location for each fabric test sample. The test sample consists of a piece of fabric $20 \times 20 \mathrm{~cm}(8 \times 8$ in) for the horizontal cover and a piece of fabric $30 \times 30 \mathrm{~cm}(12 \times 12$ in) for the vertical back cover. Shown in figure 7 , is a schematic diagram of the Fabric Classification Test procedure. As detailed in this diagram, fabrics receive Class A, $B, C$, or D ratings based on their cigarette ignition resistance performance. Class A fabrics are the most resistive materials and produce chars less than $3.8 \mathrm{~cm}$ (1.5 in) on glass fiberboard and do not ignite cotton batting; Class B fabrics char less than $3.8 \mathrm{~cm}$ (1.5 in) on glass fiberboard, but do ignite cotton; Class C chars 3.8 to $7.5 \mathrm{~cm}$ (1.5 to $3 \mathrm{in}$ ) on glass fiberboard; and Class D chars more than $7.5 \mathrm{~cm}$ (3 in) on the same material.

Glass fiberboard was chosen as the substrate material for the Fabric Classification Test (FCT) to ensure that any smoldering or char that developed in a fabric during test could only be attributed to the fabric and not to the underlayment material. Cotton batting was selected for the vertical test panels in the second part of the test to help determine whether a test fabric was a Class A or Class B (Class B ignites cotton, Class A does not).

A report entitled "Test Method for Classifying Cigarette Ignition Characteristics of Upholstery Fabrics" [5] was presented to CPSC (see Appendix E) covering initial observations obtained with the FCT test method. For this testing program, a total of 47 upholstery fabrics were classified by the FCT test method, and results yielded the following information: 
1. There were six class A fabrics consisting of vinyl plastic, heavyweight nylons, and polyester materials.

2. There were 29 Class B fabrics consisting of synthetic fiber or lightweight cellulosic materials or blends.

3. There were five Class $\mathrm{C}$ materials consisting of 1 : ghtweight or medium-weight cellulosic fabrics.

4. There were seven Class D fabrics consisting of various weights of cellulosic materials.

\section{TESTING PHASE VII - SIX-LAB EVALUATION OF FCT TEST METHOD}

After completion and distribution of information gained in the above report to CPSC and the furniture industry, ASTM, UFAC, and CFR jointly agreed to conduct a small-scale interlaboratory feasibility study to evaluate the repeatability of the FCT test method in a laboratory and the reproducibility of the method between laboratories.

To this end, a total of six laboratories agreed to participate in classification tests on 10 different cotton, rayon, and cotton or rayonblended fabrics.

The following is a list of upholstery fabric materials selected for test:

Table 2. Upholstery Test Materials

\begin{tabular}{rlc}
\hline Fabric No. & \multicolumn{1}{c}{ Fiber Content } & $\begin{array}{c}\text { Weight } \\
\left(\mathrm{g} / \mathrm{m}^{2}\right)^{*}\end{array}$ \\
\hline 1 & $100 \%$ Rayon & 440 \\
2 & $66 \%$ Viscose/21 Nylon/13 Polyester & 848 \\
3 & $43 \%$ Rayon/30 Polyprop/27 Nylon & 339 \\
4 & $72 \%$ Cotton/17 Acetate/11 Rayon & 440 \\
5 & $65 \%$ Cotton/35 Viscose & 475 \\
6 & $55 \%$ Cotton/39 Rayon/6 Acetate & 440 \\
7 & $60 \%$ Rayon/40 Cotton & 509 \\
8 & $100 \%$ Cotton & 203 \\
9 & $45 \%$ Rayon/55 Cotton & 475 \\
10 & $70 \%$ Rayon/30 Nylon & 339 \\
\hline To convert to oz/yd 2 multiply by 0.03. &
\end{tabular}


Each laboratory was furnished sufficient material to conduct four repeat Fabric Classification Tests on each fabric. The laboratories chose the lowest rating obtained for a test for that particular fabric's class.

The following table lists the test results furnished to CFR by the laboratory participants:

Table 3. Interlaboratory Fabric Test Results

Laboratory

\begin{tabular}{|c|c|c|c|c|c|c|c|}
\hline & & & $\mathrm{bbc}$ & $=01$ & & & \\
\hline & 1 & 2 & 3 & 4 & 5 & 6 & \\
\hline Fabric No. & & & si & at & & & Averages \\
\hline 1 & $\mathrm{D}$ & $\mathrm{D}$ & B & D & B & D & - \\
\hline 2 & B & B & B & B & B & B & B \\
\hline 3 & D & $\mathrm{C}$ & B & B & B & B & - \\
\hline 4 & $\mathrm{D}$ & $\mathrm{D}$ & D & D & B & D & $\mathrm{D}$ \\
\hline 5 & B & B & B & B & B & C & B \\
\hline 6 & $\mathrm{D}$ & D & D & D & D & D & $\mathrm{D}$ \\
\hline 7 & B & B & B & B & B & C & B \\
\hline 8 & B & B & B & B & B & B & B \\
\hline 9 & B & B & B & B & B & C & B \\
\hline 10 & B & B & B & B & B & B & B \\
\hline
\end{tabular}

The information gained from the above table of data was most encouraging. Four of the fabrics were exactly classified by all laboratories; four others were misclassified by only one laboratory; and two fabrics were misclassified by two laboratories.

Conclusions drawn from this interlaboratory study indicated that the Fabric Classification Test was: a viable method of test, repeatable within a lab, reproducible between laboratories, and worthy of further evaluation by a greater number of laboratories on a much larger scale. 


\section{TESTING PHASE VIII - FIFTY-FIVE-LAB EVALUATION OF THE MOCK-UP UPHOLSTERED FURNITURE AND FABRIC CLASSIFICATION TEST METHODS}

CFR (with the help and cooperation of ASTM and UFAC) set up and designed a fifty-five-lab interlaboratory evaluation study of both the Mock-Up Upholstered Furniture and Fabric Classification Test Methods in the proposed standard. Draft No. 5 of the proposed standard was used for conducting the tests. A report on this evaluation study [6] was presented to CPSC in March 1976 (see Appendix F).

Among the laboratory participants were fabric producers, furniture manufacturers, chemical suppliers, retailers, State and Federal government agencies, fiber producers, and educational institutions. Of the 55 laboratories, 38 used the Fabric Classification Test Method to classify 16 different upholstery fabrics; 38 conducted mock-up upholstered tests on a total of 11 different furniture constructions; and 21 of the laboratories conducted both tests.

Knowledge gained from the fabric classification (38-1ab) evaluation study showed that:

1. Classifications were influenced by test fabric orientation and by air gaps or spacing between the vertical panel and horizontal panel support.

2. Reproducible results were obtained by those laboratories who conducted classification tests on fabrics with the fiber direction on vertical panels matching that of the horizontal panels; i.e., machine matching machine (or warp matching warp) fiber direction and with no air gap between test panels.

3. A definite relationship was found between fabric type and the classification obtained for a test fabric.

4. Fabrics found to fall into class patterns were:

a. Wools, wool blends, viny 1 plastics, and heavyweight synthetics rated "Class A."

b. Medium-weight synthetics (nylons, olefins, etc.) and some lightweight cottons and rayons were "Class B."

c. Medium-weight cellulosics (cotton, rayon, etc.) were rated "Class C."

d. Heavyweight cellulosics $>508 \mathrm{~g} / \mathrm{m}^{2}\left(>15 \mathrm{oz} / \mathrm{yd}^{2}\right)$ were generally classed "Class D." 
It appears that the FCT test method is a viable, reproducible method of test. Two immediate advantages would be (1) that the furniture industry's burden of testing will be considerably lightened (not every fabric would require testing on the mock-up test method samples) and (2) that industry would be provided a means of determining what fabric class "works well" (passes the clgarette test) with a furniture construction and would avold unnecessary testing.

Conclusions drawn from the (38-1ab) evaluation study of the Mock-Up Upholstered Furniture Test Method in the proposed standard were:

1. Most present-day (manufactured) upholstered furniture can easily be ignited by burning cigarettes (vinyl covered, wool, and heavyweight synthetic covered furniture excepted).

2. Laboratory participants had little difficulty in identifying the safe (nonignition) and problem areas (ignition prone) in the mock-up assemblies.

3. Upholstery cover fabrics were shown to play an extremely important role in determining whether a furniture construction will resist or allow ignitions to occur in finished furniture items. Constructions which may pass the test with one fabric cover may not necessarily pass the test when covered with a different class of fabric material.

4. Class A fabrics were found compatible with most furniture constructions.

5. Class B fabrics demonstrated a need for barrier layers between cotton batt and cover fabric.

6. Class $C$ and Class D fabrics, because they smolder when exposed to burning cigarettes, may require a heat dissipating medium under cover fabrics in order to resist ignition.

7. The Mock-Up Upholstered Furniture Test Method (based on the gono go results obtained) was judged viable, reproducible, and a useful tool for the furniture industry for making determinations on whether a mock-up furniture construction used in combination with a particular upholstery fabric will pass or fall a cigarette test (see Appendix $\mathrm{E}$ for data).

\section{TESTING PHASE IX - STANDARD FABRICS}

Research and development testing did not end with the completion of the 55-1ab interlaboratory study, for an anomaly was soon discovered in the provisions of Draft No. 5 of the proposed standard. Under Draft No. 5, a mock-up furniture construction qualified for use in full-size furniture items if it passed cigarette tests with any upholstery fabric from a 
particular fabric class. By passing this single test, all other fabrics from that same fabric class would automatically qualify for use with that particular construction without any further testing. Additional testing, however, showed that this interpretation was too liberal, for within a fabric class it was discovered that high and low-level fabrics may exist, and if a high-level (easily passing) fabric were used for qualification tests of a furniture mock-up construction, there was a good chance that many low-level (barely staying within the fabric class) fabrics in the same class might fall on the same construction if tested. It was also found that this problem existed only for the Class B and Class $C$ fabrics, for the proposed standard had already provided that each Class $\mathrm{D}$ fabric intended for use on furniture would require individual testing on mock-ups and that Class A fabrics as a group were

"so good" that any fabric from that group was considered eligible for qualification testing.

In order to resolve this problem and to strengthen the mock-up test provisions in the proposed standard, a research effort was initiated to determine if "Standard Fabrics" might be found and specified for Class B and Class C upholstery fabrics for qualification tests on upholstered furniture mock-up constructions.

Mock-up tests showed that a satisfactory fabric for Class B was a $50 / 50$ cotton/polyester blend sheeting material (similar to that used to cover test cigarettes in the proposed standard) and that a sultable standard fabric for Class $C$ was a cotton ticking cloth material listed under Federal Specification CCC-C-436D.

These two fabrics were selected as "standard" because tests showed they were representative of the "low-level" fabrics in their particular fabric classes and thus would be expected to provide for a most severe test when used for qualification testing of upholstered furniture construction (by definition, a "low-level" fabric would be one which provides chars up to the limits allowed for a particular fabric class).

Based on the information gained in this study [7] (see Appendix G), the proposed standard was revised to include new provisions requiring use of the standard Class B and Class C fabrics for all furntture mockup tests where the construction is intended for use with a fabric from one of these classes.

A final version of the proposed standard incorporating these changes was submitted to CPSC on May 21, 1976 (see Appendix C).

\section{OTHER TESTS AND REPORTS}

Although not listed chronologically in the Phase Testing Programs, a number of research and development tests were made at CFR, and results were reported to CPSC. 
One such report was concerned with the temperatures developed by burning cigarettes [8] (see Appendix H). The knowledge gained from this investigation of 32 brands of cigarettes was that king-size non-filter tipped cigarettes produced higher smoldering temperatures (worst case) than their filter tip. counterparts. Based on the results of this study, the non-filter tip cigarette was selected as the standard ignition source for the Standard for the Flammability of Mattresses, FF 4-72, and for the Proposed Standard for the Flamability (Cigarette Ignition Resistance) of Upholstered Furniture, PFF 6-76.

Another report [9] documented a series of tests designed to determine the ignition resistance of 23 different types of urethane foams when the foams were tested by the Mock-Up Upholstered Furniture Test (see Appendix I).

These tests showed (1) that foam urethane constructions can be ignited by smoldering Class D upholstery fabric covers and (2) that fireretardant treatments of foams failed to prevent ignitions when covered by the "D" fabrics.

A third report [10] was concerned with the "Rationale Behind Some Decisions on What to Specify in the Proposed Standard for the Flammability of Upholstered Furniture" (see Appendix J).

Each of these reports provided useful input to the proposed flammability standard.

\section{DISCUSSION}

\subsection{The Standard}

CFR interprets the accident data presented in the Clarke-0ttoson (FIDO) report to indicate that the control of ignition in upholstered furniture may be one of the most effective, available means of reducing injury and loss due to fire in the United States. Clearly, an effort to eliminate easily ignitable furniture from reaching the marketplace must be given serious consideration.

The Standard for the Flammability (Cigarette Ignition Resistance) of Upholstered Furniture proposed to CPSC is intended to fulfill this need by reducing to a very low level the quantity of new furniture manufactured which would be cigarette ignitable.

\subsection{The Standard's Reasonableness}

Under the fabric classification test in the proposed standard, fabric producers have the option of testing and classifying each and every upholstery fabric in their inventory, or of selecting a reduced testing protocol where only representative light and heavyweight fabrics 
of a fabric type would be tested. Under the latter option, if the selected test fabrics produce the same fabric class by testing, then all intermediate weight fabrics of the same fabric type would automatically be assigned to the same fabric class without further testing. If, however, the test fabrics show different fabric classifications, then all fabrics of the same fabric type would require classification testing on an individual basis. After qualification, a fabric type would be allowed for use as a cover fabric on production furniture constructions (qualified by the mock-up test) for a period of 12 months or at time intervals designated by CPSC. In order to qualify for an extended testing cycle, a fabric producer would document (to the satisfaction of CPSC) that a fabric type had not changed (e.g., by manufacturing method fiber content or dye color process) from the material originally classified as a fabric class.

Under the mock-up upholstered furniture test in the proposed standard, manufacturers have the option of testing each different upholstery fabric on mock-up upholstered furniture constructions and using the passing or qualified assemblies in production furniture, or of testing constructions covered with standard class fabrics instead of upholstery fabric materials.

Under the latter option, no Class A, B, or C upholstery fabric would need to be destroyed by testing if certain standard fabrics are used for the qualification tests. A singular "passing" furniture construction with standard Class $C$ fabric cover would automatically qualify all Class A, B, and C upholstery fabrics for use on the same construction in production furniture without any further testing. If standard Class B fabric were used, and the furniture construction passed all tests, then all Class $A$ and $B$ fabrics would qualify for use on the furniture construction. If a manufacturer wishes, a singular Class A fabric can be used to qualify all Class A fabrics on a furniture construction without further test. Presently, the standard only requires that Class D upholstery fabrics be tested individually on each different furniture construction. The testing cycle for the mock-up furniture tests would be as described for the fabric classification test: i.e., every 12 months or at time intervals designated by CPSC.

It is fortunate that there are only a limited number of filling or stuffing materials or combinations of materials used in upholstered furniture constructions (cotton batting, foam urethane, polyester, and combinations of cotton and foam urethane or polyester in combination with cotton or foam urethane). Seat cushions are almost exclusively made with foam urethane or foam urethane covered with polyester. Manufacturers may, therefore, qualify production furniture for periods of 12 months or longer by conducting a minimal number of tests (see table 4). 
Table 4. Production Furniture Testing

\begin{tabular}{|c|c|c|c|c|}
\hline \multicolumn{2}{|c|}{ Cover Fabric } & \multirow{2}{*}{$\frac{\text { Seat Cushion }}{\text { Foam }}$} & \multirow{2}{*}{$\frac{\text { Vertical Members }}{\text { Cotton }}$} & \multirow{2}{*}{$\frac{\text { No. of Tests }}{6}$} \\
\hline A & & & & \\
\hline A & & Poly/Foam & Cotton & 6 \\
\hline Standard & B & Foam & Foam & 6 \\
\hline$"$ & B & Poly/Foam & Foam & 6 \\
\hline$"$ & B & Foam & Foam/Cotton & 3 \\
\hline$"$ & B & Poly/Foam & Poly/Cotton & 3 \\
\hline Standard & $\mathrm{C}$ & Foam & Treated Cotton & 6 \\
\hline$" 1$ & $\mathrm{C}$ & Poly/Foam & Treated Cotton & 6 \\
\hline
\end{tabular}

The above number of tests (42) is based on the assumption that tops of side arms and tops of backs of the upholstered furniture piece contains the same arrangement of filling material to fabric cover as is used in the sides and back. If such an arrangement exists (as would be the case in most production furniture), then these locations would not have to be made or tested under conditions of the test standard. If the production furniture item contains loose seat cushions, then three additional tests would be required to qualify mock-up decking constructions. Each Class D upholstered furniture construction will require testing on an individual basis.

One further consideration offered to manufacturers would be to allow for pooling of test results on different furniture constructions. Under" this provision, a central testing laboratory (approved by CPSC) would test and certify (passing) upholstered furniture constructions for use in production furniture. Manufacturers would be allowed to use the certified constructions in furniture for 12 months or longer or until CPSC determined that the construction must be retested or requalified.

The above described testing frequency or cycles would not be burdensome, nor would they impact greatly (financially) on fabric producers or furniture manufacturers.

\subsection{The Standard's Appropriateness}

Once an upholstered furniture construction has been tested, passed, and accepted as a viable construction for use in production furniture, that construction may be used by manufacturers until a requalification 
test is deemed necessary by CPSC. Proper matching of fabric class to a construction should eliminate the need for removing any great number of upholstery fabrics from the marketplace.

Construction systems found sultable with Class C fabrics might often be found suitable for lightwelght Class $D$ fabrics in the range up to about $508 \mathrm{~g} / \mathrm{m}^{2}\left(15 \mathrm{oz} / \mathrm{yd}^{2}\right)$. Heavier welght Class $\mathrm{D}$ fabrics $>508 \mathrm{~g} / \mathrm{m}^{2}$ $\left(>15 \mathrm{oz} / \mathrm{yd}^{2}\right)$ ) may only require thicker or heavier layers of smolder resistant substrate materlal (than used for Class $C$ ) to meet the requirements of the cigarette test. drawn:

Based on the above estimates, the following conclusions may be

1. The level of cholce of fabrics avallable to the consumer would not be lowered by any significant degree.

2. The fashion and craft segments of the industry would not suffer undue hardship from the proposed standard.

3. The consumer would maintain a freedom of choice in fabric selection.

4. The economic impact on the furnfture industry would not be as severe as projected by UFAC (20 to $25 \%$ cost increase of furniture at wholesale; researched by Arthur D. Little Co. and Battelle Columbus Institute) but may only impact at 5\% increase by CFR estimates (based on $\$ 3$ billion sales at wholesale; the Dept. of Commerce, Goods and Services Division Report, Jan. 75).

\subsection{The Standard's Technological Feasibility}

The biggest problem facing the furniture industry (if the proposed standard becomes law) would be "how to handle the interaction between fabric and interfor components?" Clearly, Class A, B, and C fabrics can easily be used on most present-day furniture with only slight modifications in furniture constructions while Class D fabrics will most likely require some major changes in component assembly and construction.

CFR has endeavored to make a contribution to the furniture industry's research effort by actually fabricating an upholstered chair with a Class D fabric cover for test in accordance with the proposed flammability standard. The chair passed all cigarette tests. The "passing" construction consisted of the following assembly of materials: (1) needle punched aluminum foll cover over cotton batting material in sides and back constructions, (2) the same foll materlal glued to the edges of a foam urethane seat cushion with the foll quilted or glued to the cover upholstery fabric, and (3) welt edges, of the cushion required a PVC plastic welt cord material. 
CFR believes that constructions of this type may easily be achieved by the furniture industry.

\subsection{The Standard's Cost}

Estimates of the cost of the proposed flammability standard for upholstered furniture to the furniture industry have been made [11] (see Appendix K) in a report to the Consumer Product Safety Commission. The report projects costs as listed in table 5.

Table 5. Estimated Cost of Testing

to the Furniture Industry

\section{Cost of Upgrading}

(1) Upholstery Fabric

(2) Cotton Batting Filling Material

(3) Polyester Fiberfil1

(4) Welt Cord

(5) Polyurethane Foam

(6) Muslin

(7) Down Feathers

(8) Fabric Classification Test

(9) Mock-Up Upholstered Furniture Test

* Since development of PVC tape, this cost would be 0 .

** 126.58M, New Total.

This total cost estimate of $\$ 126.58 \mathrm{M}$ assumes the most expensive case, e.g., no change in fabric mix, and an upgrading of Class $\mathrm{D}$ fabrics now being used. A manufacturer's shift to safer Class A and Class B fabrics would reduce the cost of compliance even more than the estimate given. 


\subsection{Toxicity of Combustion Products from Materials Treated with Fire Retardants}

Throughout this report, it has been repeatedly stated that the proposed standard's intent was to eliminate clgarette induced smoldering fires in upholstered furniture.

Among the 1deas proposed on "how to reduce the number of Ignitions" in furniture, it has been suggested that fire-retardant chemicals be used to impart clgarette-resistant qualities to upholstery fabric and filling materials used in furniture constructions.

It has been reported by Battelle Laboratories [12] that the addition of fire-retardant chemicals to a product will make the products of combustion from that product more toxic if it does burn. This generalization, however, is not based on experimental evidence.

The feasibility of whether to accept this hypothetical increase of combustion product toxicity (when burning does occur) as a trade-off in return for a reduction in the number of furniture fire incidents (which is the intent of the proposed standard) poses a difficult policy decision to be made by code officials and regulators.

\section{CONCLUSIONS}

This report serves as a back-up document to support the need for a Standard for the Flammability (Cigarette Ignition Resistance) of Upholstered Furniture. Of all the data and statistics cited in support of the need for a standard, probably the most significant would be the fact that $27 \%$ of the fire deaths in the United States (see Appendix B) are due to smoking materials igniting upholstered furniture and bedding. It is further estimated that upholstered furniture fires resulting from ignition by smoking materials account for $15 \%$ of the national fire deaths, and bedding fires resulting from ignition by smoking materials account for the other $12 \%$. Since a mattress standard $1 \mathrm{~s}$ now in effect, it is fully expected that loss data will begin to reflect a reduction in mattress fires as compliant mattresses are purchased to replace old mattresses.

Clearly, the goal of this proposed standard is to significantly reduce the number of deaths, infuries, and property loss caused by upholstered furniture fires.

If the Consumer Product Safety Commission promulgates the proposed standard to full standard status, then all (assuming $100 \%$ compliance) upholstered furniture reaching the marketplace would be cigarette ignition resistant. Significant public benefit would result from the reduction of ignition under this major fire loss scenario. 


\section{REFERENCES}

[1] [15 CFR Part 7] Upholstered Furniture, Notice of Finding That Flammability Standard or Other Regulation May Be Needed and Institution of Proceedings, Federal Register, Vo1. 37, No. 230, Wednesday, November 29, 1972.

[2] America Burning, The Report of the National Commission on Fire Prevention and Control, U.S. Government Printing Office, Washington, D.C. 20402.

[3] Yuill, C. H. and Hafer, C. A., Characterization of Bedding and Upholstery Fires, Final Report, SwRI Project No. $3 \cdot 2610$ to the National Bureau of Standards (March 31, 1970).

[4] Loftus, J. J., An Interlaboratory Evaluation of a Cigarette Ignition Test for Upholstered Furniture, NBS Report to the Consumer Product Safety Commission (May 22, 1975).

[5] Loftus, J. J., Test Method for Classifying Cigarette Ignition Characteristics of Upholstery Fabrics, NBS Report to the Consumer Product Safety Commission (March 6, 1975).

[6] Loftus, J. J., Interlaboratory Program for the Evaluation of a Proposed Flammability (Cigarette Ignition Resistance) Test for Upholstered Furniture, NBS Report to the Consumer Product Safety Commission (March 1976).

[7] Loftus, J. J., Evaluation of Standard B and C Fabrics for the Proposed Standard for the Flammability (Cigarette Ignition Resistance) of Upholstered Furniture, NBS Report to the Consumer Product Safety Commission (October 1976).

[8] Loftus, J. J., Results of Temperature Measurements Made on Burning Cigarettes and Their Use as Standard Ignition Source for Mattress Testing, NBS Memo Report (June 18, 1971).

[9] Loftus, J. J., Cigarette Ignition Tests on Twenty-three Polyurethane Foams, Report to the Consumer Product Safety Commission (June 29, 1976).

[10] Winger, J.H., Rationale Behind Some Decisions on What to Specify in the Proposed Standard for the Flamability of Upholstered Furniture, NBS Memo Report to the Consumer Product Safety Commission (December 12, 1974).

[11] Winger, J.H., Comments on the Bureau of Domestic Commerce's Report on the Impact of the Proposed Standard for the Flammability of Upholstered Furniture, Report to the Consumer Product Safety Commission (February 24, 1976). 
[12] Study of the Economic Impact of a Proposed Cigarette Ignition Standard for Upholstered Furniture, Report to the Consumer Product Safety Commission, Battelle Columbus Laboratories (April 14, 1975). 


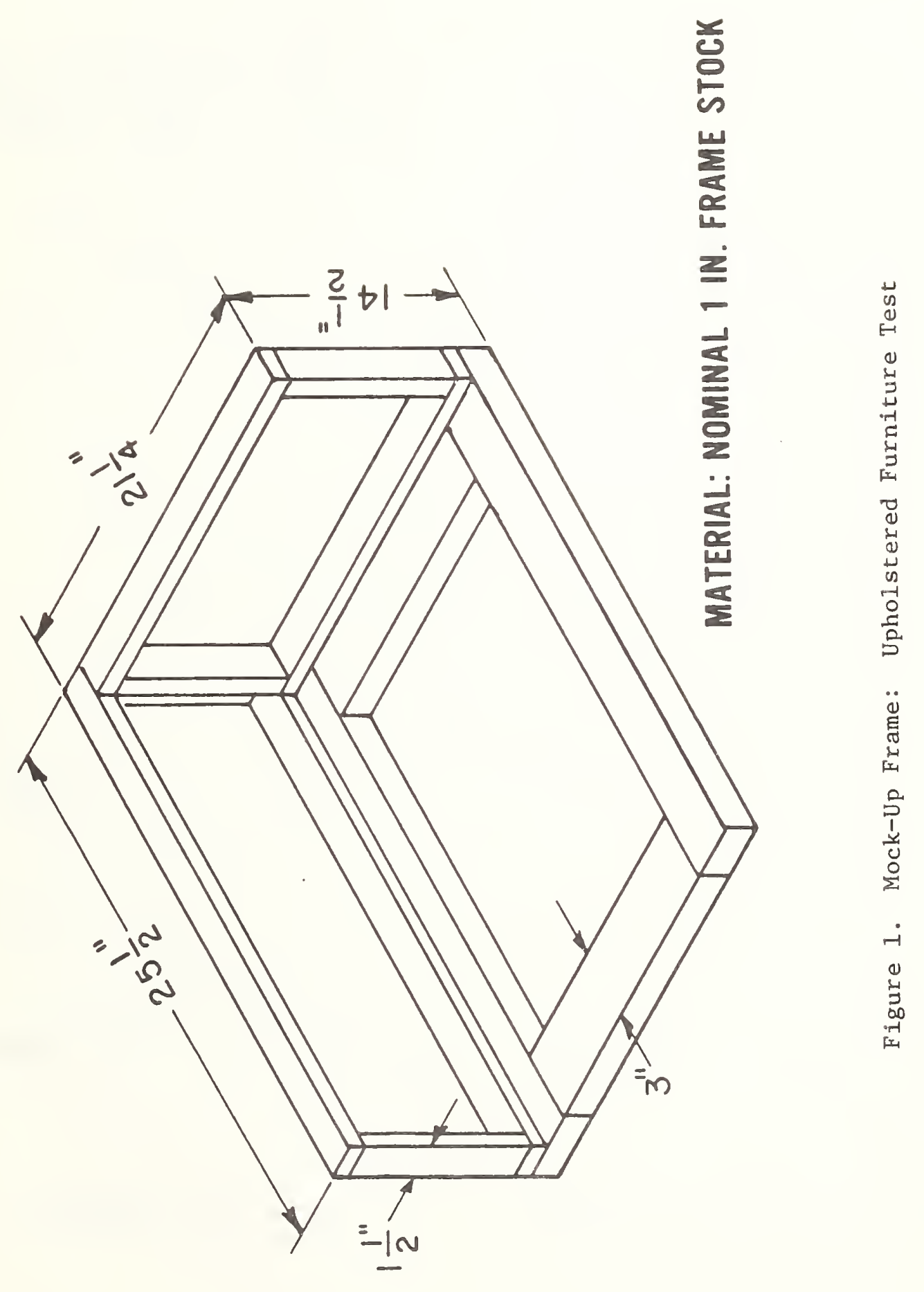



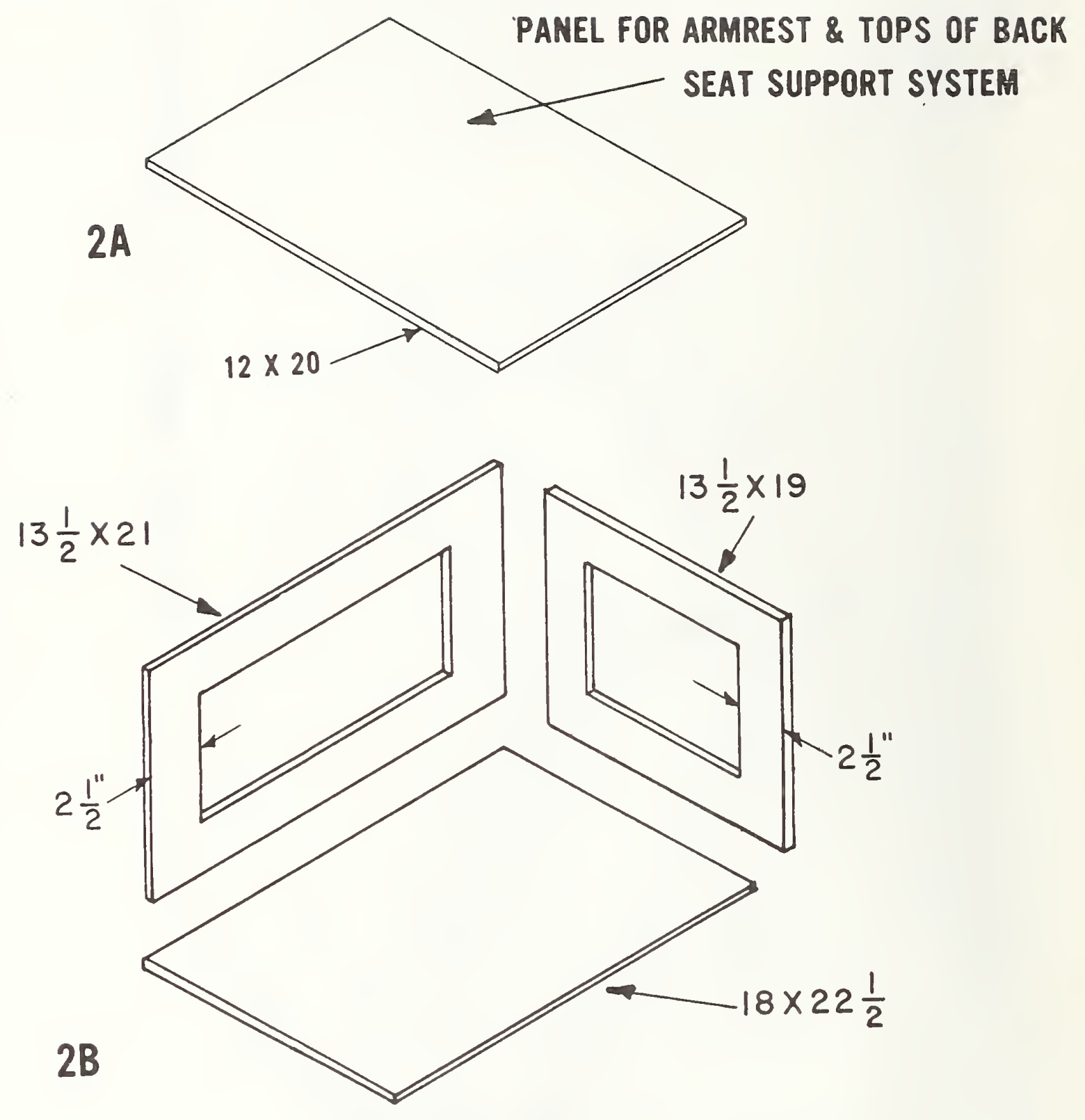

MAT. $\frac{1}{2}$ THICK PLYWOOD

(ALL DIM. INCHES)

Figure 2. Mock-Up Panels: Upholstered Furniture Test 

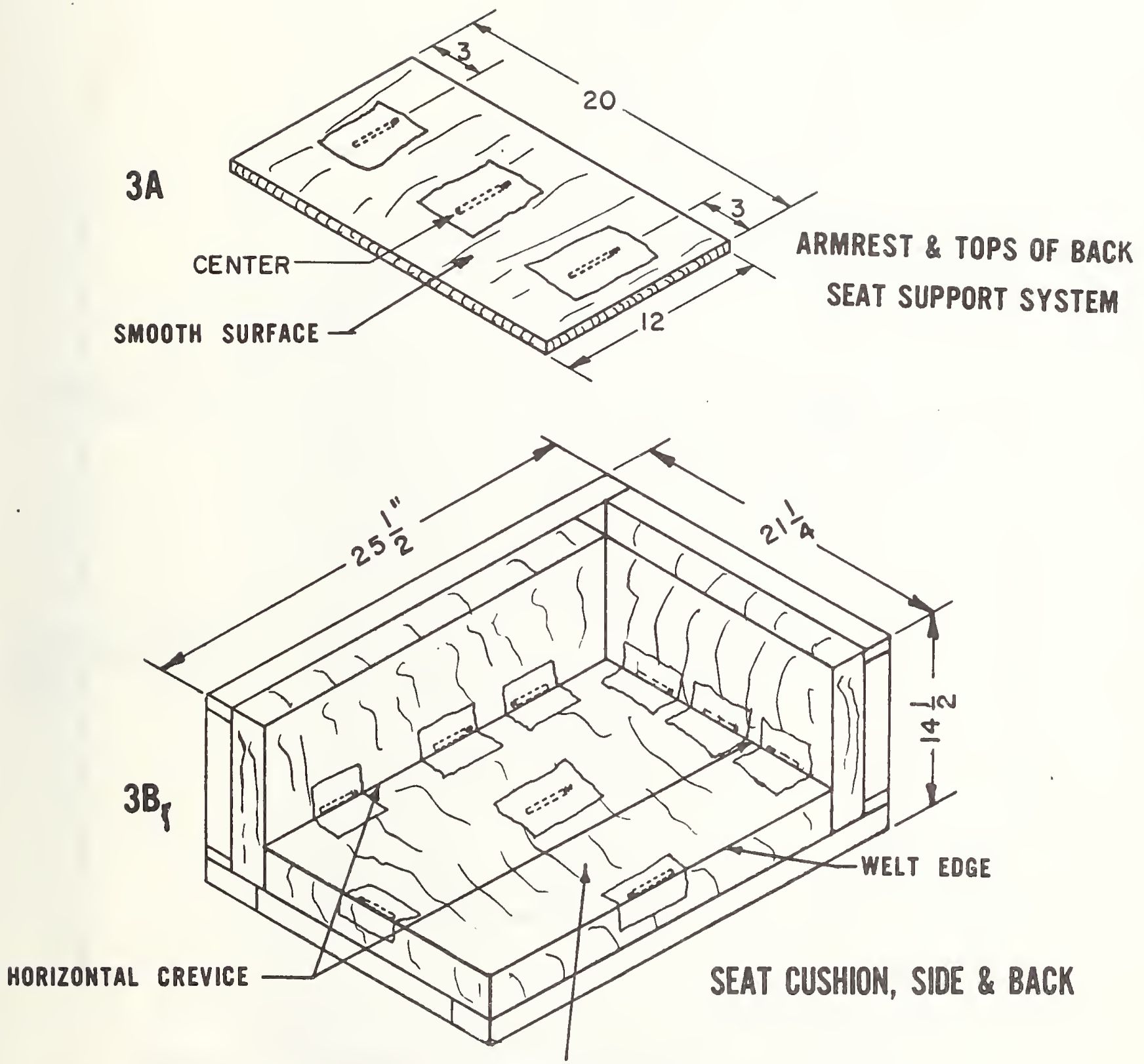

\section{SMOOTH SURFACE}




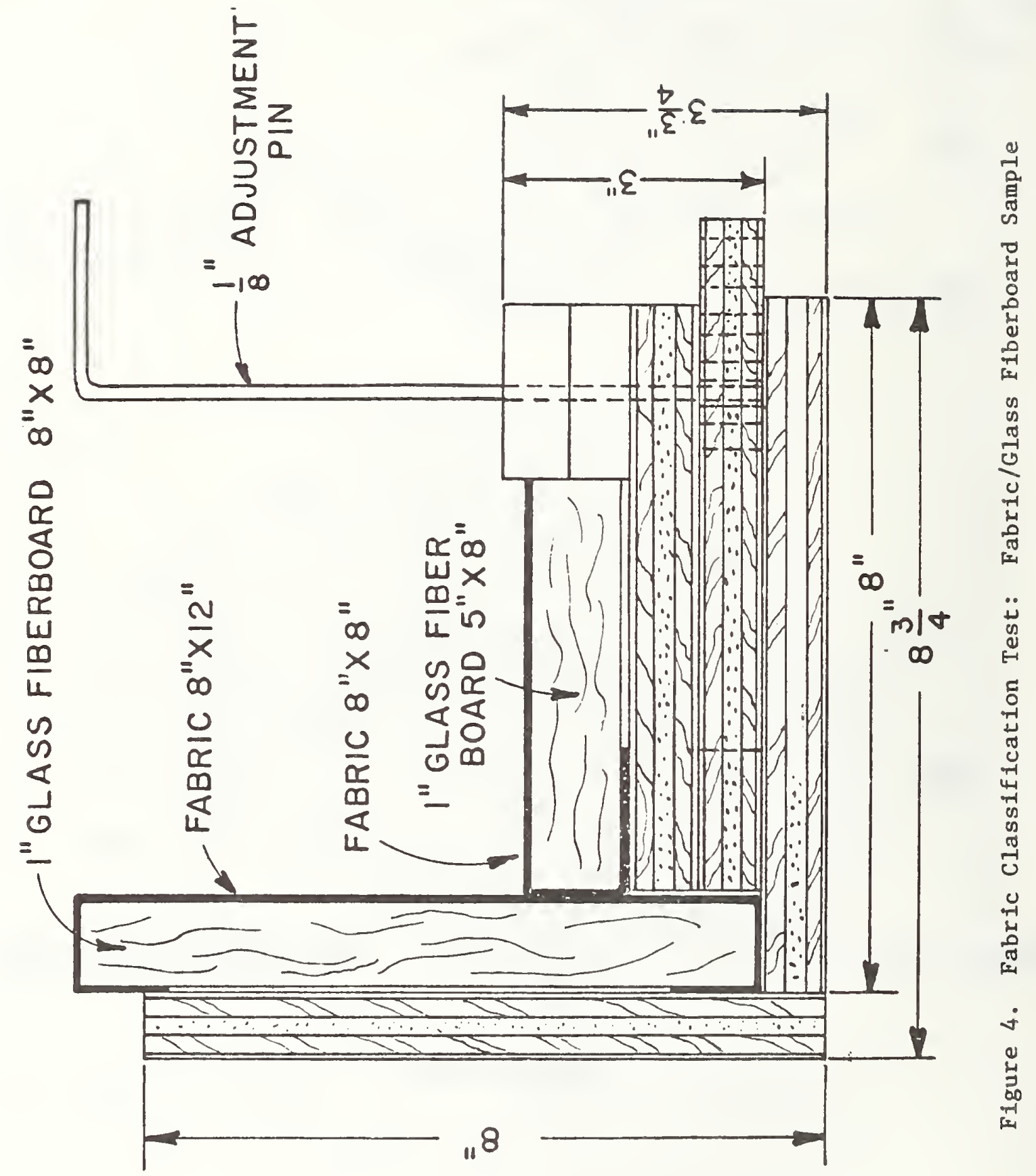




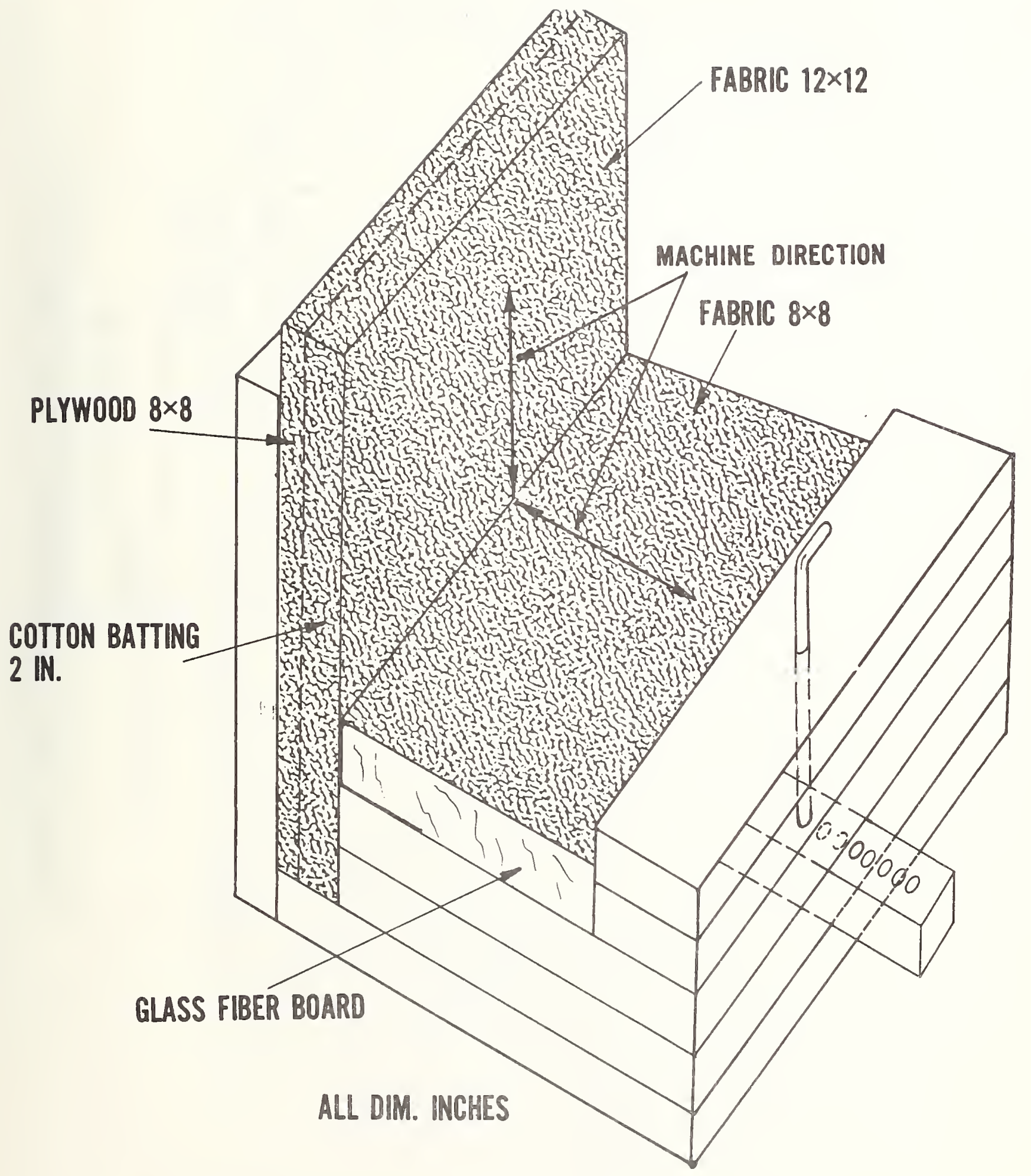

Figure 5. Fabric Classification Test: Fabric/Cotton Batting Sample 


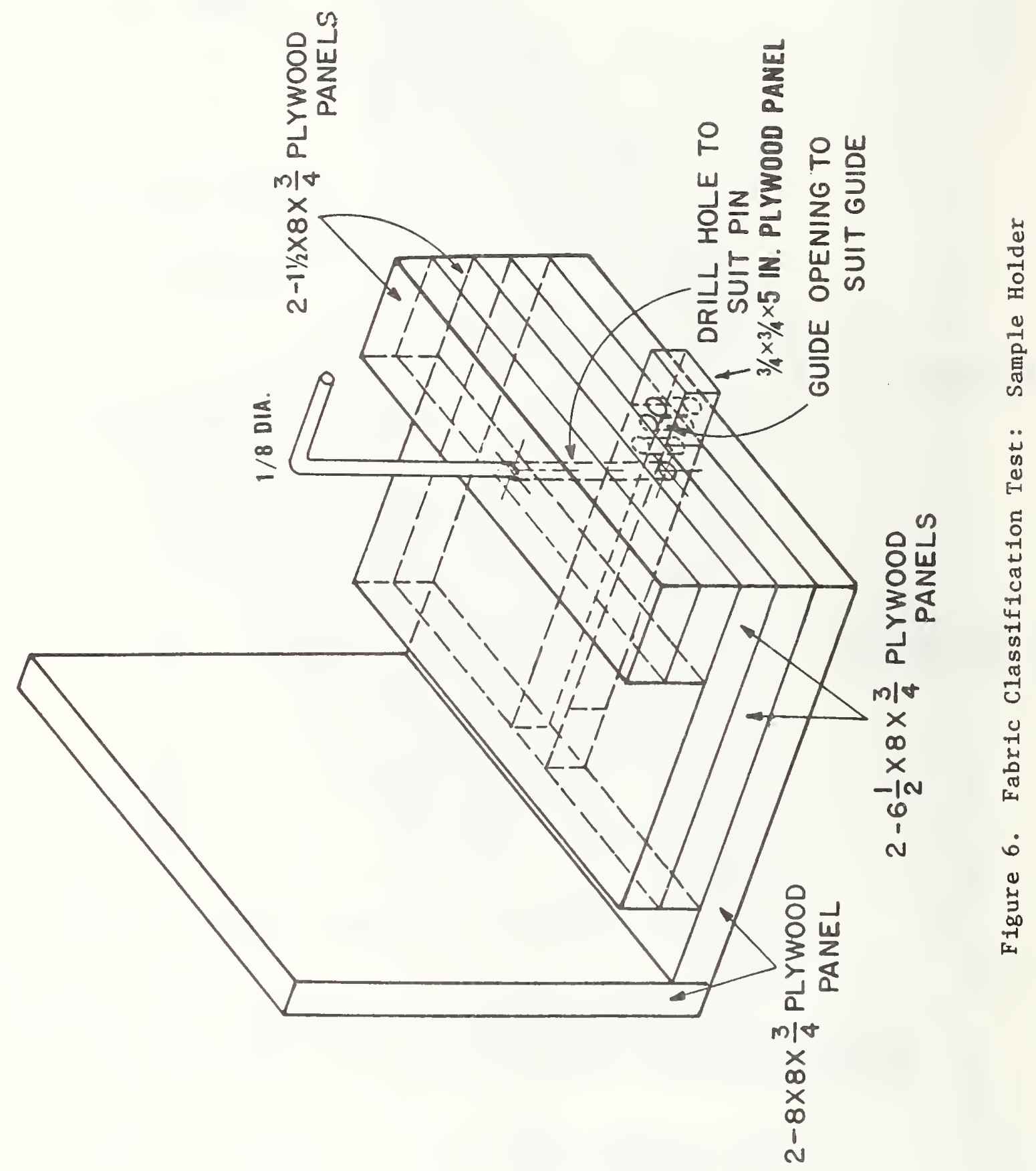




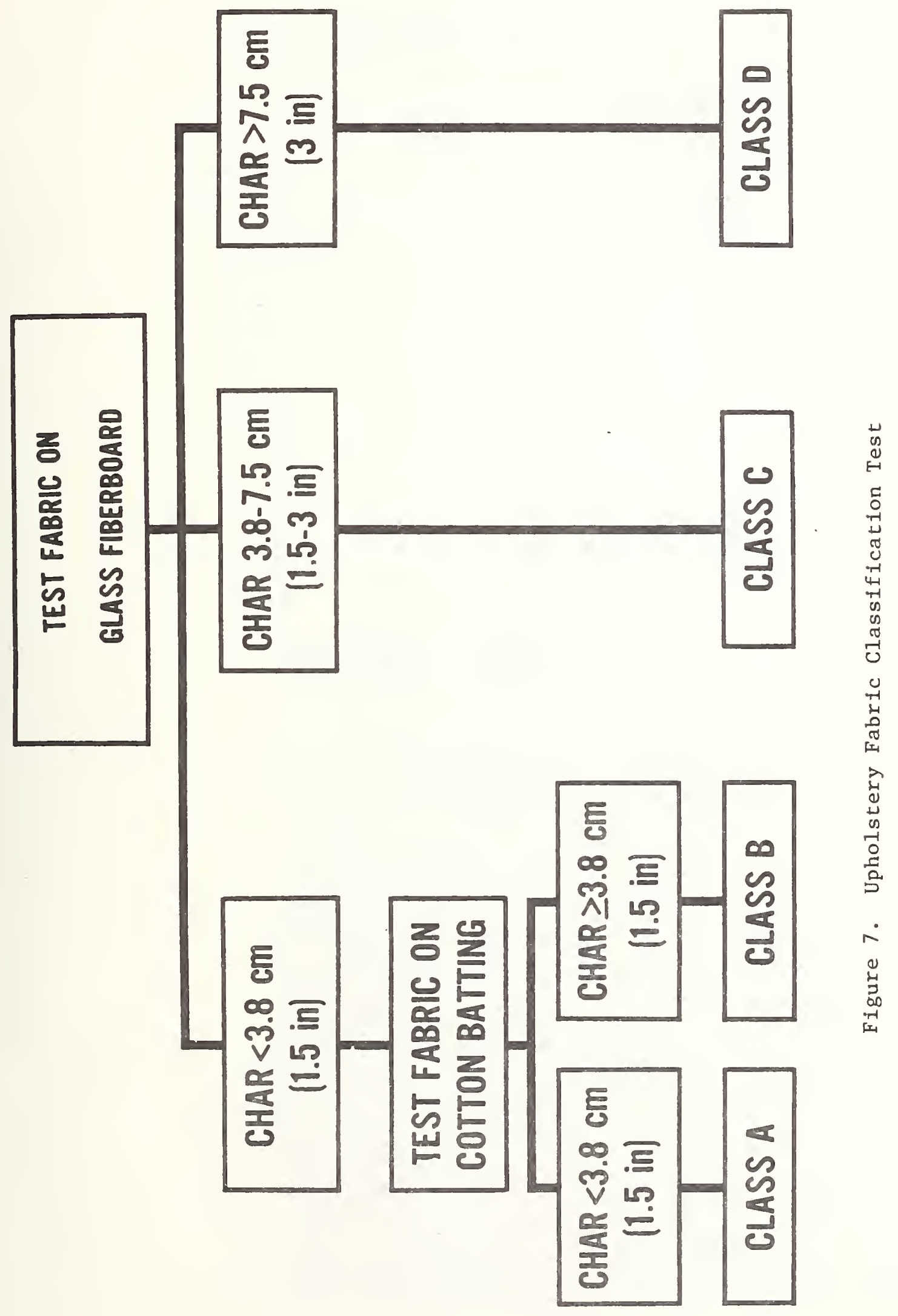




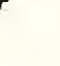


ards as conttnuous slow buming or smoldering and the resultant production of smoke or toxic atmospheres leading to desth, injury, or slgnifcant property damage.

Bases for Need. A detalled analysis of the 130 upholstered furniture Innition in. cidents in the National Bureau of Btandands" Fammable Fabrics Accident Caso and Testung Bystem (FFACTB) in April 1072 Indlcates the following:

. The icrition sequence was known in 114 of the 130 incidents. Upholstered furnture was the Arst product Ignited In 93 ( 81 percent) of these 114 incidents.

b. Of the 118 individuals directly involved in the 130 incidents, 74 were Lajored.

c. Thirty-three of these 74 individuals ded as a result of their injuries.

d. Of the 118 persons directly involved. 21 pereons became involved because of thet own or someone else's smoking.

e. Clgarettes (77.9 percent) and unbown smolding materials (8.1 percent) wers the Imnition sources in 74 of the 86 Incldents in which upholstered furniture whe the first product linited and the imition source was known. In seven of the 93 incidents in which urpholstery pren the frat to ignite the isnition source wes unimown.

In addition to the foregaing. dats $o b$ tained from publlc safety orgenizations and state and local fire departments in. dicate thet upholstered furnture ires constitute $\mathrm{ar}$ important category of

CPPARTUENT OF COMAEREE Ovice of the Secrotery

\section{[ 15 CFR Pon 7 ]} UPHOLSTERED FURNITURE

Musce of Finding That Flammobiliny Srenderd or Other Reguletion May D. Noodod and Institution of Proceodings

Finding. Pursuant to section $4(\mathrm{e})$ of the Mammable Fabrics Act, as amended (Bac. 8, 81 8tet. 569: 15 0.8.C. 1193) and 7.8 of the Mammable Fabrles Act Procedures (33 F.R. 14042, October 1, 1968), and upon the bests of investigations of research conducted pursuant to section 14 of the Flammable Frbrics Act. as amended (sec. 10, 81 Btet. 873; 18 U. S.C. 1201). It is hereby found that a nammbbtity standard or standards, or other reculation, including labeling, may be needed for upholstered fumiture, and fabslcs or related materials intended to bo uned, or which may reasonably be expeeted to be used, in these products, to protect the public against unreasanable rtst of the occurrence of Are leading to desth or personal injury, or stgnificant oroperty damage.

There now exists no natlonal tammsbillty standard for upholstered furniture affording the general public protecton from an unreasonable rists of fre. Opholstered furniture, therefore, may be produced and made avallable for consumer purchase which through ordinary use would present auch soreseeable has- fabric fires and cause major injury and economic losses. A etudy conducted between 1966 and 1988 by the Nationd Fure Protectlon Association has indlcated that smoking on upholstered furniture wes responstble for over 16 percent of the single fatality nonclothing Ares atudied. for which the causes of ignition were known and stated. ("Bingle Fatallty Fire." an NIMA Fire Record Department Btudy, "Plre Journal." January 1968.)

In 1870 report on fires in Oregon in. volving furniture, furnishings, and clothins where loss occurred, bedding and upholstery material were the initial materfal Irnited in 60.9 percent of the cases: upholstered furniture wes the Arst msterial icnited in over 23 percent of theso cases, with the remaining 37.5 percent attributed to mattresses or bedding $1 \%$. nttons. (Annual statistical Report for the Calendar Year 1970 -published in 1971. C. Walter Btickney, State Fire Marshal, Salem. Oreg.) In a New Yort State report, bedding and furnituro Isbric ismittons constituted 59 percent of the cases involving casualties and 82.6 percent of the reported iabric lantion death cases. Of these New York statistics, furntture fabric and furnlshings accounted for 21.8 and 17.5 percent of the cases resuiting in injuries and deaths, respectively. with the remainder of the cases attributed to bedding Ignitions. (New York 8tate Department of Fealth Burns Care Institute-Prevention Procram "Reported Flammable F'abrics Eplsodes, 1987-1971".)

Institution of proceedings.- Rursuant to secton $4(a)$ of the Flammable Fabrias 
Act, as amended (sec. 3,81 Stat. $589 ; 15$ U.S.C. 1193) and 7.6(a) of the Flammable Fabrics Act Procedures (33 F.R. 14642, October 1, 1968), notice is hereby given of the institution of proceedings for the development of an appropriate flammability standard or standards, or other regulation, including labeling, for upholstered furniture, and fabrics or related materials intended to be used, or which may reasonably be expected to be used, in these products.

Participation in Proceedings.-All interested persons are invited to submit written comments or suggestions within 30 days after the date of publication of this notice in the FEderal Register relative to (1) the above finding that a new flammabillty standard or standards, or other regulation, including labeling, may be needed: arnd (2) the terms or sutstance of a flammability standard or standards, or other regulation, including labeling, that might be adopted in the event that a final finding is made by the Secretary of Commerce that such a standard or standards, or other regulation, are needed to adequately protect the public against the unreasonable risk of the occurrence of fire leading to death, injury, or significant property damage. Written comments or suggestions should be submitted in at least four (4) coples to the Assistant Secretary for Science and Technology, Room 3862, U.S. Department of Commerce, Washington, DC 20230 , and should include any data or other information pertinent to the subject.

Inspection of Relevant Documents.The written comments recelved pursuant to this notice will be avallable for public inspection at the Central Reference and Records Inspection Facllity of the Department of Commerce, Room 7043, Main Commerce Bullding, 14th Street between E Street and Constitution Avenue NW., Washington, DC 20230

A supporting document is avallable for inspection in the above facility. The document contains in more detall the data which are summarized in the preceding portions of this notice.

Issued: November 24, 1972.

Richard O. Simpson, Acting Assistant Secretary for Science and Technology.

|FR Doc.72-20488 P1led 11-24-72;2:56 am | 


\section{FIRE DEATH SCENARIOS AND}

\section{FIRESAFETY PLANNING}

A useful method for analyzing such real world events is to construct typical "scenarios" to describe a series of events leading up to fire loss. The scenario concept is a common tool in long-range planning; ${ }^{1}$ we are interested in scenarios as an aid to formulating action plans for firesafety focused on both the present and the near future.

The purpose of this article is to introduce the scenario concept to fresafety program planning and to show how the available data, although imperfect, can be used to develop a quantitative ranking of scenarios for the most distressing aspect of fire losses: fire death.

Leaving aside the human behavioral aspects, it is possible to describe any fire incident in terms of the type of loss and the circumstances that surround it. This can be done using six characteristics:

Circumstances

$$
\left\{\begin{array}{l}
\text { 1) Type of Loss - Death, injury, and } \\
\text { /or property; } \\
\text { 2) Type of Occupancy - Residential, } \\
\text { industrial, etc.; } \\
\text { 3) Time - Day, night; } \\
\text { 4) Ignition Source - Smoking, elec- } \\
\text { trical appliances, etc.; } \\
\text { 5) Item Ignited or Agents of Spread } \\
\text { - Apparel, furnishings, etc.; } \\
\text { 6) Direct Cause of Loss - Smoke } \\
\text { and gas, heat and flame. }
\end{array}\right.
$$

For example, a death caused by a smoldering mattress might be described as: (1) death; (2) residence; (3) night; (4) smoking; (5) fumishings; (6) smoke and gas.

This approach can yield over a thousand possible, different scenarios for each of the three kinds of fire loss, depending on the number of elements in each of the categories. A system of 5,040 different scenarios was recently employed by the National Bureau of Standards' Center for Fire Research in developing a research plan. ${ }^{2}$

The most important function of the scenario is to focus attention on the ways in which the causal chain can be broken. But not all scenarios are equally likely to occur, so the second step is to identify the ones that

\footnotetext{
"See, for example, R. Zertner, "Scenarios in Forecasting," Chemical and Engineering News, Vol. 53, No. 40 (October 6, 1975 ), p. 22, and references cited therein.

"Reducing the Nation's Fire Losses, the Research Plan," Center for Fire Research, National Bureau of Standards, January, 1976.
} 
represent likely situations and the ones that do not. The smoking-in-bed scenario, for example, is a significant occurrence, but there are many conceivable scenarios that may be largely artificial. Therefore, a selection process must take place, leading to a ranking of the most important scenarios. Ideally, they would be listed in order of the contribution to actual fre losses that each represents.

The best way to achieve this would be by an analysis of fre loss statistics. However, in order to rank 5,000 scenarios, one needs in-depth data on hundreds of thousands of selected fire incidents. While the National Fire Data System of the National Fire Prevention and Control Administration will eventually be able to provide the necessary statistics, the present data are too limited to allow the job to be done properly.

In the interim, two options are available. A nonquantitative approach can be used to rank the scenarios by "expert judgment," or the scenarios can be simplified by removing categories and combining elements until a point is reached where actual data can be used. Both options are imperfect. The nonquantitative approach is only as good as the experts' judgment, ${ }^{3}$ and the databased approach limits the amount of information that the scenario can presently supply. In the long run, however, the quantitative approach is the method of choice simply because increasingly good statistics will eventually eliminate the need for oversimplifcation.

In anticipation of that time, and to demonstrate the surprising amount of information that can be gained now from a quantitative approach, we have surveyed the available data to identify and rank what appear to be the most frequent scenarios for fire death in the United States. The top fourteen of these are reported in this article. Together, they are believed to account for almost two-thirds of the nation's fire deaths.

\section{Fire Death Scenarios}

Figure 1 is a schematic illustration of a simplified scenario classification system. Note that "time of day" and "direct cause of loss" are omitted; this information is not yet included in most fire death reports. In addition, the term "agents of spread" has been' dropped in favor of the simpler term "item ignited." Although existing data sources contain some information on

\footnotetext{
- Both NBS and the NFPA presently rely partially on the nonquantitative Delphi technique in their planning activities. See W. Middendorf, "A Modified Delphi Method of Solving Business Problems," IEEE Transactions on Engineering Management, Vol. EM-20, No. 4 (November 1973), p. 130.
}

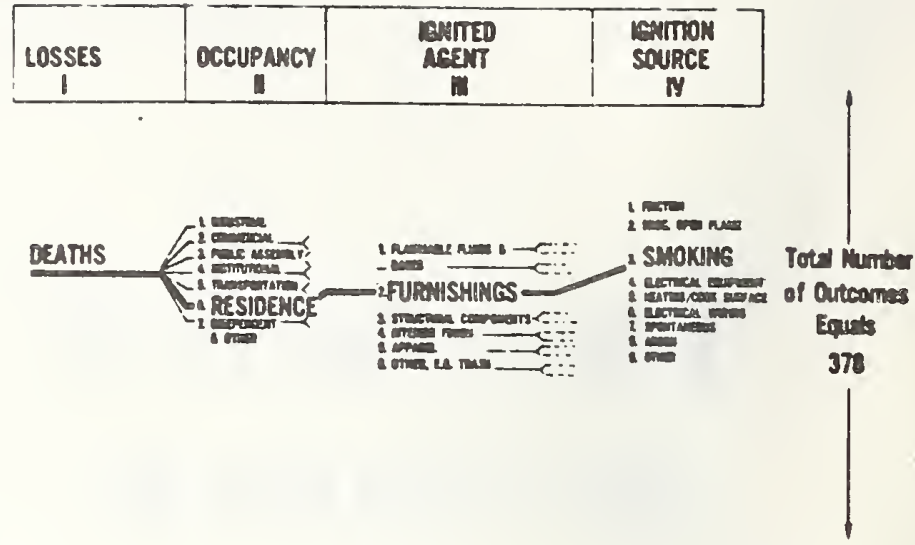

Figure 1. Elements of fire scenario and specific loss paths.

spread agents, the data-processing techniques for reducing the appropriate terms to a proper format are still incomplete. Thus, for the present, we have restricted the discussion to "item ignited." Associated with each death is one of seven occupancies, one of six ignited items, and one of nine ignition sources. A given path through the Figure, such as the one shown in boldface type, constitutes a single scenario. For the system shown, there are 518 different possible scenarios. Occupancy category No. 7, listed as "independent," reflects the fact that in a number of fire death cases, such as many of those involving apparel or those occuring outdoors, specifying the occupancy is not important in understanding how the incident occurred. In such cases, therefore, the circumstances surrounding the death are, in effect, "independent" of occupancy.

In principle, ranking the scenarios in order of importance involves: 1) ranking occupancies in order of frequency of fire death; 2) for each occupancy in turn, ranking the item ignited by frequency of fire death; ....d 3) for each ignited agent, similarly ranking the ignition sources. Data needed to accomplish these rankings are not generally available. For example, the statistics that the NFPA publishes yearly ${ }^{4}$ on fire losses cannot be used because reported fire deaths cannot be connected to specific circumstances. In other words, they do not allow us to say, for example, how many deaths are caused by toxic gases from smoldering furniture ignited by a cigarette. In fact, there is presently no single source for these data. However, we were able

- See "Fires and Fire Losses Classified, 1974," FIrE journal, Vol. 69, No. 5 (September, 1975), p. 43. 
to combine features of four different systems to yield the necessary statistics. The four systems are:

1) The FIDO (Fire Incident Data Organization) file maintained by NFPA. This is a computerized file of fire experience; data collection began in 1971. Approximately 30,000 fire-related incidents are in the data base. Each is characterized by some 60 coded attributes. $^{3}$ The incidents are primarily fires causing death, injury, or major property loss $(\$ 50,000$ or greater). However, the coded fires include approximately 11,000 fatalities, or about 20 percent of all fire deaths in the United States in the period from 1971 to 1975. A little more than one-third of these deaths are filed in sufficient detail to permit identification of the ignition source and ignited agent. This compilation is the largest known US source of in-depth fire death data, and is the mainstay of this study. Since the FIDO file is maintained from reports submitted by fire departments, relatively few fire fatalities caused solely by apparel fires are included. This reflects the fact that the apparel fire is usually small, and often is not reported to the fire service.

2) National Fire Data System (NFDS), of the National Fire Data Center, National Fire Prevention and Control Administration. The NFDS currently contains about 60,000 incidents reported by the fire services from various cities in California, Colorado, and Florida, including approximately 140 fatalities.

The NFDS was queried (from the NFPA's remote terminal in Boston) as to where the fire deaths occur, as a check on FIDO's occupancy figures. The results are shown in Table 1A. Agreement between FIDO and NFDS was remarkably good. Inspection of the Table shows only two areas where significant differences appear. The first difference is that FIDO includes more mobile home deaths than NFDS does. These figures are probably a reflection of the NFPA's three-year effort to obtain data on mobile home fires. The second difference is in the percentage of fire deaths in motor vehicles. While it is possible that this number is understated by FIDO, the small number of deaths presently in the NFDS (the difference between 4 percent and 10 percent of all NFDS fire deaths is only eight deaths) makes drawing any conclusions premature. In general, the two sets of figures agree well.

"See J. Ottoson, "Attribute Analysis," Fire Technology, Vol. 11, No. 1 (February, 1975), p. 29.

- The comparison is heartening in itself, but the routine process by which it was made is a landmark. To have the resources of the NFDS available to the fire community on a routine basis is a major advance in the communication and exchange of fire data.
Table 1.

Where US Fire Deaths Occur

1A. Reported by Fire Departments

\begin{tabular}{|c|c|c|}
\hline \multirow[b]{2}{*}{ Occupancy } & \multicolumn{2}{|c|}{ Percentage of Fire Deaths } \\
\hline & NFPA $(F I D O)$ & NFPCA (NFDS) \\
\hline Residential & 84 & 76 \\
\hline $\begin{array}{l}\text { One- and Two-Family } \\
\text { Apartment } \\
\text { Mobile Home } \\
\text { Other }\end{array}$ & $\begin{array}{r}52 \\
20 \\
7 \\
5\end{array}$ & $\begin{array}{r}55 \\
16 \\
1 \\
4\end{array}$ \\
\hline $\begin{array}{l}\text { Institutional } \\
\text { Public Assembly } \\
\text { Commercial } \\
\text { Industrial } \\
\text { Motor Vehicles } \\
\text { Others }\end{array}$ & $\begin{array}{l}2 \\
2 \\
1 \\
4 \\
4 \\
3\end{array}$ & $\begin{array}{r}2 \\
1 \\
1 \\
4 \\
10 \\
6\end{array}$ \\
\hline & 100 & 100 \\
\hline
\end{tabular}

1B. FIDO Data, Adjusted for Unreported Categories
Occupancy

Residential

Independent of Structure

Apparel

Apparel Plus Flammable Fluids

Motor Vehicles

Industrial

Institutional

Public Assembly

Commercial

Others

\section{Percentage of Fire Deaths}

72

14

11

3
3) "Accidents Caused by Fires and Flames" in Vital Statistics of the United States, Volume II (Mortality). compiled annually by the National Center for Health Statistics (CHS), Bureau of Vital Statistics, US Department of Health, Education and Welfare. The data are taken from vital statistics information compiled at the state level. Fire deaths are broken down rough!y by occupancy, but no additional information such as ignition source and agent is provided. Apparel fire deaths are included, but motor vehicle fire deaths are excluded.

4) Flammable Fabrics Accident Case and Testing System (FFACTS), developed at the National Bureau of Standards, and now maintained by the Consumer Product Safety Commission. This file contains detailed information on ignition sources for about 3,300 apparelrelated fire incidents, including 300 fre deaths.

Despite the fact that no single data base contains all the necessary information, the four listed here can

(Continued on page 117) 
be used $^{7}$ to yield a representative picture of IJS fire deaths. The most complete file of fire experience is FIDO, but it does not fairly depict the entire fire death picture, since apparel-related fres are under-represented. The CHS statistics, on the other hand, give a representation of apparel-related deaths, but do not reflect motor vehicle-related fires. Each of these two sources is missing one category, but since they are not missing the same one, it is a simple mathematical exercise to correct both sets of statistics for the missing categories. ${ }^{8}$ The FIDO data, corrected for apparelrelated fire deaths, are shown in Table 1B. This list of fre deaths by occupancy was then broken down into percentages by scenario, using FIDO, or, in the case of apparel fires, using FFACTS.

\section{The Top Fourteen Fire Death Scenarios}

The most common fire death scenario, by far, is the residential furnishings fire caused by smoking materials, which alone accounts for 27 percent of fire deaths. This figure was derived as follows. First, we estimate that 72 percent of the nation's fire deaths occur in residences, as shown in Table 1B. Of all rèsidential fire deaths in the FIDO file, 54 percent involved the ignition of fumishings. Roughly half of this total was contributed by soft goods (principally mattresses and bedclothes), and half by upholstered furniture. Of all residential fatalities involving furnishings in the FIDO fle, 70 percent were reportedly ignited by smoking materials. Thus the fraction of total fire deaths associated with the residential-furnishings-smoking scenario is $(72 \% \times 54 \% \times 70 \%=) 27 \%$. The percentages associated with the other scenarios were similarly derived. We report here only those scenarios that accounted for 2 percent or more of fire deaths; they total fourteen.

The top fourteen fre scenarios are shown in Table 2. Together, they account for about 66 percent, or nearly two-thirds, of fire deaths in the United States, based on available data.

Residential furnishings fires alone account for 36 percent of the total deaths (scenarios 1,2 , and $3 \mathrm{c}$ ).

Three scenarios tie for third place, each accounting for about 4 percent of fre deaths. The transportation scenario, 3a, primarily represents the ignition of gaso-

\footnotetext{
'For the details of this procedure, see F. Clarke and J. Ottoson, "Developing Fire Scenarios From Available Data," Fire Technology, in press.

- Aircraft-related fire deaths are not part of either set, and therefore they could not be included in the overall exercise.
}

Table 2.

The Top Fire Death Scenarios

\begin{tabular}{|c|c|c|c|c|}
\hline Rank & Occupancy & Item Ignited & $\begin{array}{l}\text { Ignition } \\
\text { Source }\end{array}$ & $\begin{array}{l}\text { Fire } \\
\text { Death }\end{array}$ \\
\hline 1 & Residential & Furnishings & Smoking & 27 \\
\hline 2 & Residential & Furnishings & Open Flame & 5 \\
\hline \multirow[t]{3}{*}{3} & a. Transportation & $\begin{array}{l}\text { Flammable } \\
\text { Fluids }\end{array}$ & Several & \\
\hline & $\begin{array}{l}\text { b. Independent } \\
\text { (Residential) }\end{array}$ & Apparel & $\begin{array}{l}\text { Heating and } \\
\text { Cooking } \\
\text { Equipment }\end{array}$ & 4 \\
\hline & c. Residential & Furnishings & $\begin{array}{l}\text { Heating and } \\
\text { Cooking } \\
\text { Equipment }\end{array}$ & 4 \\
\hline \multirow[t]{4}{*}{6} & a. Independent & $\begin{array}{l}\text { Apparel/ } \\
\text { Flammable } \\
\text { Liquids }\end{array}$ & Several & 3 \\
\hline & b. Residential & $\begin{array}{l}\text { Flammable } \\
\text { Liquids }\end{array}$ & $\begin{array}{l}\text { Heating and } \\
\text { Cooking } \\
\text { Equipment }\end{array}$ & 3 \\
\hline & c. Residential & $\begin{array}{l}\text { Flammable } \\
\text { Liquids }\end{array}$ & Open Flame & 3 \\
\hline & d. Independent & Apparel & Open Flame & 3 \\
\hline \multirow[t]{7}{*}{10} & a. Residential & $\begin{array}{l}\text { Interior } \\
\text { Finish }\end{array}$ & $\begin{array}{l}\text { Heating and } \\
\text { Cooking } \\
\text { Equipment }\end{array}$ & 2 \\
\hline & b. Residential & $\begin{array}{l}\text { Interior } \\
\quad \text { Finish }\end{array}$ & $\begin{array}{l}\text { Electrical } \\
\text { Equipment }\end{array}$ & 2 \\
\hline & c. Independent & Apparel & Smoking & 2 \\
\hline & d. Residential & Structural & $\begin{array}{l}\text { Electrical } \\
\text { Equipment }\end{array}$ & 2 \\
\hline & e. Residential & Trash & Smoking & 2 \\
\hline & \multirow{2}{*}{\multicolumn{3}{|c|}{ Others, all less than 2 percent of total }} & \\
\hline & & & & \\
\hline
\end{tabular}

line, which is generally the result of motor vehicle accidents. Precise ignition sources in this scenario were difficult to pinpoint. They were variously reported as friction, hot surface, and the like. We have therefore grouped ther "ogether as "several."

Scenario 3. the apparel fire death ignited by heating and cookıng equipment, is listed as independent of occupancy, but in fact it could also be cailed a residential fire death, since the ignition almost always occurs in the home.

Three of the four fres in sixth place involve flammable fluids. Scenario 6a, the apparel fire in which flammable liquids play a role, was caused, like the vehicle fire death, by a variety of ignition sources. An 
important segment of this scenario is the well-known "barbecue grill" fatality, involving the improper use of a gasoline or charcoal starter. Scenarios $6 b$ and $6 c$, which together account for 6 percent of all fire deaths, are ignitions of a flammable fluid in the home, such as an cxplosion caused by a gas leak. Scenario $6 \mathrm{~d}$ includes the case of a child playing with matches.

Scenarios 10a and 10b both involve ignitions of intcrior finishcs, principally wall and floor coverings, by appliances or clectrical wiring. Sccnario $10 \mathrm{c}$, another apparel fire, is the direct result of smoking. Scenario $10 \mathrm{~d}$ is the only significant instance in which a residence's structural members, such as framing, are ignited directly - in this casc, by faulty wiring. Sccnario $10 \mathrm{e}$ is the result of a rcsidential trash fire. This extremely common cause of fires ${ }^{4}$ is a rclatively uncommon causc of fire death.

In several instances, the reporting or classification system was inadequate to define preciscly even these abbreviated sccnarios. For example, the role of flammable fluids in apparel and residential fires is not adequately described. The role of these materials, which often play an intcrmediary role in the fire chain, needs to be clarified.

Implications for Firesafety Program Planning

Somc sort of fire loss ranking system is basic to any attempt to plan and evaluate firesafety programs. The scenario concept has proven to be a useful tool in planning, both at the NFPA and in the federal firc effort. As the nation's new fire data systcm matures, more and better data will permit existing scenarios to be reranked and new ones to be formulated. The sccnarios will also be exprcssible in more dctail, approaching something like the six-component system discussed earlicr. As the scenarios become morc detailed, all firesafety programs designed to reduce life loss can be focused with correspondingly greater precision. Nevertheless, there are at least thrce points, of importance to any planning effort, that are already clear.

1) Note that, with thc exception of transportation and apparel fires, all scenarios that involve 2 percent or more of the fire deaths occur in the home. Thus, fatalities occuring in largc office buildings, for exam- ple, or in nursing homes, are a very small part of the whole fire death picture, despite the public attention they attract. It is vital to protect these occupancies, but at the same time, the more glaring aspects of the problem cannot be ignored. In particular, the residential fire fatality and the role of furnishings therein need to be rccognized as crucial points for action if fire losses are to be substantially reduced.

Indeed, the national goal ${ }^{\circ}$ of reducing fire losses by 50 percent, as established by the National Commission on Fire Prevention and Control, cannot be accomplished unless the residential problem is addressed, simply because there is far less than 50 percent of the dcaths in all other occupancies combined.

2) Those features of a residence normally controlled by building codes, such as structural components and intcrior finish, are seldom the items frst ignited in fatal fires. This distinction belongs far more often ( 36 percent vs. 6 percent) to furnishings. In other words, the building contents, not the building itself, is the most likely starting point for a fatal fire. Consequently, breaking the fire chain in its early stages may best be done through such measures as improving the ignition resistance of materials, or installation of a residential smoke detector.

3) The scenarios highlight some areas where foresecablc technology will be of little or no help. Examples of these are scenarios involving the ignition of Alammable Aluids, either in conjunction with apparel or residential fires. It is helpful to recognize these areas clearly, so that other, more promising techniques, such as education of the public, can be brought to bear upon them.

The scenario approach is, in principle, extendable to other areas of fire losscs - injury and property damagr - as well as to fire deaths. Its capabilities are presently limited on all fronts, however, by the available data. Ncvertheless, we have tried to show that, even with these limitations, scenarios are useful now in shaping our attack on the fire problem.

"See Amcrica Burning - The Report of the National Contmission on Fire Prevention and Control (Washington, D.C.: US Gnvernment Printing Office, 1973). 

APPENDIX C

PART 1633--PEOPOSED STANDARD FOR THE FLAMMABILITY (CIGARETTE

IGNITION RESISTANCE) OF UPHOLSTERED FURNITURE (PFF 6-76)

Sec.

1633.1 Scole and application.

1633.2 Defintions.

1633.3 General requirements, furniture.

1633.4 Test procedure, furniture.

1633.5 General requirements, fabric.

1633.6 Test procedure, fabric.

1633.7 Test results, fabric.

1633.8 Labeling requirements.

1633.9 Glossary of terms.

1633.10 Effective date.

AUTHORITY; Sec. 4, 67 Stat. 112, as amended 81 Stat. 569-70, 90 Stat. 515; 15 U.S.C. 1193.

$\S 1633.1$ Scope and application.

(a) This Part 1633 sets forth the proposed standard that prescribes (1) requirements and a test method for determining the cigarette ignition resistance of upholstered furniture and (2) a method of classifying individual upholstery fabrics and related materials intended or promoted for use as the outer cover of upholstered furniture. This Part 1633 is applicable to all upholstered furniture manufactured for sale on or after its effective date, including furniture that is reupholstered for sale or intended for sale by a reupholsterer or its customer. 
(b) All upholstered furniture items, as defined in $\S 1633.2$ (c), are subject to the requirements of this Part 1633.

\section{$\S 1633.2$ Definitions.}

In addition to the defintions given in section 2 of the Flammable Fabrics Act as amended (sec. 2, 81 Stat. 568; 15 U.S.C. 1191) and $\$ 1607.2$ of this chapter, the following definitions apply for the purposes of this Part 1633:

(a) (1) "Upholstered furniture" means a unit of Interior furnishing (i) with a resilient surface covered, in whole or in part, with a fabric or related material, (i1) that is intended for use or may be reasonably expected to be used in homes, offices, or other places of assembly or accommodation, and (iil) that is intended or promoted for sitting or reclining upon.

(2) This definition of the term "upholstered furniture" includes, but is not limited to, seating pleces such as boudoir chairs, chairs, chaise lounges, convertible sofas, daybeds, jackknife sofa beds, lounge chairs, loveseats, ottomans, platform rockers, press-back lounges', pushback sofas, reclining chairs, recliners, sectional sofas, sleep lounges, sofas, sofa lounges, studio couches, studio divans, and swivel rockers. (These items are more fully described in $\S 163 \pm .9$ Glossary of terms.) Mattresses that are used in conjunction with these items shall continue to be regulated by the Standard for the Flammability of Mattresses (FF 4-72) set forth in Part 1632 of this chapter. 
(3) This definition of "upholstered furniture". does not include any 1tem of inflatable furniture, any mattress covered by Part 1632 of this chapter, or any chalr or stool which has an upholstered seat and upholstered sack and/or sides and the back and/or sides are not within $2.5 \mathrm{~cm}(1 \mathrm{ln})$ of the seat cushion.

(b) "Reupholstered furniture" means a unit of upholstered furriture, as defined in paragraph (a) of this section, that has been reworked to replace any materials such as the upholstery fabric, cushioning, or upholstery materials.

(c) "Item" means any product of upholstered furniture, reupholstered furniture, or any upholstery fabric or related material intended or promoted for use in upholstered furniture defined in paragraph (a) of this section.

(d) "Upholstery fabric" means the outer-most layer of fabric or related material used to enclose the main support system and upholstery material used in the furniture item. Slipcovers are excluded from this definition.

(e) "Main support system" means the frame or other supporting structure in the furniture item. Main support systems may be constructed of materials such as wood, plastic (including foam), or metal.

(f) "Upholstery material" means the padding, stuffing, or filling material used in a furniture item. This material may be either loose or attached, enclosed by an upholstery fabric, or located between the upholstery fabric and support system, if present. This definition includes, but is not limited to, materials such as springs, foams, 
cotton batting, polyester fiberfill, bonded cellulose, or down used in cushions.

(g) "Welt edge" or "edge" means the seam or border edge of a cushion, pillow, arm, or back of an item.

(h) "Quilted" means fused or stitched with thread through the upholstery fabric and one or more layers of upholstery material.

(i) "Tufted" means buttoned or laced through the upholstery fabric and upholstery material.

(j) "Fabric class" means the fabric classification of A, B, C, or $\mathrm{D}$ as defined in $\S 1633.7(\mathrm{~b})$.

(k) "Production furniture" means all upholstered furniture manufactured or reupholstered for sale.

(1) "Furniture mockup" means a representation of production furniture that utilizes the same upholstery fabric or an acceptable fabric (as defined in \& $1633.3(\mathrm{~b})(4)$ ) representing the fabric class, the same upholstery materials, and which are assembled in the order used in the production furniture. For the purpose of this Part 1633, mockup is both singular and plural.

(m) "Fabric type" means an upholstery fabric of a specific construction, color or combination of colors and color pattern, weave pattern design, finish application, fiber content, and nominal weight per unit area. With respect to film-coated fabrics, a type includes a given method of application, chemical formula, and thickness of application of the film coating. 
(n) "Loose seat cushion" means any removable or interchangeable, attached or unattached, part of an upholstered furniture item upon which one sits.

(0) "I2ght seat" means any flxed or Integral part of the upholstered furniture 1tem upon which one sits.

(p) "Seat support system" means the supporting medium for loose seat cushions.

(q) "Specimen" means a plece of upholstery fabric cut to specified dimensions for testing.

(r) "Sample" means a specified arrangement of upholstery fabric specimens and cotton batting and/or glass fiber board that is required In $\$ 1633.6$ for determining the fabric classification.

(s) "Abutment" means a horizontal crevice formed where vertica side or back panels meet horizontal panels or seat cushions.

(t) "Burn out" means a clgarette has burned its entire length.

(u) "Butt end" means the unllt end of the cigarette.

(v) "Slipcover" means a removable, fitted cover (fahric or related material) for an armcha1r, sofa, etc.

(w) "Flammability" means the susceptibility of upholstered furniture to ignition from smoldering cigarettes.

(x) "Surface location" means the designated surface locations on the mockup or furniture 1 tem for cigarette placement, such as horizontal 
crevices, seat cushions (smooth, quilt, tuft, and welt edge areas) top of armrests, top of backs, and top of loose seat support systems.

(y) "Standard fabric" means the spectfied fabrics representing fabric classes $B$ and $C$ to be used in mockup test and acceptance under $\S \S 1633.3$ and 1633.4 .

\section{§ 1633.3 General requirements, furniture.}

All upholstered furniture manufactured for sale on or after the effective date of this Part 1633, Including furniture that is reupholstered for sale or intended for sale by a reupholsterer or its customer, must have been previously tested and accepted under the method described herein.

(a) Summary of test method for flammability of upholstered furniture. The test method requires the use of lighted clgarettes covered with a piece of sheeting material to measure the ignition resistance of upholstered furniture items reproduced in mockup. Exposed mockup surface locations to be tested include horizontal crevices where seat cushion and vertical panels meet; seat cushion surface locations including smooth surface, quilt, tuft, and relt edge; top surfaces of upholstered armrests; top surfaces of tops of backs; and top surfaces of seat support systems. A measurement of char length determines whether the particular combination of upholstery materials and the upholstery fabric class meets the test criterton. 
(b) Qualification. (1) Prior to manufacture of production furniture, mockups of each specified surface location of that furniture must be tested according to $\S 1633.4$ and must meet the requirements of $\$ 1633.3(\mathrm{~d})$. The number and types of surface locations that must be tested in mockup will depend on the construction and design of the production furntture to be manufactured. Section 1633.4 (b) prescribes mockup preparation, describes each type of test location, and how -nd under what circumstances the mockup must be constructed for the qualification of production furniture.

(2) A total mockup assembly or set which includes one or two vertical panels (back, side, both, or combination of two sides or two backs), one seat cushion (loose or tight), one loose seat support system, one top of armrest, and one top of back can be used to ouali:y several production furniture items (see $1633.3($ b) (4)) provided that a1] the production furniture items are constructed from the same upholstery materials, same upholstery fabric class, except Class D (classes defined at $\S 1633.7(\mathrm{~b})(4))$, and their assemblies for testing according to $\$ 1633.4$ are the same. Separate mockup tests are not required to qualify furniture items that are different only in size and shape. The basic objective is to qualify each specified st rface location with the required number of cigarettes. Therefore, as many as feasible surface locations representing different furniture items with common surface locations can be qualified at one time. In order to qualify furniture items to be manufactured with Class D fabrics, each fabric must be tested separately over each assembly of upholstery materials for which it is 
intended to be used in.production furniture, and be accepted in mockup. If a furniture item is manufactured to contain either smo th, quilted, or tufted cushions or seats, each type of cushion shall be tested and accepted separately in mockup assemblies.

(3) If it is determined or suspected, as a result of testing according to $\S 1633.4$, that a component material has influenced the ignition resistance of the furniture mockup, a dimensional or other change (except an increase in thickness) in that material shall be deemed a difference in materials for purposes of mockup testing, unless it is previously shown to the satisfaction of the Consumer Product Safety Commission that such dimensional or other changes will not reduce the ignition resistance of the furniture mockup. If it has been shown, as a result of testing according to $\S 1633.4$, that an upholstery matcrial has not influenced the resistance to ignition of the mockup, substitution of another material for said material shall not be deemed a difference in materials for mockup testing.

(4) Except for Class D upholstery fabrics (see $\S 1633.7$ (b) (4)), all fabrics within the same class may be substituted for one another, on production furniture, over the particular assembly of upholstery materials used in the mockup, without further testing acc rding to $\$ 1633.4$ after a furniture mockup covered with the appropriate fabric (any fabric representing Class $\mathrm{A}$ or the standard fabric for Class B or C) has been tested and accepted. Upholstery fabrics that fall into Class $\mathrm{D}$ must each be tested on a furniture mockup as described in $\$ 1633.4$, for each assembly of upholstery materials over which the fabric is intended to be 
used in production furniture, and be accepted thereon. At the option of the manufacturer, a Class A, B, or C fabric may be qualified on an Individual furniture mockup as is required for Class D fabrics.

(5) Each mockup qualification must be repeated at intervals not to exceed 3 calendar months if it is anticipated that production furniture based on such mockup qualification will be manufactured in the following 3-month period. In no event shall production furniture be manufactured if mockup qualification testing has not been performed within the past 3 months. The frequency of testing after the initial qualification, however, may be changed to a different period not to exceed 6 calendar months if there is documentation to show that each of the materials used in the production furniture that contributed to the cigarette ignition resistance characteristics of the furniture mockup came from a single manufacturing lot of such material. Specifications may be used in lieu of manufacturing lots provided the specifications contain sufficient details to control those parameters of the material that influence cigarette ignition resistance.

(c) Test criterion. After testing in accordance with $\S 1633.4$, individual cigarette test locations pass the test if the char length is not more than $7.5 \mathrm{~cm}$ ( $3 \mathrm{in}$ ) in any direction measured from the nearest point of the original cigarette location. In the interest of safety, the test operator should discontinue the test immediately and record a failure for that test location if an obvious ignition occurs.

(d) Acceptance criterion. Production furniture represented by qualified mockups may be manufactured for sale in commerce if all 
Individual cigarette test locations on the required mockup surface locations pass the test criterion of paragraph (c) of this section. Any surface location which sustained one cigarette test failure out of the three tested at that location may be retested with three additional cigarettes, and if none fail in the retest, then production furniture may be manufactured. If two or more cigarettes fail at any surface location, then production furniture may not be manufactured unt 11 t'ie design or materials used in that surface location have been changed, retested, and passed. For acceptance of the seat cushion surface location, the three cigarettes include the combination of the two. cigarettes on the welt edge and the one cigarette on the smooth area or quilted area or tufted area as applicable. Therefore, a retest of the seat cushion surface location includes all three cigarettes in the alove described two areas.

$\S 1633.4$ Test procedure, furniture.

(a) Apparatus--(1) Mockup frame and panels. (i) The mockup frame and panels for the test materials are illustrated and detailed in Figure 1 and Figure 2. The wooden framework shown in Figure 2 serves to support mockup reproductions of upholstered sides, backs, seat support systems, tops of upholstered furniture armrests, tops of backs, and tight seat cushions of production furniture, as shown in Figure 3.

(ii) An assembly of mockups as shown in Figure 3 and described in paragraph (a)(1)(i) of this section may consist of two vertical panels which may be two backs or two sides per seat cushion construction (tight 
or loose) or one back and one side per seat cushion. The seat support system, armrests and tops of backs are tested (F1gure 3) in separate constructions specified in paragraphs (b) (4) and (b) (7) of this section.

(2) Ignition source. The ignition source for the test shall be cigarettes without filter tips made from natural tobacco and which are $85 \pm 2 \mathrm{~mm}(3.4 \pm 0.1 \mathrm{in})$ long with a packing density of $0.270+0.020 \mathrm{~g} / \mathrm{cm}^{3}$ and a total weight of $1.1+0.1 \mathrm{~g}$.

(3) Sheeting material. Cotton or cotton-polyester blend bedsheeting material, with a weight of $125 \pm 28 \mathrm{~g} / \mathrm{m}^{2}\left(3.7 \pm 0.3 \mathrm{oz} / \mathrm{yd}^{2}\right)$, white in color, and not treated with flame retardants shall be used to cover the test cigarettes. The material shall be laundered in an automatic home washing machine and dried in a tumble dryer at least once before use. For testing, the sheeting material is cut into pieces approximately 12.5 by $12.5 \mathrm{~cm}$ ( 5 in by $5 \mathrm{in}$ ). An alternate sheeting material may be approved by the Consumer Product Safety Commission.

(4) Test room. The test room shall be draft protected and equipped with a suitable system for exhausting smoke and noxious gases produced during testing.

(5) Fire extinguisher. A pressurized-water fire extinguisher or other suitable fire extinguishing equipment shall be immediately available.

(6) Water bottle and water bucket. A bottle of water fitted with a spray nozzle shall be provided to extinguish any ignited portions of the mockup. A bucket of water shall be provided for immersing smoldering or burning materials removed from the mockups. 
(7) Scale. A linear scale at least 6 inches long, graduated in millimeter, 1/10-inch or 1/16-inch divisions, shall be used to measure char length.

(8) Standard fabrics. The following standard fabrics representing Classes $B$ and $C$ shall be used to qualify furniture constructions in mockup testing:

(1) Class B. Cotton or cotton and polyester blend bed sheeting materlal, welght $125 \pm 28 \mathrm{~g} / \mathrm{m}^{2}\left(3.7 \pm 0.8 \mathrm{oz} / \mathrm{yd}^{2}\right)$, white in color, and not treated with flame retardants shall be used to qualify all mockups to be used with Class B upholstery fabrics. This is the same fabric as used for covering cigarettes (paragraph (a)(3) of this section) and may or may not be laundered.

(ii) Class C. Cotton ticking listed under Federal Specification CCC-C-436D, Cloth, Ticking Tw111, Cotton, shall be used to qualify all mockups to be used with Class $C$ upholstery fabric. Specifically, the fabric shall be Type I, Class I, untreated and $9 \pm 0.50 z / y^{2}$.

(9) Other apparatus. In addition, straight pins, a staple gun, a knife or scissors, and tongs are required to carry out the testing.

(b) Mockup preparation--(1) Upholstery fabric. The standard fabric for the class (see $\$ 1633.4(a)(8)$ for Classes B and C fabrics), a fabric representing the class (Class $A$, see $\S 1633.2(j)$ ) or the particular fabric to be used in the production furniture (required for class $D$, optional for $A, B$, or $C$ ), shall be selected for testing. A swatch of fabric large enough to be cut into four specimens, each measuring about 55 by $68 \mathrm{~cm}$ ( 22 in by 27 in), shall be cut across the width of the fabric. 
(2) Upholstery material. Padding, stuffing, and filling materials that have the same specifications as the materials to be used in the production furniture construction shall be chosen for testing.

(3) Loose seat cushion. Seat cushions covered with the appropriate upholstery fabrlc shall be made for testing. Seat cushions shall be constructed in the same size (up to 69.0 by 69.0 by $13.0 \mathrm{~cm}(27.0$ by 27.0 by 5.0 in)) and manner and with the same materials as those tu be used in production furniture.

(4) Loose seat support system. Seat support systems shall be made for testing (if they are part of the production furniture) by attaching to the horizontal panel (figure 2) of the test apparatus the same upholstery materials used in actual furniture construction. The decking, standard fabric, or upholstery fabric shall be stretched over the top of the support materials and fastened to the underside of the wood framework with staples.

(5) Tight seat. If the production furniture is to be constructed with a tight seat, it shall be duplicated for testing in the mockup. For the purpose of this Part 1633, ottomans shall be considered tight seats for purposes of mockup testing. Tight seats shall be duplicated in mockup by making cushions $45 \pm 5 \mathrm{~cm}$ by $55 \pm 5 \mathrm{~cm}$ ( $18 \pm 2$ in by $22 \pm 2$ in) having the same thickness of upholstery material (or up to 4 inches) and the standard fabric, class fabric, or same fabric as that to be used in the production furniture. The cushion assembly shall be attached to the horizontal panel of the test apparatus. (Figure 2) by extending the fabric around the panel edges and stapling the fabric to the underside of the wood panel. 
(6) Side and back panels. Constructions of furniture sides and backs shall be made for testing (if they are part of the production furniture and are within $2.5 \mathrm{~cm}$ ( 1 in) of a seat cushion), by upholstering one surface of the vertical test panel (Figure 2) with the appropriate upholstery material and the standard fabric, class fabric, or same upholstery fabric to be used in production furniture, whichever is applicable. The fabric shall be stretched tightly over the upholstery material and shall be fastened to the backside of the panel with staples. All edges of the panels shall be covered with fabric. If the side and back construction of the production furniture are the same, only one vertical panel must be assembled and tested to qualify that vertical panel and seat custion combination.

Bolsters filled with the same material as used in the sides or backs need not be tested in mockup. However, if bolsters are filled with different material than the sides or backs, they shall be tested in the mockup assembly as a vertical panel either by constructing a bolster with the standard fabric, class fabric, or the same fabric as used in production furniture or by constructing a vertical panel in the same manner as described above for sides and backs.

(7) Armrests and tops of backs. Constructions of armrests and tops of backs shall be made for testing (if, (i) they are part of the production furniture, (ii) present a surface large enough and so inclined as to support a cigarette, and (iii) contain upholstery materials that differ in any way from those used in the side and back panel constructions) by upholstering a piece of $1.3 \mathrm{~cm}(0.5 \mathrm{in})$ thick plywood 
approximately 30 by $50 \mathrm{~cm}$ (12 by $20 \mathrm{ln}$ ) with the same upholstery material to be used in the production furniture, and an acceptable upholstery fabric (standard fabric, class fabric, or same fabric to be used in the production furniture, whichever is applicable). All details of arrangement and thickness of upholstery material in the mockup must reproduce the construction of full-size furniture. Method of assembly shall be the same as outlined in paragraph (b)(6) of this section fic side and back panels. It is not necessary to include welt cord if it has been tested in another part of the mockup (for example, in the cushion).

(c) Condtioning. The furniture mockup or all materials and components used to construct the mockup shall be conditioned at a temperature greater than $18^{\circ} \mathrm{C}\left(65^{\circ} \mathrm{F}\right)$ and a relative humidity less ti.an 55 percent for at least 48 hours prior to testing. Cigarettes and sheeting material shall also be conditioned in this manner. If the test room conditions do not meet the above specifications, then testing must be inftiated within 10 minutes after the materials are removed from the conditioning room. At no time shall the test mockup or its components be exposed to any environmental conditions that promote resistance to cigarette ignition.

(d) Mockup assembly. A furniture mockup shall be assembled by attaching the side and/or back panels to the mockup frame and placing a seat cushion (either loose or tight seat construction) against the panels, as shown in figure 3. The assembly may be placed on a table or platform in the test area and shall be under an exhaust hood or other suitable means for exhausting the products of combustion from testing. 
The seat support system for, loose cushion items, the tops of armrests, and the tops of backs shall be tested separately.

(e) Testing--(1) General. (1) Each test cigarette shall be well Iighted and rurned not more than 4 mo (0.16 in) when placed on a spec1fied test location. After placement, each cigarette shall be covered with a piece of sheeting material.

(ii) If a test cigarette extinguishes before burning its full length on a specified test surface location, that cigarette test must be repeated with a freshly lit cigarette on a different portion of the same type of surface location. If there is no longer space to repeat the test on that surface location, a new vertical panel and cushion shall be constructed. A test on a surface location (for example, seat-back crevice) is considered complete when the number of cigarettes specified in paragraph (e)(1)(ii) of this section and $\S 1633.3$ (d) have (A) burned their full lengths, (B) extinguished before burning their full lengths, or (C) resulted in fallures, as outlined in $\$ 1633.3(\mathrm{c})$.

(1ii) Except as Indicated above at least 3 cigarettes shall be burned on each surface location. The surface locations include hor izontal crevice(s) where seat cushion and vertical panels meet; seat cushion (combination of welt edge and smooth or quilted or tufted area); tops of upholstered armrests; tops of upholstered backs; and loose seat support systems.

(iv) CAUTION: EVEN UNDER THE MOST CAREFULLY OBSERVED CONDITIONS, SMOLDERING COMBUSTION CAN PROGRESS TO A POINT WHERE IT CANNOT BE READILY EXTINGUISHED. IT IS IMPERATIVE THAT A TEST BE DISCONTINUED AS SOON AS IGNITION HAS DEFINITELY OCCURRED. IMMEDIATELY WET THE EXPOSED AREA WITH A WATER SPRAY FROM IHE WATER BOTTLE, REMOVE THE CHARRED OR BURNED 
MATERIAL, AND IMMERSE THE MATERIAL IN A BUCKET OF WATER. VENTILATE THE TEST AREA.

(v) PRODUCTS OF COMBUSTION (SMOKE AND GASES) CAN BE IRRITATING AND DANGEROUS TO TEST PERSONNEL. TEST PERSONNEL MUST AVOID EXPOSURE TO SMOKE AND. GASES PRODUCED DURING TESTING AS MUCH AS POSSIBLE. I' IS SUGGESTED THAT A LARGE HOOD WITH A LOW AIR VELOCITY (NOT GREATER THAN 200 FEET PER MINUTE MEASURED AT THE MOCKUP) BE IN OPERATION DURING TESTING AND THAT TEST PERSONNEL PEMAIN OUTSIDE THE TEST AREA AS MUCH AS POSSIBLE.

(2) Horlzontal crevice tests. (1)(A) At least three cigarettes shall be burned in each horizontal crevice surface location-one at the center and one to each side of the center clgarette. The two cigarettes mext to the center cigarette shall be placed In the crevice so that their butt ends burn out at least $7.5 \mathrm{~cm}$ (3 in) from the outermost edge of the side or back panel. (See flgure 3 for placement of the cigarettes.)

(B) It is extremely important that the test cigarettes be placed horfzontally and as much as possible of the entire length of the clgarette burn out against the vertical panel surface as well as the cushion welt; therefore, if the cigarette needs support to remain in contact with the panel, use three straight pins-one at the tip, center, and butt end of the cigarette. The pins should not penetrate the cigarette but may be used in the welt or cushion surface as necessary. The heads of the pins should not extend above the cigarette.

(11) After placement, each clgarette shall be covered with sheeting material. Pin one edge of the sheeting naterial to the vertical panel (approximately $5 \mathrm{~cm}$ (2 $\mathrm{fn}$ ) above the clgarette) and drape the remaining 
material to completely cover the test cigarette. To ensure that a good sheeting-material-to-cigarette contact is made, a finger shall be run across the full length of the covered clgarette.

(1ii) The test clgarettes shall be allowed to burn out in the test location unless an obvious ignition occurs. If this happens, stop the test, extingulsh the burning material, ventilate the test area, and record a fallure for the cigarette test location.

(1v) If the clgarette burns out in the test location, the maximum char length in any direction from the nearest point of the original location of the clgarette shall be measured with a scale. The char length measurement for each test cigarette shall be recorded except where the cigarette is extinguished because of an obvious ignition. In this case, record an "I" for ignition for that cigarette location.

(3) Seat cushion tests. One covered cigarette shall be burned on each different surface location encountered in a seat cushion except two cigarettes shall be burned on the welt edge. For the purposes of this test, smooth surfaces, welt edges, fused or threaded portions of quilts, and tuft depressions are consldered different surface locations on a seat cushion. Test cigarettes shall be arranged so that the butt ends burn out on the threads of a quilt or in tuft cepressions. The smooth surface of a quilted or tufted cushion is not required to be tested. For the welt edge, it may be necessary to use straight pins in the seat cushion to support the test cigarettes and ensure that they burn out against the welt. Three straight pins may be used--one at the tip, center, and butt end of the cigarette--while ensuring that the pins do not penetrate the cigarette and the heads of the pins do not extend 
above the surface of the cigarette. For smooth surface cushions, the test cigarette shall be burned on the center of the cusrion.

(4) Armrests, tops of backs, and seat support systems tests. Test constructions defined in paragraphs (b)(4) and (b)(7) of this section shall require testing under this paragraph (e)(4). Three test cigarettes shall be burned on horizontal mockup test panels duplicating armrests, tops of backs, and seat cushion support systems. One shall be buined at the center of the panel and the two others shall be burned at least 7.5 $\mathrm{cm}$ ( 3 in) from the edges of the test panel. (See figure 3 for the location of the cigarettes on the test panels.)

1633.4(f) Qualification using production furniture.

A finished furniture item may be used in lieu of the mockup, a: the discretion of the manufacturer, with the following limitations. If a finished furniture item made with a class B, C, or D fabric meets the qualification requirements $(1633.3(\mathrm{~b}))$, that qualification extends only to the particular combination of fabric and upholstery materials assembly used in the tested finished furniture item. If a finished furniture item made with a class A fabric meets the qualification requirements, that qualification extends to all class A fabrics in combination with the particular upholstery materials assembly used in the tested finished furniture item.

$\$ 1633.5$ General requirements, fabric.

Al1 upholstery fabrics used in or intended or promoted for use in upholstered furniture manufactured or reupholstered on or after the effective date of this Part 1633 must be tested and classified according to this method. 
(a) Summary of test method for flammability of upholstery cover

fabrics. Lighted cigarettes covered with a piece of sheeting material shall be burned in crevices made by the abutment of vertical and horizontal fabric-covered glass fiber board panels (Figure 4). Horizontal fabriccovered glass fiber boards abutted with vertical fabric-covered cotton batting (Figure 5) shall also be tested in this manner for some upholstery fabrics as required in $\S 1633.5(\mathrm{~b})$. Based on char measurements on the vertical and horizontal panels, upholstery fabrics shall be classified as Class A, B, C, or D (see $\S 1633.7$ (b)).

(b) Qualification. (1) Each fabric type must be tested and classified prior to use in production furniture and at intervals not to exceed 12 consecutive months thereafter. This requirement is applicable to all upholstery fabric manufactured after the effective date of this Part 1633. Upholstery fabric in inventory and/or manufactured prior to such effective date shall be classified only once according to this qualification procedure. For upholstery fabric manufactured after the effective date, tests are to be made at 12-month intervals. If the manufacturing process is discontinued within any 12-month interval, a test must be made when production is resumed, and the qualifying time - interval is to be measured from the time production is resumed.

(2) Fabric types with various print or pattern designs require careful specimen selection to ensure that when tested, all different areas of the design shall be exposed to the cigarette ignition source for a portion of the time the cigarette is burning on the test sample. 
(3) Upholstery fabric's supplied or furnished to the manufacturer or reupholsterer by the customer for use on a partfcular furniture Item(s), "Customers Own Material (COM)," must be tested and classified before fabrication of the furniture item, unless the fabric already bears a classification label. The manufacturer or reupholsterer shall use only those furniture constructions that have been proven by mockup testing to be acceptable for the same fabric class as that of the "com" fabric.

(4) For the purposes of this section, upholstery fabrics to be used in the manufacture of upholstered furniture need not be tested and classified by the manufacturer of the unit of upholstered furniture provided that fabric has been guaranteed by the fabric producer to have been tested and classified in accordance with $\S 1633.5,1633.6$, and 1633.7 of this Part 1633.

$\S 1633.6$ Test procedure, fabric.

(a) Apparatus--(1) Sample holder. The sample holder shall consist of two wooden panels, each approximately 20 by $20 \mathrm{~cm}$ ( 8 by 8 i 1) and $1.9 \mathrm{~cm}(0.75 \mathrm{in})$ thick, joined together at one edge. As shown in figure 6, a movable horizontal panel support is positioned on a centrally located guide and is held in place by a metal pin.

(2) Glass fiber substrate. The glass fiberboard used for the upholstery cover fabric test shall be approximately $2.5 \mathrm{~cm}$ (1 in) thick with a density of $40 \pm 8 \mathrm{~kg} / \mathrm{m}^{3}\left(2.5+0.51 \mathrm{bs} / \mathrm{ft}^{3}\right)$. I/ For testing, the

1/ Glass fiber board that meets Federal specification HH-I-558B is acceptable. Under this specification, the board is Form A, Class 1, and plain faced. Copies of the specifications may be obtained from the Business Service Centers of the General Service Administration's regional offices. 
glass fiber board is cut into squares approximately 20 by $20 \mathrm{~cm}$ ( 8 by 8 in) for vertical panels and pieces approximately 12.8 by $20 \mathrm{~cm}$ (5 by 8 in) for horizontal panels. Horizontal panels shall be cut to eliminate any air gap that may be created when the vertical and horizontal panels are abutted (see Figures 4 and 5).

(3) Cotton batting substrate. The cotton batting used for the upholstery fabric test shall be approximately $5 \mathrm{~cm}$ ( 2 in) thick with a density of $32 \pm 8 \mathrm{~kg} / \mathrm{m}^{3}\left(2 \pm 0.51 \mathrm{bs} / \mathrm{ft}^{3}\right)$ and shali not be treated with any substance that imparts fire retardancy. The batting shall be a blend of cotton staple and linters, all new (unused) material, and shall contain a minimum of 25 percent of cotton staple.

(4) Support panels. For the upholstery fabric/cotton batting test, vertical panels shall be plywood approximately 20 by $20 \mathrm{~cm}$ ( 8 by 8 in) and approximately $1.3 \mathrm{~cm}$ (0.5 in) thick. Horizontal panels shall be pieces of glass fiber board approximately 12.8 by $20 \mathrm{~cm}$ ( 5 by 8 in).

(b) Conditioning. All upholstery fabric specimens and test materials (including cotton batting, glass fiber board, cigarettes, and sheeting material) shall be conditioned at a temperature greater than $18^{\circ} \mathrm{C}\left(65^{\circ} \mathrm{F}\right)$ and at a relative humidity less than 55 percent for at least 48 hours prior to testing. The cut fabric specimens shall be susperded in a manner that will allow free air circulation around them. (Note: If the test room conditions do not meet these specifications for the conditioning room, then testing must be initiated within 10 minutes after the specimens are removed from the conditioning room. At no time shall the test materials be exposed to any environmental conditions that promote resistance tc cigarette ignition.) 
(c) Glass fiber board test--(1) Upholstery fabric specimens. Fabric specimens shall be selected from finished fabric ifter its last processing step as a fabric. A swatch, chosen as representative of the fabric surface and large enough for at least three specimens approximately 20 by $20 \mathrm{~cm}$ ( 8 by $8 \mathrm{in}$ ) for horizontal panels and three specimens approximately 20 by $30 \mathrm{~cm}$ ( 8 by $12 \mathrm{in}$ ) with the machine direction cut as the longest dimension for vertical panels, shall be cut across the width of the fabric.

(2) Mounting of specimens. Straight pins shall be used to attach the upholstery fabric specimens to the glass fiber boards. As shown in figure 4, the fabric shall cover the surface, top, and bottom edges of the vertical panel and the surface and abutting edge of the horizontal panel. The fabric shall be mounted with the machine direction as shuwn in Figure 5 .

(3) Sample assembly. The fabric covered glass fiber board panels shall be mounted in the sample holder, as shown in Figure 5. The fabric covered horizontal panel shall firmly abut the vertical panel.

(d) Cotton batting test--(1) Upholstery fabric specimens. For the cotton batting test, at least three fabric specimens approximately 30 by $30 \mathrm{~cm}$ (12 by $12 \mathrm{in}$ ) shall be cut for vertical p.inels and three specimens approximately 20 by $20 \mathrm{~cm}$ ( 8 by $8 \mathrm{in}$ ) for horizontal panels in the same manner as described in paragraph (c)(1) of this section.

(2) Mounting of specimens. The vertical panel shall be prepared for testing by covering one surface of a $20 \times 20 \mathrm{~cm}$ ( $8 \times 8$ in) plywood support panel with a layer of cotton batting approximately 2 inches thick followed by the upholstery fabric. The fabric shall be stretched 
tightly over the surface of the assembly, wrapped around each edge, and fastened to the backside of the panel with staples. The horizontal panel shall be prepared by covering a glass fiber board panel with the upholstery fabric. Stralght pins shall be used to attach the fabric to the glass fiber board. The fabric shall be mounted with the machine direction as shown in Figure 5.

(3) Sample assembly. The test panels shall be mounted in the sample holder for testing in the same manner as outlined in paragraph (c) (3) of this section.

(e) Testing. A minimum of three cigarette tests (one cigarette per test sample) shall be conducted on each upholstery fabric in the glass fiber board and/or cotton batting tests. Each loaded sample holder shall be placed on a table or platform in a draft-protected area of the test room under an exhaust hood or other sultable means for exhausting the products of combustion from testing. For testing, a lighted cigarette (burned no more than 4 (0.16 in) before placement) shall be placed in the center (equal distance from each side) or the crevice and immediately covered with a plece of sheeting material. Pin one edge of the sheeting material to the vertical panel approximately $5 \mathrm{~cm}$ (2 in) above the clgarette. The clgarette shall be completely covered and shall be in contact with the sheeting material. (Note: A finger shall be run along the length of the covered clgarette to ensure good fabricto-cigarette contact.) 
$\$ 1633.7$ Test results, fabiric.

(a) Observations. (1) A sample test is considered complete when a test cigarette has burned its full length in the crevice area and all smoldering and smoke evolution from the test sample have ceased. A minimum of three and a maximum of five cigarettes shall be required to classify an upholstery fabric.

(2) If a test cigarette extinguishes before burning its full length, the test shall be repeated with a fresh sample until either (1) three Individual cigarettes have burned their full lengths on three individual test samples or (ii) three individual cigarettes extinguish on three individual test samples before burning their full lengths. Testing may be discontinued as soon as a char length is obtained in excess of $3.8 \mathrm{~cm}(1.5 \mathrm{in})$ as specified for class B fabric in 1633.7 (b)(2), or in excess of $7.5 \mathrm{~cm}$ (3 in) as specified in class $D$ fabric in 1633.7(b)(4).

(3) Measure the maximum length of char on the vertical and horizontal test panel surfaces and the char from the tịp and butt ends of the test clgarette along the crevice location of the test sample. Panel char measurements shall be made from the crevice location (line where the horizontal panel abuts the vertical panel) with the ruler or scale perpendicular to the crevice. Measurements sha'l be made to the nearest smallest gradation of the linear scale used, and the maximum char length measured shall be recorded for each sample.

(b) Classification. Upholstery fabrics shall be tested in accordance with $\S 1633.6$ and shall be placed in the fabric class corresponding to the results obtained. As shown in figure 7, all fabrics shall be 
tested by the glass flber board test prescribed by $\$ 1633.6(\mathrm{c})$. Those that produce chars less than $3.8 \mathrm{~cm}$ ( $1.5 \mathrm{in})$ long when maasured according to paragraph (a) of this section shall also be tested by the cotton batting test (F1gure 7) prescribed by $\$ 1633.6(d)$. The following are the fabric classes:

(1) Class A. Class A fabrics shall be those for which all chars are less than $3.8 \mathrm{~cm}(1.5 \mathrm{in})$ on test panels in the glass fiber brard test ( $\$ 1633.6(\mathrm{c})$ ) and in the cotton batting test ( $\$ 1633.6(\mathrm{~d})$ ) (cotton is not ignited).

(2) Class B. Class B fabrics shall be those for which all chars are less than $3.8 \mathrm{~cm}(1.5 \mathrm{in})$ on test panels in the glass fiber board test and produce one or more chars of $3.8 \mathrm{~cm}(1.5 \mathrm{In})$ or greater in the cotton batting test (cotton is ignited).

(3) Class C. Class C fabrics shall be those that produce one or more chars of $3.8 \mathrm{~cm}(1.5 \mathrm{in})$ or greater but less than $7.5 \mathrm{~cm}$ ( 3 in) on test panels in the glass fiberboard rest.

(4) Class D. Class D fabrics shall be those that produce one or more chars of $7.5 \mathrm{~cm}$ ( $3 \mathrm{in}$ ) or greater on test panels in the glass fiber board test.

\section{$\S 1633.8$ Labeling requirements.}

(a) All fabrics intended or promoted for use as upholstery fabrics must be labeled with a classification letter, A, B, C, or D (see $\S$ $1633.7(b)$ ), as determined by testing according to $\$ 1633.6$ and $\$ 1633.5(b)$.

(b) All items of upholstered and reupholstered furniture must be permanently labeled to identify the fabric class used. 
$\$ 1633.9$ Glossary of terms.

(a) Boudoir chair. A chair, usually small in scale, designed for use in the bedroom.

(b) Chair. A seat with a back and legs or other support, often with arms.

(c) Chaise lounge. An upholstered furniture couch-chair or couch with a chair back. It has a permanent backrest and no arms.

(d) Convertible sofa. An upholstered sofa that converts into an adult-size bed. Mattress unfolds out and up from under the seat cushIoning.

(e) Daybed. A daybed has a foundation usually supported by coll or flat springs mounted between arms on which a mattress is placed. It has permanent arms and no backrest.

(f) Inflatable furniture. Gas or liquid filled, may be a chair, lounger, or other, type, used for sitting or reclining upon.

(g) Jackknife sofa bed. An upholstered sofa that converts into an adult-size bed. Back folds down to become part of bed.

(h) Lounge chair. A comfortable chair designed for resting "nd relaxing that may swivel or be stationary.

(i) Loveseat. A short sofa for seating two persons.

(j) Ottoman. A small upholstered seat with no arms or back that is usually designed as a footrest with a lounge chair.

(k) Platform rocker. A lounge chair with a spring mechanism designed to rock back and forth on an attached base that rests on the floor.

(1) Press-back lounge. A lounge that is longer and wider than most conventional sofa beds. When the lounge back is pressed lightly, C-27 
it levels off to form, with the seat, a flat sleeping surface. The seat slopes in the sitting position for added comfort.

(m) Push-back sofa. A sofa that becomes a bed when its back is pushed flat. Lift the back and it is a sofa again. Styled in tight or loose cushions.

(n) Reclining chair. A lounge chair with a mechanism that permits the seat and back surfaces to be moved to a supine position.

(o) Recliner. The same as a reclining chair.

(p) Sectional sofa. A set of two or more seating sections or pieces that when positioned together will make up a seating group. The sections may be curved or straight and any number may be used to make the grouping. An arm may or may not be used on either end section.

(q) Sleep lounge. An upholstered seating section that is mounted on a sturdy frame. This may have bolster pillows along the wall as backrests or may have headrests.

(r) Sofa. A long upholstered seat or couch with a back and two arms or raised ends.

(s) Sofa lounge. An upholstered seating section that is mounted on springs and in a special frame that permits it to be pulled out for sleeping. It has an upholstered backrest-bedding box that is hinged.

(t) Studio couch. This consists of an upholstered seating section on an upholstered foundation. Many types convert to twin beds.

(u) Studio divan. This is a twin-size upholstered seating section with a foundation that is mounted on a metal bed frame. It has no arms or backrest and sleeps one. 
(v) Swivel rocker. A platform rocker containing an additional mechanism that permits it to plvot around a central balancing point.

\section{$\$ 1633.10$ Effective date.}

The effective date of this standard shall be one year from promulgation.

Interested persons are invited to submit written comments regarding this proposal on or before___ (insert date that is on a workday at least 30 days after publication hereof in the FEDERAL REGISTER). Comments and any accompanying material should be submitted, preferrably in five copies, to the Secretary, Consumer Product Safety Commission, Washington, D.C. 20207. Received responses may be seen at the Office of the Secretary, 3rd Floor, 1111-18th Street, NW., Washington, D.C., during working nours Monday through Friday.

Dated:

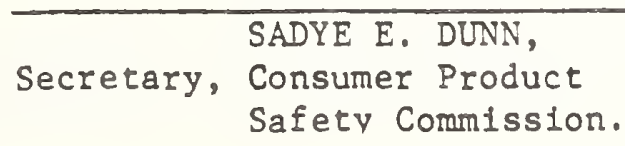




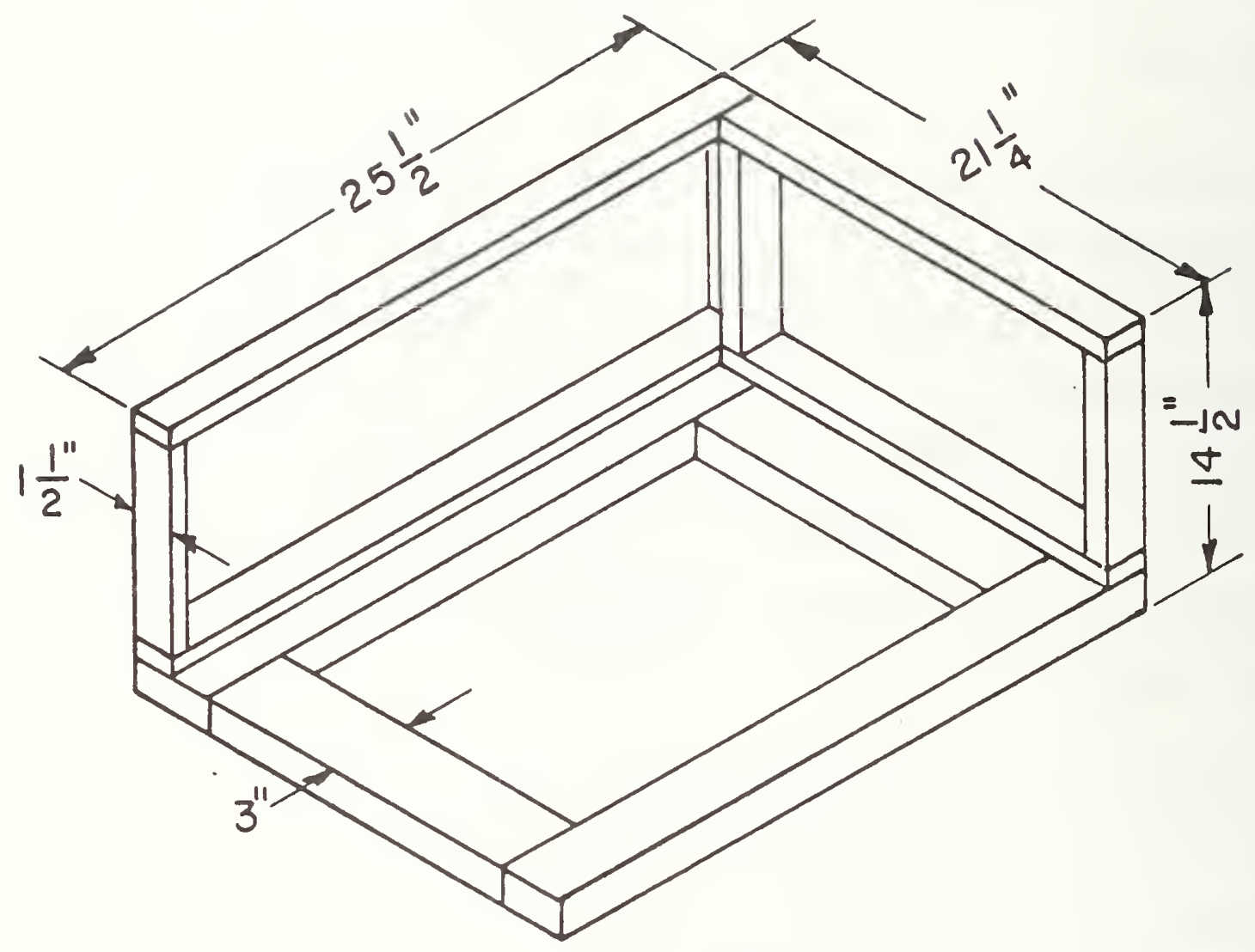

MATERIAL: I"FRAME STOCK

Figure 1. Mock-Up Frame: Upholstered Furniture Test 

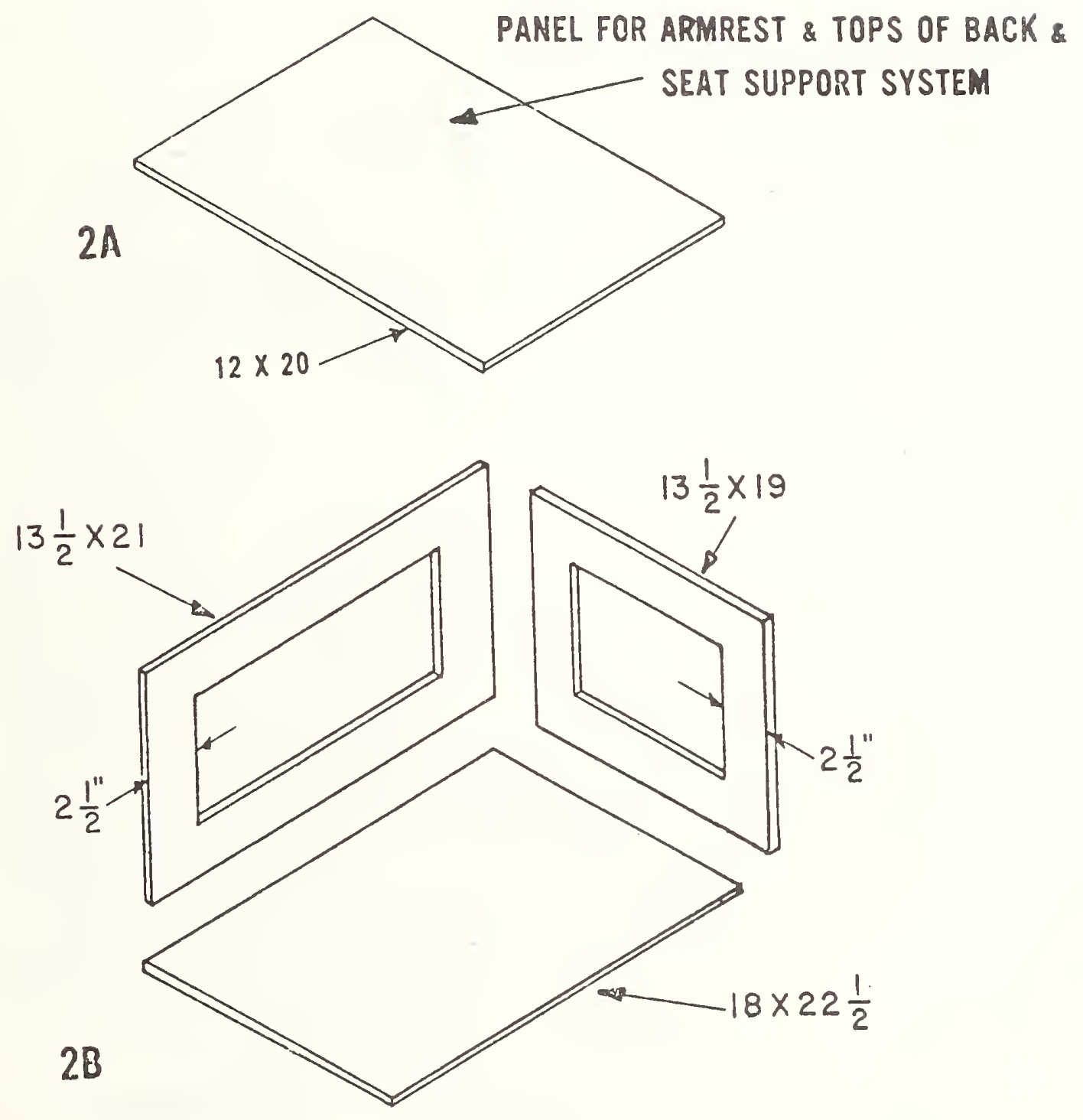

MAT. $\frac{1}{2}$ THICK PLYWOOD

( ALL DIM. INCHES)

Figure 2. Mock-Up Panels Upholstered Furniture Test

$$
\text { C-31 }
$$



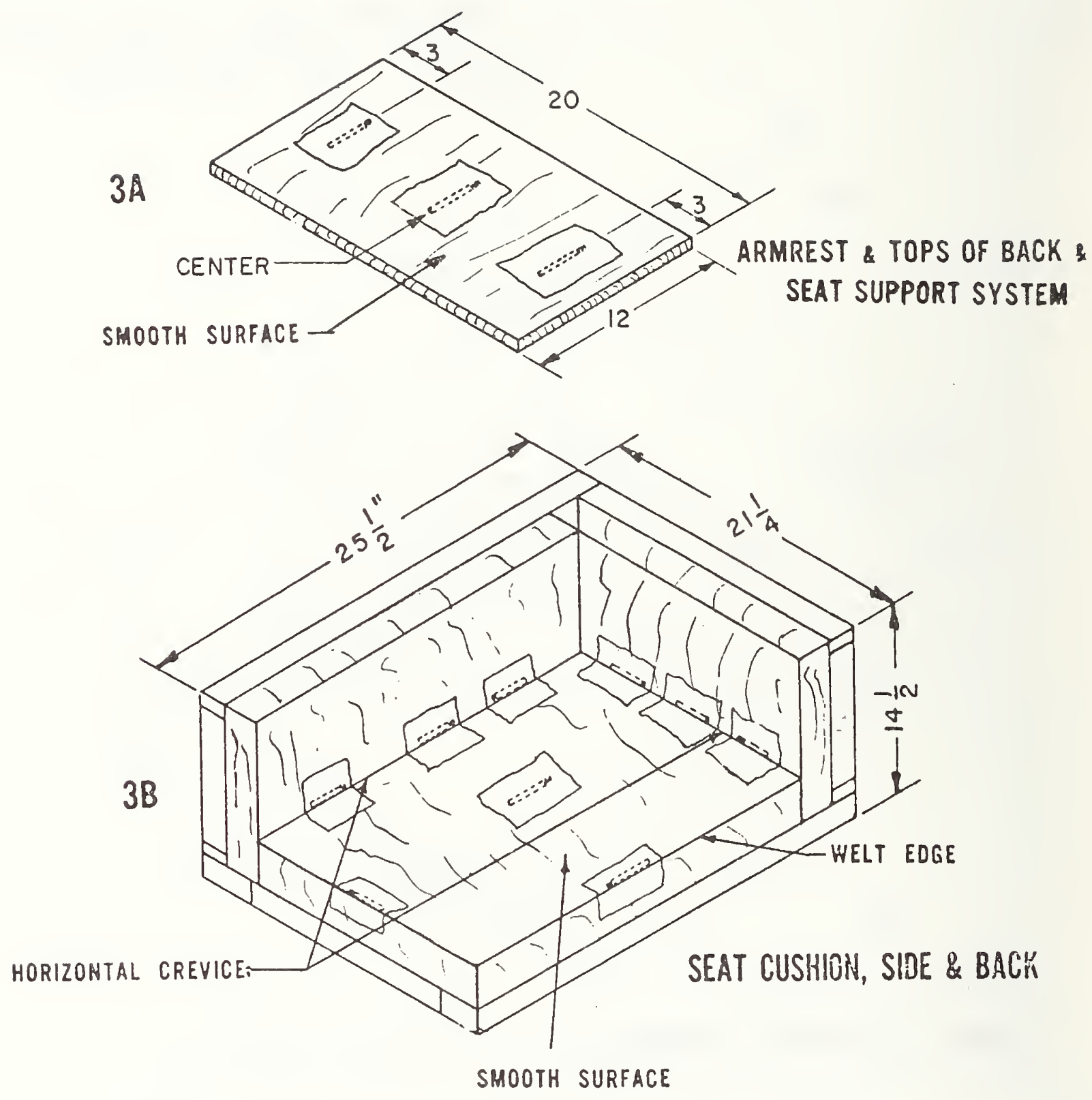

Figure 3. Mock-Up Upholstered Furniture Test 


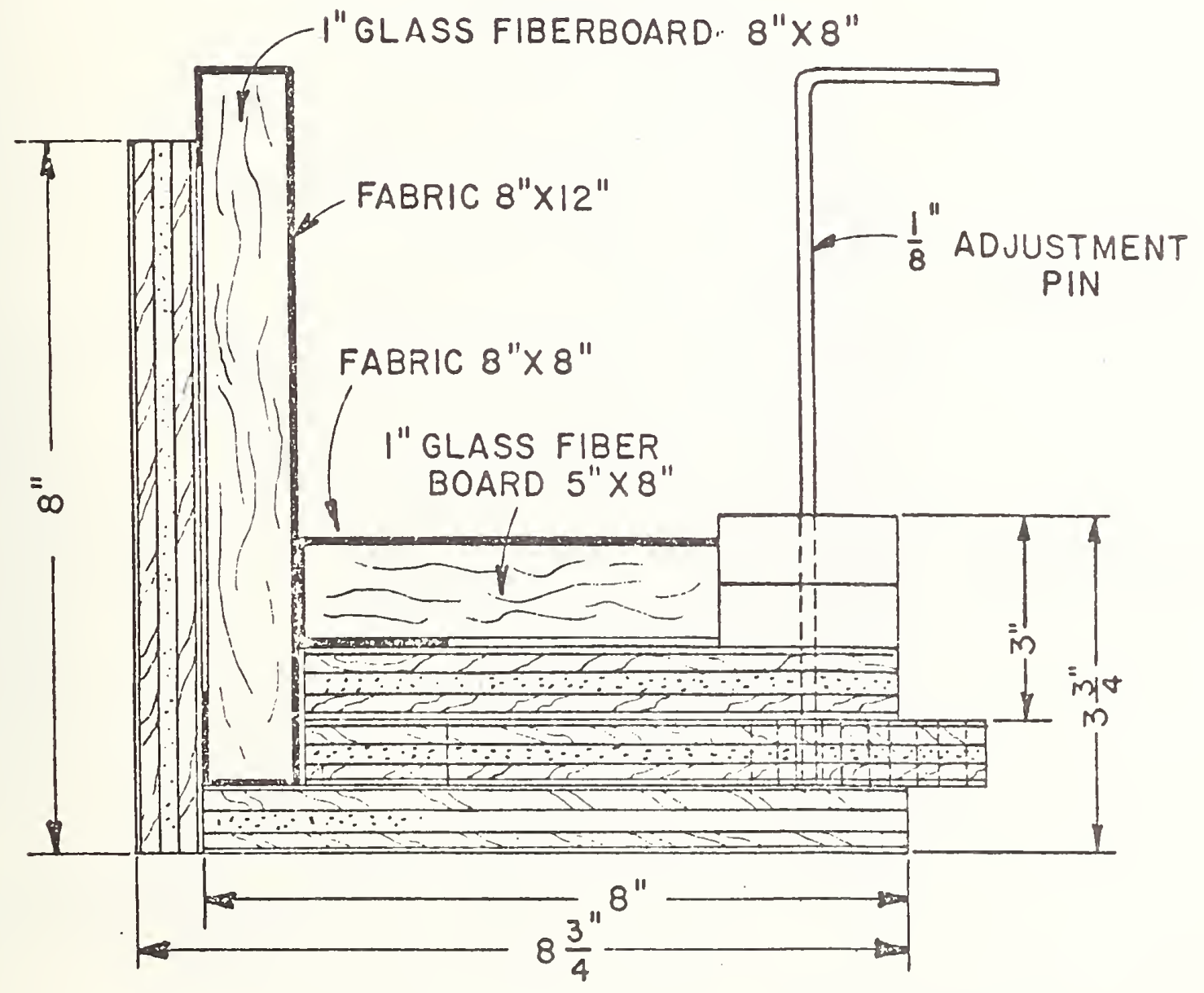

Figure 4. Upholstery Fabric Test

Fabric/Glass Fiberboard Sample 


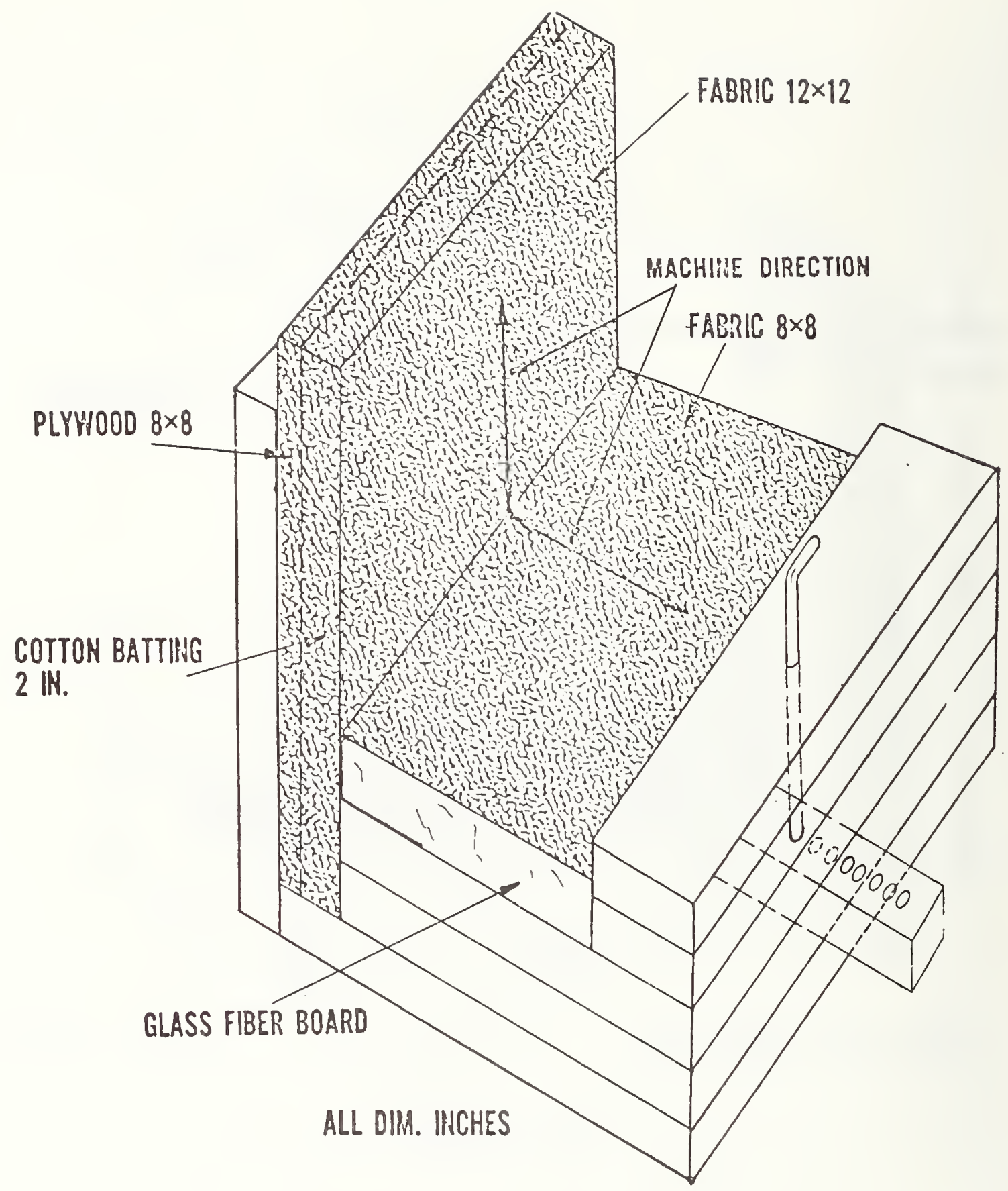

Figure 5. Upholstery Fabric Test

Fabric/Cotton Batting Sample 


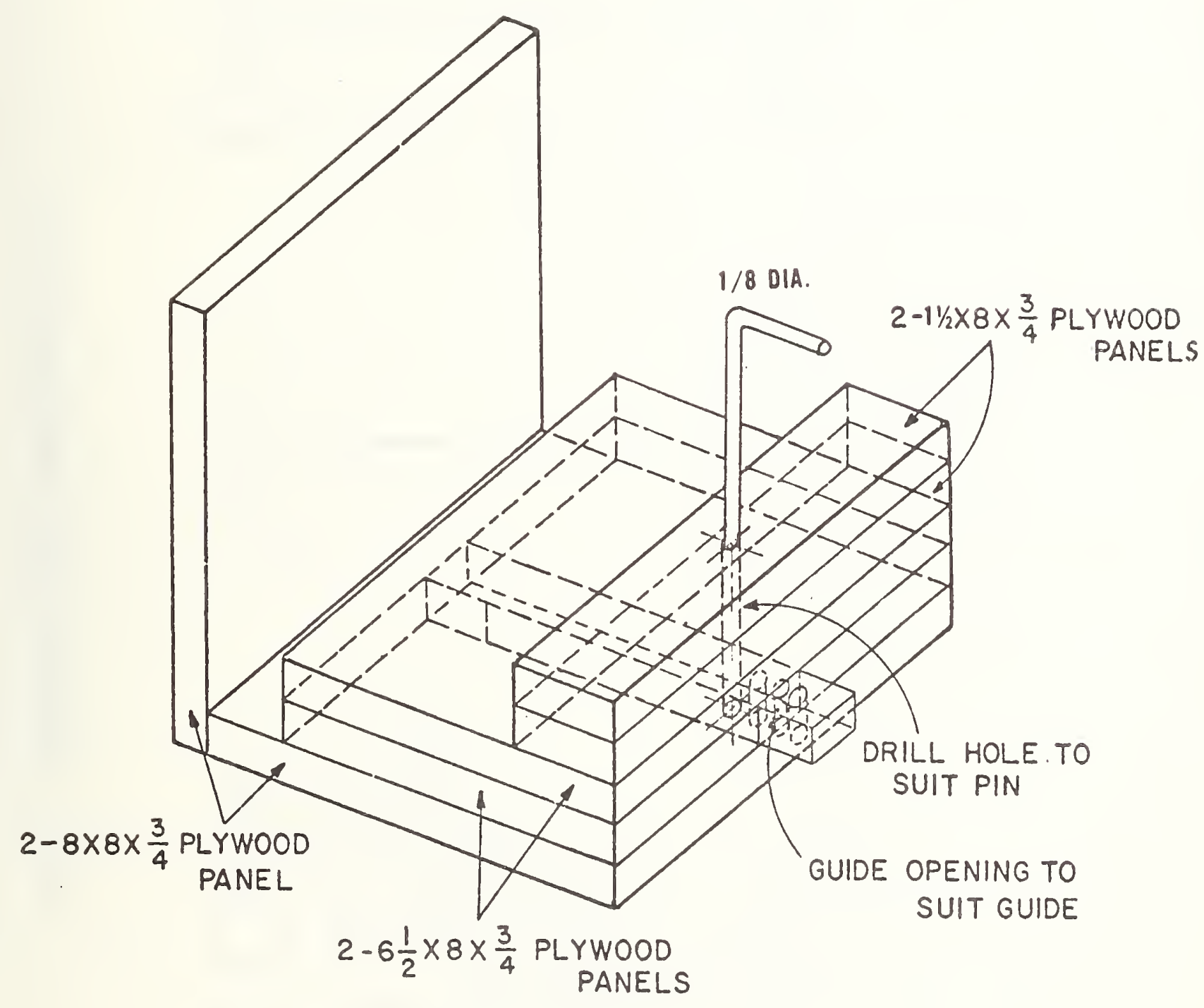

Figure 6. Sample Holder - Upholstery Fabric Test

C-35 


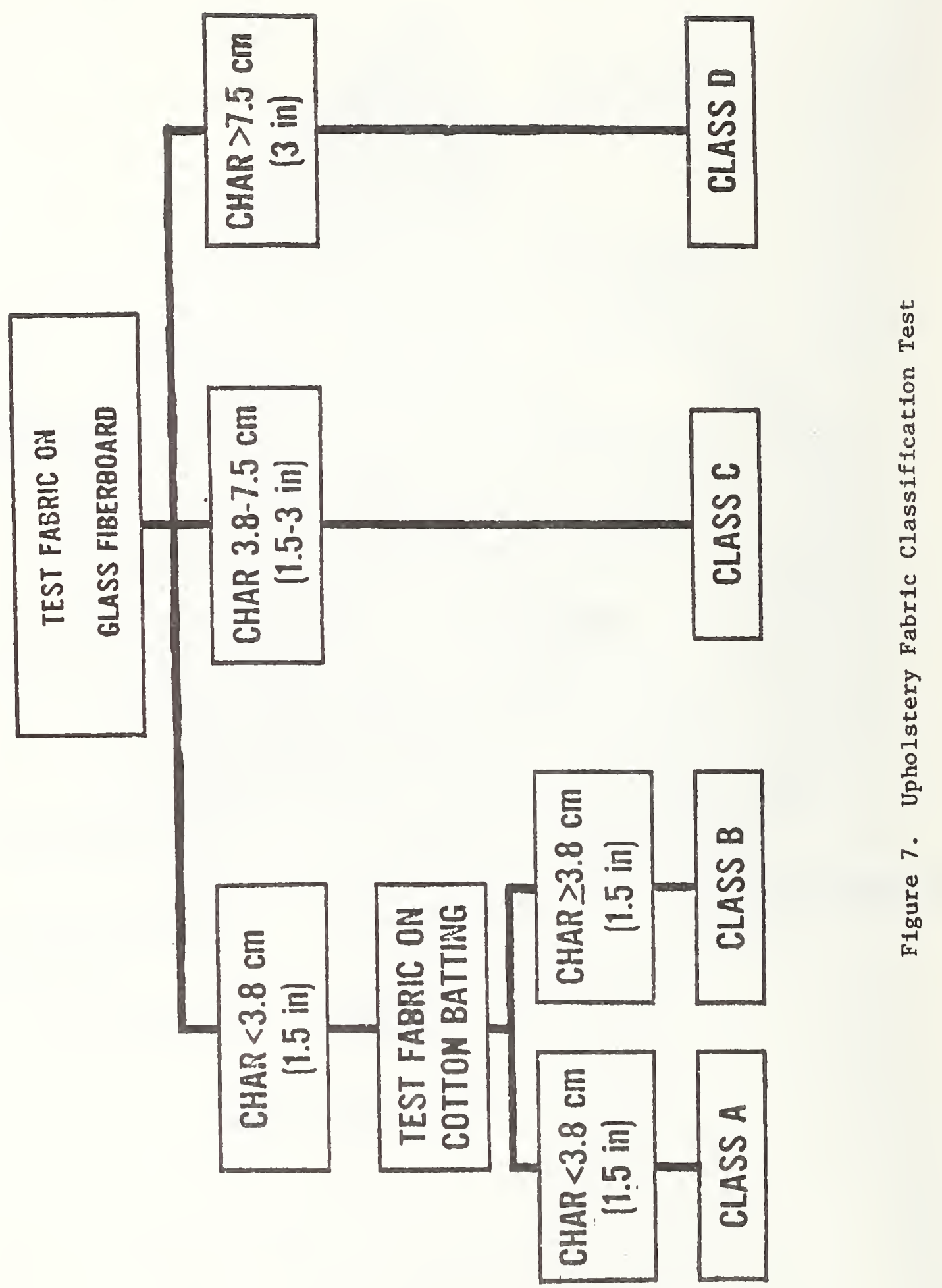


APPENDIX D

An Interlaboratory Evaluation of a Cigarette Ignition Test for Upholstered Furniture

Joseph J. Loftus

May 22, 1975 


\section{Abstract}

Seven laboratories participated in an interlaboratory evaluation study on the feasibility of a proposed cigarette ignition resistance test for upholstered furniture. The objective of the roundrobin was twofold, first to obtain data for evaluating the test method for reproducibility and repeatability; and secondly to determine if tests on small-scale mock-ups of upholstered furniture constructions would provide ignition results equable to fullsize upholstered furniture pieces.

A statistical analysis of the data showed that the proposed test method was indeed realistic and reproducible. Additionally, it was demonstrated that small-scale furniture mock-up samples may be tested in lieu of full-size furniture pieces with full confidence that the test results would be meaningful and equable. 


\section{Introduction}

The interlaboratory study was conducted under the sponsorship of the ASTM Subcommittee for Furniture Flanmability and the Consumer Product Safety Commission (CPSC). The following is a list of participants:

Burlington Industries, Incorporated

California Department of Consumer Affairs

Collins and Aikman

Courtaulds North America, Incorporated

Guilford Laboratories, Incorporated

Drexe1 Enterprises, Incorporated

National Bureau of Standards (NBS)

Code numbers were assigned to each laboratory, and the number " $4 \mathrm{~A}$ " was assigned to NBS. Each participant was required to test three full-size upholstered chairs, each identical in construction but covered by a different upholstery fabric material. Additionally, the laboratories tested six fabrics (including the three used on the chairs) on small-scale upholstered furniture mock-up constructions. Again, the constructions were identical and differed one from the other only by the fabric cover material. 
For the purposes of the round-robin, to satisfy statistical requirements, each laboratory burned a total of 18 cigarettes (nine covered by a piece of sheeting material and nine uncovered) on each different test location in the furniture mock-up samples. This dual testing program was conducted to provide for a comparison of the severity and reproducibility of covered versus uncovered cigarette tests.

Tests on full-size upholstered chairs involved the burning of four cigarettes on each test location (two covered by a piece of sheeting material and two uncovered). Test locations included tops of chair backs, armrest surfaces, crevices (seat cushion abutting side and back), seat cushion surfaces, and seat cushion welt edges.

The data obtained in this testing program was submitted to NBS statisticians for analysis, and their report is included in the following report.

$\underline{\text { Test Materials }}$

Upholstery Fabrics - Table I lists the six upholstery fabrics used in the testing program. The fabrics were selected as representative of those used by the furniture industry and were identified by a code letter; no producer's identification was intended or implied. 
Upholstery Filling Material - The filling material used for the mock-up test panels and for the test chairs was a cotton batting material of nominal 2 lb/cu ft density.

Upholstered Seat Cushions - Four-inch thick urethane foam (nominal 1.5 lb/cu ft density) seat cushions (four per fabric) were fabricated especially for the test program.

Sheeting Material - One hundred percent cotton sheeting material (washed and dried once to remove starch and sizing material) was used as the cover material in the covered cigarette tests.

Upholstered Chairs - A total of 21 barrel back chairs were made by a single manufacturer especially for the round-robin study. Three different upholstery fabrics were used as the cover materials on the chairs (nylon 'F", Olefin 'D", and cotton print cloth "C"). The chairs had 4-inch thick urethane foam seat cushions (10ose). The chair backs, sides, and armrests were all fabricated with a nominal 1-inch thick layer of cotton batting over urethane foam.

Test Method

Draft \#5 of the proposed cigarette ignition test for upholstered furniture, dated $3 / 4 / 74$, was used for conducting the test. 


\section{Sample Conditioning}

All of the test materials, including the upholstered chairs and test cigarettes, were conditioned at temperatures greater than $65^{\circ} \mathrm{F}$. and relative humidity $(\mathrm{RH})$ less than 55 percent for at least 48 hours prior to test.

\section{Sample Preparation}

Test panels for the furniture mock-up tests were prepared for test following procedures and methods of assembly outlined in the test method (see appendix). Briefly, a 2-inch thick layer of cotton batting was placed on a plywood test frame and then covered by a piece of test fabric. The fabric was fastened to the frame with staples after being drawn tightly over the cotton filling material. The horizontal panels (upholstered seat cushions) used for the mock-up test consisted of 4-inch thick urethane foam cushions covered by matching test fabrics. When assembled on the test rack, the cushion firmly abutted the vertical test panel (see Figure 1). 
Test Procedure

Furniture Mock-up Test - In order to accommodate 18 test cigarettes for each test location, it was necessary to build three separate mockups for each of the six fabric materials. Each test cigarette was burned no more than $4 \mathrm{~mm}$ before placement on a test location. Tests were made in the crevices of the abutting seat cushion and vertical test panels and on the surface and welt edge of the seat cushion (see Figure 1).

Chair Tests - Figure 2 shows cigarette test locations on a test chair. The procedures for conducting the tests were the same as for the furniture mock-up samples. Duplicate covered and uncovered cigarette tests were made on each test location.

\section{Interpretation of Test Results}

A test location "passed" the test if the test cigarette burned its full length on the location and did not cause an ignition.

A test location "failed" the test if the test cigarette caused a char or smoldering combustion which spread 2 inches or more in any direction from the test cigarette. 


\section{Test Results}

Mock-up Tests

Table II lists the results of cigarette tests on upholstered furniture mock-up samples. An examination of this table showed the following:

(1) A total of 2,268 cigarettes (1,134 covered and 1,134 uncovered) were burned in test locations on a total of 126 furniture mock-up samples.

(2) Of the 1,134 covered cigarette tests, 520 (or 46 percent) caused ignitions.

(3) Of the 1,134 uncovered cigarette tests, 343 (or 30 percent) caused ignitions.

(4) A11 laboratories reported "passing" (nonignition) results for every test made on the surfaces of the urethane foam seat cushions.

(5) Nylon "F" fabric "passed" all cigarette tests on all test locations in all seven laboratories. 
(6) Olefin 'D" fabrics "passed" all seat cushion welt edge tests in all laboratories.

(7) Cellulosic fabrics A, B, C, and E "failed" covered cigarette tests in every laboratory.

(8) Olefin ' $D$ " fabric melted on exposure to the heat from burning cigarettes and produced some "passing" results of covered cigarettes in crevice tests.

(9) A total of 538 ignitions were recorded by all laboratories for all cigarette tests in crevice locations of the mock-ups (279 of these were covered cigarette ignitions and 259 were uncovered cigarette ignitions).

(10) A total of 333 ignitions were recorded by all laboratories for all cigarette tests on welt edges of seat cushions (242 of these were covered cigarette ignitions and 93 were uncovered cigarette ignitions).

(11) Cotton batting under cellulosic fabric materials was shown most vulnerable to cigarette ignition in the mock-up furniture samples. 
Chair Tests

Cigarette ignition test results on full-size upholstered chairs are listed in Table III. An examination of this table showed the following :

(1) A total of 420 cigarettes (210 covered and 210 uncovered) were burned on the test chairs by the seven laboratories.

(2) The laboratories reported a total of 110 ignitions in the cotton print cloth " $C$ " fabric chair, 15 ignitions in the Olefin " $D$ " fabric chair, and 13 ignitions in the nylon " $F$ " fabric chair.

(3) Of the 15 ignitions reported for the Olefin " $D$ " fabric chair, 10 were in the chair sides and only five ignitions were recorded for chair arms and tops of backs.

(4) All laboratories reported "passing" results for every cigarette test on chair seat cushion surfaces.

(5) Al1 laboratories reported "passing" results for every cigarette test on welt edges of seat cushions covered by nylon "F" and Olefin ' $\mathrm{D}$ ' fabrics. 
(6) Cotton print cloth " $\mathrm{C}$ " fabric (seat cushion surface excepted). "failed" every test location for both covered and uncovered cigarette tests.

\section{Conclusions}

Based upon the results obtained, the following conclusions are drawn:

(1) Covered cigarette tests are more severe than uncovered cigarette tests.

(2) Covered cigarette tests are more reproducible than uncovered cigarette tests.

(3) Ignitions in upholstered furniture constructions are clearly related to the type and kind of cover fabric used on the construction.

(4) Synthetic fabrics showed fewer ignitions in the furniture mockups and chairs than did the cellulosic cover fabrics.

(5) A relationship was found which showed that tests on small-scale mock-up samples are equable to tests on full-size chairs. 
(6) A statistical analysis of the interlaboratory test results showed, that with few exceptions, the results were satisfactory in terms of laboratory-to-1aboratory variability.

(7) The proposed test method for measuring the ignition resistance of upholstered furniture to burning cigarettes was proven meaningful and viable by the round-robin testing program and merits consideration for promulgation as a test standard. 

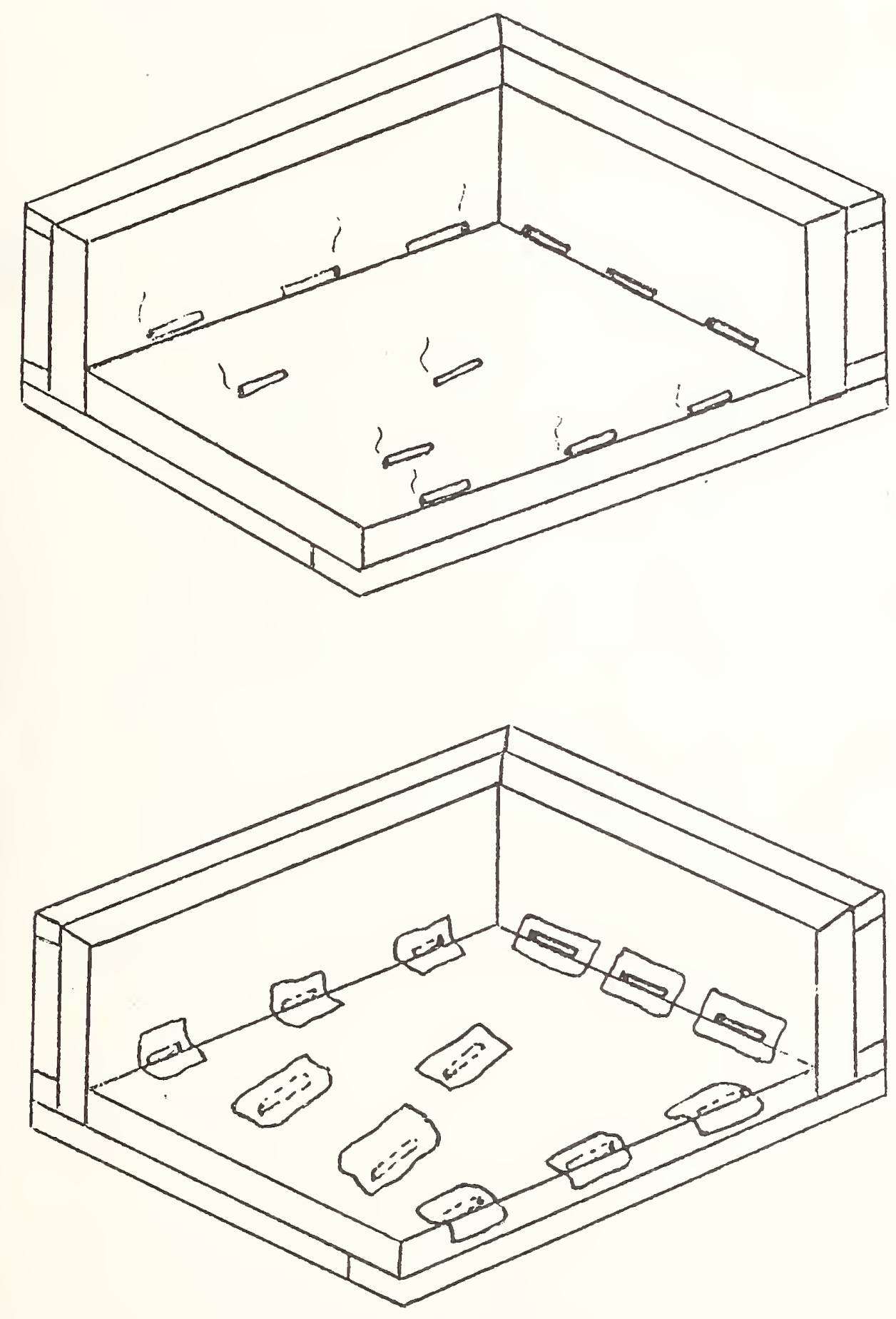

Figure 1. Covered and Uncovered Cigarette Test Locations in Mock-Up Furniture Test 


$$
\because \quad \because=\ldots \rightarrow \quad \because=1
$$
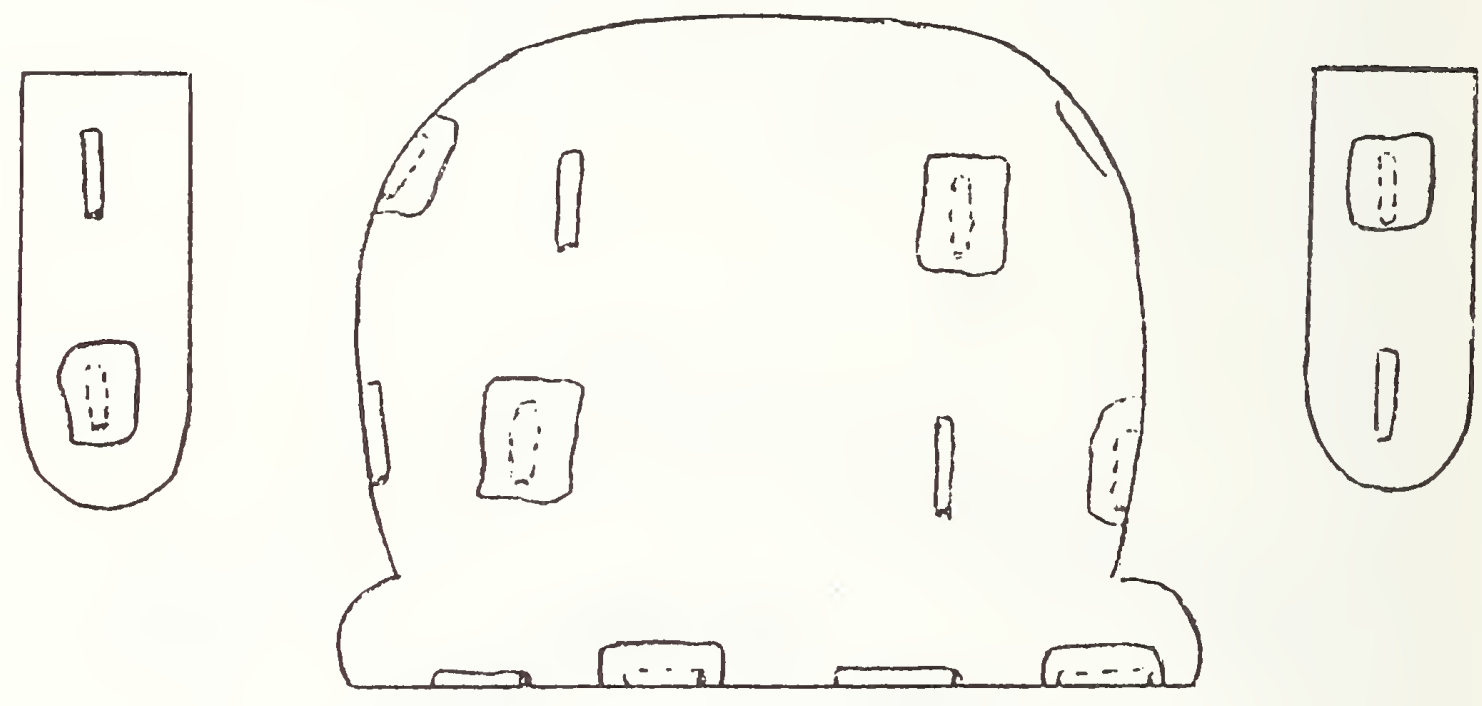

Figure 2. Cigarette Test Locations in Upholstered Chair Tests 
Table I

Test Fabric Material

\begin{tabular}{clllr}
$\begin{array}{c}\text { Fabric } \\
\text { Designation }\end{array}$ & \multicolumn{1}{c}{$\begin{array}{c}\text { Fiber } \\
\text { Content }\end{array}$} & \multicolumn{1}{c}{ Style } & \multicolumn{1}{c}{ Color } & $\begin{array}{c}\text { Fabric Wt. } \\
\text { oz/yd }^{2}\end{array}$ \\
\hline A & $100 \%$ Cotton & Wide Rib & Yellow/Orange & 12.8 \\
B & Cotton/Rayon & Velvet & Olive & 14.1 \\
C & $100 \%$ Cotton & Print Cloth & Flower/Beige & 5.4 \\
D & $100 \%$ Olefin & Woven & Green/Gold & 10.2 \\
E & Cotton/Rayon & Velvet & Green & 13.6 \\
F & $100 \%$ Nylon & Woven & Beige & 14.6
\end{tabular}









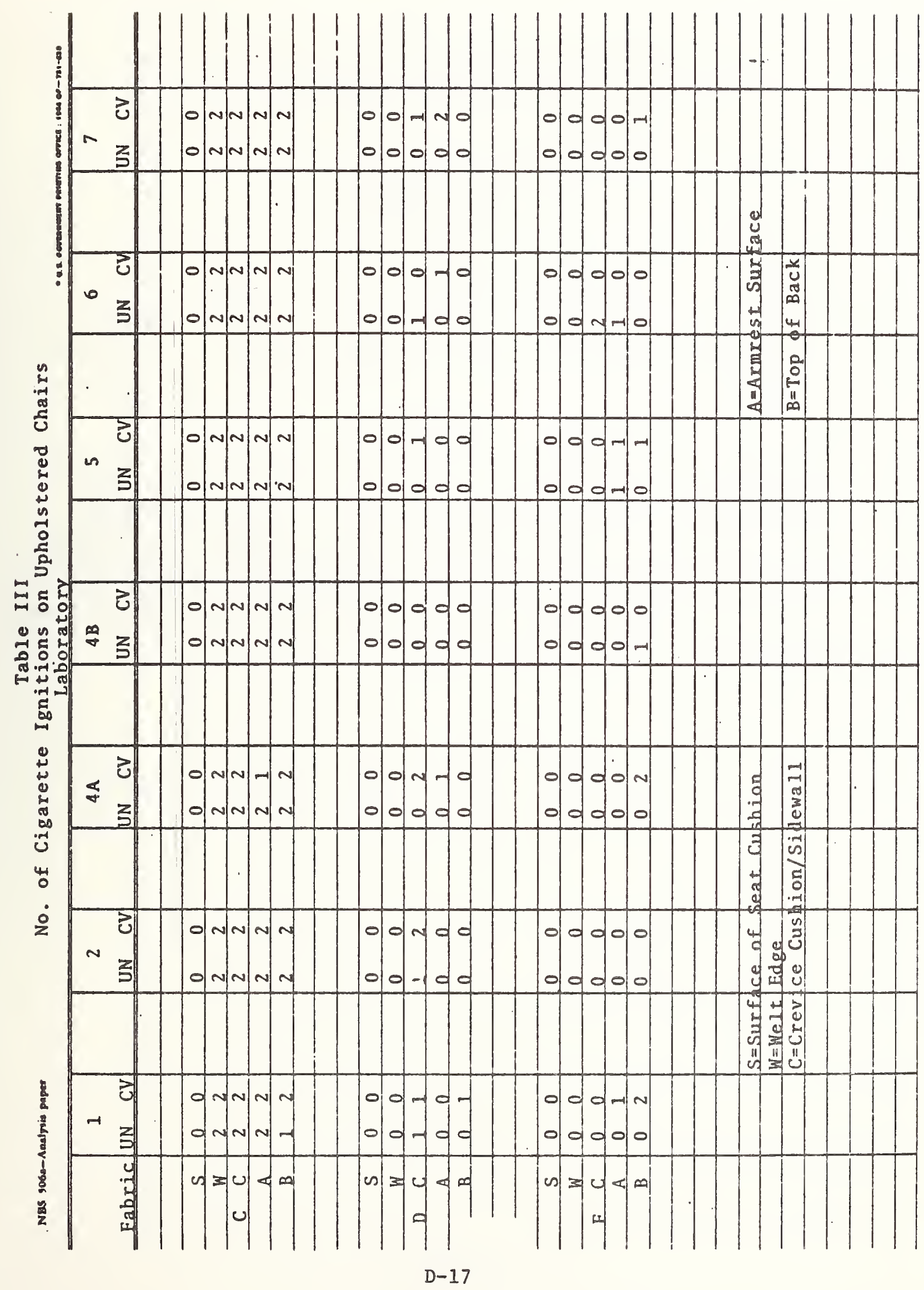




\section{"Statistical Analysis of Cigarette Tests}

on Upholstered Furniture"

by

John Mande1

$\frac{\text { Table I }}{\text { Summarizes the results, in terms of percent failure. }}$

Table II

Tabulates the chi-square values. These are measures of the consistency of results between laboratories. In this case, the expected value of each chi-square is 6 . Values that are appreciably larger than 6 indicate a lack of consistency among laboratories. The values with an asterisk are significant at the 5 percent level. Four such values were observed in a total of 48 cases, whereas one would expect, on the average, 5 percent of 48 or 2.4 cases. Thus, these results are, with few exceptions, satisfactory in terms of laboratory-to-laboratory variability. 
$\underline{\text { Table I }}$

Percent Failure

Ignitions Based on Char

Welt Test

\begin{tabular}{|c|c|c|c|c|c|c|}
\hline Fabric & A & B & C & $D$ & E & F \\
\hline $\begin{array}{c}\text { Uncovered } \\
\text { Covered }\end{array}$ & $\begin{array}{r}44.4 \\
100.0\end{array}$ & $\begin{array}{r}4.8 \\
92.1\end{array}$ & $\begin{array}{r}98.4 \\
100.0\end{array}$ & $\begin{array}{l}0.0 \\
0.0\end{array}$ & $\begin{array}{r}0.0 \\
90.5\end{array}$ & 0 \\
\hline & \multicolumn{6}{|c|}{ Crevice Test } \\
\hline Fabric & A & B & C & D & E & F \\
\hline $\begin{array}{l}\text { Uncovered } \\
\text { Covered }\end{array}$ & $\begin{array}{l}100.0 \\
100.0\end{array}$ & $\begin{array}{r}95.2 \\
100.0\end{array}$ & $\begin{array}{r}100.0 \\
98.4\end{array}$ & $\begin{array}{l}17.5 \\
44.4\end{array}$ & $\begin{array}{r}98.4 \\
100.0\end{array}$ & $\begin{array}{l}0 . \\
0 .\end{array}$ \\
\hline
\end{tabular}

Upholstered Chair

\begin{tabular}{rrrrrr}
$\begin{array}{r}c \\
\text { Cotton }\end{array}$ (C) & \multicolumn{2}{c}{ Olefin (D) } & \multicolumn{2}{c}{ Nylon (F) } \\
Unc. & Cov. & Unc. & Cov. & Unc. & Cov. \\
100.0 & 100.0 & 0.0 & 0.0 & & \\
100.0 & 100.0 & 21.4 & 50.0 & 14.0 & 0.0 \\
100.0 & 92.9 & 0.0 & 28.6 & 14.3 & 0.0 \\
92.9 & 100.0 & 0.0 & 7.1 & 7.1 & 42.3
\end{tabular}




\section{Table II}

Chi Square Values

\begin{tabular}{|c|c|c|c|c|c|c|}
\hline \multirow[b]{2}{*}{ Fabric } & \multicolumn{6}{|c|}{ Welt Test } \\
\hline & A & B & $\mathrm{C}$ & $\mathrm{D}$ & $\mathrm{E}$ & $\mathrm{F}$ \\
\hline \multirow[t]{2}{*}{$\begin{array}{c}\text { Uncovered } \\
\text { Covered }\end{array}$} & $\begin{array}{l}1.80 \\
6.00\end{array}$ & $\begin{array}{l}8.59 \\
5.21\end{array}$ & $\begin{array}{l}6.10 \\
6.00\end{array}$ & $\begin{array}{l}6.00 \\
6.00\end{array}$ & $\begin{array}{l}6.00 \\
3.68\end{array}$ & $\begin{array}{l}6.00 \\
6.00\end{array}$ \\
\hline & \multicolumn{6}{|c|}{ Crevice Test } \\
\hline Fabric & A & B & $\mathrm{C}$ & $\mathrm{D}$ & $E$ & $\mathrm{~F}$ \\
\hline Incovered & 6.00 & $18.90 *$ & 6.00 & $15.20 *$ & 6.10 & 6.00 \\
\hline Covered & 6.00 & 6.00 & 6.10 & $14.40^{*}$ & 6.00 & 6.00 \\
\hline
\end{tabular}

Upholstered Chair

$\begin{array}{llll}\text { Cotton (C) } & \text { Olefin (D) } & \text { Nylon (F) } \\ \text { Unc. Cov. } & \text { Unc. Cov. } & \text { Unc. Cov. }\end{array}$

$\begin{array}{lllllll}\text { Welt } & 6.00 & 6.00 & 6.00 & 6.00 & 6.00 & 6.00 \\ \text { Crevice } & 6.00 & 6.00 & 5.09 & 8.00 & 14.00 * & 6.00 \\ \text { Arm } & 6.00 & 0.92 & 6.00 & 9.10 & 5.83 & 5.83 \\ \text { Back } & 0.92 & 6.00 & 6.00 & 6.46 & 6.46 & 9.92\end{array}$




\section{APPENDIX E}

Test Method for Classifying Cigarette Ignition Characteristics of Upholstery Fabrics

Joseph J. Loftus

March 6, 1975 


\section{Summary}

A test method has been developed for evaluating upholstery fabric materials for ignition resistance. Under the method, fabrics are classified as $A, B, C$, or $D$ based on char and/or ignition measurements. The test is conducted by burning cigarettes (covered by a piece of sheeting material after placement) in the crevices of fabric-covered test assemblies, made by abutting horizontal and vertical test panels. Two types of assemblies are used in the test: fabric/glass fiber board and fabric/cotton batting. "Fabric Class $A^{\prime \prime}$ materials do not ignite either assembly. "Fabric Class $\mathrm{B}^{\prime \prime}$ materials ignited the cotton batting assembly. "Fabric Classes $\mathrm{C}$ and $D^{\prime \prime}$ ignited on both assemblies, but differed in char measurement on the fabric/glass fiber board assembly.

The above method was used to evaluate 47 different upholstery fabric materials for ignition resistance to cigarettes. Data showed that fabric type, construction, and weight influenced the outcome of test results. Cellulosic fabrics, especially those in the weight range above $305 \mathrm{~g} . / \mathrm{m}{ }^{2}$ $\left(9 \mathrm{oz} \cdot / \mathrm{yd} .^{2}\right)$, were found to be more susceptible to ignition than were synthetic fabric materials. 


\section{Introduction}

The test method described in this report supplements a previously developed flammability test for upholstered furniture which is currently being evaluated in a sma1l-scale interlaboratory study. In theory, an ideal flammability test for upholstered furniture would require testing of each different fabric/upholstery material construction used in any one furniture plant; however, in practice, such an undertaking would not be economically feasible.

In order to better understand the magnitude of the effort required by an upholstered furniture test, one need only consider that there exist, today, about 2,000 manufacturers and 5,200 furniture plants throughout the United States. Many of these facilities maintain a large inventory of furniture cover fabrics and considering the color selection available for each pattern, it would not be unrealistic to assume that as many as 5,000 different choices may be available at one time. Fortunately, however, the number of filling, padding, or stuffing materials used in combination with these fabrics, are few, as was found in a recent survey* of the marketplace. This survey showed that:

Schmulling, D., "A Materials Survey of the Furniture Industry", private communication. 
a. Flexible urethane foam and cotton batting are the principal filling materials used in furniture constructions.

b. Approximately 95 percent of the seat cushions are flexible urethane foam of about $1.5 \mathrm{lb} . / \mathrm{cu}$. ft. density. About half of these cushions are wrapped in a polyester batting.

c. Cushion backs are generally made with slab or shredded urethane foam.

d. Most upholstered backs and arms are cotton batting over urethane foam.

e. In upholstered furniture pieces, loose cushions are used about 90 percent of the time; upholstered arms, about 86 percent; and upholstered backs, about 63 percent.

Concerning cover fabric materials:

a. About 340,000,000 linear yards (54 inches wide) of fabric were used in 1972 .

b. About 65 percent of the fabrics were cellulosic (cotton, rayon, and cotton/rayon blends) and 35 percent were synthetic, mostly nylon, polyester, and olefin. 
c. Approximately 78 percent of the fabrics were woven and 22 percent were vinyls.

From this survey, it is clear that the number of upholstery fabric materials available for use on different furniture constructions is enormous, and they present a major problem to implementing a workable and reasonable flammability test for upholstered furniture. However, the test method described here would help to reduce this problem considerably by requiring that each upholstery fabric be classified before its use on a particular furniture construction. 


\section{Requirements}

The basic requirements for any laboratory test method are that it be simple in concept and easy to operate and that it yield realistic, reproducible results based on sound principles. It should be relatively insensitive to minor variables, but be capable of operating over a wide range of conditions. In this test, upholstery cover fabrics are exposed to burning cigarettes on the outside surface only to simulate the usual case in accidental furniture fires and to permit evaluation of the effectiveness of the fabric in resisting ignition. In terms of ignition resistance, the method for testing and classifying cover fabrics is outlined in the following diagram: 


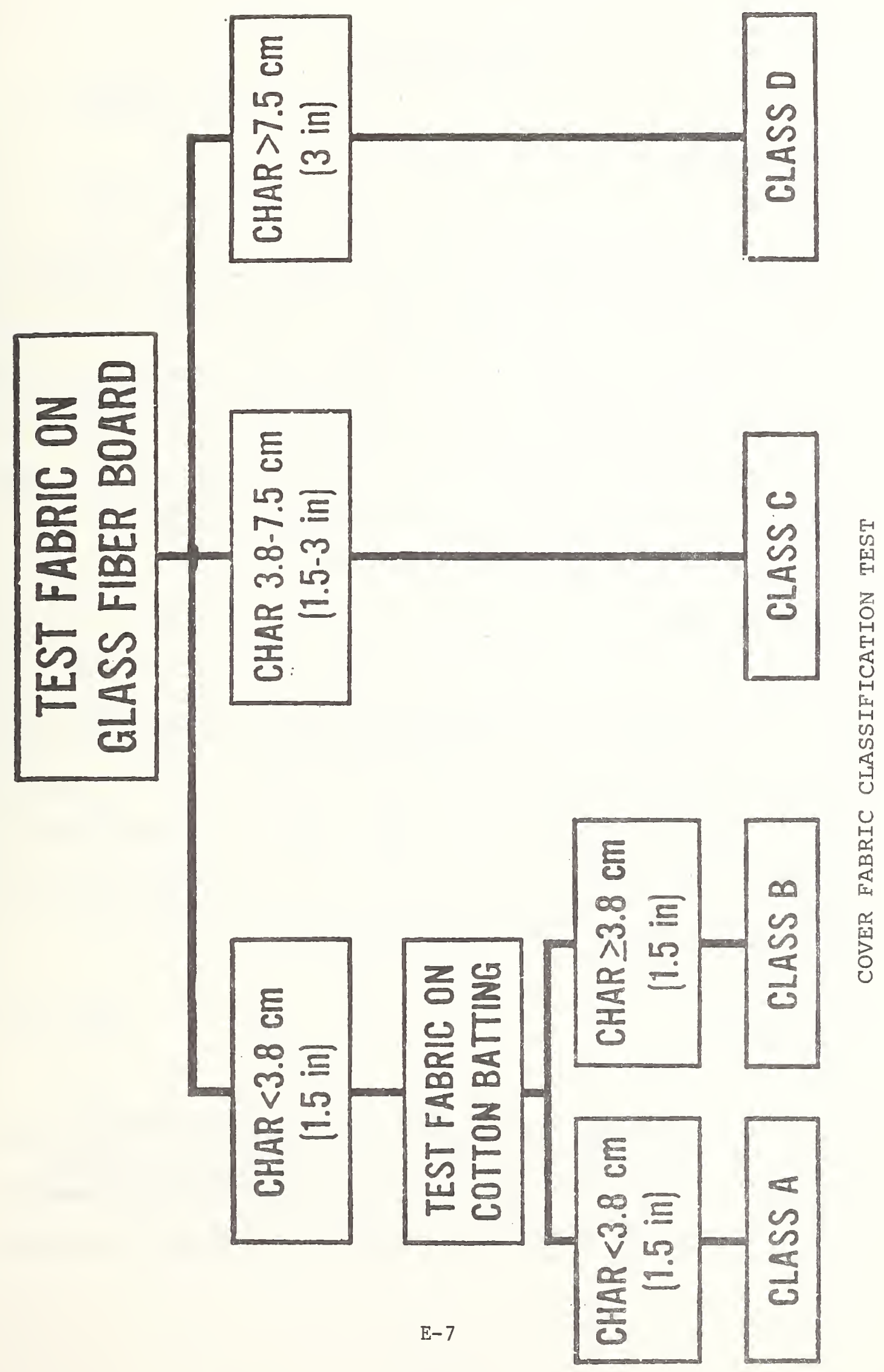


7

\section{Test Apparatus}

a. Sample Holder

The sample holder used in this test is shown in detail in Figure 1. Briefly, it consists of two wood panels, each $20 \times 20 \mathrm{~cm} .(8 \times 8$ in. $)$ and nominal $1.9 \mathrm{~cm}$. (0.75 in.) thickness, joined together at one edge. For test, the horizontal support accomnodates a $12.5 \times 20 \mathrm{~cm}$. $(5 \times 8$ in.) sample against a $20 \times 20 \mathrm{~cm}$. $(8 \times 8$ in.) vertical panel. (See Figure 4 in the proposed upholstered furniture standard.)

b. Substrate Board

The substrate board used for test was a glass fiber board material that is sold commercially as a thermal insulation and which meets Federal Specification HH-I-558B. Under this specification, the board is Form A, Class I, plain faced, $2.5 \mathrm{~cm}$. (1 in.) thick, and density $40 \pm 8 \mathrm{~kg} \cdot / \mathrm{m}^{3}(2.5 \pm 0.5 \mathrm{lb} . / \mathrm{cu}$. ft. $)$.

c. Pane1 Support

For the cotton batting test, plywood panels $20 \times 20 \mathrm{~cm}$. ( $8 \times 8$ in.) and nominal $1.3 \mathrm{~cm}$. (0.5 in.) thick were used as supporting members for the fabrication of upholstery fabric/cotton batting test panels. 
d. Ignition Source

Cigarettes without filter tips made from natural tobacco with a density of $0.270 \pm 0.20 \mathrm{~g} . / \mathrm{cm}^{3}$ and a total weight of $1.1 \pm 0.1 \mathrm{~g}$. were used in the test.

e. Sheeting Material

Cotton bed-sheeting material, weight $125 \pm 28 \mathrm{~g} . / \mathrm{m}{ }^{2}(3.7 \pm 0.8 \mathrm{oz} . /$ $\mathrm{yd}^{2}{ }^{2}$ ), white in color, and not treated with flame-retardant chemicals was used in the test. The material was laundered once in an automatic home washer and dried in a tumble dryer before use in the test. For testing, the sheeting was cut into $12.5 \times 12.5 \mathrm{~cm}$. ( $5 \times 5$ in.) pieces.

f. Scale

A scale graduated to $2.5 \mathrm{~mm}$. (0.1 in.) was used to measure char length.

g. Pins

Straight pins were used to attach the upholstery fabric to the glass fiber board material. 
h. Water Bottle

A water bottle fitted with a spray nozzle was readily available for extinguishing ignitions.

i. Test Room

A test room with a draft-protected area provided with a hood exhaust for smoke and fumes produced by testing, was used for testing. 


\section{Test Materials}

a. Upholstery Fabrics

The upholstery fabrics selected for test are listed and described in Table 1. Most popular types and blends are represented with weights ranging from 213 to $719 \mathrm{~g} \cdot / \mathrm{m}^{2}$ (6.3 to $23.4 \mathrm{oz} . / \mathrm{yd}^{2}{ }^{2}$ ).

b. Cotton Batting

Cotton batting, nominal $5 \mathrm{~cm}$. (2 in.) thick, obtained from a local supplier and represented as typical of the material used by the furniture industry was used for test. The material density was about $24 \mathrm{~kg} . / \mathrm{m}^{3}$ (1.5 lb./cu. ft.).

c. Flexible Urethane Foam

Flexible urethane foam, nominal $1.3 \mathrm{~cm}$. (0.5 in.) thick and $24 \mathrm{~kg} . / \mathrm{m}^{3}$ (1.5 lb./cu. ft.) density, purchased from the same supplier was used as a cover layer over cotton batting for additional tests on furniture combinations. 


\section{Conditioning}

The test fabric, foam, substrate, filling materials, and cigarettes were conditioned in a room maintained at a temperature of at least $18^{\circ} \mathrm{C} .\left(65^{\circ}\right.$ F.) and less than 55 percent relative humidity for a minimum of 48 hours prior to testing. 


\section{Glass Fiber Board Test}

a. Sample Preparation

Vertical fabric/glass fiber board panels were prepared for test by covering the surface, top, and bottom edges of a $20 \times 20 \mathrm{~cm} \cdot(8 \times 8$ in.) piece of glass fiber board with a $20 \times 30 \mathrm{~cm} .(8 \times 12$ in. $)$ piece of fabric. The fabric was attached to the back of the substrate board with straight pins. Horizontal test panels were prepared in the same manner by covering the surface and one edge of a $12.5 \times 20 \mathrm{~cm}$. ( $5 \times 8$ in.) piece of glass fiber board with a $20 \times 20 \mathrm{~cm}$. ( $8 \times 8$ in. $)$ piece of fabric material.

b. Test Procedure

The conditioned test panels were mounted in the sample holder (Figure 2) with the horizontal panel firmly abutting the vertical panel, and the assembly was placed on a laboratory bench surface near an exhaust hood. A lighted cigarette [burned no more than $0.4 \mathrm{~cm} .(0.25 \mathrm{in.})$ before placement] was placed in the crevice of the panels and was immediately covered with a piece of sheeting material. The uppermost edge of the sheeting material was pinned to the vertical test panel and fabric/cigarette contact was ensured by muning a finger over the covered cigarette. 
After a test cigarette had burned its full length in the crevice area, the sheeting material was removed, and char measurements on the fabric surface were made. Using a scale, both vertical and horizontal chars were measured (to 0.1 in.) on the respective test panels; in addition, a horizontal crevice char measurement was also recorded. At least three tests were made on each fabric material; however, if one cigarette extinguished before burning its full length, the test was repeated until a total of three cigarettes self-extinguished or three cigarettes burned their full length. In any event, no more than five tests were required for evaluating an upholstery fabric material. The data obtained in the fabric/glass fiber board test was used to determine which fabrics were "Fabric Class C" or "Fabric Class D" materials. Those fabrics not igniting on this test assembly qualified for the fabric/cotton batting test. 


\section{Fabric/Cotton Batting Test}

a. Sample Preparation

Vertical test panels were prepared for test by covering one surface of a plywood support panel with a nominal $5 \mathrm{~cm}$. (2 in.) thick layer of cotton batting, followed by a piece of $30 \times 30 \mathrm{~cm}$. (12 $\times 12$ in.) test fabric stretched tightly over the surface, wrapped around the edges, and stapled to the backside of the plywood panel. Horizontal test panels consisted of a nominal $12.5 \times 20 \mathrm{~cm} .(5 \times 8$ in. $)$ piece of glass fiber board covered with a $20 \times 20 \mathrm{~cm}$. $(8 \times 8$ in.) piece of fabric material.

For testing, the prepared panels were mounted in the sample holder with the horizontal panel firmly abutting the vertical test panel as shown in Figure 3 (Figure 5 in the proposed upholstered furniture standard).

\section{b. Test Procedure}

Those fabrics which did not ignite in the fabric/glass fiber board test were subjected to the fabric/cotton batting test. The exact same test procedures previously outlined were followed. Those fabrics found to produce chars greater than $3.8 \mathrm{~cm} .(1.5 \mathrm{in.})$ or to ignite the cotton batting were rated "Fabric Class $B$ " materials. 
Fabrics that produced chars less than $3.8 \mathrm{~cm}$. (1.5 in.) and prevented ignition of the cotton batting were rated "Fabric Class A" materials.

c. Test Results

Each of the 47 upholstery cover fabrics listed in Table 1 were evaluated for resistance to ignition, by a burning cigarette.

Results showed that the group contained (6) "Fabric Class A" materials, (29) 'Fabric Class B" materials, (4) 'Fabric Class C" materials, and (7) "Fabric Class D" materials.

An examination of this table showed the following:

1. 'Fabric Class A" materials were heavyweight vinyl plastics, nylons, and polyester materials.

2. "Fabric Class B" materials contained 23 synthetic and six cellulosic fabrics. The cellulosics in this group were lightweight or tightly woven materials.

3. 'Fabric Class C" and "Fabric Class D" materials were "all cellulosie"-type materials. 
d. Additional Test Results

After classification of the test fabric materials into different Fabric Class categories, additional cigarette tests were made on the "Fabric Class $B, C$, and $D$ " materials. "Fabric Class A" materials were not tested because they did not ignite the cotton batting in the fabric/cotton batting test. In these tests, a 1/2-inch thick urethane foam layer was used to cover cotton batting. Test results on the fabric/foam/cotton combinations listed in.Table 1 show:

1. "Fabric Class $B$ " materials did not ignite or ignite the cotton batting.

2. 'Fabric Class C" and "Fabric Class D" materials ignited, burned through the foam layer, and ignited the cotton batting material. 
A cigarette ignition resistance test for classifying upholstery cover fabric materials into different Fabric Classes has been developed. The method supplements the flammability test for upholstered furniture by helping to reduce the number of mock-up tests required under the furniture test. With a Fabric Class given to each upholstery fabric material, upholsterers and re-upholsterers will be provided with information on whether a certain fabric would prevent ignitions on different furniture constructions. In view of the enormous number of cover fabrics available for use on furniture pieces, mock-up furniture testing and associated record-keeping would present a very severe hardship for these individuals; however, with the fabric test, this burden would be lessened considerably.

Based on the data of this report and results of more recent testing, the following table was developed that shows how different upholstery fabrics perform on different substrate materials.

Ignition Performance of Upholstery Fabric Materials FILLING MATERIAL

\begin{tabular}{|c|c|c|c|c|}
\hline $\begin{array}{l}\text { Fabric } \\
\text { Class }\end{array}$ & Cotton Batting & $\begin{array}{l}1 / 2^{\prime \prime} \text { Thick Foam } \\
\text { or Polyester Over } \\
\text { Cotton Batting } \\
\end{array}$ & $\begin{array}{c}\text { Retardant } \\
\text { Treated } \\
\text { Cotton Batting } \\
\end{array}$ & $\begin{array}{l}\text { Aluminized } \\
\text { Fabric Over } \\
\text { Cotton Batting } \\
\end{array}$ \\
\hline A & $\mathrm{N}$ & $\mathrm{N}$ & $\mathrm{N}$ & $\mathrm{N}$ \\
\hline B & I & $\mathrm{N}$ & $\mathrm{N}$ & $\mathrm{N}$ \\
\hline $\mathrm{C}$ & I & I & $\mathrm{N}$ & $\mathrm{N}$ \\
\hline D & $\bar{I}$ & I & I & $\mathrm{N}$ \\
\hline
\end{tabular}




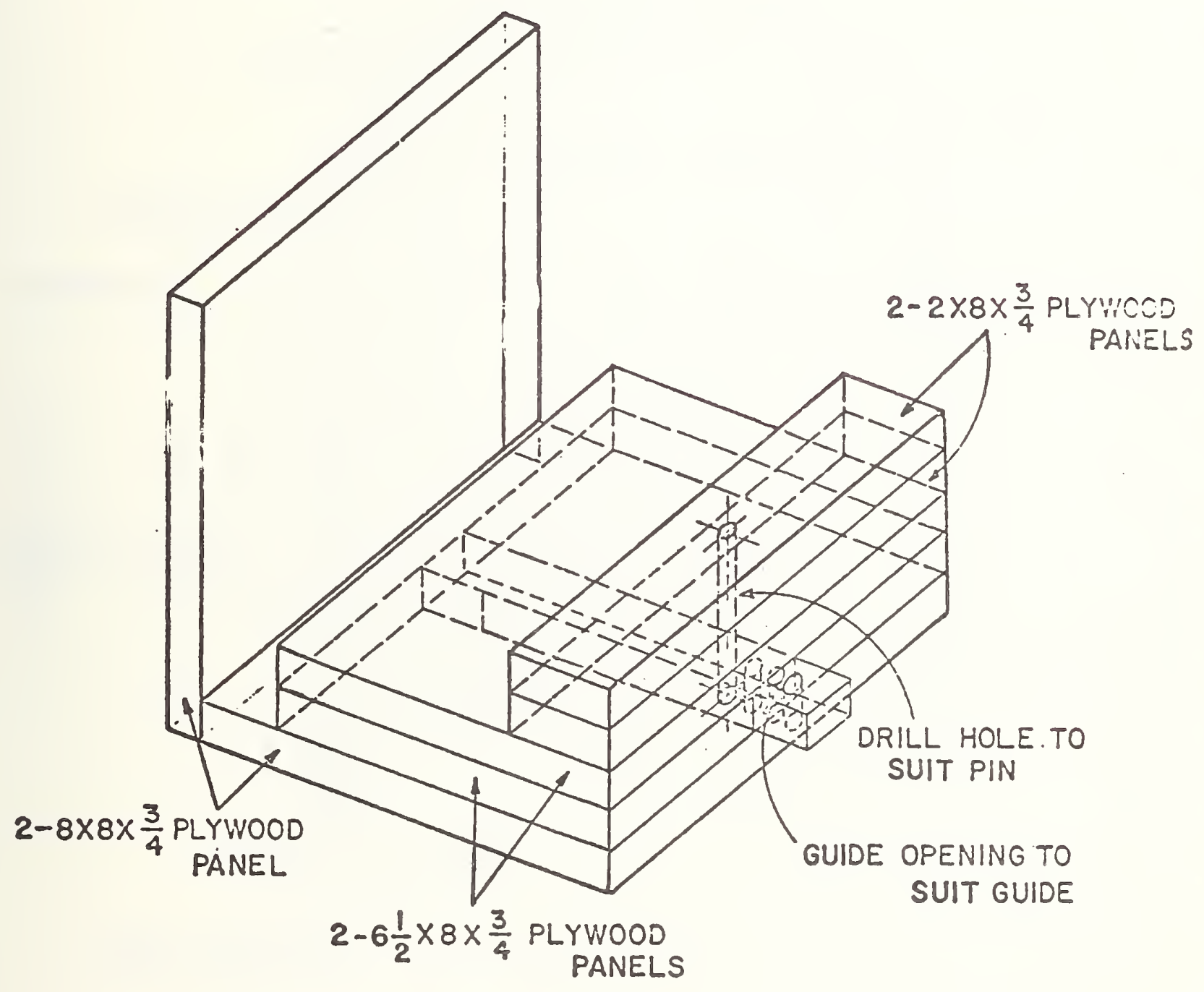

Figure 1. Sample Holder Cover Fabric Test 


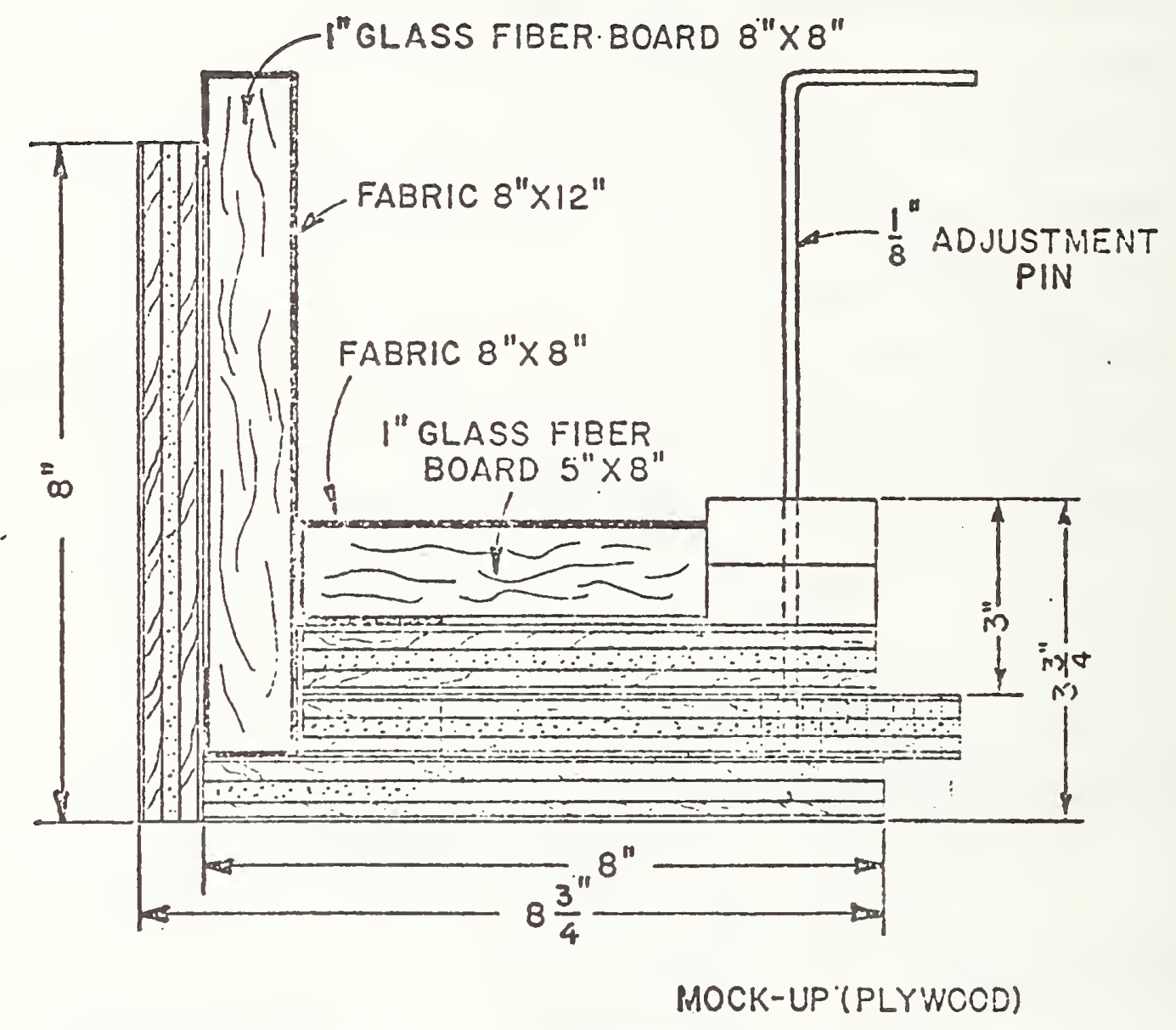

Figure 2. Cover Fabric Glass Fiber Board Test 


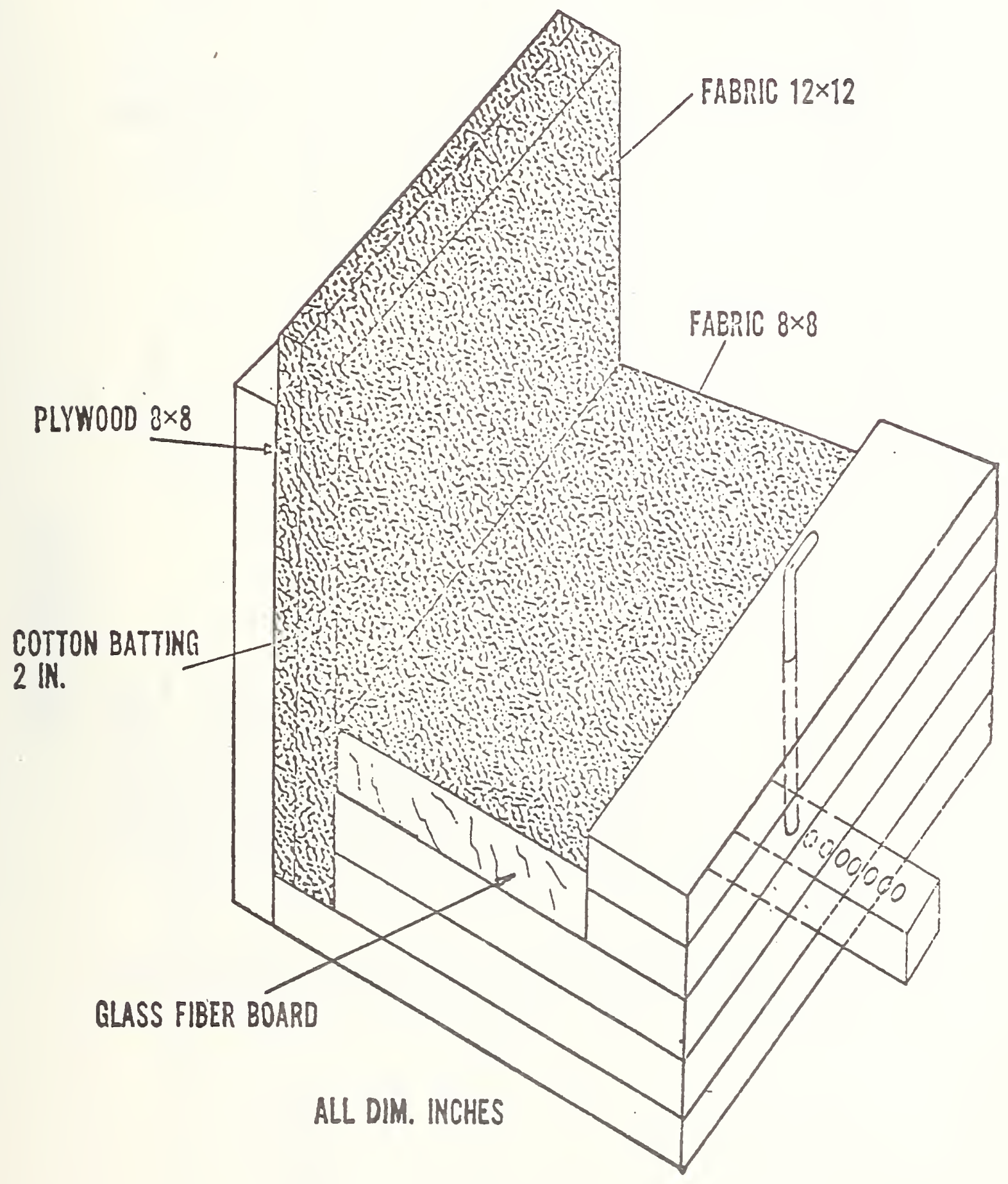

Figure 3. Cover Fabric Cotton Batting Test 


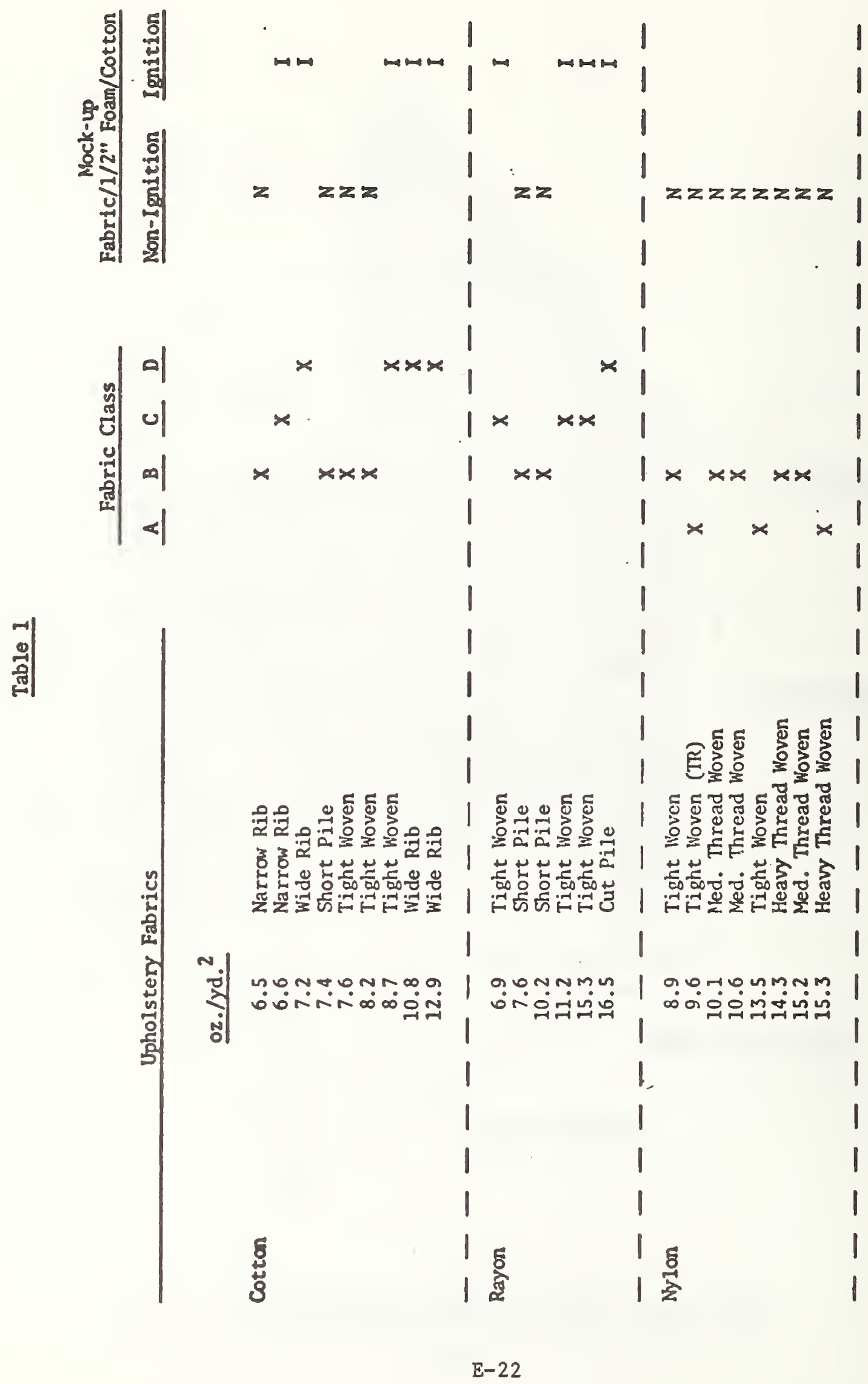




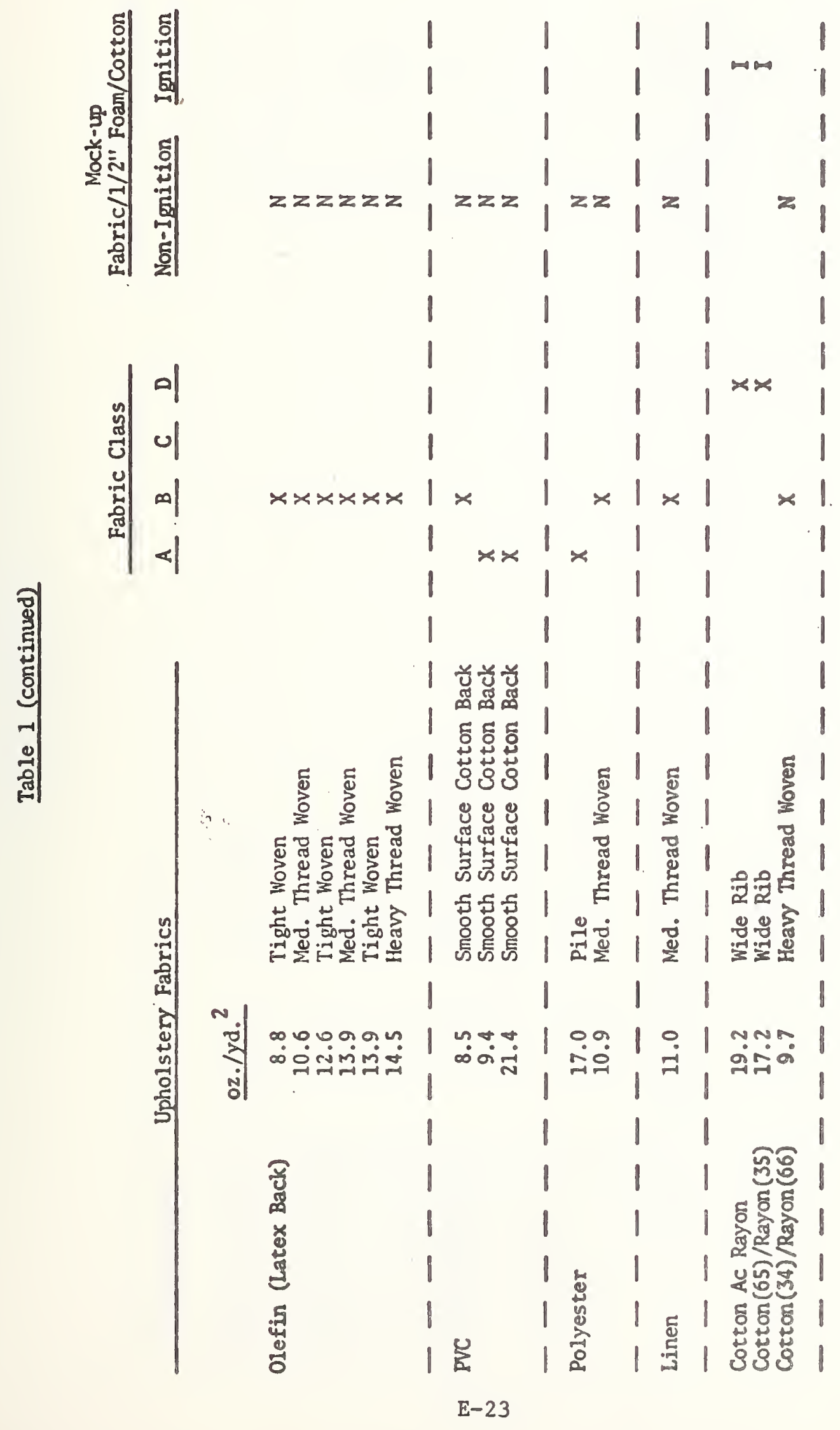




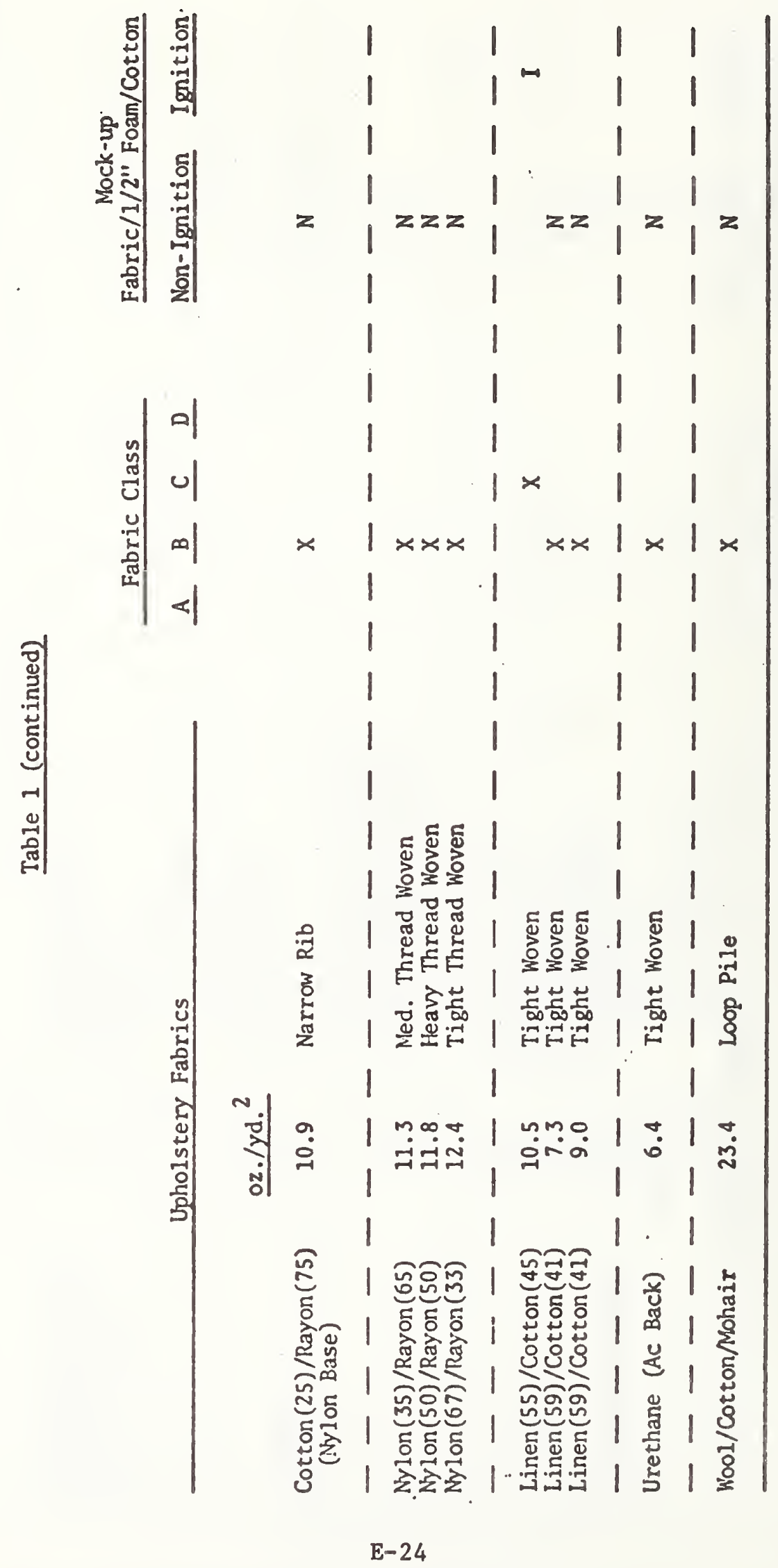




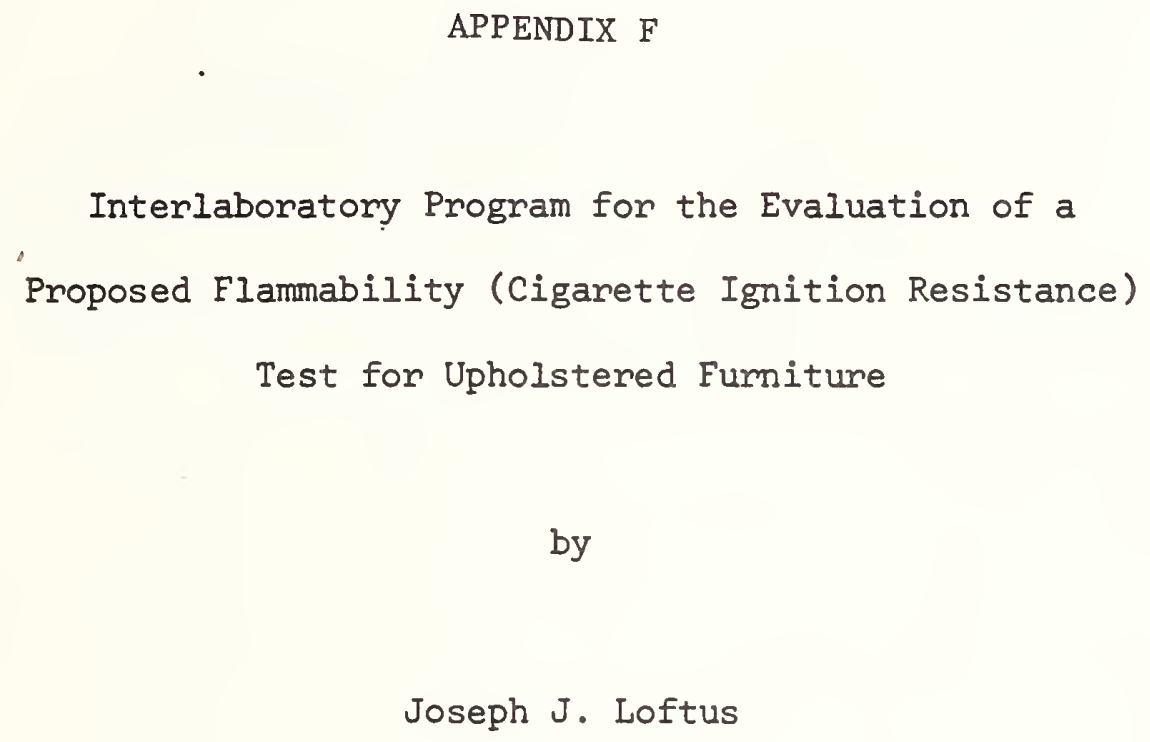

March 1976

Center for Fire Research

National Bureau of Standards

Washington, D.C. 
Table of Contents

Page

Abstract . . . . . . . . . . . . . . . . . 1

Introduction . . . . . . . . . . . . . . . . . 2

Test Materials . . . . . . . . . . . . . . . 5

Test Methods . . . . . . . . . . . . . . . . 8

Material Conditioning . . . . . . . . . . . . . . 9 9

Sample Preparation ... . . . . . . . . . . . . . . 9

Test Procedures . . . . . . . . . . . . . . . 11

Interpretation of Test Results . . . . . . . . . . . 13

Test Results . . . . . . . . . . . . . . . . 14

Fabric Classification Test Method . . . . . . . . . 14

Upholstered Furniture Mock-Up Test Method . . . . . . . 19

Arm and Top of Back Test Method . . . . . . . . . 25

Decking Test Method . . . . . . . . . . . . 28

Full-Size Upholstered Chair Test Method . . . . . . . . 28

Summary . . . . . . . . . . . . . . . . 35

Fabric Classification Test Method . . . . . . . . . 36

Upholstered Furniture Mock-Up Test Method . . . . . . . . 37

Arm and Top of Back Test Method . . . . . . . . . . 39

Decking Test Method . . . . . . . . . . . . 40

Full-Size Upholstered Chair Test Method . . . . . . . . 41

Conclusions and Recommendations . . . . . . . . . . . 42 42 


\author{
Interlaboratory Program for the Evaluation of a \\ Proposed Flammability (Cigarette Ignition Resistance) \\ Test for Upholstered Furniture
}

Joseph J. Loftus

March 1976

\title{
Abstract
}

A total of 55 laboratories participated in an interlaboratory evaluation study to determine the feasibility of a "Proposed Standard for the Flammability (smolder resistance to cigarettes) of Upholstered Furniture", PFF 6-74.

Thirty-seven of the laboratories used the "Fabric Classification Test Method" in the proposed standard to classify a total of 16 different upholstery fabrics as Class $A, B, C$, or D materials.

Thirty-eight laboratories used the "Upholstered Furniture Mock-Up Test Method" in the proposed standard to make smolder resistance measurements on 11 different upholstered fumiture constructions. 
Three laboratories used the mock-up fumiture test procedures to bum cigarettes on six new full-size upholstered chairs to compare test results with those obtained for similar tests on mock-up furniture constructions made with the same fabric and filling materials.

This report summarizes the results of tests from all laboratories and presents an analysis of the data.

\title{
Introduction
}

The interlaboratory study on the flammability of upholstered fumiture was conducted under the financial sponsorship of the Consumer Product Safety Commission (CPSC) and with the cooperation of the ASTM Subcommittee D13.52 and its task force on funiture flammability. The following is a list of participants:

\author{
A. Brandt Company \\ Action Industries \\ American Enka Company \\ Bassett Upholstery Division \\ Berkline Corporation \\ Bernhardt Industries \\ Broyhill Industries
}

$$
\text { F-4 }
$$


Burlington Industries

Cannon Mills Company

Chatham Manufacturing Company

Collins and Aikman Corporation

Consumer Product Safety Commission

Cotton, Incorporated

Courtaulds North America, Incorporated

Dan River, Incorporated

Deering Milliken Research

Dolly Madison Company

Drexel Heritage

E. I. du Pont de Nemours and Company, Incorporated

Erwin-Lambeth, Incorporated

FMC Corporation

Fox Manufacturing Company

Guilford Laboratories

Guilford Mills

Hercules, Incorporated

Hickory Chair

Hickory Tavern

Hoechst Fibers, Incorporated

J. C. Penney Company

J.P. Stevens

Joan Fabrics Corporation 
Kay Lyn, Incorporated

Kroehler Manufacturing Company

LaFrance Industries

M. Lowenstein $\varepsilon$ Sons, Incorporated

Mayo Manufacturing Company

Mohasco Corporation

Monsanto Textiles Company

National Bureau of Standards

Norwalk Furniture

Para-Chem, Incorporated

Radford College

Schnadig Corporation

Schweiger, Incorporated

Sears, Roebuck and Company

Silver Craft Furniture Company

Simmons Company

Southern Furniture Company of Conover, Incorporated

Sperry \& Hutchinson Company

State of California, Bureau of Home Furnishings

Tennessee Eastman Company

Thayer Coggins, Incorporated

U.S. Furniture Company

U.S.D.A., Southern Regional Research Laboratory

Walsh Chemical Company 
The study was designed to determine if the Fabric Classification and Fumiture Mock-Up Test Methods would produce repeatable results within a laboratory and reproducible results between laboratories. In addition, it sought to determine if tests on mock-ups of furniture constructions would produce results which would relate to those obtained on full-size fumiture pieces.

Code numbers were assigned to each of the laboratory participants, and the number 29-11 was assigned to the National Bureau of Standards (NBS).

\section{Test Materials}

Materials--Fabric Classification Test Method

Table 1 lists the 16 upholstery fabric materials used in the testing program. The fabrics were selected as representative of those used by the fumiture industry and were identified by a code number; no producers' identification was intended or implied. An attempt was made to incorporate most of the fiber types and blends in current use. Fabric weights ranged from 5.7 to $23.0 \mathrm{oz} / \mathrm{yd}^{2}$ with the average weight measured at $14 \mathrm{oz} / \mathrm{yd}^{2}$. In addition to the test fabrics, each laboratory was furnished with glass fiber board substrate material, sheeting fabric (for 
covering test cigarettes), cotton batting, and test cigarettes. For record purposes, these materials are identified as follows:

Glass Fiber Board - Nominal $2.5 \mathrm{~cm}$ ( 1 in) thick with a density of $40 \pm 8 \mathrm{~kg} / \mathrm{m}^{3}(2.5 \pm 0.5 \mathrm{lb} / \mathrm{cu} \mathrm{ft})$. The board was Form A, Class I, plain faced, and meets Federal Specification HH-I-558B.

Sheeting Fabric - One hundred percent cotton, white in color, weight $125 \pm 28 \mathrm{~g} / \mathrm{m}^{2}\left(3.7 \pm 0.8 \mathrm{oz} / \mathrm{yd}^{2}\right)$ washed and dried once, in a home washer and dryer before use.

Cotton Batting - Nominal $5 \mathrm{~cm}$ (2 in) thick with a density of $32 \pm 8$ $\mathrm{kg} / \mathrm{m}^{3}(2 \pm 0.5 \mathrm{lb} / \mathrm{cu} \mathrm{ft})$. The batting was made of at least 75 percent linters and 25 percent cotton staple and was not treated with any material to impart fire retardancy.

Test Cigarettes $-85 \pm 2 \mathrm{~mm}(3.4 \pm 0.1$ in) long without filter tips.

Materials--Upholstered Furniture Mock-Up Test Method

Table 2 lists all of the materials supplied to each participant for the furniture mock-up test. These materials included full-size upholstered urethane foam seat cushions; eight different upholstery fabrics 
(selected from the fabric classification test listing); and three types of filling materials--cotton batting, urethane foam, and polyester fiberfill. Sufficient material was furnished to allow for the construction of 11 different fumiture assemblies.

The urethane foam cushions and foam pieces for side panels were in the density range of $24 \pm 0.4 \mathrm{~kg} / \mathrm{m}^{3}$ (1.5 $\left.\pm 0.2 \mathrm{lb} / \mathrm{cu} \mathrm{ft}\right)$.

The polyester fiberfill supplied was nominal $2.5 \mathrm{~cm}$ ( 1 in) thick.

Materials--Full-Size Upholstered Chair Test Method

Table 3 lists a complete description of the materials used by a furniture manufacturer in fabricating 18 full-size upholstered chairs for test. All filling materials used in their construction were the same type as those selected for the mock-up furniture tests. Two chair styles were made--one with loose or unattached seat and back cushions and the other with tight or attached seats and backs. The four upholstery fabrics selected as cover materials for the chairs were chosen from the fabric classification test listing. 


\section{Test Methods}

\section{Fabric Classification Test Method}

The test method and procedures used in the interlaboratory study are described in complete detail in the proposed standard (see Appendix). Briefly, cigarettes are burned (covered by a piece of sheeting material) in the crevice location of two abutting fabric covered test panels. Glass fiber board and cotton batting are used as the substrate materials in the test. Based on length of char or ignition measurements, test fabrics are rated as Class $A, B, C$, or $D$ materials.

Upholstered Furniture Mock-Up Test Method

The test method and procedures used for conducting the Upholstered Fumiture Mock-Up Test Method are described in complete detail in the proposed standard. Briefly, cigarettes are burned (covered by a piece of sheeting material) on the surface and welt edge of seat cushions and in crevice locations where the cushion abuts mock-up vertical test panels. The test procedure also calls for testing mock-up arm, top of back constructions, and deckings of loose seat cushion furniture items. Under the proposed standard, each cigarette test location must pass (nonignition) the test. 
Full-Size Upholstered Chair Test Method

The test method used for testing the upholstered chairs was the same as used for mock-up testing.

Material Conditioning

All laboratories were instructed to condition all test materials, upholstered chairs and test cigarettes, for at least 48 hours in a room area at a temperature greater than $65^{\circ} \mathrm{F}$ and relative humidity (RH) less than 55 percent, prior to testing.

\section{Sample Preparation}

Sample Preparation--Fabric Classification Test Method

Each laboratory prepared and cut samples of test fabric, substrate glass fiber board panels, and cotton batting material for test, in accordance with procedures outlined in the Fabric Classification Test Method. Each of the 16 test fabrics required test panels for four tests on glass fiber board substrates and four tests on glass fiber board/ cotton batting assemblies. 
Sample Preparation--Upholstered Furniture Mock-Up Test Method

Six of the upholstered furniture test mock-ups required full-size seat cushions and the construction of vertical test panels. The loose or unattached seat cushions were "factory made" and were supplied ready for test. Tight seat constructions were made as required by each individual laboratory participant. Five other constructions required the preparation of horizontal test panels for arm or top of back and decking tests. All test panels and tight seat cushions were prepared using procedures and methods of assembly outlined in the Upholstered Furniture Mock-Up Test Method.

Sample Preparation--Full-Size Upholstered Chair Test Method

No special preparations were required prior to test. Three laboratories each received six chairs for test, three of these were made with loose or unattached seat cushions and backs and three were made with tight seat cushions and backs. 
Test Procedures

\section{Procedure--Fabric Classification Test Method}

Figure 4 in the proposed standard illustrates a glass fiber board assembly for the fabric classification test. Each laboratory was instructed to burn a single cigarette (covered by a $12.5 \times 12.5 \mathrm{~cm}$ piece of cotton sheeting) at the center of the crevice location of the test assembly and to perform this test a total of four times on each of the 16 upholstery sample fabrics. After each test cigarette had burned its full length (or extinguished), char measurements were made on the vertical and horizontal fabric surfaces and along the crevice from the butt and tip ends of the test cigarette.

Figure 5 in the proposed standard illustrates the cotton batting test assembly for the fabric classification test. This test was also conducted four times on each of the 16 test fabrics by each of the laboratories. In lieu of char measurements, the laboratories were instructed to record ignition or nonignition results for each test.

\section{Procedure--Upholstered Furniture Mock-Up Test Method}

Figure 3 in the proposed standard illustrates the mock-up upholstered furniture test assembly and the location of test cigarettes on 
the construction. Cigarettes burned no more than $4 \mathrm{~mm}$ ( $0.16 \mathrm{in}$ ) before placement were positioned on the test locations, covered with a piece of sheeting material, and allowed to burn their full length (or to extinguishment) in the location. Laboratories were instructed to stop the test at any point in time where an obvious ignition had occurred and to record an ignition for that particular test location. In those cases where no ignition occurred in a test location, char measurements were made a) up the vertical side panel, along the crevice and horizontally on the seat cushion surface; b) up the vertical back panel, along the crevice and horizontally on the seat cushion; c) on the seat cushion surface; and d) on the welt edge of the seat cushion.

Tests on horizontal panels for arms, top of back and decking assemblies were made in the same manner as on a seat cushion surface. The mock-up is illustrated in Figure 3. Three cigarettes were burned on each panel.

Each laboratory burned a total of eight cigarettes on each upholstered furniture mock-up construction and three cigarettes on each arm and top of back assembly or decking constructj.

Data sheets were supplied to all laboratories, and they were instructed to fill them out and to submit the data to NBS for analysis and review. 
Procedure--Full-Size Upholstered Chair Test Method

Figure 8 (not shown in the proposed standard) shows the cigarette test locations for the chairs tested by each of three laboratories. Deckings were tested in the loose seat chair construction in addition to conducting loose bolster tests on the chairs.

The procedures for conducting the tests on the chairs were the same as outlined for the furniture nock-up tests.

\section{Interpretation of Test Results}

Interpretation of Test Results--Fabric Classification Test Method

The schematic diagram (Figure 6 ) in the proposed standard outlines, in detail, the means used to classify the test upholstery fabrics. Briefly, Class A fabrics do not smolder on glass fiber board substrates and do not ignite cotton batting. Class B fabrics do not smolder on glass fiber board but do ignite cotton batting. Class C fabrics ignite and smolder at least $3.8 \mathrm{~cm}(1.5 \mathrm{in})$ on glass fiber board and ignite cotton batting. Class $D$ fabrics ignite and smolder more than $7.5 \mathrm{~cm}(3.0$ in) on the glass fiber board and ignite cotton batting. 
Interpretation of Test Results--Upholstered Furniture Mock-Up and FullSize Upholstered Chair Test Methods

A passing (nonignition) result was reported by a laboratory if the test cigarette burned its full length on a test location and did not ignite the test fabric or filling material used in the mock-up construction.

A failing (ignition) result was reported by a laboratory if a test cigarette ignited the test fabric and/or filling material or produced a char measurement greater than $7.5 \mathrm{~cm}(3.0$ in) in any direction from the test cigarette.

Test Results

Results--Fabric Classification Test Method

Table 4 lists the results of the Fabric Classification Test Method.

An analysis of the data from the 37 laboratory participants showed the following: 


$\begin{gathered}\text { Class "A" } \\ \text { Fabrics }\end{gathered}$
1 Wool/Nylon Blend
8 Wool/Nylon Blend
9 Vinyl Plastic
Class "B"
Fabrics

7 Nylon

15 Nylon

11 Olefin

14 Nylon

2 Nylon

10 Rayon/Nylon/ Polyester

Class "C" Fabrics

13 Rayon

4 Cotton

12 Rayon

3 Acetate/Rayon

16 Rayon

6 Cotton

\section{\# Labs \\ Reporting Class "A"}

36

31

37

\# Labs

Reporting Class "B"

37

37

35

35

34

34

\# Labs

Reporting Class "C"

35

32

29

27

27

21
\% Labs

Reporting Class "A"

97

84

100

\& Labs

Reporting Class "B"

100

100

95

95

92

92
$\%$ Labs

Reporting Class "C"
95

90

78

74

74

58 


\begin{tabular}{c} 
Class "D" \\
Fabrics \\
\hline
\end{tabular}

5 Cotton

\# Labs
Reporting Class "D"

37
\% Labs

Reporting Class "D"

100

All 37 laboratories showed complete agreement in assigning four of the 16 test fabrics to a particular fabric classification; namely, \#5 to Class D, \#7 to Class B, \#9 to Class A, and \#15 to Class B.

Ten of the 16 fabrics were placed in Class A, B, and D categories with laboratory agreement ranging from 84-100 percent.

The six sample fabrics rated as Class $C$ materials showed a wide range (58-95 percent) in laboratory agreement.

This rather large spread can be attributed to certain test parameters introduced into the evaluation study.

These factors included fiber type in a test fabric, weave direction, or orientation of a fabric when mounted in the test apparatus and an air gap lan air gap here meaning a space or opening up to $1.8 \mathrm{~cm}(0.5 \mathrm{in})$ between the vertical test panel and the platform support for the horizontal test panel in the test apparatus]. 
Each of these parameters will be discussed separately.

Fiber Type - An examination of the above listing shows that fabrics in the Class $C$ and Class $D$ categories were cellulose fiber materials and that fabrics in the Class $A$ and Class B categories were synthetic fiber fabrics or plastic material.

Test observations based on the fiber type in the upholstery fabric sample materials are listed as follows:

Synthetic Fabrics --

(a) melt

(b) scorch

(c) do not support smoldering combustion

(d) Class A rated fabrics did not permit ignitions in cotton batting

(e) Class $B$ rated fabrics allow ignitions in cotton batting

Cellulosic Fabrics --

(a) ignite when exposed to burning cigarettes

(b) once ignited, will support smoldering combustion 
(c) ignite and contribute to the ignition of cotton batting

(d) Class $C$ and Class $D$ ratings were based on length of char measurement on g?ass fiber board and on cotton batting ignition

Fabric Weave Direction or Orientation - Ten laboratories each were assigned the task of testing the 16 test fabric samples in one of the four fabric orientations:

$$
\begin{aligned}
& \text { Laboratories 1-10 warp/warp } \\
& \text { 11-20 warp/cross warp } \\
& \text { 21-30 cross warp/cross warp } \\
& \text { 31-40 cross warp/warp }
\end{aligned}
$$

An analysis of the fabric classification test results showed that those laboratories who conducted tests in the warp/warp fiber orientation obtained the most reproducible results.

Air Gap - A total of 25 laboratories used $12.5 \mathrm{~cm}$ (5 in) wide pieces of glass fiber board for horizontal fabric test panels and thus conducted their tests with an air gap or spacing between the vertical fabric test panels and the horizontal sunport for horizontal panels in the test apparatus. 
Twelve laboratories used approximately $10.3 \mathrm{~cm}$ (4.5 in) wide pieces of glass fiber board (cut to the same width as the horizontal platform) for their horizontal panels and conducted their tests with essentially no air gap or spacing.

At least two sample fabrics, \#3 and 6 , were found to produce fabric classifications which could be directly related to the presence or absence of the air gap.

Results--Upholstered Fumiture Mock-Up Test Method

Tables 5 to 9 list the results of the fumiture mock-up tests for eight different upholstery fabrics on 11 different fumiture constructions. Based on these results and those obtained in the Fabric Classification Test Method, the following observations are made:

1. Class A fabrics \#1 and 8 on mock-up constructions \#2, 3 , and 4 produced the following: 


\section{\% Labs Reporting Ignitions}

\begin{tabular}{|c|c|c|c|c|c|c|c|c|c|c|}
\hline \multirow{2}{*}{$\begin{array}{l}\text { Construction \# } \\
\text { Side } \\
\text { Back } \\
\text { Cushion } \\
\text { Fabric \# }\end{array}$} & \multicolumn{3}{|c|}{$\begin{array}{l}\quad \quad 2 \\
\text { Cotton } \\
\text { Foam } \\
\text { Foam }\end{array}$} & \multicolumn{3}{|c|}{$\begin{array}{l}\quad \quad 3 \\
\text { Cotton } \\
\text { Foam } \\
\text { FF/Foam }\end{array}$} & $\begin{array}{l}1 / 2^{\prime \prime} \\
\text { Foam } \\
\text { Tight }\end{array}$ & & $\begin{array}{l}4 \\
\mathrm{am} /\end{array}$ & Cotton \\
\hline & $S$ & W & C & $S$ & W & C & $S$ & 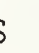 & W & C \\
\hline 1 & 0 & 0 & 0 & 0 & 0 & 0 & $\epsilon$ & & 51 & 0 \\
\hline 8 & 0 & 0 & 0 & 0 & 0 & 0 & 0 & D & 35 & 3 \\
\hline
\end{tabular}

$$
\begin{aligned}
& S=\text { Surface of Cushion } \\
& W=\text { Welt Edge of Cushion } \\
& C=\text { Crevice of Mock-Up Assembly }
\end{aligned}
$$

As shown above, all 38 laboratory participants reported that Class A fabrics \#1 and 8 did not allow ignitions on:

(a) foam urethane seat cushion surfaces or welt edges

(b) fiberfill/foam urethane seat cushion surfaces or welt edges

(c) cotton batting and foam urethane vertical mock-up panels in combination with the above cushions

Two laboratories ( 6 percent) reported that sample fabric \#1 allowed an ignition in the cotton batting seat cushion in construction \#4. 
One laboratory ( 3 percent) reported that sample fabric \#8 permitted an ignition in the crevice location of construction $\# 4$ and burned the side panel of the construction ( $1 / 2$ inch foam urethane over cotton batting).

Both Class A fabrics (\#1 and 8) allowed ignitions in the welt edge of the cotton batting seat cushion of construction \#4. (Actually, in these tests, welt edges, per se, did not exist; however, some of the laboratories burned cigarettes on the curved edges of the cushions.)

2. Class $\mathrm{B}$ fabrics \#2 and 7 produced the following results when tested on mock-up furniture constructions \#1, 3, 4, and 5:

Class B Fabrics

\% Labs Reporting Ignitions

\begin{tabular}{|c|c|c|c|c|c|c|}
\hline $\begin{array}{l}\text { Construction \# } \\
\text { Side } \\
\text { Back } \\
\text { Cushion }\end{array}$ & $\begin{array}{l}1 / 2^{\prime \prime} \\
\text { Foam } \\
\text { Foam }\end{array}$ & $\begin{array}{r}1 \\
\text { Foar }\end{array}$ & Cotton & \multicolumn{3}{|c|}{$\begin{array}{l}\quad 3 \\
\text { Cotton } \\
\text { Foam } \\
\text { FF/Foam }\end{array}$} \\
\hline Fabric \# & S & $5 \mathrm{~W}$ & c & S & $W$ & C \\
\hline 2 & 0 & 0 & 0 & 0 & 0 & 60 \\
\hline 7 & 0 & 0 & 9 & 0 & 0 & 72 \\
\hline
\end{tabular}


Class B Fabrics (con't)

\section{\% Labs Reporting Ignitions}

\begin{tabular}{|c|c|c|c|c|c|c|c|}
\hline $\begin{array}{l}\text { Construction \# } \\
\text { Side } \\
\text { Back } \\
\text { Cushion }\end{array}$ & $\begin{array}{l}1 / 2^{\prime \prime} \\
\text { Foam } \\
\text { Tight }\end{array}$ & $\begin{array}{c}4 \\
\text { Foam/ } \\
\text { Cott }\end{array}$ & Sotton & $\begin{array}{l}1 / 2^{\prime \prime} \\
\text { Foam } \\
\text { Tight }\end{array}$ & & ar & Cotton \\
\hline Fabric \# & S & $W$ & $C$ & s & s & N & $c$ \\
\hline 2 & 34 & 55 & 95 & 0 & ) & D & 18 \\
\hline 7 & 26 & 71 & 97 & 0 & & 0 & 16 \\
\hline
\end{tabular}

As indicated above, all 38 laboratories reported that Class B fabrics did not allow ignitions to occur in:
(a) foam urethane seat cushion surfaces or welt edges
(b) fiberfill/foam urethane cushion surfaces or welt edges
(c) tight foam urethane cushion surfaces or welt edges
(d) crevice location of construction \#1 (fabric \#2)

Both Class B fabrics (\#2 and 7) allowed ignitions to occur:

(a) in the cotton batting filled side panels of construction \#3

(b) in $1 / 2$ inch foam/cotton panels of constructions \#1, 4, and 5

(c) in all locations of construction \#4 where a cotton seat cushion was used. 
3. Class $C$ upholstery fabrics \#3, 4, and 6 produced the following results when tested on mock-up constructions \#1, 4, 5, and 6:

Class C Fabrics

Labs Reporting Ignitions

\begin{tabular}{|c|c|c|c|c|c|c|}
\hline $\begin{array}{l}\text { Construction \# } \\
\text { Side } \\
\text { Back } \\
\text { Cushion }\end{array}$ & $\begin{array}{l}1 / 2^{\prime \prime} \\
\text { Foam } \\
\text { Foam }\end{array}$ & $\begin{array}{c}1 \\
\text { Foan }\end{array}$ & Cotton & $\begin{array}{l}1 / 2^{\prime \prime} \\
\text { Foam } \\
\text { Tight }\end{array}$ & $\begin{array}{c}4 \\
\text { Foam } \\
\text { Cot }\end{array}$ & $\begin{array}{l}\text { Cotton } \\
\text { on }\end{array}$ \\
\hline Fabric \# & S & $W$ & C & S & W & C \\
\hline 3 & 3 & 75 & 97 & 73 & 93 & 100 \\
\hline 4 & 9 & 84 & 100 & -- & --- & --- \\
\hline 6 & 9 & 92 & 100 & 58 & 100 & 100 \\
\hline
\end{tabular}

\begin{tabular}{|c|c|c|c|c|c|c|}
\hline $\begin{array}{l}\text { Construction \# } \\
\text { Side } \\
\text { Back } \\
\text { Cushion }\end{array}$ & $\begin{array}{l}1 / 2^{\prime \prime} \\
\text { Foam } \\
\text { Tight }\end{array}$ & EOa & n/Cotton & & $\begin{array}{c}6 \\
\text { Foam }\end{array}$ & \\
\hline Fabric \# & $S$ & W & C & S & $W$ & C \\
\hline 3 & 6 & 6 & 100 & 6 & 78 & 97 \\
\hline 4 & - & - & --- & 3 & 81 & 97 \\
\hline 6 & 3 & 3 & 100 & 3 & 86 & 97 \\
\hline
\end{tabular}


(a) Out of a total of 38 laboratories, one laboratory ( 3 percent) reported an ignition in the foam urethane seat cushion covered by Class $C$ fabric \#3, and three laboratories ( 29 percent) showed ignition in the same type of cushion covered by fabrics $\# 4$ and 6 .

(b) The welt edges of the factory-made foam urethane seat cushions were ignited by 75-92 percent of the testing laboratories.

(c) On a tight foam seat cushion, two laboratories ( 6 percent) reported ignition in the curved edge (welt) of the cushion covered by fabric \#3, and one laboratory ( 23 percent) ignited the cushion under fabric \#6 cover.

(d) The crevice locations in all four constructions were found extremely vulnerable to cigarette ignition. Except for one laboratory reporting nonignition, ignition of the crevices was total (97-100 percent).

(e) Vertical mock-up panels filled with foam urethane or $1 / 2$ inch foam urethane/cotton batt were easily ignited by the class $C$ fabrics.

(f) The tight cotton seat cushion in construction \#4 was found easily ignitable by the Class $C$ fabric materials.

4. Class D upholstery fabric \#5 produced the following results when tested on mock-up furniture constructions \#1 and 6:

Class D Fabrics

\% Labs Reporting Ignitions

\begin{tabular}{|c|c|c|c|c|c|c|}
\hline $\begin{array}{l}\text { Construction \# } \\
\text { Side } \\
\text { Back } \\
\text { Cushion }\end{array}$ & $\begin{array}{l}1 / 2^{\prime \prime} \\
\text { Foam } \\
\text { Foam }\end{array}$ & $\begin{array}{c}1 \\
\text { Foam }\end{array}$ & Cotton & & $\begin{array}{l}6 \\
\text { Fo } \\
\text { Fo } \\
\text { Fo }\end{array}$ & \\
\hline Fabric \# & $S$ & W & C & $S$ & $\mathrm{~W}$ & C \\
\hline 5 & 63 & 91 & 100 & 90 & 94 & 100 \\
\hline
\end{tabular}


(a) All 38 laboratories reported that the sample fabric ignited the crevice locations of foam urethane seat cushions and involved the vertical mock-up panels filled with foam urethane and 1/2 inch foam urethane over cotton batt.

(b) Welt edges of the foam cushions were ignited by 91-94 percent of the laboratories.

(c) Seat cushion surfaces were ignited by 63-90 percent of the laboratories.

Results--Mock-Up Arm and Top of Back Test Method

Tables 10-13 list results fumished by 38 laboratories. Each laboratory tested eight different upholstery fabrics on four different mock-up constructions, \#7, 8, 9, and 10. An analysis of these data for percent laboratories reporting ignition showed the following: 
\& Labs Reporting Ignitions

\begin{tabular}{|c|c|c|c|c|c|}
\hline \multirow{2}{*}{$\begin{array}{c}\text { Fabric } \\
\#\end{array}$} & \multirow{2}{*}{$\begin{array}{l}\text { Fabric } \\
\text { Class }\end{array}$} & \multicolumn{4}{|c|}{ Constructions } \\
\hline & & $\begin{array}{c}\# 7 \\
2 \text { in } \\
\text { Cotton }\end{array}$ & $\begin{array}{c}\$ 8 \\
1 / 2 \text { in } \\
\text { Foam Over } \\
2 \text { in Cotton }\end{array}$ & $\begin{array}{c}\# 9 \\
2 \text { in } \\
\text { Foam } \\
\text { Urethane }\end{array}$ & $\begin{array}{c}\# 10 \\
1 \text { in } \\
\text { Polyester Over } \\
2 \text { in Cotton }\end{array}$ \\
\hline 1 & A & 5 & 0 & 0 & 0 \\
\hline 8 & A & 3 & 0 & 0 & 0 \\
\hline 2 & B & 87 & 5 & 0 & 0 \\
\hline 7 & B & 84 & 5 & 0 & 0 \\
\hline 3 & C & 100 & 5 & 3 & 0 \\
\hline 6 & C & 100 & 10 & 3 & 0 \\
\hline 4 & C & 100 & 7 & 3 & 0 \\
\hline 5 & D & 100 & 87 & 87 & 40 \\
\hline
\end{tabular}

On construction \#7 ( 2 in cotton batting), it is seen that the sample fabrics produced the following:

(a) Of the 38 laboratory participants testing Class A fabric performance on cotton batt filled arms, two laboratories ( $\sim 5$ percent) reported ignition under fabric \#1, and only one laboratory ( $\sim 3$ percent) showed an ignition for fabric \#8.

(b) Class B, C, and D fabrics easily ignited the cotton batting material. 
On construction \#8 ( $1 / 2$ in urethane over 2 in cotton), it was found that:

(a) Class A fabrics did not ignite the construction in any laboratory.

(b) Class B fabrics resisted ignition in all but 2 laboratories.

(c) Class $C$ fabrics \#3, 6, and 4 were reported by 2, 4, and 3 laboratories, respectively, to have ignited the test assembly.

(d) Class D fabric (\#5) easily ignited the construction. Eightyseven percent of the laboratories reported ignition.

On construction \#9 (2 in foam urethane):

(a) Both the Class A and B sample fabrics resisted every cigarette ignition attempt by all 38 laboratory participants.

(b) Only one laboratory reported that Class C fabrics \#3, 6, and 4 ignited the foam urethane substrate.

(c) Class D fabric (\#5) was reported by 87 percent of the laboratories to have ignited the foam urethane construction.

On construction \#10 ( 1 in polyester over 2 in cotton batting):

(a) Class A, B, and C sample fabrics resisted every cigarette ignition attempt by all laboratories.

(b) A total of 15 laboratories (40 percent of total) reported that Class D fabric \#5 caused ignitions in the test construction. 
Results--Decking. Test Method

Table \#11 lists results for tests on two decking assemblies.

Construction
$\begin{gathered}\text { Sateen fabric over } \\ \text { cotton batting }\end{gathered}$
$\begin{gathered}\text { Sateen fabric over } \\ \text { bonded cellulose }\end{gathered}$

\& Labs Reporting Ignitions

97

0

(a) As indicated above, all laboratories reported that no ignitions were observed in the bonded cellulose assembly.

(b) All but 1 laboratory ( $\sim 3$ percent of total) reported ignitions in the cotton system.

Results--Full-Size Upholstered Chair Test Method

The following tables list results of tests conducted by three laboratories on six full-size upholstered chairs and shows a comparison with results obtained by the laboratories on similar constructions reproduced in mock-ups. 
Chair Tests

\section{Class A Fabric (\#1) on Construction \#1}

\begin{tabular}{|c|c|c|c|c|c|c|c|c|}
\hline & & & & $\mathrm{ck}-\mathrm{U}$ & & & hair & \\
\hline & & & & & & & & \\
\hline Test Location & & Fill & \#29 & 31 & 39 & $\# 29$ & 31 & 39 \\
\hline Surface of Cushion & Foam & & $\mathrm{N}$ & $\mathrm{N}$ & $\mathrm{N}$ & $\mathrm{N}$ & $\mathrm{N}$ & $\mathrm{N}$ \\
\hline Welt Edge of Cushion & Foam & & $\mathrm{N}$ & $\mathrm{N}$ & $\mathrm{N}$ & N & $\mathrm{N}$ & $\mathrm{N}$ \\
\hline Crevice--Side & $1 / 2^{\prime \prime}$ & Foam/Cotton & $\mathrm{N}$ & $\mathrm{N}$ & $\mathrm{N}$ & $\mathrm{N}$ & $\mathrm{N}$ & $N$ \\
\hline Crevice--Back & Foam & & $\mathrm{N}$ & $\mathrm{N}$ & $\mathrm{N}$ & $\mathrm{N}$ & $\mathrm{N}$ & $\mathrm{N}$ \\
\hline Arm & $1 / 2^{\prime \prime}$ & Foam/Cotton & $\mathrm{N}$ & $\mathrm{N}$ & $\mathrm{N}$ & $\mathrm{N}$ & $\mathrm{N}$ & $\mathrm{N}$ \\
\hline Top of Back & Foam & & $\mathrm{N}$ & $\mathrm{N}$ & $\mathrm{N}$ & $\mathrm{N}$ & I & $\mathrm{N}$ \\
\hline
\end{tabular}

The above table indicates excellent correlation of test results. The one ignition recorded by laboratory \#31 represents a single ignition in four tests. 


\section{Class B Fabric (\#2) on Construction \#3}

\begin{tabular}{l|l|lll|ccc} 
& \multicolumn{3}{|c}{ Mock-UP } & \multicolumn{3}{c}{ Chair } \\
\multicolumn{1}{|c|}{ Test Location } & Fill & $\# 29$ & 31 & 39 & $\# 29$ & 31 & 39 \\
Surface of Cushion & FF/Foam & N & N & N & N & N & N \\
Welt Edge of Cushion & FF/Foam & N & N & N & N & N & N \\
Crevice--Side & Cotton & I & I & N & N & N & N \\
Crevice--Back & Foam & N & N & N & N & I & N \\
Arm & Cotton & I & I & I & N & N & N \\
Top of Back & Foam & N & N & N & N & N & N \\
Decking & Cotton & I & I & I & I & I & N
\end{tabular}


Chair Tests

Class B Fabric (\#2) on Construction \#4

\begin{tabular}{|c|c|c|c|c|c|c|c|}
\hline \multirow[b]{3}{*}{ Test Location } & \multirow[b]{3}{*}{ Fill } & \multicolumn{3}{|c|}{ Mock-Up } & \multicolumn{3}{|c|}{ Chair } \\
\hline & & \multicolumn{6}{|c|}{ Lab } \\
\hline & & \#29 & 31 & 39 & $\# 29$ & 31 & 39 \\
\hline Surface of Cushion & Cotton & $\mathrm{N}$ & I & N & I & I & I \\
\hline Welt Edge of Cushion & Cotton & N & I & I & I & I & $I$ \\
\hline Crevice--Side & 1/2" Foam/Cotton & I & I & I & I & $I$ & I \\
\hline Crevice--Back & Foam & I & I & I & I & $I$ & I \\
\hline Arm & 1/2" Foam/Cotton & $\mathbb{N}$ & N & $N$ & $\mathrm{~N}$ & N & $\mathbb{N}$ \\
\hline Top of Back & Foam & $\mathrm{N}$ & $\mathrm{N}$ & $\mathrm{N}$ & $\mathbf{N}$ & $\mathrm{N}$ & $\mathbb{N}$ \\
\hline
\end{tabular}

The above test results show unanimous agreement between laboratories in all but the following test locations:

Construction \#3

(a) Crevice of mock-up. -. The cotton filled vertical panel was not ignited by 1 laboratory.

(b) Crevice of chair. -- The foam back was ignited by 1 laboratory.

(c) Decking of chair. - One laboratory failed to obtain ignitions on this test location. 
Construction \#4

(d) Two laboratories did not ignite a cotton batt tight seat cushion.

(e) One laboratory failed to ignite the welt edge of the tight cotton seat cushion.

The obvious explanation for the nonignition results reported for items $\# a, c, d$, and e, above, would be that the laboratories were not proficient in making tight cotton seat cushions and thus failed to obtain good "fabric to cotton batt" contact in their mock-up constructions. This is shown by a comparison of mock-up tight cotton seat cushion results ( 1 ignition/3 laboratories) with the "factory made" "tight cotton cushion" chair results which show all three laboratories igniting the factory chair cushion.

No explanation can be given for the crevice "foam ignition" reported by one laboratory on the test chair. 


\section{Class C Fabric (\#3) on Construction \#6}

\begin{tabular}{l|l|lll|lll} 
& & \multicolumn{3}{|c}{ Mock-Up } & \multicolumn{3}{c}{ Chair } \\
\multicolumn{1}{|c|}{ Test Location } & Fill & $\# 29$ & 31 & 39 & $\# 29$ & 31 & 39 \\
Surface of Cushion & Foam & N & N & N & N & N & N \\
Welt Edge of Cushion & Foam & N & I & I & I & I & I \\
Crevice--Side & Foam & I & I & I & I & I & I \\
Crevice--Back & Foam & I & I & I & I & I & I \\
Arm & Foam & N & N & N & N & N & N \\
Top of Back & Foam & N & N & N & N & N & N \\
Decking & Cotton & I & I & I & I & I & I
\end{tabular}


Chair Tests

\section{Class C Fabric (\#3) on Construction \#5}

\begin{tabular}{|c|c|c|c|c|c|c|c|c|}
\hline \multirow[b]{3}{*}{ Test Location } & \multirow{3}{*}{\multicolumn{2}{|c|}{ Fill }} & \multicolumn{3}{|c|}{ Mock-Up } & \multicolumn{3}{|c|}{ Chair } \\
\hline & & & \multicolumn{6}{|c|}{ Lab } \\
\hline & & & \#29 & 31 & 39 & $\# 29$ & 31 & 39 \\
\hline Surface of Cushion & Foam & & $\mathrm{N}$ & $\mathrm{N}$ & N & N & $\mathrm{N}$ & $\mathrm{N}$ \\
\hline Welt Edge of Cushion & Foam & & N & $\mathrm{N}$ & $\mathrm{N}$ & $\mathrm{N}$ & $\mathrm{N}$ & N \\
\hline Crevice--Side & $1 / 2^{\prime \prime}$ & Foam/Cotton & I & I & I & I & I & I \\
\hline Crevice--Back & Foam & & I & I & I & I & I & I \\
\hline Arm & Foam & & $\mathrm{N}$ & $\mathrm{N}$ & $\mathrm{N}$ & $\mathrm{N}$ & I & $\mathrm{N}$ \\
\hline Top of Back & Foam & & $\mathrm{N}$ & $\mathrm{N}$ & $\mathrm{N}$ & $\mathrm{N}$ & I & $\mathrm{N}$ \\
\hline
\end{tabular}

The above test results for Class $C$ fabric \#3 shows excellent agreement between laboratories except for three test locations where one of the laboratories reported results differing from the other two.

These test locations were:

(a) Welt edge of a foam seat cushion in mock-up test. -- One laboratory reported no ignition.

(b) Foam filled "chair" arm. -- One laboratory reported ignition. 
(c) Foam filled top of back "chair test". -- One laboratory reported ignition.

For item (a), the welt edge ignition is the result of a single cigarette ignition attempt by one laboratory.

No explanation can be given for one laboratory reporting ignition in items (b) and (c) when that same laboratory reported nonignition results for tests on the same fabric on foam urethane in mock-up tests.

Chair Tests

\section{Class C Fabric (\#4) on Construction \#6}

\begin{tabular}{l|c|ccc|ccc} 
& \multicolumn{3}{|c}{ Mock-Up } & \multicolumn{3}{c}{ Chair } \\
\multicolumn{1}{|c|}{ Test Location } & Fill & $\# 29$ & 31 & 39 & $\# 29$ & 31 & 39 \\
Surface of Cushion & Foam & $\mathrm{N}$ & $\mathrm{N}$ & $\mathrm{N}$ & $\mathrm{N}$ & $\mathrm{N}$ & $\mathrm{N}$ \\
Welt Edge of Cushion & Foam & $\mathrm{I}$ & $\mathrm{I}$ & $\mathrm{I}$ & $\mathrm{I}$ & $\mathrm{I}$ & $\mathrm{I}$ \\
Crevice--Side & Foam & $\mathrm{I}$ & $\mathrm{I}$ & $\mathrm{I}$ & $\mathrm{I}$ & $\mathrm{I}$ & $\mathrm{I}$ \\
Crevice--Back & Foam & $\mathrm{I}$ & $\mathrm{I}$ & $\mathrm{I}$ & $\mathrm{I}$ & $\mathrm{I}$ & $\mathrm{I}$ \\
Arm & Foam & $\mathrm{N}$ & $\mathrm{N}$ & $\mathrm{N}$ & $\mathrm{N}$ & $\mathrm{N}$ & $\mathrm{N}$ \\
Top of Back & Foam & $\mathrm{N}$ & $\mathrm{N}$ & $\mathrm{N}$ & $\mathrm{N}$ & $\mathrm{N}$ & $\mathrm{N}$
\end{tabular}


Class C fabric \#4 produced excellent test results with each laboratory reporting identical results for tests on the mock-up and fullsize upholstered chairs.

\section{Summary}

Based on results obtained in the interlaboratory evaluation study, the following judgments are made:

\section{Summary--Fabric Classification Test Method}

1. An analysis of test results from 37 laboratories suggests that for the Fabric Classification Test Method sample upholstery fabrics should be tested in the warp/warp fabric direction.

2. The recommendation for warp/warp fabric direction (for test) would agree with the industry practice of manufacturing furniture with the upholstery cover fabric running in the warp "up the chair" direction.

3. The analysis also indicates that the test should be conducted with no air gap or spacing between the vertical test panel and the horizontal platform support. This would mean that each laboratory would trim 
the glass fiber board material for the horizontal test panel to the same dimension as the platform support.

4. Although results indicated that the air gap was more severe, the absence of the air gap would remove any chance of bias in conducting the test.

5. Class $A$ and Class $B$ upholstery fabrics do not smolder and thus exhibited excellent, repeatable and reproducible results for the within laboratory and between laboratory comparison study.

6. Synthetic fiber type fabrics (nylon, olefin, etc.), vinyl plastic, and wool and wool blends, with few exceptions, will generally be rated as Class $A$ and Class $B$ materials.

7. Cellulosic fiber type upholstery fabrics--cotton, rayon, and cotton/rayon blends--will generally be found to produce Class $C$ and Class D classifications.

Summary--Upholstered Funniture Mock-Up Test Method

1. A total of 38 participating laboratories gained valuable experience in using the mock-up furniture test method to make determinations 
on how an upholstery fabric "Class" will perform on different fumiture constructions.

2. Class A upholstery fabrics were found (by all laboratories) to "work" favorably on mock-up fumiture constructions consisting of foam urethane or fiberfill/foam seat cushions in combination with vertical test panels filled with cotton batt or foam urethane.

3. Class B upholstery fabrics were shown (by all laboratories) to be acceptable as cover materials on foam urethane and fiberfill/foam urethane seat cushions used with foam urethane filled mock-up panels.

4. A $1.3 \mathrm{~cm}(1 / 2 \mathrm{in})$ thick layer of foam urethane used directly under Class B fabrics and over cotton batt helped to reduce the number of ignitions in cotton batt filling material; however, these results established the fact that the foam layer was "not quite thick enough" to offer 100 percent protection to cotton underlays when Class B fabrics were used as the cover materials.

5. Ninety-seven percent of the laboratories reported that Class $C$ fabrics work (pass test) on urethane seat cushion surfaces, but a large number of laboratories observed ignitions in the welt edges of the seat cushions. In crevice tests with this cushion in combination with foam 
urethane and 1/2 inch foam urethane/cotton mock-up panels, all laboratories but one reported ignitions in every test.

6. Class D fabric (test sample \#5) produced ignitions on all test locations of foam urethane seat cushions and like the Class C fabrics, ignited foam urethane and $1 / 2$ inch foam urethane/cotton test panels.

7. All fabric classes in combination with cotton batt seat cushion construction and adjacent side panels permitted ignition.

8. Class A fabrics were reported by all but one on two laboratories to resist ignitions on cotton batt seat cushion surfaces and crevices; surprisingly, 30-50 percent of the laboratories obtained ignitions on the curved edge of the tight seat cushion (edges are called welts in the tables).

Summary--Arm and Top of Back Test Method

1. Excellent, repeatable and reproducible test results were obtained for tests on mock-up arm and top of back test panels.

2. As expected, the number of ignitions observed in the test panels was found directly related to the fabric class used as the cover material. 
Class A fabrics were shown to be superior to the Class B, C, and D fabrics which respectively showed increasing numbers of ignitions in the filling materials.

3. The filling materials, if ranked on the basis of test performance, would be listed as follows:

\section{\# Labs Reporting Ignitions}

$\begin{array}{lccccc} & \text { Class A } & \text { Class B } & \text { Class C } & \text { Class D } \\ \text { \#1 Fiberfill/Cotton Batt } & 0 & 0 & 0 & 15 \\ \text { \#2 Foam Urethane } & 0 & 0 & 1 & 33 \\ \text { \#3 1/2 Inch Foam Urethane/Cotton } & 0 & 2 & 2-4 & 33 \\ \text { \#4 Cotton Batt } & 3 & 8 & 38 & 38\end{array}$

Summary--Decking Test Method

1. Excellent results were obtained for tests of decking systems.

2. All laboratories (but one) reported ignitions in the cotton filled decking system covered by cotton sateen fabric material. 
3. All laboratories reported passing (nonignition) results for a bonded cellulose system covered by the same fabric material.

\section{Summary--Full-Size Upholstered Chair Test Method}

A comparison of full-size chair test results with upholstered furniture mock-up tests on the same constructions showed excellent reproducible results.

1. Testing of factory made seat cushions in mock-up or on a chair presents no problems; similar test results were obtained on both sets of cushions.

2. If anything, the mock-up arm test is more reproducible than the chair arm test because in the mock-up test a better fabric-to-substrate contact is achieved.

3. The test laboratories were not proficient in making tight cotton seat cushions for test. More reproducible results were obtained in tests on the factory made seat cushions. 


\section{Conclusions and Recommendations}

Based on the results of the interlaboratory evaluation study to determine the feasibility of the proposed Fabric Classification and Upholstered Furniture Mock-Up Test Methods in the proposed flammability standard (smolder resistance) of upholstered furniture, the following conclusions and recommendations are drawn:

\section{Fabric Classification Test Method}

1. Reproducible results between laboratories can be expected in the Fabric Classification Test Method if the sample fabric is tested in the warp/warp fiber "up the chair" direction.

2. The horizontal glass fiber board panel in the test must be cut to the same width as the horizontal platform support for the horizontal test panel. This should eliminate any air gaps and prevent any bias which may creep into the testing procedure.

3. Synthetic fabric type materials are not subject to fiber orientation or ain gap in the Fabric Classification Test Method.

4. Cellulosic fabrics are affected by both fiber orientation and air gap, some more so than others. Lightweight, open weave fabrics were found to be most susceptible. 
5. A knowledge of fiber type in a sample fabric should prove most helpful to manufacturers in helping them to classify their present or future fabric inventories.

6. As a general rule--

Class A fabrics would include wool, wool blends, vinyl plastics, and heavyweight synthetics.

Class B fabrics would include mid-weight synthetics and possibly some lightweight cottons, rayons, and cotton/rayon blends.

Class $C$ fabrics would encompass mid-weight cottons, rayons, and cotton/rayon blends.

Class $D$ fabrics would include heavyweight cellulosics; i.e., cottons, rayons, and blends of these materials.

7. Topical treatments or backcoating of upholstery fabrics may be investigated as a means for upgrading Class $C$ and Class $D$ fabrics to Class A or Class B performance. 
44

Upholstered Fumiture Mock-Up Test Method

1. The laboratory participants had little difficulty in identifying the safe (nonignition) and problem areas (ignition prone) in the mock-up assemblies.

2. The study showed that most present day (manufactured) fumiture can be easily ignited by burning cigarettes.

3. Upholstery cover fabrics were shown to play an extremely important role in determining whether a fumiture construction will resist or allow ignitions to occur in a finished fumiture item. Constructions which may work, "pass the test", with one fabric cover may not necessarily pass the test when covered by a different class of fabric material.

4. Generally, Class A upholstery fabrics were found compatible with most furniture constructions; however, the study did show up one problem area, "the curved edge (welt) of tight cotton seat cushions". All fabric classes permitted or contributed to ignitions of this assembly.

5. The ignition performance of Class B upholstery fabrics demonstrated a need for barrier layers between cotton batt and the cover fabric. 
6. Class $C$ and Class $D$ fabrics, because they often smolder when exposed to burning cigarettes, may require heat dissipating mediums directly under the fabric in order to resist ignition.

7. Although the mock-up furniture test produced qualitative test results which are not conducive to easy statistical analysis (statisticians prefer continuous quantitative measurement), the following statement can be made based on the go-no go test results obtained in the testing program:

The furniture mock-up test is real, repeatable, and viable and is capable of determining whether a furniture construction used in combination with a particular cover fabric will pass or fail a burning cigarette test.

\section{Full-Size Upholstered Chair Test Method}

1. The proposed test standard allows for the testing of full-size furniture items in lieu of testing mock-up furniture constructions. Given a choice, it is believed that the mock-up test would be a more severe and reproducible test. This would be especially true where the "fabric to filling" contact is most critical. Non or difficult to ignite materials would not be affected by this, but where easily ignitable or combustible materials are used directly under the cover fabric, there could be a difference in test results. Agreement between mock-up and 
finished furniture piece test results was found excellent between the testing laboratories. Where differences between laboratories were noted, these differences were found directly related to the "fabric to filling" contact described above.

\section{General}

The results and analysis of the interlaboratory evaluation study indicate that the test methods in the recommended Proposed Standard for the Flammability (smolder resistance) of Upholstered Furniture are repeatable and reproducible. It is recommended that the Proposed Standard for the Flammability of Upholstered Furniture be published in the Federal Register for comment. 


\section{List of Tables}

Table 1 - Listing of upholstery sample fabrics

Table 2 - Listing of mock-up materials

Table 3 - Listing of upholstered chair materials

Table 4 - Fabric classification test results

Table 5 - Construction \#1, mock-up test results

Table 6 - Construction \#2 and \#3, mock-up test results

Table 7 - Construction \#4, mock-up test results

Table 8 - Construction \#5, mock-up test results

Table 9 - Construction \#6, mock-up test results

Table 10 - Construction \#7, arm and top of back mock-up test results

Table 11 - Construction \#8, arm and top of back mock-up test results

Table 12 - Construction \#9, arm and top of back mock-up test results

Table 13 - Construction \#10, arm and top of back mock-up test results

Table 14 - Construction \#11, decking test results 


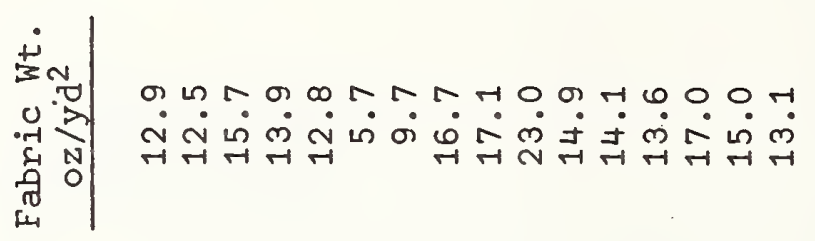

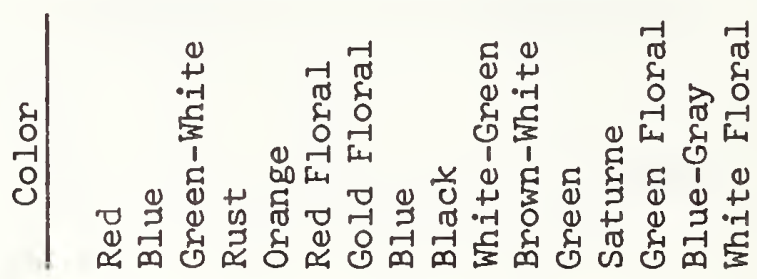

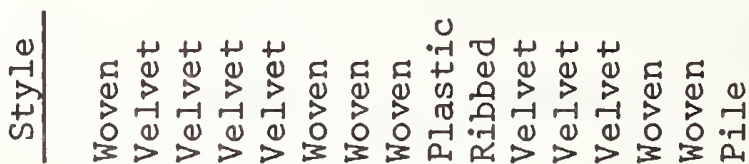

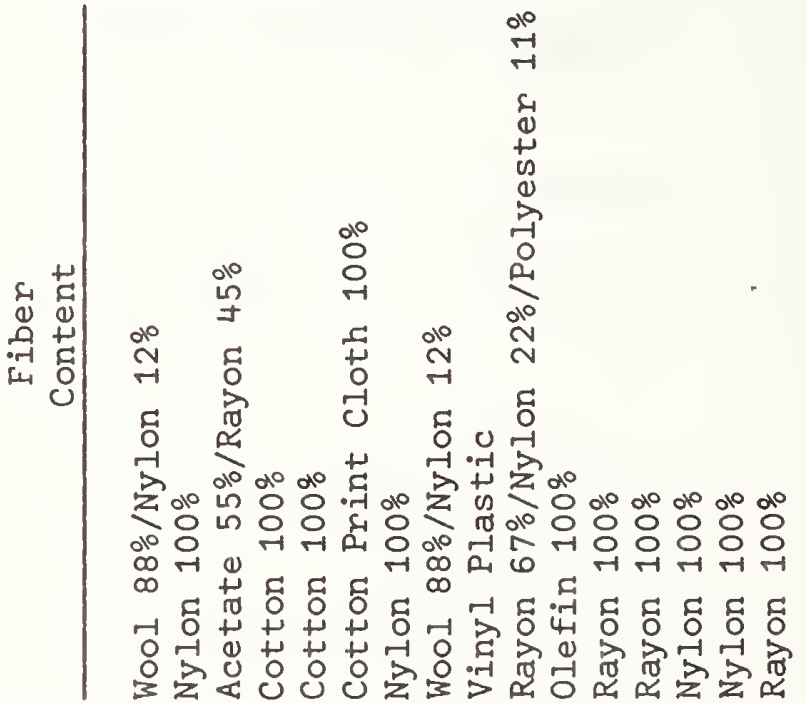

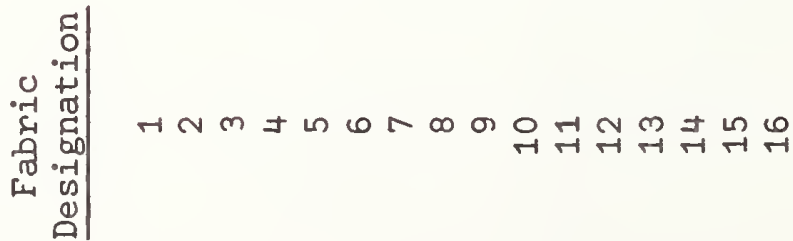



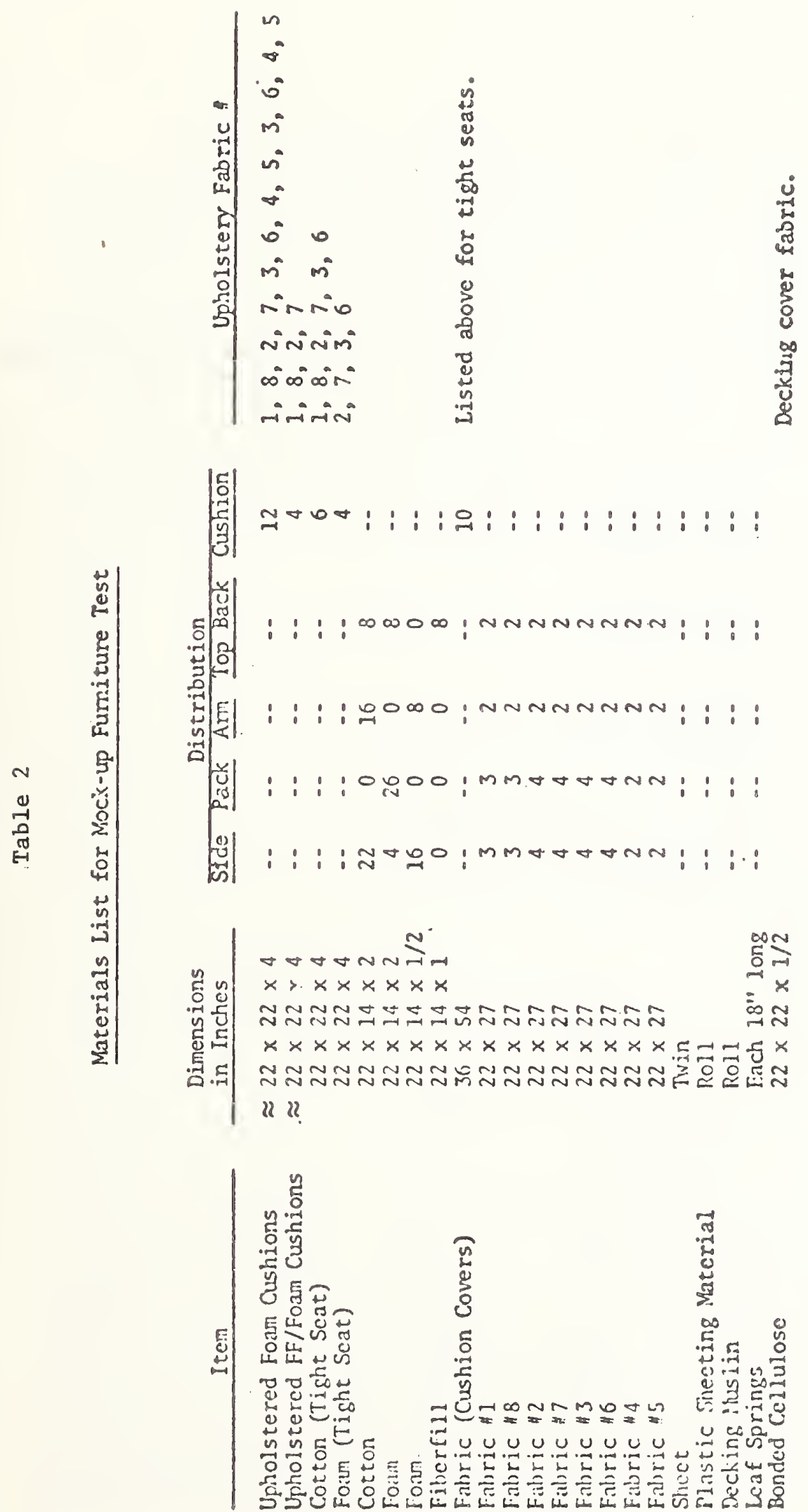

D. 
Table 3

\section{Materials List for Full-Size Upholstered Chair Test}

Tight Seat--Tight Back Chair Style

Fabric \#1--Wool $88 \% /$ Nylon $12 \%$

4" Foam Urethane Seat

1/2" Urethane/2" Cotton Sides

2" Foam Urethane Back

Fabric \#2--Nylon $100 \%$

4" Cotton Batting Seat

1/2" Foam Urethane/2" Cotton Sides

2" Foam Urethane Back

Fabric \#3--Acetate $55 \% /$ Rayon $45 \%$

4" Foam Urethane Seat

1/2" Foam Urethane/2" Cotton Sides

2" Eoam Urethane Back

Loose Seat--Loose Back Chair Style::

Fabric \#2--Nylon $100 \%$

4" Fiberfill/Urethane Foam Seat

2 " Cotton Sides

4" Foam Urethane Back

Fabric \#3--Acetate 55\%/Rayon $45 \%$

4" Foam Urethane Seat

2" Foam Urethane Sides

4" Foam Urethane Back

Fabric \#4--Cotton 100\% (Pile)

4" Foam Urethane Seat

2" Foam Urethane Sides

4" Foam Urethane Back 
TABLE 4

RESULTS OF FABPIC CLASSIFICATION TESTS IN

PFF-6.74- UPHOLSTERED FIUNITURE FLAMMABILITY

\begin{tabular}{|c|c|c|c|c|c|c|c|c|c|c|c|c|c|c|c|c|}
\hline $\begin{array}{l}1 \mathrm{AB} \\
\text { NO. }\end{array}$ & 1 & 2 & 3 & 4 & 5 & 6 & 7 & 2 & 9 & 10 & 11 & 12 & 13 & 14 & 15 & \\
\hline 1 & A & $B$ & C & $c$ & $D$ & B & B & $A$ & A & $B$ & $B$ & $c$ & C & $B$ & $B$ & $D$ \\
\hline 2 & A & $B$ & C & C & $D$ & $\mathrm{~B}$ & B & A & A & $B$ & C & C & C & $B$ & $\underline{B}$ & C \\
\hline 3 & A & B & C & C & $D$ & C & B & B & A & B & c & c & c & B & $B$ & c \\
\hline 4 & $A$ & $B$ & C & c & $D$ & B & B & A & A & $B$ & $B$ & $c$ & C & A & $B$ & C \\
\hline 5 & A & $B$ & D & $c$ & $D$ & $C$ & $B$ & $A$ & A & $B$ & $B$ & C & C & $B$ & $B$ & C \\
\hline 6 & A & B & $c$ & C & D & c & $B$ & A & A & 8 & $B$ & $c$ & C & 8 & 8 & $c$ \\
\hline 7 & A & $B$ & c & C & I & $B$ & 8 & A & A & $B$ & B & $B$ & c & $B$ & $B$ & $D$ \\
\hline 8 & A & B & c & C & $D$ & B & B & A & A & B & $B$ & C & C & B & B & c \\
\hline iq & A & B & C & $D$ & $D$ & B & $B$ & A & A & B & $B$ & C & C & $B$ & $B$ & $c$ \\
\hline 10 & A & $B$ & C & C & D & $C$ & B & A & A & $B$ & $B$ & $c$ & $C$ & $B$ & $B$ & c \\
\hline 11 & A & $B$ & C & C & $D$ & 8 & $B$ & A & A & $A$ & $B$ & C & C & 3 & $B$ & $B$ \\
\hline 12 & $B$ & $B$ & C & C & D & B & $B$ & 8 & A & $B$ & $B$ & C & $c$ & $B$ & B & $c$ \\
\hline 13 & $A$ & & C & $C$ & $D$ & C & & A & $A$ & & & & & & & \\
\hline 14 & A & $C$ & $D$ & C & $D$ & C & $B$ & A & A & $C$ & $B$ & $D$ & $D$ & $B$ & $B$ & $D$ \\
\hline 15 & A & $B$ & $C$ & C & $D$ & C & $B$ & $B$ & $A$ & $B$ & $B$ & $C$ & C & $B$ & $B$ & c \\
\hline 16 & A & $B$ & $B$ & $C$ & $D$ & $B$ & B & A & A & $B$ & $B$ & $B$ & $C$ & B & $B$ & C \\
\hline 17 & & & & & & & & & & & & & & & & \\
\hline 18 & $A$ & $D$ & $D$ & $C$ & $D$ & $D$ & B & A & $A$ & $A_{1}$ & C & $B$ & $c$ & B & $B$ & A \\
\hline 19 & A & $B$ & $D$ & $C$ & $D$ & $B$ & $B$ & A & A & $B$ & $B$ & $c$ & $c$ & 8 & B & $c$ \\
\hline 20 & A & $B$ & D & $D$ & $D$ & $B$ & $B$ & A & $A$ & $B$ & $B$ & $D$ & C & 8 & $B$ & $C$ \\
\hline 21 & A & $B$ & $D$ & 0 & $D$ & $B$ & $B$ & E & A & $B$ & $B$ & $D$ & $C$ & $B$ & $B$ & IC \\
\hline 22 & & & & & & & & & & & & & & & & \\
\hline 23 & A & $B$ & $C$ & C & $D$ & $C$ & $B$ & $A$ & A & $B$ & C & C & $C$ & $B$ & $B$ & C \\
\hline 24 & $A$ & B. & $C$ & $D$ & $D$ & $C$ & $B$ & A & $A$ & $B$ & $B$ & $C$ & C & $B$ & $B$ & C \\
\hline 25 & A & $B$ & C & C & $D$ & C & 3 & A & A & $B$ & 8 & $C$ & C & $B$ & $B$ & $C$ \\
\hline 26 & $A$ & $B$ & C & $C$ & $D$ & $B$ & $B$ & A & $A$ & $\mathcal{B}$ & $B$ & $B$ & C & $B$ & $B$ & B \\
\hline 27 & A & $B$ & C & C & $D$ & C & 3 & A & A & $B$ & 3 & $C$ & $c$ & $B$ & $B$ & $D$ \\
\hline 28 & A & $B$ & $C$ & C & $D$ & C & B & $B$ & $A$ & A & $B$ & C & C & $B$ & $B$ & C \\
\hline 29 & A & $B$ & $D$ & $D$ & $D$ & $C$ & $B$ & A & A & $E$ & $B$ & $C$ & C & $B$ & $B$ & c \\
\hline 30 & A & $B$ & . C & $C$ & $D$ & $B$ & $B$ & A & A & $B$ & $B$ & $c$ & c & $B$ & $B$ & $C$ \\
\hline 31 & $\therefore$ & $B$ & $D$ & $c$ & $D$ & C & $B$ & $A$ & A & $E$ & C & $C$ & $C$ & $B$ & $B$ & C \\
\hline 32 & A & $B$ & $C$ & $\therefore$ & I & $C$ & $B$ & A & $A$ & $B$ & $B$ & $C$ & $C$ & $B$ & 8 & $C$ \\
\hline 33 & A & $B$ & $C$ & C & $D$ & C & $B$ & $A$ & A & $B$ & $B$ & $C$ & $C$ & $A$ & $B$ & $D$ \\
\hline 34 & A & $B$ & C & C & $D$ & C & $B$ & A & P & $B$ & $B$ & $c$ & c & $B$ & $B$ & $C$ \\
\hline 35 & $A$ & $B$ & $C$ & $C$ & $D$ & C & $B$ & 8 & $A$ & $B$ & B. & C & $C$ & $B$ & $B$ & $C$ \\
\hline 36 & A & $B$ & $C$ & $C$ & $D$ & $C$ & $B$ & $A$ & $A$ & $B$ & $B$ & $C$ & $C$ & $B$ & $B$ & \\
\hline 37 & $A$ & $B$ & $C$ & $C$ & $D$ & $c$ & $B$ & $A$ & $A$ & $\beta$ & $B$ & C & $C$ & $B$ & $\beta$ & \\
\hline 38 & A & $B$ & $C$ & C & $D$ & C & $B$ & $A$ & $A$ & $B$ & $B$ & D & $D$ & $B$ & $B$ & \\
\hline 39 & A & $B$ & $D$ & $C$ & $D$ & C & $B$ & $A$ & A & $B$ & $B$ & $C$ & C. & $B$ & $B$ & \\
\hline 40 & $A$ & $B$ & $C$ & $C$ & 0 & 63 & $B$ & $A$ & $A$ & $\bar{B}$ & $B$ & $C$ & $C$ & 13 & $B$ & \\
\hline
\end{tabular}


TABLE 5

MOCK-LLP TEST RESULTS IN

PFF-6-74 - UFHOLSTERED FURNITURE

$\frac{\text { CONSTRUCTION \#I }}{\text { BACK-FOAM }} \frac{\text { FLAMMABILITY }}{\text { ROUND ROBIN }}$

SIDE. $1 / 2$ "FOAM/COTION

CUSHION-FOAM

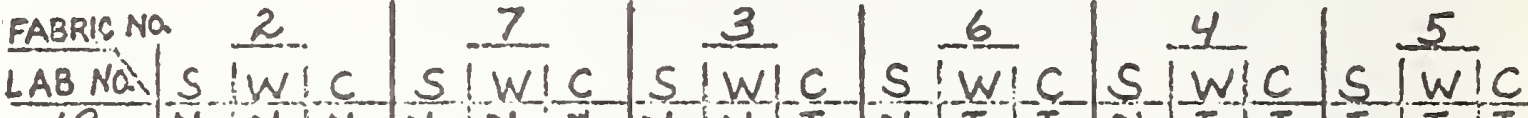
$-19-N N N N N N N$ N N N N N N N I I I I I No N N N N N NIII NIII NIII N I I I $23 N N N N N N$

2.5 $26-N$ N N N IN N N I I $27-N N N N N$ N N I I -28 N $N$ N N N N N N N I I $29-N N N-N-N-N-\frac{N}{N}-1$ $-30-N \quad N \quad N \quad N \quad N \quad N \quad N \quad N$ $N$ N N N N N N NII $33-N N N N N$ N N N I $34 N N N N N I N N I I I$ $35 N A N N N N N I I T$ $36 N N N N N N N N$

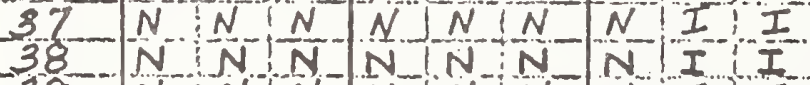
$39-N \quad N \quad N \quad N \quad N-N \quad I . I$ BO N N N N NIISNIII

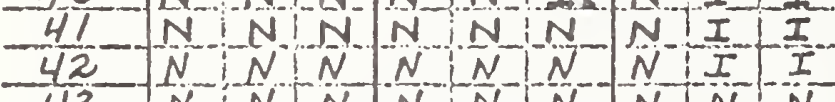

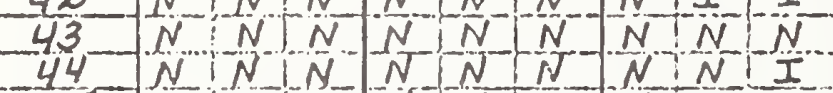
$45 N N N N N N N$ N N I I $46-N N N \quad N N N$ N N N -48 N N N N NIN NILI $-49 N N$ N N NIISNIII $51 N N N$ N NIN NIII $52 N L N N$ N N N NIIII $53 \quad N \quad N \quad N \quad N|N| N \mid N I I I$ $-55 \quad N$ N N N NINIIII $56 \quad N \quad N|N \quad N| N \quad N \quad N$ 58 NiNin

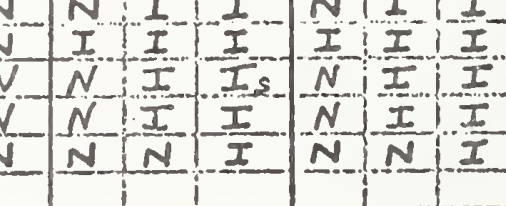
III NIII IIII. $N=N$ N I I N NII

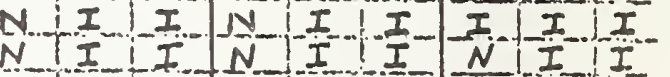
NII N I I I I I I $N I I N N I N N=$

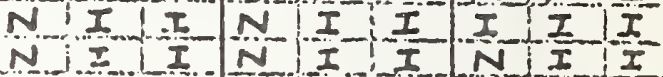
NIIINIII $N I I I$ NIIIN NII NIII

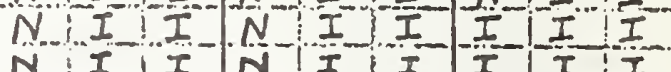

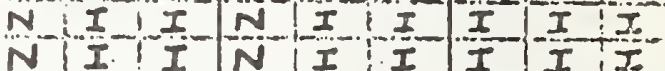
$N$ I N IIIIII $N-I I I N-I-I-I I I$ $N(I)$ I I I N I I NIII NII I III NII $N$ I I N N I I N I I I $N$ N I I I I I I I $N \mid N I N I_{I} I_{I}$ I I I I N I I I I I I N N N I I N N I N N N I $N-1 I^{N}$ NIIIINIIII IIIII NIIINIIINIII NII I I I I I I I $N \frac{I}{N} I \frac{N}{N} I_{I} I I I I I$ $N$ N N N I I I IIII I 1 I I I I 
TABLE 6

MOCK-LLP TEST RESULTS IN

\section{CONSTRUCTION 2 \\ BACK-FOAM \\ SIDE-COTTON \\ CLSHION-FOAM}

PFF-6-74 - LIPHOLSTERED FURNITURE

FLAMMABILITY

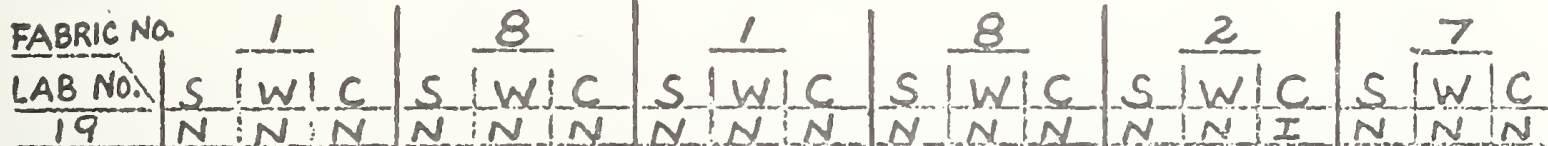

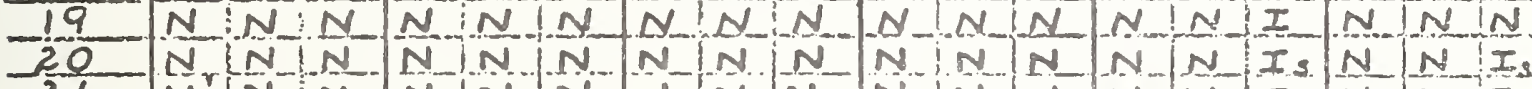

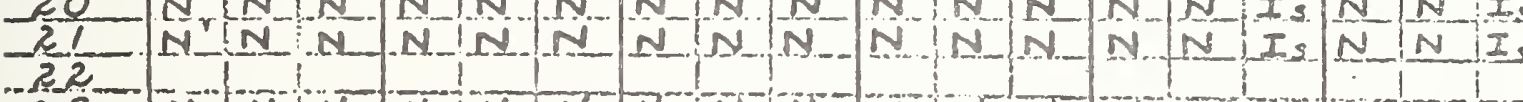

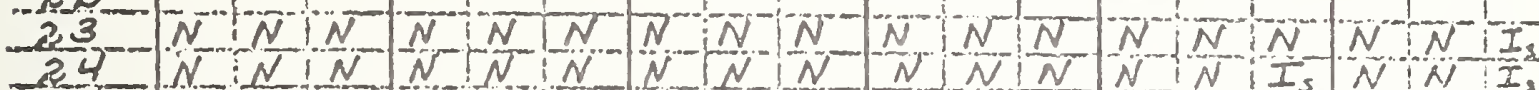

S N N N N N N N N N N N NIN N N I N N N I

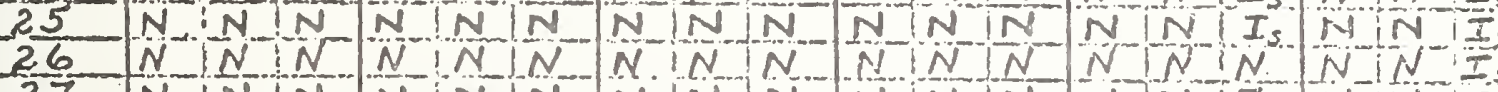

$27 N I N I N N N N$ N N N N N N N N

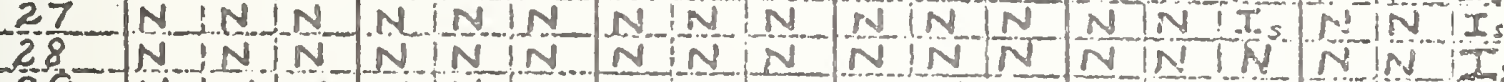

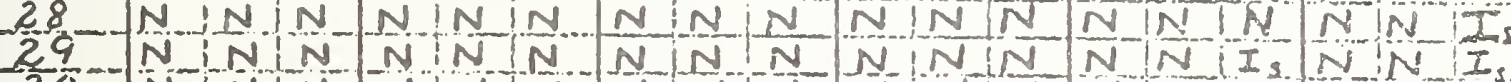

30 N NIN NINTN NININ N NIN N N I N N

31 NININ NIN N NIN N

$34 N N N$ N N NJN NIN N N N N N N IS NINI

$35-N I N I N N I N \mid N N I N / N$ NININ NTNLN N N N

$37 N$ N N NIN N N N N I I NIN Is

38N N N NIN N N N N N N N N N I N NIN IE

N N NIN NININ NIN IN

$42 N$ I N N N N N N N N N N N N IS N N I

$4 N^{N} N N N N N N N N$ N N N N N N N N

$4 S N N N N$ N N N N N N N N N N N N N N N N

$46 N N N N N N N N N N N N N=$

$17-N-N N N N N N$ N N N NININ NININ NIN N

$49 N N N N N N N N N N N$ $N$ N N

$N I N N N I N I_{S} N D_{3}$ 
TABLE 7

MOCK-LIP TEST RESULTS IN PFF-6.74- UPHOLSTERED FURNITURE

CONSTRUCTION 44 FLAMMABILITY

BACK - FOAM

SIDE- $1 / 2^{\prime \prime}$ FOAM/COTON

CUSHION-TIGHT COTON

\begin{tabular}{|c|c|c|c|c|c|c|c|c|c|c|c|c|c|c|c|c|c|c|}
\hline ABBRIC NO & & 1 & & & 8 & & & 2 & & & 7 & & & 3 & & & 6 & \\
\hline HO. & $S$ & & C. & $S$ & $W$ & $C$ & $S$ & & C. & $S$ & $w$ & C. & S & $w$ & c. & $S$ & $W$ & \\
\hline & $N$ & & & N. & & $N$ & & & & & & $I$ & & & $I$ & & & \\
\hline & $N$ & I & $N$ & $N$ & $N$ & $N$ & $N$ & & $I$ & I. & I & $I$ & $N$ & $I$ & $I$ & $N$ & $I$ & \\
\hline & $N$ & $I$ & $N$ & $N$ & $N$ & $N$ & $N$ & $I$ & $I$ & $N$ & $I$ & $I$ & $N$ & $I$ & $I$ & $N$ & $I$ & \\
\hline$\frac{22}{23}$ & & $T$ & N & & & & & & & & & & & & & & & \\
\hline 24 & $N$ & $\frac{1}{N}$ & $N$ & $-\frac{N}{N}$ & $\frac{I}{N}$ & 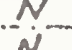 & $N$ & & $\frac{I}{-1}$ & $N$ & $=$ & 1 & $I$ & $I$ & $I$ & $N$ & & \\
\hline 25 & $N$ & $I$ & $N$ & $\frac{N}{N}$ & $\frac{N}{I}$ & N & $N$ & & $\frac{1}{2}$ & N & $\frac{7}{T}$ & $T_{T}^{-1}$ & Th & $\frac{I}{T}$ & $I$ & 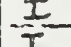 & $=$ & \\
\hline 6 & $N$ & $N$ & $N$ & $N$ & $N$ & $N$ & $N$ & $N$ & I & $N$ & I & I & 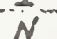 & T. & 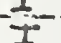 & $\frac{1}{N}$ & $\frac{1}{T}$ & \\
\hline 7 & $N$ & $I$ & $N$ & $N$ & I & $N$ & $N$ & & $I$ & $N$ & $I$ & $I$ & $I$ & $I$ & I & $N$ & $x$ & \\
\hline 8 & $N$ & IN & $N$ & $N$ & $N$ & $N$ & $N$ & & $I$ & $N$ & $N$ & $x$ & N & $N$ & I & $N$ & $I$ & \\
\hline & $N$ & $N$ & $N$ & $N$ & $N$ & $N$ & $N$ & $N$ & $I$ & $N$ & $N$ & $I$ & $I$ & $I$ & $I$ & $I$ & $I$ & \\
\hline 30 & $N$ & & $N$ & $N$ & & $N$ & $N$ & & $I$ & $N$ & & $I$ & $I$ & & $I$ & $N$ & & $I$ \\
\hline 31 & $N$ & I & $N$ & $N$ & $I$ & $N$ & $I$ & - & $I$ & I. & $I$ & $I$ & & $I$ & $I$ & $I$ & $I$ & \\
\hline & $N$ & $I$ & $N$ & $N$ & $I$ & $N$ & $N$ & $I$ & $I$ & $N$ & $I$ & $I$ & $I$ & $I$ & $I$ & 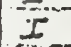 & $I$ & \\
\hline & $N$ & $I$ & $N$ & $N$ & $I$ & $N$ & $I$ & $N$ & $I$ & $N$ & $I$ & $I$ & $I$ & $I$ & $I$ & $I$ & $I$ & \\
\hline 34 & $N$ & $N$ & $N$ & $N$ & $N$ & $N$ & $N$ & I & $I$ & $N$ & $I$ & $I$ & $N$ & $I$ & $I$ & $N$ & $I$ & \\
\hline & $N$ & & $N$ & $N$ & & $N$ & $N$ & $N$ & Is & $N$ & & $I$ & $N$ & & $I$ & $N$ & & \\
\hline 36 & $N$ & $\mathrm{~N}$ & $N$ & $N$ & $N$ & $N$ & $N$ & $N$ & $I$ & $I$ & $I$ & $I$ & $I$ & $I$ & $I$ & $I$ & $I$ & \\
\hline 37 & $N$ & $I$ & $N$ & $N$ & $N$ & $N$ & $I$ & $I$ & $I$ & $N$ & $I$ & $I$ & $I$ & $I$ & $I$ & $I$ & $I$ & \\
\hline & $N$ & & $N$ & $N$ & & $N$ & $I$ & & $I$ & $I$ & & $I$ & $I$ & & $I$ & $I$ & & \\
\hline & $N$ & $I$ & $N$ & $N$ & $N$ & $N$ & $N$ & $I$ & $I$ & $N$ & $I$ & $I$ & $N$ & $I$ & $I$ & $N$ & $I$ & \\
\hline 40 & $N$ & $I$ & $N$ & $N$ & $I$ & Is & $I$ & $I$ & $I$ & $N$ & $N$ & $I$ & $I$ & $I$ & $I$ & $I$ & $I$ & \\
\hline 41 & $N$ & & $N$ & $N$ & & $N$ & $I$ & & $I$ & $N$ & & $I$ & I & & $I$ & $I$ & & \\
\hline 42 & $N$ & $I$ & $N$ & $N$ & $I$ & $N$ & & & & $N$ & $I$ & $I$ & & & & & & \\
\hline 43 & $N$ & $N$ & $N$ & $N$ & $N$ & $N$ & $N$ & $I$ & $I$ & $N$ & $N$ & $I$ & $I$ & $I$ & $I$ & $I$ & $I$ & \\
\hline 44 & $N$ & $N$ & $N$ & $N$ & $N$ & $N$ & $I$ & $I$ & $I$ & $I$ & $I$ & $I$ & $I$ & $I$ & $I$ & $I$ & $I$ & \\
\hline 45 & $N$ & $I$ & $N$ & $N$ & $I$ & $N$ & $N$ & $N$ & $N$ & $N$ & I & $I$ & $I$ & $I$ & $I$ & $I$ & $I$ & \\
\hline 46 & $\mathbf{N}$ & $N$ & $N$ & $N$ & $N$ & $N^{-}$ & $N$ & $I$ & $I$ & $N$ & $I$ & $I$ & $I$ & $I$ & $I$ & $N$ & $I$ & \\
\hline 47 & $I$ & $N$ & $I$ & $N$ & $N$ & $N$ & $I$ & $I$ & $I$ & $N$ & $I$ & $I$ & $I$ & $I$ & $I$ & $I$ & $I$ & \\
\hline 48 & $N$ & $I$ & $N$ & $N$ & $N$ & $N$ & $\bar{I}$ & $N$ & $I$ & $I$ & $I$ & $I$ & $I$ & $I$ & $I$ & $I$ & $I$ & \\
\hline 49 & $N$ & $N$ & $N$ & $N$ & $N$ & $N$ & $I$ & $I$ & $I$ & $N$ & $I$ & $I$ & $I$ & $I$ & $I$ & $N$ & $I$ & \\
\hline 50 & & & & & & & & & & & & & & & & & & \\
\hline 51 & $N$ & $N$ & $N$ & $N$ & $I$ & $N$ & $N$ & $I$ & $I$ & $N$ & $I$ & $I$ & $I$ & I & $I$ & $N$ & $I$ & \\
\hline 52 & $N$ & $N$ & $N$ & $N$ & $N$ & $N$ & $N$ & $N$ & $I$ & $N$ & $N$ & I & $\underline{N}$ & $N$ & $I$ & $N$ & $I$ & \\
\hline & $N$ & I & $N$ & $N$ & $I$ & $N$ & $N$ & I & $I$ & $N$ & $I$ & $I$ & $N$ & $I$ & $I$ & $N$ & $I$ & I \\
\hline & $N$ & & $N$ & $N$ & $N$ & $N$ & $I$ & $N$ & $I$ & $I$ & $I$ & $I$ & $I$ & $I$ & $I$ & $I$ & $I$ & \\
\hline & $N$ & $I$ & $N$ & $N$ & $N$ & $N$ & $I$ & $I$ & I & $I$ & $I$ & $I$ & I & $I$ & $I$ & $I$ & I & \\
\hline 56 & $I$ & $I$ & $N$ & $N$ & $I$ & $\underline{N}$ & $I$ & $I$ & $I$ & $I$ & $I$ & $I$ & $I$ & $I$ & $I$ & $I$ & $I$ & \\
\hline & $N$ & $\vec{N}$ & $N$ & $N$ & $N$ & $N$ & $\mathrm{~N}$ & $I$ & $I$ & $I$ & $I$ & $I$ & $I$ & $I$ & $I$ & $I$ & $I$ & I \\
\hline 58 & $N$ & $N$ & $N$ & $\mathrm{~N}$ & $N$ & $N$ & $N$ & $N$ & $N$ & $N$ & $N$ & $N$ & $N$ & $N$ & $I$ & $N$ & $I$ & $I$ \\
\hline & & & & & & & & & & & & & & & & & & \\
\hline
\end{tabular}


TABLE \&

MOCK-LIP TEST RESULTS IN

PEF-6-74- UPHOLSTERED FURNITURE

CONSTRUCTION 5

BACK. FOAM

FLAMMABILITY

S IOE- 1/2 FOAM/COTON

ROUND ROBIN

CUSHION-TIGAT FOAM

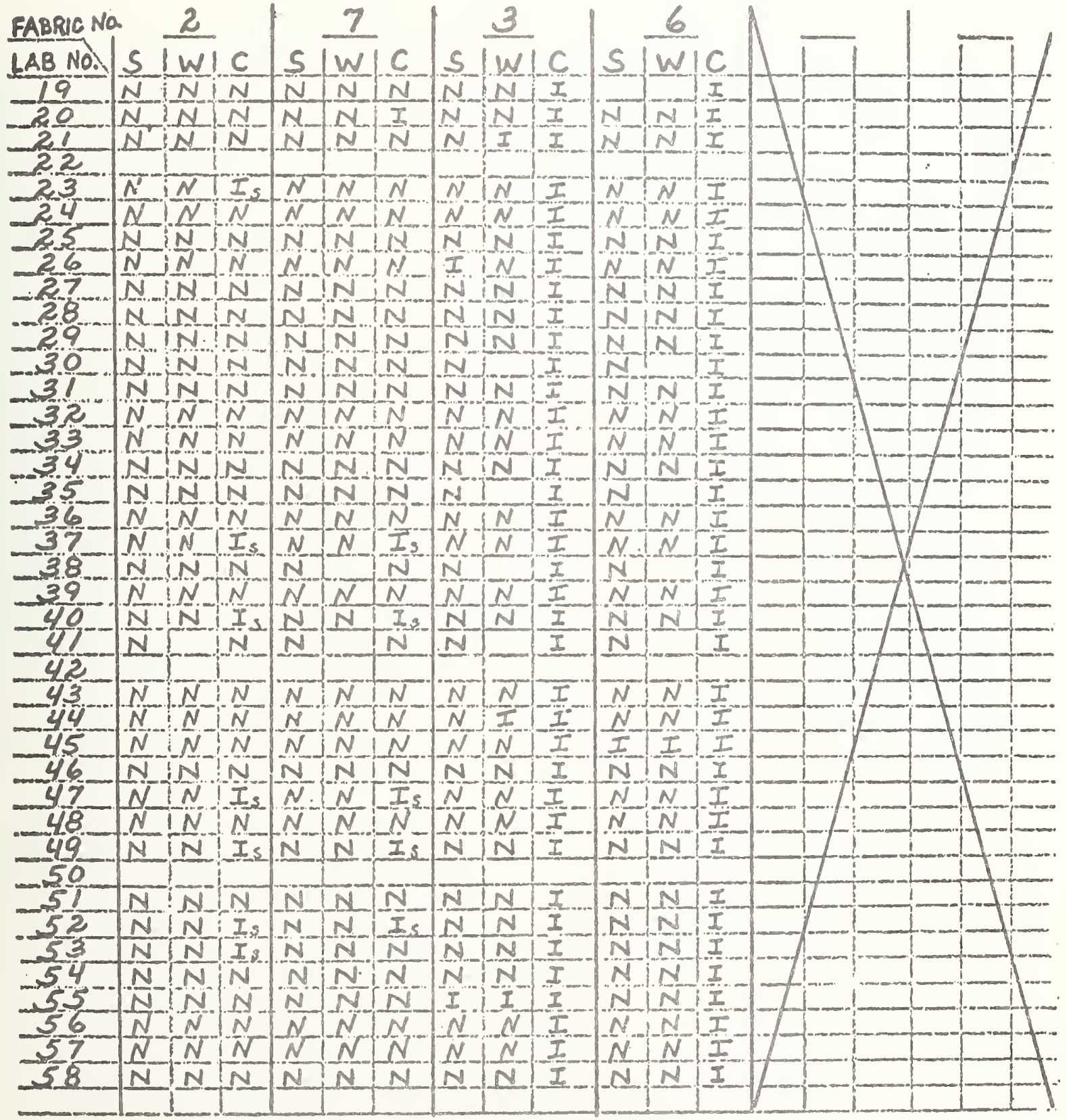


TABLE 9

MOCK-UP TEST RESULTS IN PFF-6-74- UPIIOLSTERED FLLRNITURE

CONSTRUCTION 6 BACK-FOAM FLAMMABILITY

SIDE. FOAM ROUND ROBIN

\section{CUSHION-FOAM}

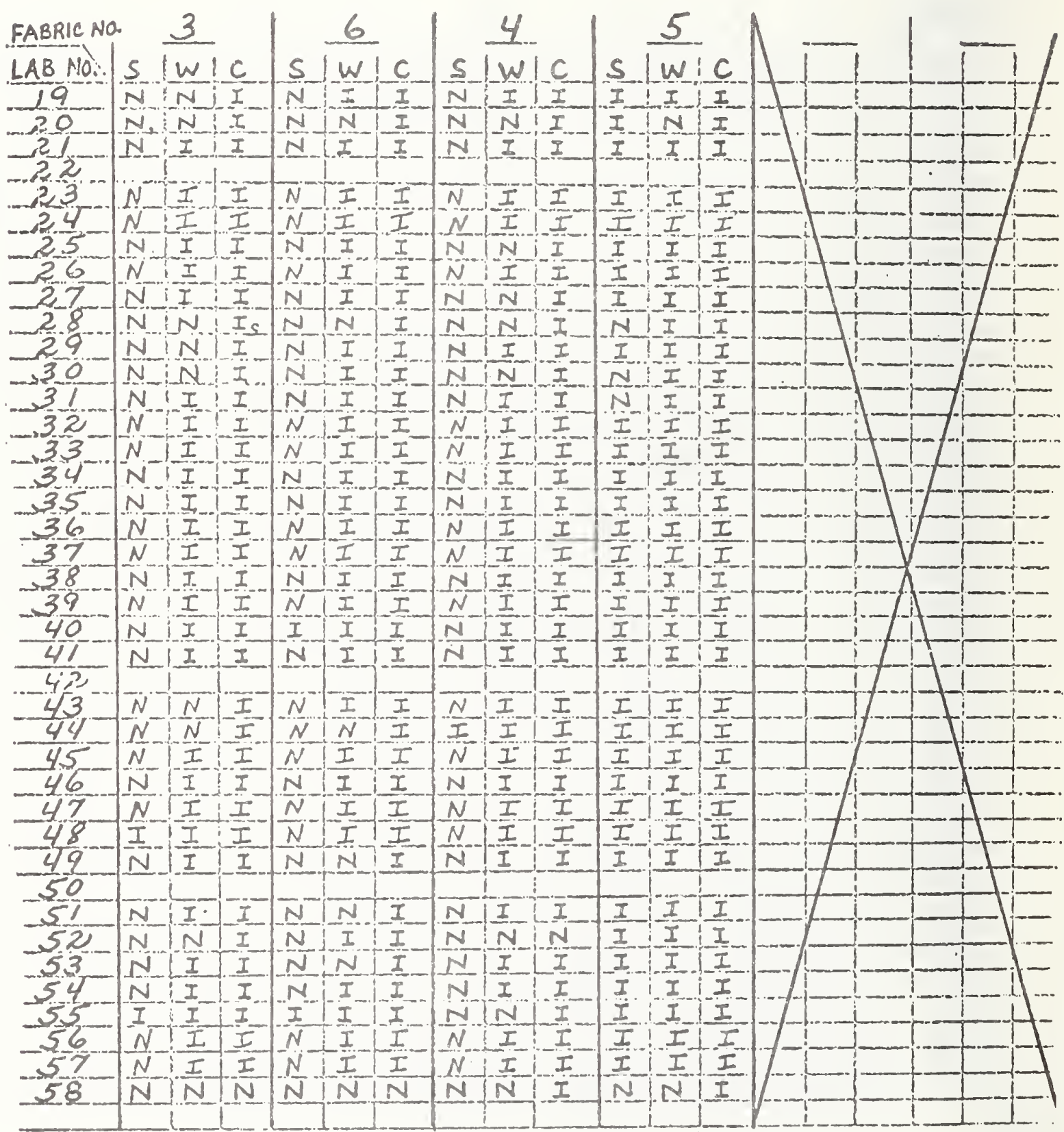


TABLE 10

$$
\begin{aligned}
& \frac{\text { ARM \& TOP OF BACK TEST RESULTS }}{\text { PEF-6-Z4-UPHOLSTERED FURNITURE }} \\
& \frac{\text { FLAMMABILITY }}{\text { ROUND ROBIN }} \\
& \text { CONSTRUCTION } 7
\end{aligned}
$$

\section{2" THICK COTTON}

FABRICNO.

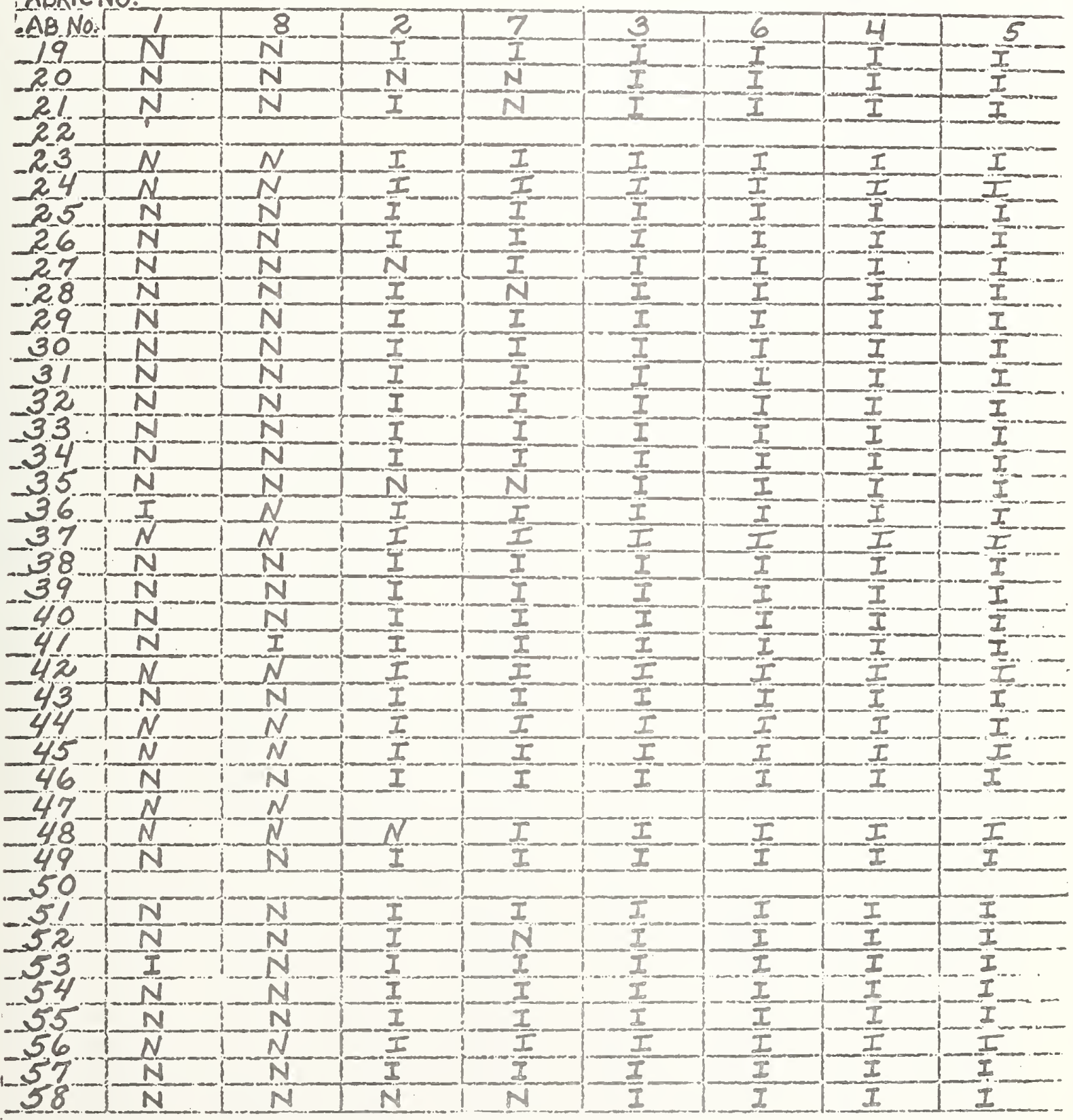


ABM TOP OF BACK TEST RESULTS IN PEF-6-74-UPHOLSTERED FURNITURE FLAMMABILITY ROUND ROBIN

CONSTRUCTION \#8

\section{$1 / 2^{\prime \prime}$ FOAM/COTTON}

FABRCNO.

\begin{tabular}{|c|c|c|c|c|c|c|c|c|}
\hline$\angle A B N$ & $\nabla i$ & 8 & 2 & 7 & 3 & 6 & 4 & $\frac{5}{1}$ \\
\hline$-\frac{19}{80}$ & $N$ & $\frac{N}{N}$ & $\frac{N}{N}$ & $-\frac{N}{N}$ & $\frac{N}{N}$ & $\frac{N}{N}$ & $\frac{N}{N}$ & $\frac{I}{N}$ \\
\hline & $\mathrm{N}$ & $N$ & $N$ & $N$ & $\mathrm{~N}$ & $\mathrm{~N}$ & $N$ & $I$ \\
\hline & & & & & & & & \\
\hline & $-\frac{4}{N}$ & $N$ & $N$ & N & $-N$ & $\frac{N}{N}$ & $N$ & \\
\hline & $N$ & $N$ & $\frac{N}{N}$ & $N$ & $N$ & $-N$ & $N$ & $\frac{T}{N}$ \\
\hline & $N$ & $N$ & $N$ & & $N$ & $N$ & $N$ & \\
\hline & $N$ & $N$ & $\mathrm{~N}$ & $N$ & $N$ & $N$ & $N$ & $I$ \\
\hline & $N$ & $N$ & $N$ & $N$ & $N$ & $N$ & $N$ & $I$ \\
\hline & $N$ & $N$ & $N$ & & $N$ & $N$ & $N$ & \\
\hline & $N$ & $N$ & $N$ & $N$ & $N$ & $-N$ & $N$ & $I$ \\
\hline 5 & $N$ & $N$ & $N$ & $N$ & $N$ & $N$ & $N$ & $I$ \\
\hline 32 & $N$ & $N$ & $\underline{V}$ & $\ldots$ & $N$ & $N$ & $N$ & $I$ \\
\hline & & $N$ & $N$ & $N$ & $N$ & $N$ & $N$ & $=$ \\
\hline 8 & $N$ & $-N$ & $N$ & $N$ & $-N$ & $-N$ & $N$ & $-I$ \\
\hline & $N$ & $-N$ & $N$ & $N$ & $\ldots N$ & $-\alpha$ & $N$ & $N$ \\
\hline & $N$ & $N$ & $N$ & $N$ & $N$ & $-N$ & $N$ & $I$ \\
\hline & $N$ & $N$ & $N$ & $N$ & $N$ & $N$ & $N$ & I \\
\hline & $N$ & $N$ & $-N$ & $-N$ & $N$ & $N$ & $N$ & $I$ \\
\hline & $N$ & $N$ & $-N$ & $\ldots$ & $N$ & $N$ & $N$ & $T$ \\
\hline & $N$ & $N$ & -1 & & $-\frac{1}{N}$ & -1 & $-\frac{1}{N}$ & $T$ \\
\hline 4 & $N$ & $-N$ & 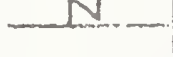 & & $N$ & $N$ & $N$ & $\frac{I}{T}$ \\
\hline & $N$ & $N$ & & & $N$ & $\mathrm{~N}$ & $N$ & $-\frac{I}{I}$ \\
\hline & $N$ & $N$ & $N$ & & $N$ & $N$ & $N$ & \\
\hline & & $N$ & $N$ & 1 & $N$ & $I$ & $I$ & $I$ \\
\hline & $N$ & $\mathrm{~N}$ & $N$ & $N$ & $N$ & $N$ & $N$ & $I$ \\
\hline 7 & & $-i \Gamma$ & & & & I & & $N$ \\
\hline & $\frac{N}{N}$ & $-\frac{N}{N}$ & $N$ & & $\frac{N}{I}$ & $-\frac{N}{I}$ & $I$ & $-{ }_{I}^{N}$ \\
\hline & & & & & & & & \\
\hline & $N$ & $-N$ & $-N$ & & $-N$ & $-N$ & $-y$ & \\
\hline & $\frac{N}{N}$ & $N$ & $-N^{-1}$ & $-N$ & $\frac{N}{N}$ & $-N$ & $N$ & $-\frac{1}{I}$ \\
\hline & $N$ & $N$ & $N$ & $N$ & $N$ & & 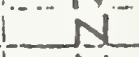 & $\bar{I}$ \\
\hline & & $N$ & $N$ & $\ldots$ & $N$ & $-N$ & $-N$ & $-I$ \\
\hline & $N$ & & $\ldots$ & $N$ & $N$ & $N$ & $N$ & $-\frac{1}{I}$ \\
\hline & $\frac{N}{N}$ & $N$ & & $N$ & $N$ & $I$ & $N$ & $I$ \\
\hline
\end{tabular}


TABLE 12 ARM \& TOP OF BACK TEST RESULTS IN PFE-6-74-UPHOLSTERED FURNITURE

CONSTRUCTION 9

$$
\frac{\text { FLAMMABILITY }}{\text { ROUND ROBIN }}
$$

2" FOAM

\begin{tabular}{|c|c|c|c|c|c|c|c|c|}
\hline $\begin{array}{c}A B N O \\
19\end{array}$ & $\frac{1}{N}$ & 8 & $\stackrel{2}{N}$ & $\frac{7}{N}$ & $-\frac{3}{N}$ & $-\frac{6}{N}$ & 4 & $-\frac{5}{5}$ \\
\hline & $N$ & $N$ & $N$ & $N$ & $\frac{N}{N}$ & & & \\
\hline & $N$ & $N$ & & & $N$ & & & \\
\hline & & $N$ & $N$ & & & $N$ & & \\
\hline & $d$ & $N$ & & $-\frac{N}{N}$ & $N$ & $\frac{N}{N}$ & $N$ & \\
\hline & $\Lambda$ & $N$ & $N$ & $N$ & & 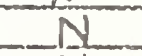 & & \\
\hline & $\mathrm{N}$ & $N$ & $-N$ & $N$ & $N$ & N & & \\
\hline & $\frac{N}{N}$ & $N-$ & $N$ & $N$ & $N$ & $N$ & $-N$ & \\
\hline & $N$ & $N$ & $N$ & $N$ & $N$ & $N$ & $N$ & \\
\hline & $\frac{N}{n}$ & $N$ & $\frac{N}{N}$ & $N$ & $-N$ & $N$ & $N$ & \\
\hline & $-\frac{N}{N}$ & $N$ & $N$ & $N$ & & $N$ & $N$ & \\
\hline 3 & $N$ & $N$ & $N$ & $N$ & $\mathrm{~N}$ & $N$ & $N$ & -1 \\
\hline 5 & $-N$ & N & $N$ & $-N$ & $-N$ & $-\frac{N}{N}$ & $N$ & \\
\hline 6 & $-N$ & $N$ & $-N$ & $N$ & $N$ & $N$ & $N$ & \\
\hline & $N$ & $-\frac{N}{N}$ & $N$ & $N$ & $\frac{N}{N}$ & $-N$ & $N$ & \\
\hline & $N$ & $N$ & $N$ & & & $\frac{N}{N}$ & & \\
\hline & $N$ & & $N$ & $N$ & $N$ & $N$ & - & \\
\hline & $N$ & $N$ & $-N$ & & $N$ & $N$ & $N$ & \\
\hline & & & & & & $N$ & & \\
\hline & $\mathrm{N}$ & $N$ & $N$ & & & $N$ & $N$ & \\
\hline$\frac{4}{15}$ & $N$ & N & $N$ & $N$ & $-N$ & N & $\stackrel{N}{-}$ & \\
\hline & & & & & & $-\frac{1}{N}$ & & \\
\hline & $N$ & $N$ & $N$ & $N$ & $N$ & $N$ & $N$ & \\
\hline & & $N$ & $N$ & & $N$ & $N$ & & \\
\hline & $N$ & $N$ & $N$ & & & $N$ & $N$ & \\
\hline & $N$ & $N$ & $N$ & -5 & & $N$ & $N$ & \\
\hline & $N$ & $N$ & $N$ & $N$ & $N$ & $N$ & $N$ & $\ldots$ \\
\hline 54 & $N$ & $N$ & $N$ & $N$ & $N$ & $-N$ & $N$ & $\frac{I}{I}$ \\
\hline 5 & $-N$ & $N$ & $N$ & $N$ & $N$ & $N$ & 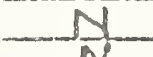 & \\
\hline & $-N$ & $N$ & $-N$ & $N$ & & $N$ & $N$ & \\
\hline 8 & $\mathrm{~N}$ & $N$ & $N$ & $N$ & $N$ & $N$ & $N$ & $I$ \\
\hline
\end{tabular}

FABRIC NO. 
ABM \& TOP OF BACK TEST RESULTS IN PFE-6-74-UPHOLSTERED FURNITURE $\frac{\text { FLAMMABILITY }}{\text { ROUND ROBIN }}$

CONSTRUCTION \#10

$$
\text { ROUND ROBIN }
$$

\section{I"FF/2" COTTON}

FABRIC NO.

\begin{tabular}{|c|c|c|c|c|c|c|c|c|}
\hline$A B$ & $-T$ & 8 & 2 & 7 & 3 & 6 & 4 & $-I$ \\
\hline 19 & $N$ & $N$ & $N$ & $N$ & $N$ & $N$ & $N$ & {$[I$} \\
\hline 20 & $\frac{N}{N}$ & $\frac{N}{N}$ & $N$ & $N$ & $N$ & $\frac{N}{N}$ & $N$ & $\frac{I}{N}$ \\
\hline & & & & & & & & \\
\hline & $N$ & $-N$ & $\mathrm{~N}$ & $-N$ & $N$ & $N$ & $N$ & \\
\hline 5 & $-N$ & $N$ & $N$ & $-\frac{N}{N}$ & $\frac{N}{N}$ & $-N$ & $N$ & \\
\hline & $N$ & $N$ & $N$ & $N$ & $N$ & $N$ & $N$ & $N$ \\
\hline & $\Lambda$ & $N$ & $N$ & $-N$ & & $N$ & $N$ & \\
\hline 8 & $N$ & $N$ & $N$ & $N$ & I. & 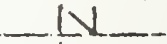 & 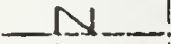 & \\
\hline & $-N$ & $-N$ & $\mathrm{~N}$ & $-N$ & $N$ & 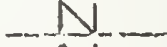 & $N$ & $N$ \\
\hline & $-N$ & $-N$ & 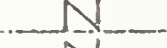 & $N$ & $N$ & $N$ & $-N$ & $N$ \\
\hline & 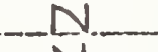 & $N$ & $N$ & $N$ & $N$ & $N$ & $N$ & -3 \\
\hline & $M$ & $N$ & $N$ & $-N$ & $-N$ & $N$ & $N$ & $N$ \\
\hline 4 & $-N$ & $N$ & $N$ & $N$ & $N$ & $N$ & $N$ & $N$ \\
\hline 5 & & & $\mathrm{~N}$ & $N$ & $N$ & $N$ & N & -1 \\
\hline & $N$ & $N$ & $N$ & $N$ & $N$ & $N$ & $N$ & \\
\hline 7 & $N$ & $N$ & $-N$ & $N$ & $N$ & $N$ & $N$ & I \\
\hline & $N$ & $N$ & $N$ & $\mathrm{~N}$ & $N$ & $N$ & $-N$ & \\
\hline 39 & $N$ & $N$ & $N$ & $\underline{N}$ & $N$ & $N$ & $N$ & $N$ \\
\hline fio & $N$ & $N$ & $N$ & $N$ & $N$ & $N$ & $N$ & L I \\
\hline 42 & $N$ & $N$ & $N$ & $\frac{N}{N}$ & $N$ & $-N$ & $\frac{N}{N}$ & - \\
\hline 43 & $N$ & $N$ & $N$ & $N$ & & $N$ & $N$ & \\
\hline & & & & $N$ & $N$ & $N$ & $N$ & \\
\hline 45 & $N$ & & $\ldots$ & $N$ & $\ldots N$ & $N$ & $N$ & \\
\hline 46 & $N$ & $N$ & $N$ & 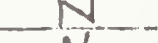 & $N$ & $N$ & $N$ & $-N$ \\
\hline 47 & $\ldots$ & & & $N$ & $N$ & $N$ & $N$ & \\
\hline 49 & $N$ & $N$ & $N$ & & $N$ & $N$ & $N$ & $\frac{N}{I}$ \\
\hline 30 & & & & & & & & \\
\hline & $-N$ & $N$ & $N$ & $r$ & $N$ & $N$ & $N$ & -5 \\
\hline & $N$ & $N$ & $N$ & $-N$ & $-N$ & $N$ & $N$ & $I$ \\
\hline 4 & $\because N$ & $N$ & $\because r=$ & $N$ & $N$ & $N$ & $N$ & $N$ \\
\hline & $N$ & $-N$ & $N$ & $N$ & $N$ & $N$ & $N$ & I \\
\hline & $N$ & $N$ & N & $N$ & $N$ & $N$ & $I$ & \\
\hline & $N$ & $N$ & $N$ & $N$ & $N$ & $-N$ & $-N$ & \\
\hline & $N$ & $N$ & $N$ & $N$ & $N$ & $N$ & $N$ & $\perp$ \\
\hline
\end{tabular}


TABLE 14

DECKING TEST BESULTS IN PFE-6-74-UPHOLSTERED EURNITURE $\frac{\text { ELAMMABILITY }}{\text { ROUND ROSIN }}$

\section{CONSTRUCTION HIII}

\begin{tabular}{|c|c|c|}
\hline LAB. NO. & COTION & $\begin{array}{l}\text { BONDED } \\
\text { CELLULOSE }\end{array}$ \\
\hline 19 & $I$ & $N$ \\
\hline 20 & I & $N$ \\
\hline 21 & $I$ & $N$ \\
\hline 22 & & \\
\hline 23 & $I$ & $N$ \\
\hline 24 & $I$ & I \\
\hline 25 & $I$ & $\mathrm{LV}$ \\
\hline 26 & $I$ & $N$ \\
\hline 27 & $I$ & $N$ \\
\hline 28 & $I$ & $N$ \\
\hline 29 & $I$ & $N$ \\
\hline 30 & $I$ & $N$ \\
\hline 31 & $I$ & $N$ \\
\hline 32 & $I$ & $N$ \\
\hline 33 & $I$ & $N$ \\
\hline 34 & $I$ & $\nabla$ \\
\hline 35 & $I$ & $N$ \\
\hline 36 & $I$ & $N$ \\
\hline 3.7 & I. & $N$ \\
\hline 38 & $I$ & $N$ \\
\hline 39 & $I$ & $N$ \\
\hline 40 & $I$ & $\mathrm{~N}$ \\
\hline 41 & $N$ & $N$ \\
\hline 42 & & \\
\hline 43 & $I$ & $\mathrm{~N}$ \\
\hline 44 & $=$ & $N$ \\
\hline 45 & $\frac{T}{T}$ & $N$ \\
\hline 46 & $I$ & N \\
\hline $4 \%$ & I & $N$ \\
\hline 48 & $I$ & $=0$ \\
\hline 49 & $I$ & $-N$ \\
\hline 50 & & \\
\hline 51 & $I$ & $N$ \\
\hline 52 & $I$ & $\underline{N}$ \\
\hline 53 & $I$ & $N$ \\
\hline 54 & $I$ & $-\alpha$ \\
\hline 53 & $I$ & $N$ \\
\hline 36 & $I 0$ & $N$ \\
\hline 57 & $I$ & $N$ \\
\hline 58 & $I$ & \\
\hline
\end{tabular}




\section{L1st of Figures}

Note: See Figures 1-7 in the "Proposed Standard for the Flammability of Upholstered Furniture" (Append1x C)

Figure 1 - Mock-up frame, upholstered furniture test

Figure 2 - Mock-up panels, upholstered furniture test

Figure 3 - Mock-up upholstered furniture test

Figure 4 - Cover fabric, glass fiber board test

Figure 5 - Cover fabric, cotton batting test

Figure 6 - Cover fabric, classification test

Figure 7 - Sample holder, cover fabric test

Figure 8 - Cigarette location on test chairs 


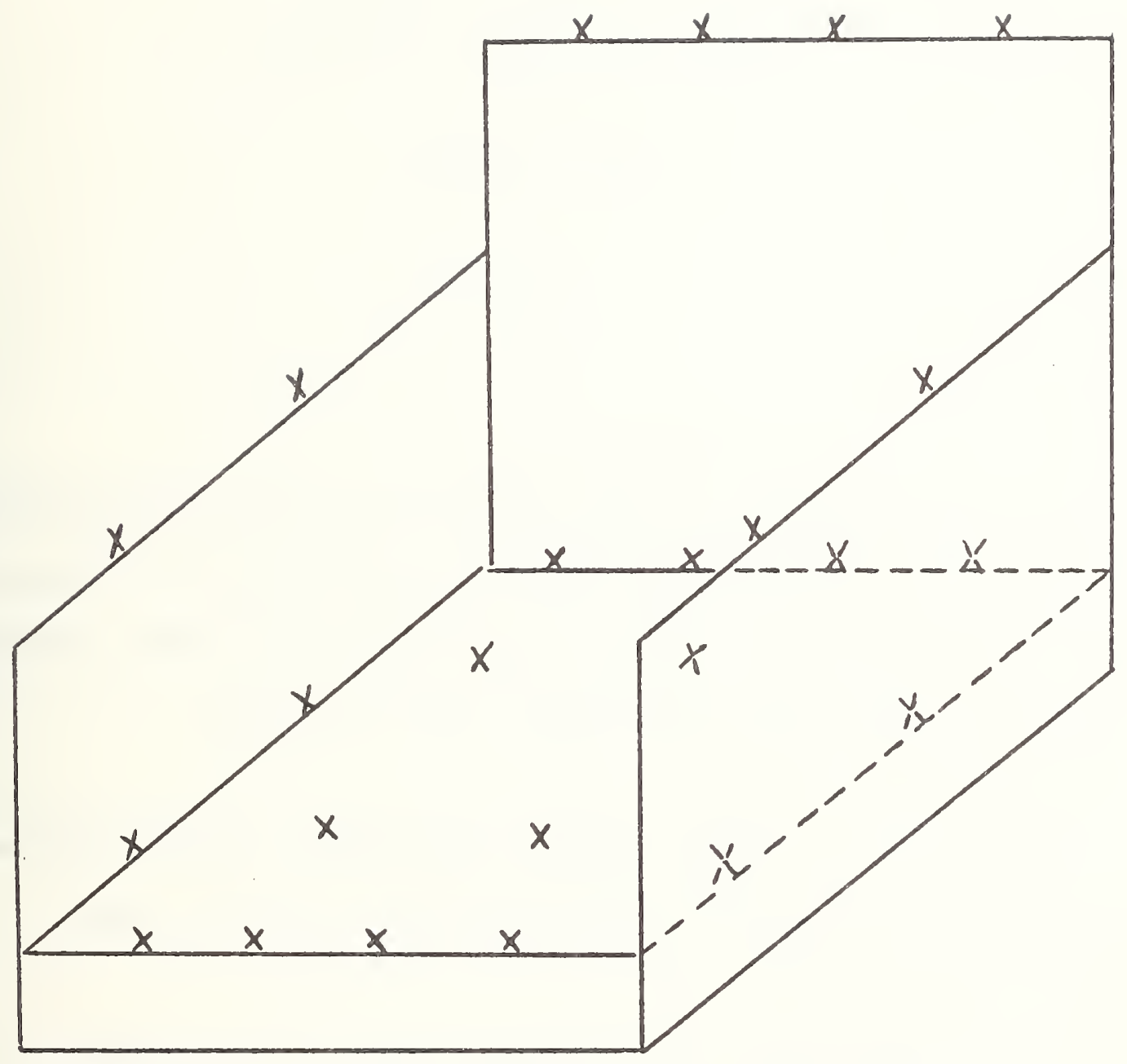

Figure 8. Cigarette Location on Test Chairs

$$
\text { F-65 }
$$




\begin{abstract}
ADDENDUM
Interlaboratory Program for the Evaluation of a Proposed Flammability (Cigarette Ignition Resistance)

Test for Upholstered Furniture
\end{abstract}

Joseph J. Loftus

May 1976

The interlaboratory test report calls for testing upholstery fabrics in the machine direction for the Fabric Classification Test Method and the elimination of air gaps between the vertical test panels and the horizontal platform support for the horizontal test panels.

In the study, 10 of the laboratory participants used the machine fabric direction, and eight of these laboratories used no air gap.

The following table lists the sample fabric and the number of laboratories assigning each fabric to a particular fabric classification: 
Fabric Laboratories

\begin{tabular}{|c|c|c|c|}
\hline Class A & - & $\# 1$ & 10 \\
\hline & & $\# 9$ & 10 \\
\hline & & $\# 8$ & $9(A), 1(B)$ \\
\hline Class B & - & \# 7 & 10 \\
\hline & & $\# 10$ & 10 \\
\hline & & \#15 & 10 \\
\hline & & $\# 2$ & 10 \\
\hline & & $\# 11$ & $9(B), 1(C)$ \\
\hline & & \#14 & $9(B), 1(A)$ \\
\hline & & \# 6 & $6(B), 4(C)$ \\
\hline Class C & - & \#13 & 10 \\
\hline & & $\# 3$ & $9(C), 1(D)$ \\
\hline & & $\# 4$ & $9(C), 1(D)$ \\
\hline & & \#12 & $9(\mathrm{C}), 1(\mathrm{~B})$ \\
\hline & & $\# 16$ & $8(C), 2(D)$ \\
\hline Class D & - & $\# 5$ & 10 \\
\hline
\end{tabular}


A summary of data supplied by the laboratory participants showed the following:

Fabric \#8, 1 Lab(B) - Reported a single cotton batt ignition.

Fabric \#11, $1 \mathrm{Lab}(\mathrm{C})$ - Vertical char, three samples--1.5, 1.6, 1.6 in.

Fabric \#14, 1 Lab(A) - Did not ignite cotton batt in four tests.

Fabric \#6, 4 Labs(C) - This fabric is lightweight open weave cotton. Two laboratories( $C$ ) used an air gap. One laboratory reported a single 2.5 in. char, and one laboratory reported that all four tests produced crevice chars $>2$ in.

Fabric \#3, 1 Lab(D) - This laboratory used an air gap, and one sample charred 3.2 in.

Fabric \#4, 1 Lab(D) - This laboratory reported a single char measurement of 4.8 in.

Fabric \#12, $1 \mathrm{Lab}(\mathrm{B})$ - This laboratory did not char $1.5 \mathrm{in}$, in four tests.

Fabric \#16, 2 Labs(D) - One laboratory reported a single measurement of 4.0 in., and one laboratory reported two measurements of vertical char $>3.0$ in.

\section{Comments}

1. The proposed flammability standard, as written, would allow three of the sample fabrics, \#8, 4, and 16, a retest to determine fabric class. Each of these fabrics received a lower class assignment based on a single char measurement by a single laboratory. 
2. Results for fabrics \#3 and 6 , where the test was conducted with an "air gap", would not be accepted under the proposed standard.

3. Results from one laboratory on fabric \#11 show a measurement judgment that chars are $0,0.1$, and 0.1 above the allowed limit of 1.5 in. for a "C" fabric.

4. Results for single laboratory tests on fabrics \#14 and 12 would indicate that good fabric/filling contact was not achieved by the testing laboratory. All nine remaining laboratories experienced little difficulty in igniting cotton batt or measuring crevice chars $>1.5$ in. 


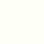

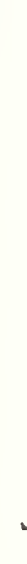


Evaluation of Standard Class B and C Fabrics

for the Proposed Standard for the Flammability

(Cigarette Ignition Resistance) of Upholstered Furniture

Joseph J. Loftus

October 1976

\section{Introduction}

The Fabric Classification Test in the recommended Proposed Standard for the Flammability (Cigarette Ignition Resistance) of Upholstered Furniture, PFF 6-76, groups fabrics with similar performance when exposed to burning cigarettes. However, the fabrics within a class still exhibit a range of performance from the lower to the upper classification criteria, as is true with any classification scheme. Continuing evaluation of the Fabric Classification Test indicates a potential problem with Classes $B$ and $C$ if the manufacturer is free to choose any fabric within those classes to qualify his furniture mock-up; i.e., choose a fabric whose performance is near the upper classification criterion for the mock-up test. This could result in the production of furniture, a high percentage of which would ignite when exposed to burning cigarettes if tested. 
Because of this problem, the National Bureau of Standards (NBS) set out to locate and evaluate "Standard" Class B and C fabrics for use in the mock-up qualification test in the proposed standard. This report describes the two fabrics selected as Standards and their evaluation.

\section{Test Materials}

The upholstery fabrics and number identifications used in this table are the same fabrics as were used in a recently completed 55-1ab interlaboratory evaluation study to determine the feasibility of the proposed flammability standard for upholstered furniture.

\section{Class B Fabrics}

$0 z / y d^{2}$

$\begin{array}{lrl}\text { \#2 } & 12.5 & 100 \% \text { Nylon } \\ \# 7 & 9.7 & 100 \% \text { Nylon } \\ \# 10 & 23.0 & 67 \% \text { Rayon, 22\% Nylon, 11\% Polyester } \\ \# 11 & 14.9 & 100 \% \text { Olefin } \\ \# 14 & 17.0 & 100 \% \text { Nylon } \\ \# 15 & 15.0 & 100 \% \text { Nylon } \\ \text { "B" } & 3.7 & \begin{array}{c}\text { Cotton/Polyester Sheeting Standard } \\ \text { Material }\end{array}\end{array}$




\begin{tabular}{|c|c|c|}
\hline & $0 z / y d^{2}$ & \\
\hline \#3 & 15.7 & $55 \%$ Acetate, $45 \%$ Rayon \\
\hline \# 4 & 13.9 & $100 \%$ Cotton \\
\hline \# 6 & 5.7 & $100 \%$ Cottion \\
\hline \# 12 & 14.1 & $100 \%$ Rayon \\
\hline$\# 13$ & 13.6 & $100 \%$ Rayon \\
\hline$\# 1.6$ & 13.1 & $100 \%$ Rayon \\
\hline "C" & 9.0 & $\begin{array}{l}100 \% \text { Cotton Ticking Cloth Standard } \\
\text { Material, Federal Specification CCC- } \\
\text { C-436D, Type I, Class I Untreated }\end{array}$ \\
\hline
\end{tabular}

\section{Test Method}

The fabric classification test method in the proposed upholstered furniture flammability standard was used for conducting the tests. Briefly, the method requires the burning of a test cigarette (covered by a piece of bed-sheeting material) in the crevice of abutting horizontal and vertical test panels (test fabric covers on glass fiber board substrate), see Figure 1.

For the purposes of this study, three thermocouples (Chromel and Alumel, 28-gauge) were located in the crevice of the test panels, one couple 0.2 inch from the lit end, a second central ( 1.6 inch) to the test cigarette, and the third 
0.2 inch from the butt end. A multipoint recorder was used to record the output of the thermocouples when the test fabrics heated or smoldered on exposure to the burning of a cigarette. Peak temperature rises for cach test location were used to compare the smoldering performance of the various test fabrics with the selected standard fabric materials.

\section{Test Results}

A total of 10 cigarette tests were made on each of the .test fabric materials. Fourteen fabrics were tested--six Class B, six Class C, Standard Fabric B, and Standard Fabric C. Tables 1 and 2 show average peak temperature values for 10 tests at the tip, middle, and butt end locations of the test cigarette. Also included in the Tables is a comparison of the average values for all Class $B$ and Class $C$ fabrics with the corresponding standard class fabrics. Standard deviations are also listed for each test location.

Data listed for Class B test fabrics in Table 1 and illustrated in Figure 2 shows that fabric \#10 (the heaviest material tested, $23.0 \mathrm{oz} / \mathrm{yd}^{2}$ ) produced the lowest temperatures for the tip and middle cigarette locations $\left(77-189^{\circ} \mathrm{C}\right.$, respectively) whereas fabric \#I4 produced the lowest butt end temperature $\left(110^{\circ} \mathrm{C}\right)$. 
By comparison, the Standard Class B fabric material showed higher values for the tip and middle locations and a butt end temperature average of only $6^{\circ} \mathrm{C}$ less than the average for the six Class B fabrics. Five of the Class B fabrics were $100 \%$ synthetic fiber materials and one (\#10) was a blend of cellulosic and synthetic fibers.

Table 2 lists the temperature values obtained for tests on six Class $C$ fabric materials and the Standard Class C fabric. Figure 3 illustrates the closeness of these values, especially for the middle and butt end temperature measurements where the spread is only 25 and $5^{\circ} \mathrm{C}$. Although slightly lower in every case, the Standard "C" fabric temperature averages were shown to be within the standard deviations for the six other class C fabric materials. All of the Class C fabrics tested were celluiosic fiber materials.

Conclusions

Class B Fabrics

The results of these tests give a clear indication of what might occur if, for example, a good (low temperature) fabric (\#10) were used to qualify all Class $B$ fabrics for 
use on finished furniture pieces. As shown in Figure 2, all of the other Class B fabrics produced higher temperatures than \#10 on the tip and middle cigarette locations and thus would be expected to ignite furniture assemblies that would not be ignited by fabric \#10. By comparison, the sheeting material selected as Standard for Class B mock-up testing produced the highest temperatures on the tip and middle and greater values than four of the six fabrics on the butt end.

These test results thus indicate that the standard fabric for Class B (sheeting material) would be more suitable for mock-up furniture assembly qualification than other Class B materials simply because it provides for the "worst case" conditions; i.e., if a mock-up assembly passes the cigarette test under the "worst case" fabric, then most other fabrics in the Class B category on that same assembly would "pass" the test if tested.

\section{Class C Fabrics}

All Class $C$ fabrics smolder in the crevice area in the Fabric Classification Test and thus would not be expected to produce a wide divergence in temperature measurements. This expectation was proven in tests of six Class $C$ fabrics and the Standard C fabric material. Figure 3 illustrates test 
results which show the Standard Class C fabric producing a median temperature in tip measurements, and low middle on butt temperatures. However, the spread from the highest to lowest temperatures recorded for all fabrics including the proposed Standard fabric was only 46 and $26^{\circ} \mathrm{C}$ for the middle and butt end temperature measurements. Such a spread of data is not very significant, for this type of variance was noted for tests on single fabric samples.

Although not recorded by the thermocouples in these tests (because of their fixed location in the crevice), but of great significance to temperature rise was the fact that the Standard C fabric produced highly visible glowing conditions on fabric portions away from the couple location even after smoldering in the crevice location had ceased. If the Standard fabric selection was based simply on temperature measurements alone, it would appear that one Class $C$ fabric would be equal to any other for qualification testing on furniture mock-ups; however, because the Standard C material provided for an additional hazardous dimension (i.e., more intense glowing than other test fabrics) it was chosen to represent all Class $C$ fabrics for qualification tests because it would indeed represent the worst case condition for Class C materials. 
Two fabrics have been selected as Standard Class B and Class C materials:

(a) Standard Class B fabric is a cotton or cotton/ polyester bed-sheeting material ( $\left.3.7 \mathrm{oz} / \mathrm{yd}^{2}\right)$ and is the same material as used to cover test cigarettes in the proposed standard test methods.

(b) Standard Class $C$ fabric is a cotton ticking cloth material ( 9 oz/yd ${ }^{2}$, Type I, Class I untreated) covered by Federal Specification CCC-C-436D.

It is recommended that the recommended Proposed Standard for the Flammability (Cigarette Ignition Resistance) of Upholstered Furniture, PFF 6-76, be modified to require that Standard Class B and Class C fabrics be used for all qualification tests of upholstered furniture mock-up assemblies when the assemblies or constructions are intended for use with Class $B$ or Class C upholstery fabric covers. Under the proposed standard, passing results with the Standard fabrics would qualify the constructions covered with fabrics from that class for the production of full-size upholstered furniture pieces. 
Table 1

Class " $B$ " Upholstery Fabrics

Peak Temperature* Rise ${ }^{\circ} \mathrm{C}$

\begin{tabular}{|c|c|c|c|c|c|c|c|c|c|}
\hline Fabric & 非14 & $\# 15$ & 非 & 非 7 & 非10 & 非11 & Std. "B" & Ave. & 6 Fabrics \\
\hline Tip & 135 & 113 & 119 & 139 & 77 & 102 & 148 & & 114 \\
\hline Middle & 204 & 213 & 243 & 251 & 189 & 230 & 282 & & 222 \\
\hline Butt & 110 & 138 & 218 & 122 & 147 & 210 & 153 & & 158 \\
\hline
\end{tabular}

Std. ${ }^{\circ} \mathrm{C}$

Dev. $\alpha$

\begin{tabular}{|c|c|c|c|c|c|c|c|c|}
\hline Tip & 21 & 25 & 30 & 45 & 20 & 23 & 25 & 27 \\
\hline Middle & 26 & 21 & 31 & 46 & 40 & 38 & 43 & 34 \\
\hline Butt & 28 & 33 & 36 & 50 & 27 & 49 & 42 & 37 \\
\hline
\end{tabular}

*Average for 10 Tests 
Table 2

Class "C" Upholstery Fabrics

Peak Temperature* Rise ${ }^{\circ} \mathrm{C}$

\begin{tabular}{lcccccccc} 
Fabric & 非 & 非 & 非 3 & 非16 & 非12 & 非13 & Std. "C" & Ave. 6 Fabrics \\
Tip & 522 & 318 & 534 & 235 & 261 & 484 & 373 & 392 \\
Middle & 581 & 557 & 572 & 556 & 543 & 550 & 535 & 560 \\
Butt & 594 & 586 & 568 & 581 & 582 & 583 & 577 & 582 \\
\hline
\end{tabular}

Std. ${ }^{\circ} \mathrm{C}$

Dev. $\alpha$

\begin{tabular}{lllllllll} 
Tip & 21 & 85 & 27 & 107 & 143 & 37 & 90 & 70 \\
Middle & 23 & 36 & 20 & 13 & 50 & 26 & 36 & 28 \\
Butt & 15 & 20 & 23 & 21 & 16 & 16 & 44 & 19 \\
\hline
\end{tabular}

*Average for 10 Tests 


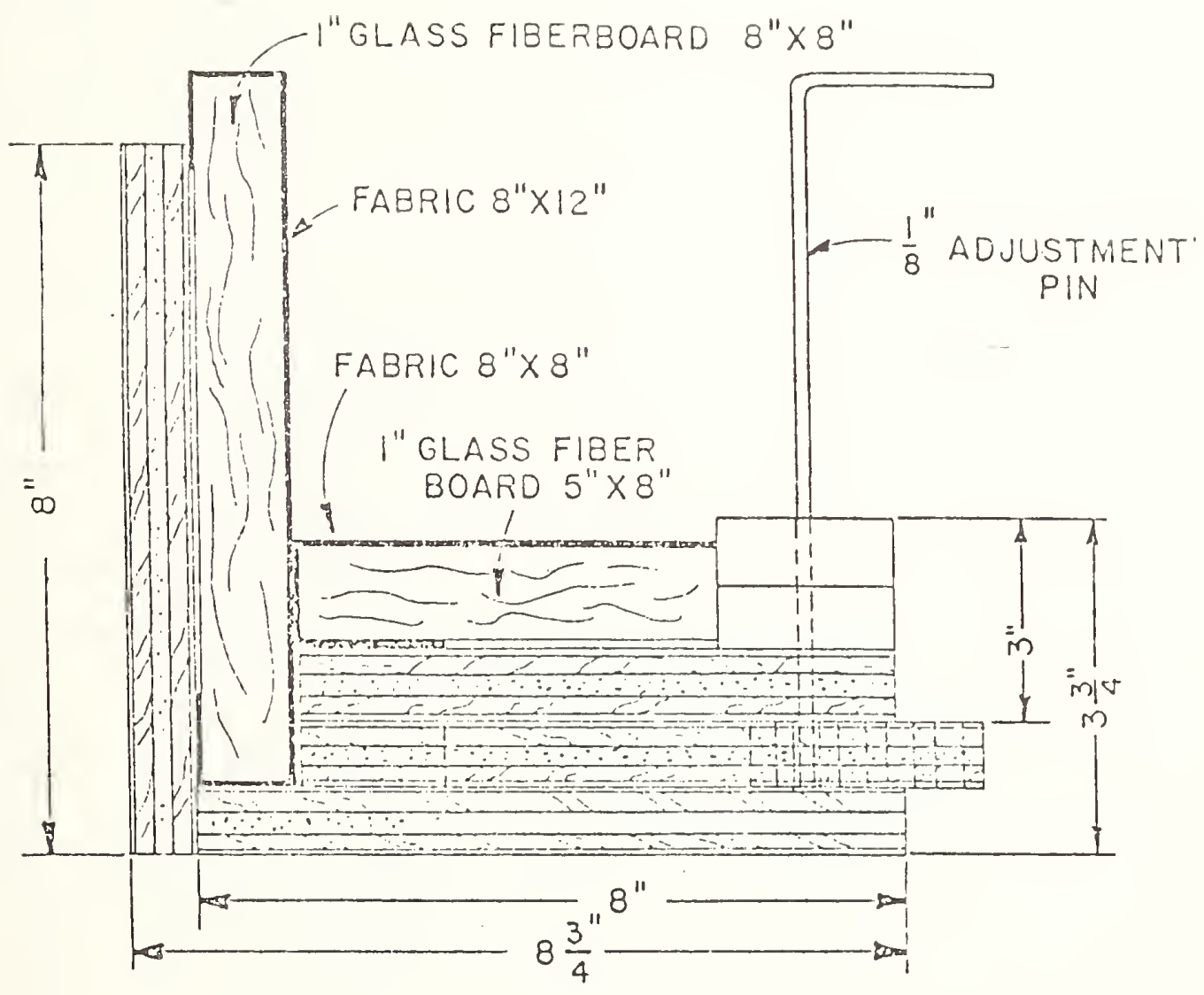

Figure 1. Upholstery Fabric Test

Fabric/Glass Fiberboard Sample 


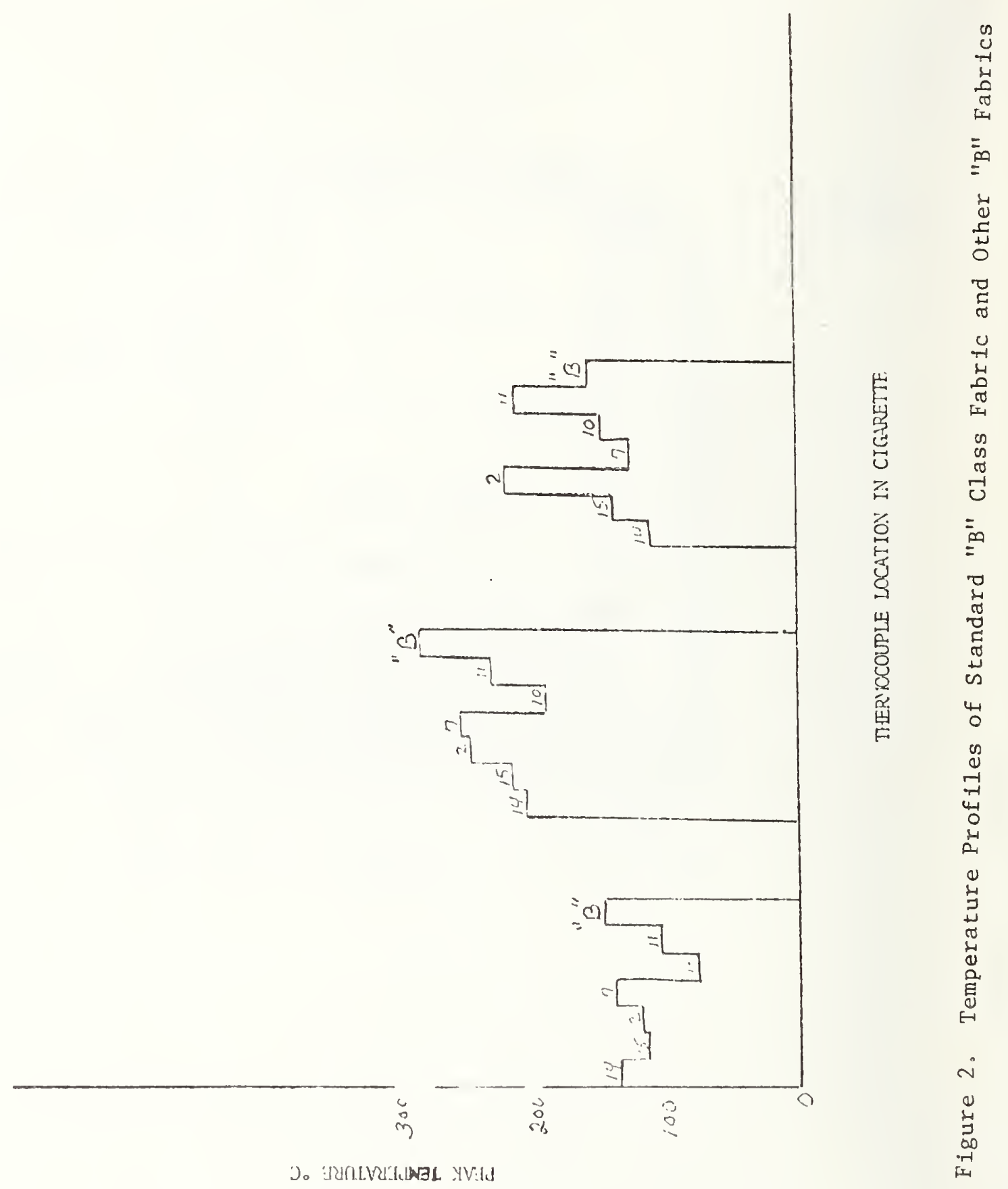



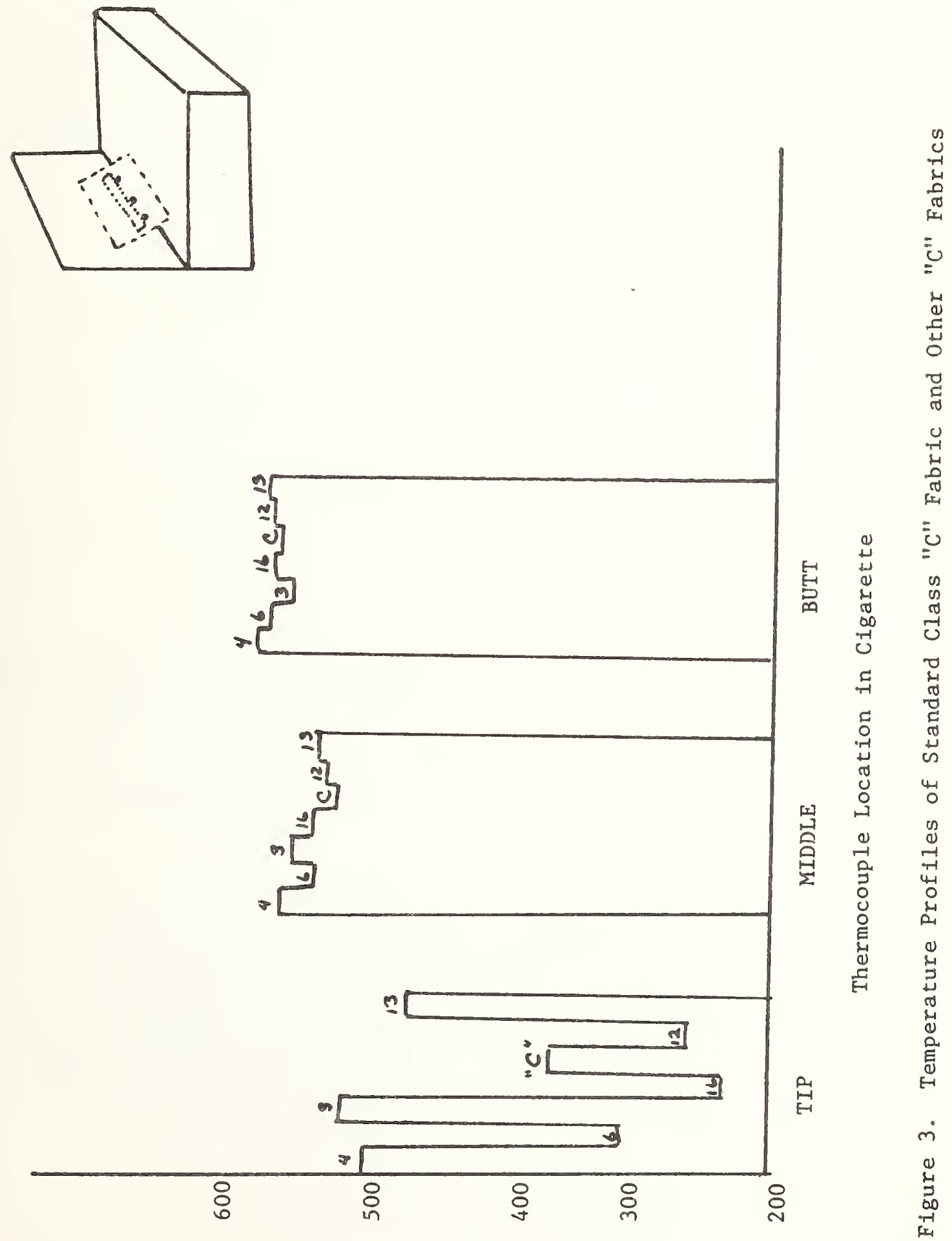

0
$\mu$
$\omega$

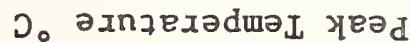




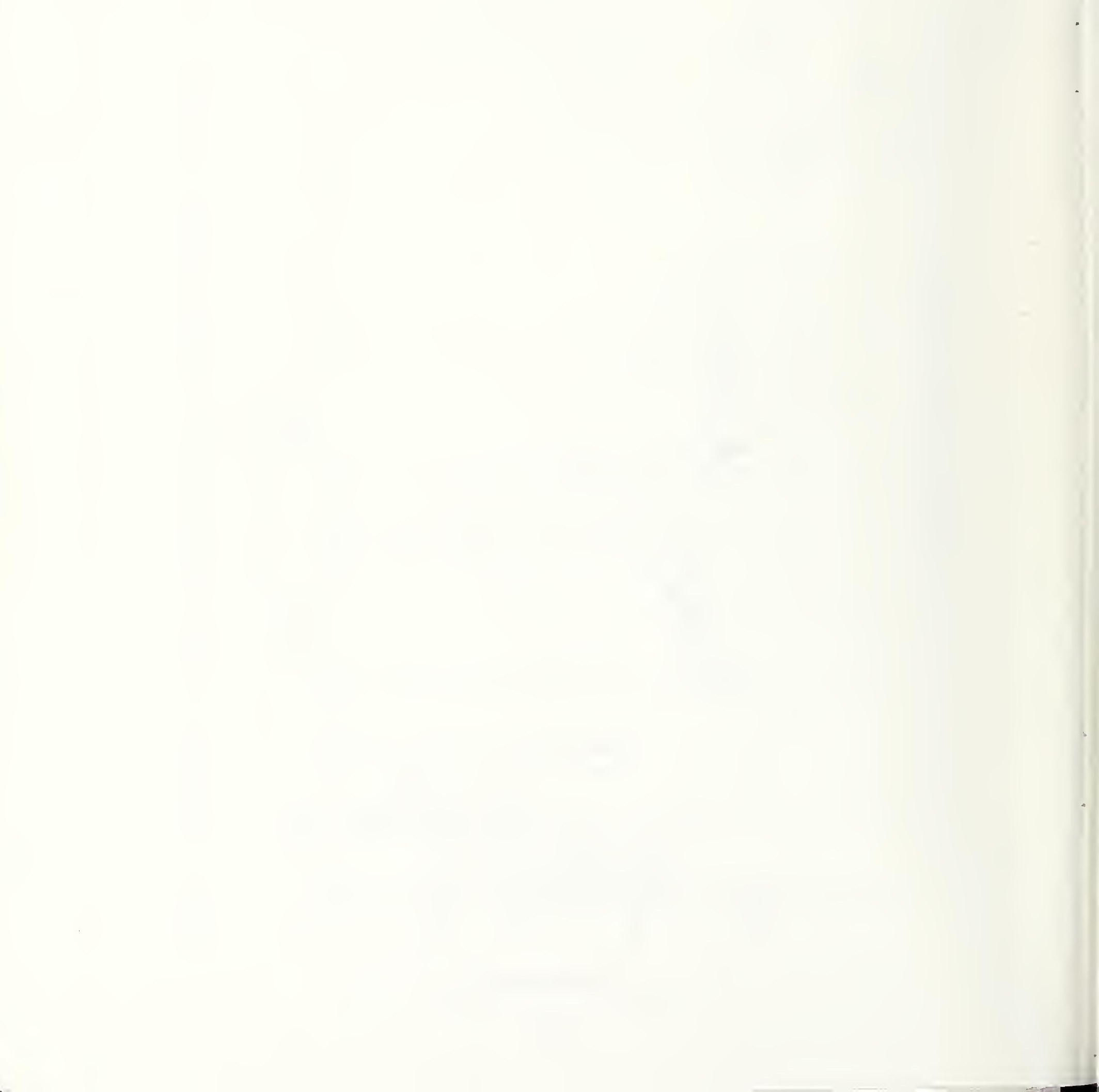




\section{APPENDIX H}

June 18,1971

405.00

Results of Temperature Measurements Made on Burning Cigarettes and Their Use as a Standard Ignition Source for Mattress Testing

L. James Sharman, Chief

Test Development Unit

Office of Flammable Fabrics

\section{Abstract}

Peak temperature rise measurements have been made on 32 different brands of cigarettes. Results show that the non-filter tip clgarettes burn "hotter" at the butt end then do the filter tips. The Pall Mall cigarette (selected as standard for the mattress test) was shown to produce a peak temperature at the butt end of $717^{\circ} \mathrm{C}$ or $58^{\circ} \mathrm{C} \mathrm{h} 1$ gher than the average for 26 filter tip brands of $659^{\circ} \mathrm{C}$. The average for all king size non-filters tested exceeds the filter brands by $22^{\circ} \mathrm{C}$. $\left(681^{\circ} \mathrm{C}\right.$ to $\left.659^{\circ} \mathrm{C}\right)$. Measurements made at 1 or 2 inch distances from the butt ends showed no significant temperature differences between the two types of cigarettes.

\section{Introduction}

An evaluation study of cigarettes and the temperatures they develop on burning was recently completed by the Test Development Unit. The purpose of the study was to gain some background information on the cigarette to determine if such an item could be used as a reliable ignition source for ignition studies. The proposed Method of Test for Measuring the Ignition Resistance of Mattresses calls for the use of a lighted cigarette as the source of ignition in the test, i.e., it was deemed feasible to conduct such an investigation.

For this study, 32 different brands of cigarettes were purchased at local retail outlets and included among them were 16 brands previously reported to represent $81.3 \%$ of sales (Tobacco Reporter 1968). A11 types of cigarettes were selected including regular and king size, extra long $(100 \mathrm{~mm})$, slims, cellulose fllter tip, cellulose plus charcoal filter tip and mentholated. Test results indicate that temperature measurement may be a useful and desirable means for evaluating cigarettes under normal burning condtions. This report gives a description of the test method and an analysis of the results obtained. 
Apparatus and Test Method

A $3 \times 3 \times 1 / 2$ inch thick asbestos board (See Figure 1) was used to support three chromel and alumel 24 gauge (.020 inch) thermocouples. In a typical test the couples pierce the cigarette cylinder wall to one radius depth at three locations, $1 / 8$ inch from the butt end, and at 1 and 2 inch distances from the butt thermocouple. Butt end here means measured from the point where the tobacco ends and not from the filter tip end. The cigarettes were tested in a horizontal position, were ignited (with the aid of a vacuum bulb) and allowed to burn their full length to extinguishment. Temperatures developed by the cigarettes on burning were recorded on a twelve point potentlometer recorder.

\section{Results and Discussion}

Table 1 lists the various brands of clgarettes tested and the measurements obtained. Table 2 presents a summary of test results and includes the standard deviation for the butt end temperature of the burning cigarette.

The regular size $(7.0 \mathrm{~cm})$ non-filter tip cigarettes showed the highest packing density $\left(0.284 \mathrm{~g} / \mathrm{cm}^{3}\right)$, highest calculated heat value and the highest butt temperature values. Heat calculations show $1006 \mathrm{ca} 1 / \mathrm{cm}^{3}$ for the Pall Mall (standard for the mattress ignition resistance test) and $1004 \mathrm{cal} / \mathrm{cm}^{3}$ for the average of 26 filter tip cigarettes.

As expected, the butt temperature of the non-filter tip cigarettes was in most cases higher than that recorded for the filter brands. This type of clgarette burns "hotter" because the butt ends have a freer access to oxygen to complete combustion, then do the filter tip cigarette brands where the filter hinders or retarc's the combustion process and thus produces lower temperatures in the butt end.

\section{Conclusion}

A total of 32 cigarette brands (26 filter and 6 non-filter) on burning produced butt temperatures ranging from $601^{\circ}$ to $722^{\circ} \mathrm{C}$. Records show that the butt end was the "hottest" part of the cigarette. Because these temperatures far exceed the ignition temperature of most mattress fillings, Cotton Batting, $425^{\circ} \mathrm{C}$; Foam Rubber, $420^{\circ} \mathrm{C}$; and Urethane Foam, $435^{\circ} \mathrm{C}$; it would appear that the type or brand of cigarette used as an ignition source in evaluating the ignition resistance of mattresses does not appear critical. However, in an effort to provide the most severe type of ignition source for the test, the use of a non-filter king size 
$\mathrm{K}^{\text {(sic) }}$

cigarette (Pall Mall - $717^{\circ} \mathrm{C}$ ) appears to be allogical choice for the ignition source. The $\mathrm{Pall}$ Mall cigarette produced the hot test temperature at the butt end, from among all the king size and nonfilters tested, and therefore, was selected to be used as the stand$(\overbrace{\text { sic }}^{\mathrm{a}}$ are ignition source in the mattress test.

Joseph J. Loftus

Chemist

Office of Flammable Fabrics

Attachments

JJL : gh 


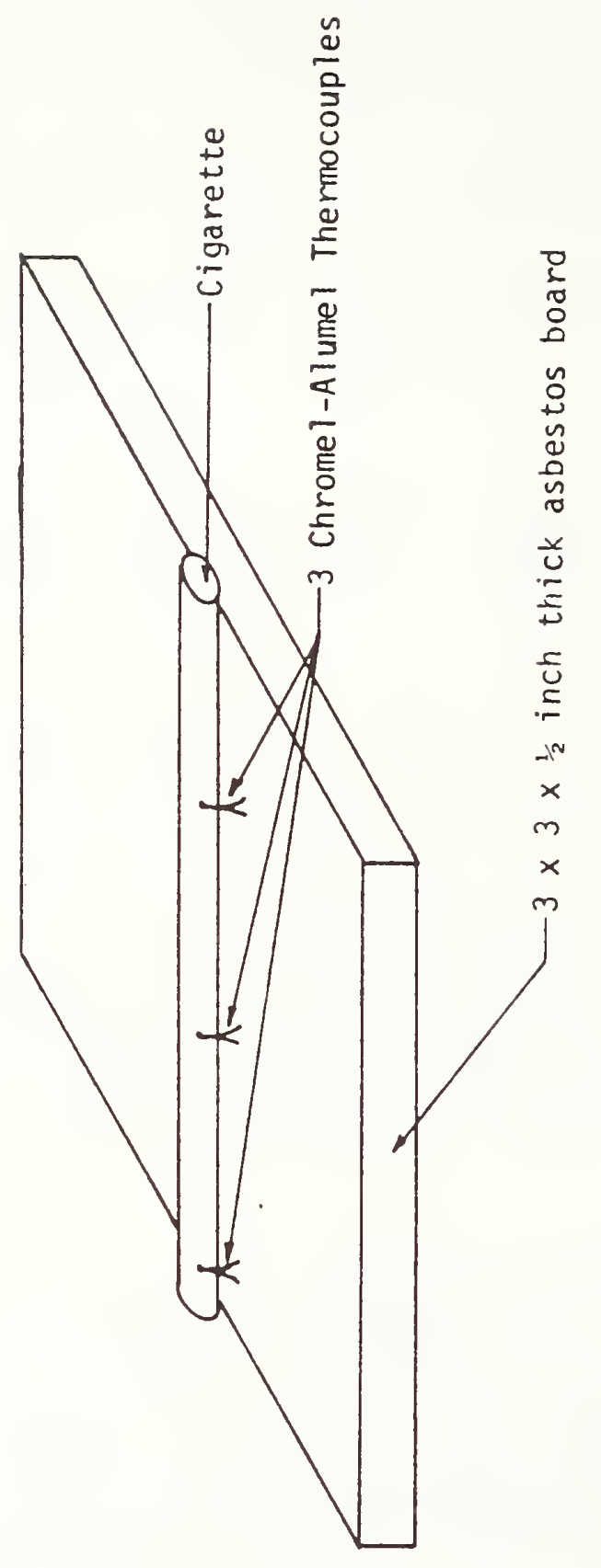

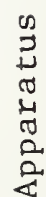

$\underset{\infty}{\infty}$

告

点

ธ

苞

先

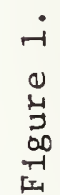

H- 4 


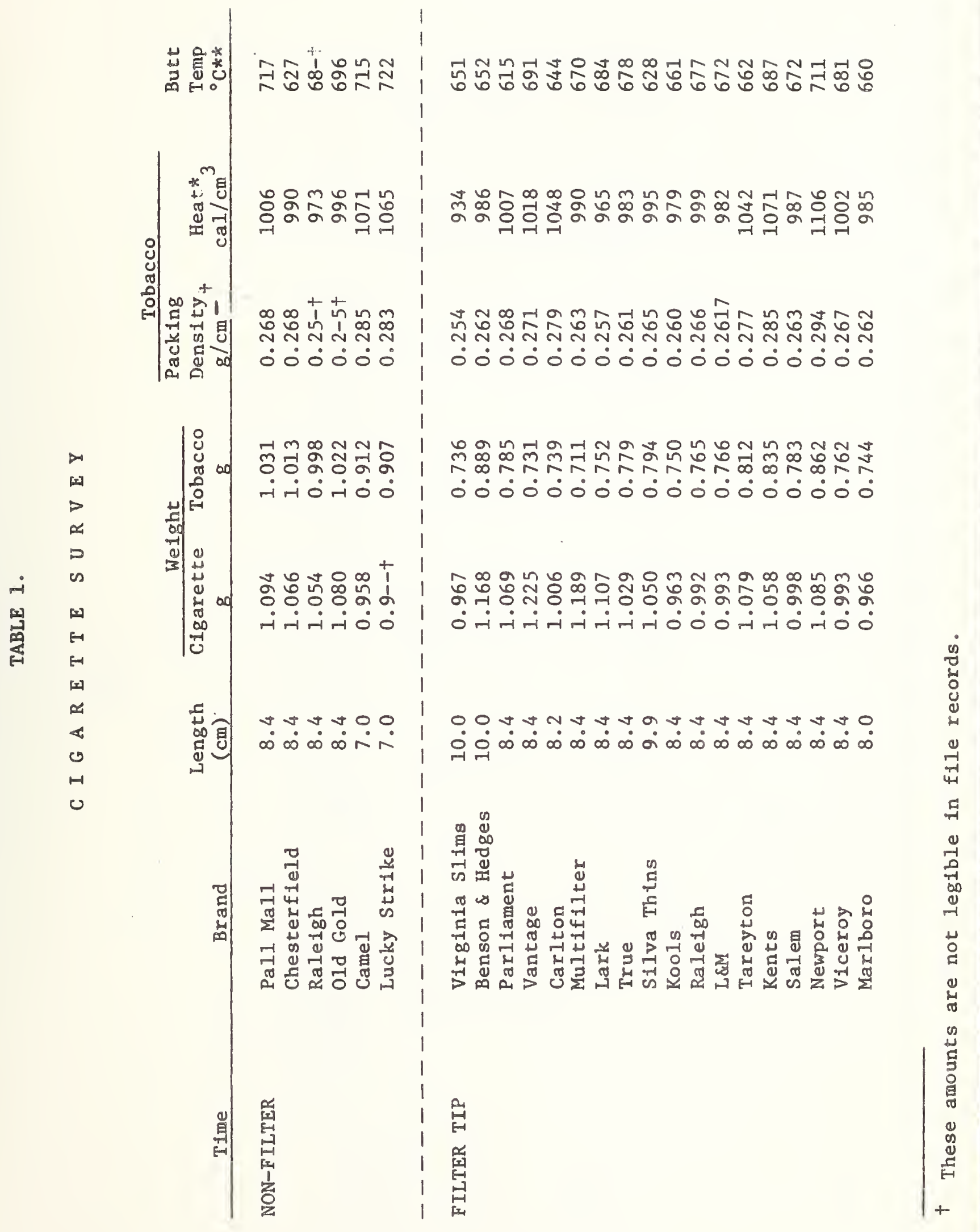




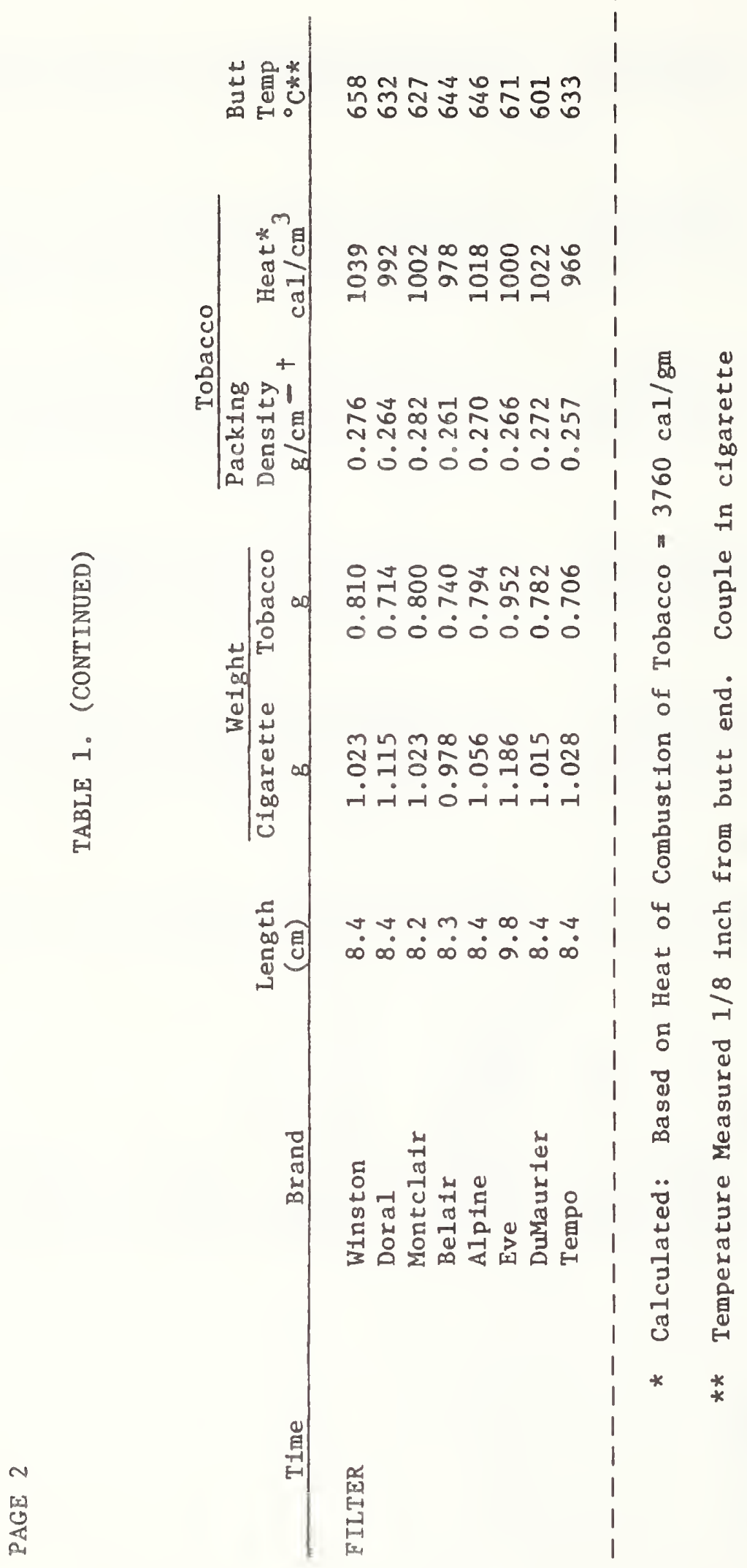




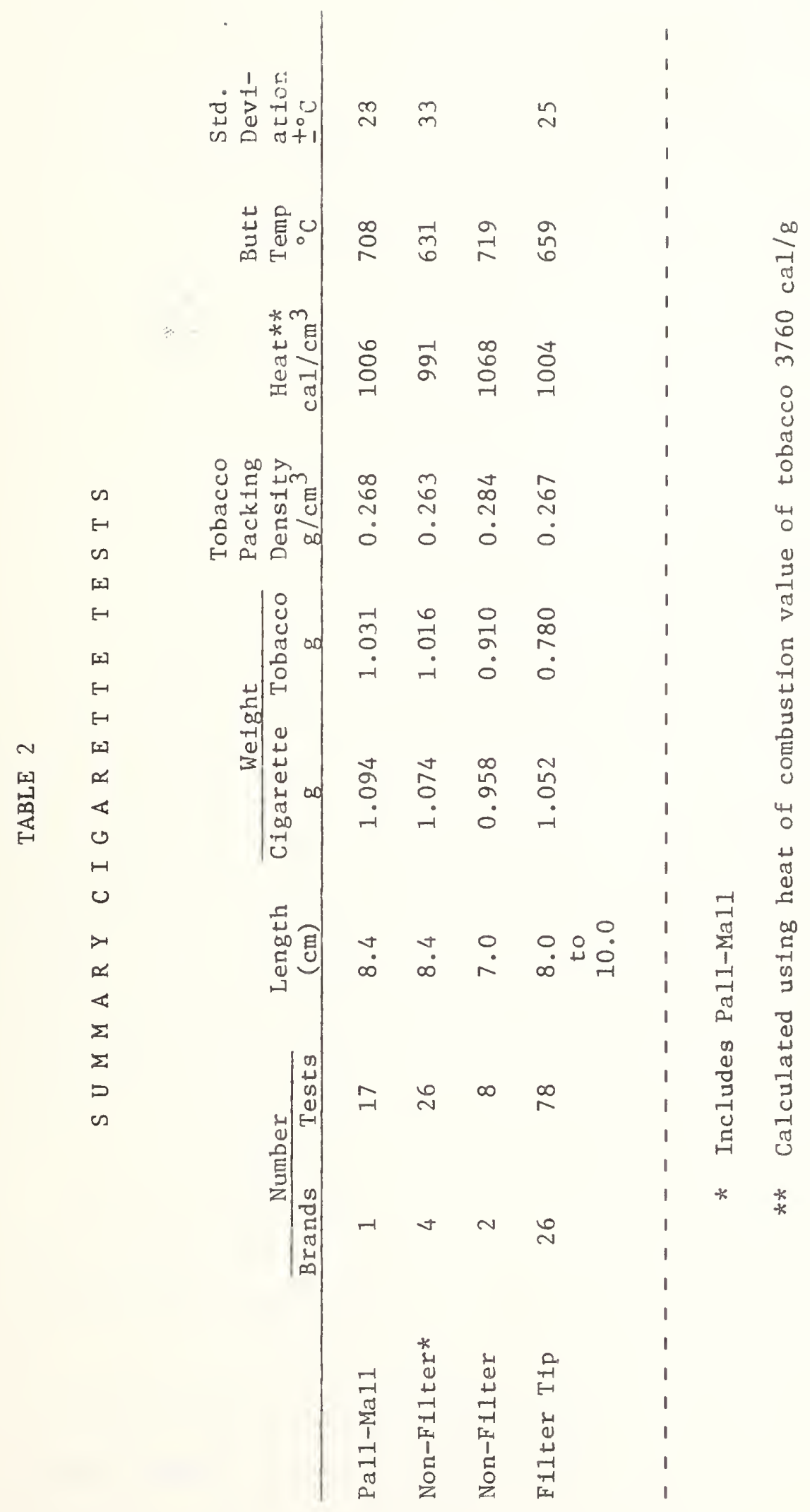



APPENDIX I

\begin{abstract}
Cigarette Ignition Resistance Tests of Twenty-Three Polyurethane Foams
\end{abstract}

Joseph J. Loftus

June 29,1976

\begin{abstract}
A total of 23 different samples of foam urethane were evaluated for resistance to ignition by burning cigarettes when the materials were used as filling material in mock-up upholstered furniture samples. Under conditions of test, using a Class $\mathrm{V}$ upholstery fabric on 12 of the samples, six foams smoldered and eventual1y burst into flames, and six other foam samples smoldered to extinction.
\end{abstract}

Eleven foams were tested as barrier (protective) layers over cotton batting in furniture constructions using Class $B$ and Class C upholstery fabrics as cover materials.

None of the Class B fabric samples ignited, but al1 eleven foams allowed or permitted ignitions in cotton batting under the Class $C$ fabric cover material. 
ire-retardant treated foams did not appear to offer any added protection to the furniture assemblies.

\section{Introduction}

One of the spin-offs from the development work on a Proposed Standard for the Fiammability (Cigarette Ignition Resistance) of Upholstered Furniture (PFF 6-74) was the opportunity to make cigarette ignition resistance measurements on flexible urethane foam used in mock-up upholstered furniture constructions.

Enormous amounts of foam urethane are used every year in the construction of upholstered furniture. Seat cushions are almost totally made of foam, and large quantities go into the fabrication of arms and backs of furniture items. Often a piece of furniture will be made with the foam material in combination with other stuffing or filling materials.

For the purposes of this study, two mock-up constructions were used: (1) foam seat/foam back and (2) glass fiber board seat/foam barrier over cotton batting back. 
All tests were made in the crevice location of the test assemblies.

The following is a report on results obtained in this study.

\section{Test Materials}

Table 1 lists the number, material description, thickness, and density for the 23 foam urethane samples. The materials were supplied by six different foam urethane manufacturers. Six of the foams were furnished in nominal 4inch thickness, and the remaining pieces ranged from $1 / 2$ to 1 -inch thickness. Densities ranged from 1.0 to $4.1 \mathrm{lb} /$ $\mathrm{cu} f t$.

The numbers listed under material description were manufacturers' numbers, and no identification of the manufacturer is intended or implied in this report.

The Class D fabric used for test was a cotton/rayon velvet material of $17.9 \mathrm{oz} / \mathrm{yd}^{2}$, a fabric which is particularly susceptible to smoldering ignition. 
The Class $B$ fabric was a 100 percent nylon material of $14 \mathrm{oz} / \mathrm{yd}^{2}$, and the Class $C$ fabric used was a cotton/ rayon material of $14.1 \mathrm{oz} / \mathrm{yd}^{2}$.

\section{Test Method}

With modifications, the test procedures outlined in the Proposed Standard for the Flammability (Cigarette Ignition Resistance) of Upholstered Furniture (PFF 6-74) were ured for conducting the tests on the foam materials.

\section{Sample Preparation}

Foam/Foam--

Small-scale mock-up seat cushions were prepared for test by cutting 4 -inch wide $x$-inch long $x$ sample thickness samples of foam from the slab stock furnished for test.

Each piece was covered by a 6 x 6 -inch piece of upholstery fabric, and the fabric was fastened to the 
seat cushion with straight pins. Vertical panels were made in the same manner.

For the nominal 4-inch thick foam samples, a $2 \times 2 \times 6-$ inch cross section was cut out of a $4 \times 4 \times 6$-inch piece of foam, and the L-shaped samples were covered by the Class D upholstery fabric and pinned.

Foam/Foam Over Cotton Batting--

Foam urethane barrier layer samples were prepared by covering $8 \times 8$-inch pieces of $1 / 2$-inch thick plywood with 2 -inch thick layers of cotton batting followed by a layer of foam urethane (range $1 / 2$ to 1 -inch thickness) and a 12 $x$ 12-inch piece of cover fabric material. The fabric was drawn tightly over the assembly and fastened to the backside of the plywood panel with staples. The seat cushions used for the assembly were made by covering a $5 \times 8 \times 1$ inch piece of glass fiber board with an $8 \times 8$-inch piece of upholstery fabric and using straight pins to fasten the fabric to the board. 


\section{Test Procedure}

The sample holder used in the Fabric Classification Test in the proposed standard for upholstered furniture was used to support the test panels for test.

Each test cigarette was well lighted and burned no more than $4 \mathrm{~mm}$ (0.16 in) when placed in the crevice location of the test samples. After placement, each cigarette was immediately covered with a $5 \times 5$-inch piece of sheeting material. The cigarettes were allowed to burn their full length for test.

All tests were conducted within a fume hood provided with an exhaust system to remove smoke and gases produced by testing.

\section{Test Criteria}

Test samples which ignited and supported smoldering "failed" the cigarette test. 
Test samples which resisted cigarette ignition and prevented smoldering in the foam urethane or cotton batting substrate "passed" the test.

\section{Test Results}

Class D upholstery fabric ignited and smoldered on all 12 foam urethane samples tested. Smoldering involved the foam materials, and copious amounts of smoke and gases were evolved from each of the test materials.

The door to the fume hood was necessarily closed to about a 1 -inch opening across the hood width of about 61 inches for the latter part of each test, and thus air was drawn past the samples at a fairly rapid rate. Under these conditions, a total of six foam materials burst into flames and six smoldered to extinction. Results of these tests are listed in Table 2.

Of the glass fiber board/foam over cotton batting assemblies, Foams \#13 to 23 were not ignited when a Class B upholstery fabric was used as the cover material. However, all of these foams were ignited and smoldered 
when covered by a Class C upholstery fabric. Results are listed in Table 3 .

Summary

1. Class D upholstery fabric ignited and smoldered on every foam urethane sample tested. Six foams burst into flame in times ranging from 24-40 minutes. Six foams smoldered to extinction and did not flame.

2. Fire-retardant treatments used in some of the foams were not able to prevent smoldering ignitions in the foams.

3. One of the foams which did not flame was a conventional foam w/o fire-retardant treatment (Sample \#5).

4. Class B upholstery fabric did not ignite, smolder, or permit ignitions in the cotton batt substrates covered by a barrier layer of urethane foam. These results were repeated for all 11 foams tested in the thickness range of $1 / 2$ to 1 inch. 
5. Class C upholstery fabric did ignite, smolder, and permit ignitions to occur in the same 11 foam over cotton batt samples that easily "passed" the cigarette test under Class B fabrics.

\section{Conclusions}

Urethane foams used in upholstered furniture can be ignited by a smoldering cigarette if a Class D upholstery fabric is used as the cover material on the furniture item.

Fire-retardant treatments tested were found not capable of resisting or preventing ignition in foams covered by the "D" fabric..

From results obtained in this study, it appears that Class $D$ and perhaps Class $C$ upholstery fabric cover material needs flame-resistant treatment or back-coatings to prevent smoldering ignitions. Previous work has shown that heat dissipating mediums perform quite well in preventing ignitions in foam with " $D$ " fabrics. 
The usefulness of the Fabric Classification Test in the Proposed Standard for the Flammability (Cigarette Ignition Resistance) of Upholstered Furniture was clearly demonstrated in this testing program. Based on past experience, it was expected that a Class B fabric would not ignite a furniture assembly consisting of a barrier layer of foam urethane over cotton batting and that a Class $C$ fabric would ignite this same type of assembly. Test results confirmed these expectations, the Class B fabric passed all tests, and the Class C fabric failed all tests.

The various fillings and/or combinations of fillings used in the fabrication of the test urethane foam samples may provide for a positive functional purpose in regard to comfort, decor, or esthetics, but none of the foam systems tested provided superior smolder-resistant performance. In all cases where smoldering was observed, copious amounts of smoke and noxious gases were produced.

Furniture items made with any of these foam materials would, on smoldering, soon make a room or home quickly untenable and dangerous to life. 


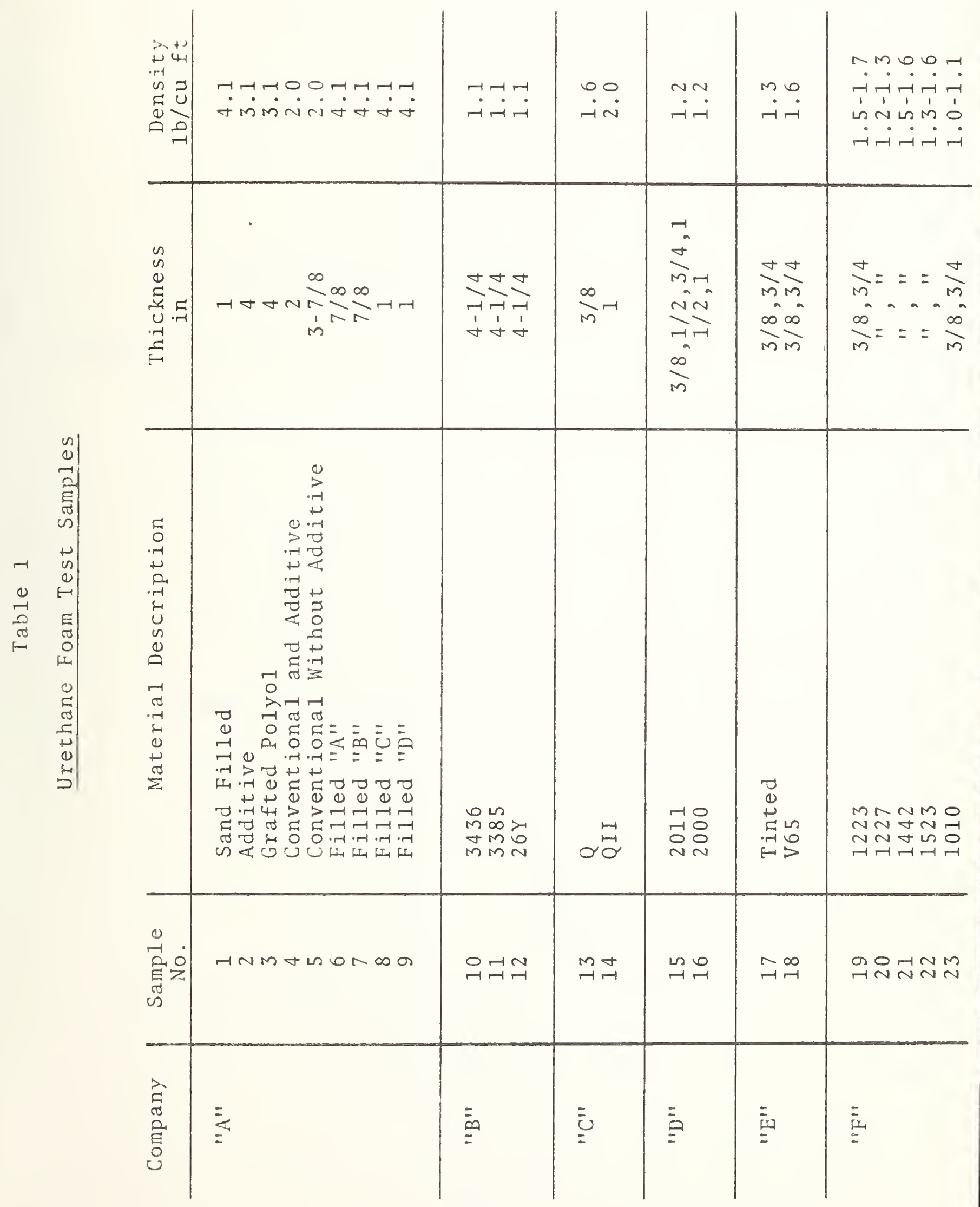


Table 2

Urethane Foam--Flaming Test Results

$\begin{array}{ll}\text { \#2 Additive } & \text { Time to Ignition } \\ 3 \text { Grafted Polyol } & 32 \text { min } \\ 4 \text { Conventional and Additive } & 24 " \\ 7 \text { Filled } & 40 " \text { " } \\ 8 \text { Filled } & 24 " \\ 9 \text { Filled } & 20 " " ~\end{array}$

Urethane Foam--No Flaming Test Results

\# 1 Sand Filled

5 Conventional W/O Fire Retardant

$6 \quad$ Filled

$10 \# 3436$

$11 \# 3385$

$1226 Y$ 


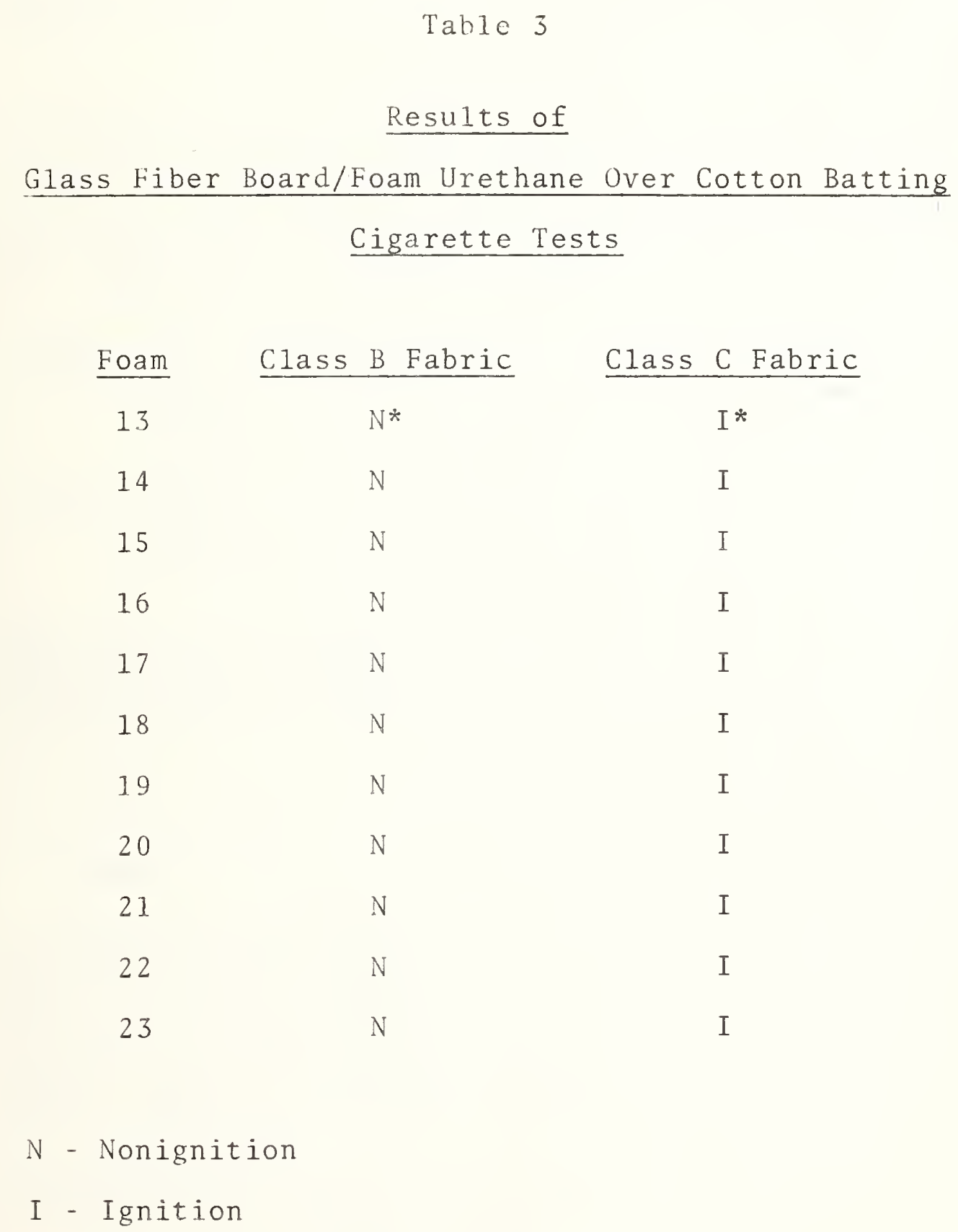



MEMORANDUM FOR: Rjchard Armstrong, Director

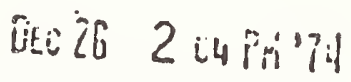

Eureau of Enginenring Scicnces?i... ?-? ?.REA!!

Consumer Product safety commisionilli: Erillij

Fron: James Winger, Program Chief

Program for Fire Prevention--prociucts

Programatic Center for Fire Research

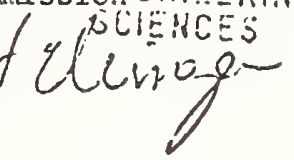

Through: Irwin Benjamin, Assoclate Director for Fire Technology Walter Leight, Acting Chief, Office of Consumer Product Safety

Dale Scott, Bureau of Ingineering Sciences, Consumer

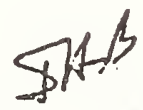

Broduct Säfety Commission

Subject: Rationale Behind Some Decisions on What to Specify in the "Proposed Standard for the Flammability of Upholstered Furniture"

This memo is to give the rationale behind some of the important declsions which were made in the reccmmended proposed standard for the Flammability of Upholstered Furniture. For convenience, each comment is identified by the paragraph number and title in the proposed standard.

\section{2. (a) Upholstered Eurniture}

\section{Exclusions}

The available accident information indicates that inflatable furnjture, dining room chairs, bar stools, etc., are seldom the first item to ignite in a fire accienent and seldom contribute to such an accident is any substantial wiy. The spacing between the upholstered seat and vertical upholetcred sides and back was chosen as a kay to differentiate betvcen furniture which is unlikely to suffer ignition: dining rcon chairs, bar stools, etc., and the furniture which the accident information indicates should be included in the standard.

Laboratory investigation show's the following reasons for excluaIng such rurniture:

a) small mass of combustible material

b) lack of crevice aress, which have been shown to be the area most susceptible to cignrette ignitjon 
2(1) Furniture Mock-up

\section{Differences in Size and Shape}

Differences in size and shape of furniture are not required to be tested because the test in the crevice formed by horizontal and vertical surfaces is usually the configuration most susceptible to ignition by clgarettes, i.e., this conflguration is the most critical.

\section{Substitution of Materials}

Substitution, without additional testing, of materials which have no effect on cigarette ignition characteristics is permitted, to reduce. the total testing burden. Some components of upholstered furnlture can be changed without affecting the clgarette ignition characteristics, the most obvious being springs and frame.

\section{3 (b) Test Criterion}

\section{Three-inch Char Length}

The intent of the criterion is to istermine whether or not sustained Ignition occurs in the test. With char 'engths of the order of 2 Inches, the test materials have been observed to ielf-extinguish. We have no evidence of self-extinguishment when the char has progressed to 3 inches.

\section{3(c) Acceptance Criterion}

\section{Zero Failures}

our investigations indicate that technology is avaliable to the industry so that furniture can be manufactured that will always pass the test. Comments from interested parties and further investigation may indicate a need to permit a very low failure level (one test location) provided a retest of the same type of mock-up passes at all locations.

\section{$.4(a)$ (1) Specimen Support}

Mock-up

A furniture design reproduced in mock-up was chosen as the 1 tem to be tested for the following reasons: 
a) Furniture is not produced on a production line basis items of the same design are not produced continuously. It is usually impossible to select a representative item of furniture from production.

b) Individual furniture items are expensive and flammability tests are destructive.

\section{4(a) (2) Ignition Source}

\section{Cigarettes}

Cigarettes are used as the source of ignition in the test because accident information (Elammable Fabrics Accident Case and Testing System) indicate that cigarettes are the ignition source in 80 percent of the upholstered furniture fire acciaents when the upholstered furniture is the first item to ignite.

\section{$4(a)(3)$ Sheeting Material}

\section{Cover the Test Cicarattes}

Covering the test cigarette makes the test more severe: i.e.. Igni. tion is more likely to occur. This is true regardless of what is used as the cover material. Essentially, the same igrition results are obtained when the cigarette is covered with newspaper, soft tissue paper, or articles of clothing. A cigarette-covering material is necessary in the test to simulate this more severe condition which probably occurs in many of the accidents. Bed-sheeting material is specified because it is readily obtained, it is cheap, and it improves the reproducibility of the test.

\section{.4 (b) (1) Qualification, General}

\section{Test Frequency}

The test frequency is based on investigation which indicates that normal purchasing and inventory maintenance in the furniture industry are such that satisfactory component uniformity cannot be assured for longer than 3 months. At the manufacturer's option and his records indicating control over his materials, the frequency may be reduced to 6 mor.ths. 


\section{4(d) Conditioning}

$552 \mathrm{RH}, 65^{\circ} \mathrm{F} .+, 48$ Hours

Our experience with products of this type (primarily with mattresses) indicates that the choice of any relative humidity below 55 percent has little effect on test results. The same can be said for temperatures above $65^{\circ} \mathrm{F}$. Conditioning at high humidity and/or low temperature can pernit items to pass an ignition test that otherwise would fail. Bulky materials such as fiber batts or foam equilibrate with room conditions quite slowly, the 48-hour conditioning time is required to give some assurance that a condition approaching equilibrium has been achieved.

\section{$.4(f)$ General Testing}

\section{Three Cigarettes}

In order to satisfy statistical requirements, a minimum of three cigarette tests is reconmended for each type of test location. Furthex study may show that a different number of tests is necessary.

\section{Different Test Locations}

In most cases, different upholstery materials are used for different areas of a furniture item. Therefore, in order to insure that the furniture item is cigarette resistant, such areas where a cigarette may come to rest must be tested.

\section{.5 General Requirements, Fabric}

\section{Fabric Test}

The fabric test is not intended to accept or reject any fabric. It is intended to group fabrics with similar cigarette ignition characteristics. The reason for a fabric test which classifies fabric Is to reduce the testing burden on industry: If a furniture manufacturer tests and passes a furniture construction with a fabric cover from a particular class, he then can manufacture that furniture construction with any fabric from the particular class without further testing.

\section{.6 (b) Qualification}

\section{Test Frequency}

cigarette ignition characteristics of fabrics are dependent on the fiber or blend, fabric construction, dye type, flrish, and coating: 
however, the Ignition characteristics normally are not sensitive to minor variations in these fabric parameters. Therefore, the ignition characteristics usually are not affected by normal prnduction variation. These fabric parameters can and do change, witi: time, to the extent that the fabric cigaretie ignition characteristics can be affected. Therefore, it is necessary to repeat the fabric classification test at some low frequency to assure that the fabric continues to be properly classified. The 12 -month frequency was chosen to satisfy this requirement.

cc8 I. Benjamin

w. Lelght

D. Scott

w. Thomas

J. Loftus

s. Greenwald 
ग) 


\section{APPENDIX K \\ MEMORANDUM ON COMMENTS ON THE BUREAU OF DOMESTIC COMMERCE'S ECONOMIC IMPACT OF THE PROPOSED STANDARD FOR UPHOLSTERED FURNITURE}

February 24, 1976

MEMORANDUM FOR Mr. Walter Lefght, Chief Office of Consumer Product Safety Center for Consumer Product Technology

From: Mr. James H. Winger, Chief

Program for Fire Prevention-Products

Fire Safety Engineering Division

Through: Dr. John W. Lyons, Director

Center for Fire Research

Mr. Irwin A. Benjamin, Chief

Fire Safety Engineering Division

Subject: Comments on the Bureau of Domestic Commerce's Econoric Impact of the Proposed Standard for Upholstered Furniture

Attached are the Center for Fire Research's comments on the Bureau of Domestic Commerce's impact report on the proposed standard for upholstered furniture. These comments were requested by Walter Thomas of the Bureau of Engineering Sciences in a letter dated February 5, 1976.

Five copies of the comments are attached.

\section{Attachments}

bcc: Dr. Lyons

Mr. Benjamin

Mr. Buchbinder

Mr. Davis

Mr. Greenwald 
Comments on the Bureau of Domestic Commerce's

Report on the Impact of the Proposed Standard for the Flammability of Upholstered Furniture

\section{Introcuction}

The purpose of this document is to provide information helpful in evaluating "Report on the Impact of the Proposed Standard for the Flammability of Upholstered Furniture," prepared by the Bureau of Domestic Commerce (BDC). The National Bureau of Standards has gained considerable background on the upholstered furniture industry and an understanding of the potential impact of the proposed standard for upholstered furniture in carrying out its responsibilities under the Flammable Fabrics Act, as delegated by the Department of Commerce prior to May 1973; and in consulting for the Consumer Product Safety Commission since that time. The comments offered below are based on this background and understanding.

Ciments are offered on the need for an upholstered furniture standard, the proposed provisions, and the means of compliance with the proposed standard. In addition, several areas in the $B D C$ estimates are identified and discussed where the proposed standard will either have a substantially decreased impact or some cases no impact at all. Cost calculations based on these revised figures are presented, which lead to a greatly reduced estimate of the economic impact of the proposed standard.

II. Need for a Standard

The CPSC has the responsibility to determine the need for a standard for the flammability of upholstered furniture and has used NBS as a consultant in this work. In addition, in pursuit of the goal to provide a technical base for reducing fire losses NBS has been studying the most common types of ignition related to injuries; and from this work, some additional background concerning the need for a standard has been developed.

Data supporting the need for a standard has previously come from two studies, the National Household Fire Survey, carried out by the Bureau $C^{-}$the Census, and the Flatmable Fabrics Accident Case and Testing System (FFACTS), developed by NBS and now maintained by CPSC. Together, these studies make three points:

${ }^{\circ}$ Upholstered furniture is the item first ignited in 106,000 fires yearly in the U.S.

'For first-to-ignite upholstered furniture cases $j$ rvestigated in depth, 54\% involved personal injuries.

The $r$ : tio of deaths to injuries in such fires is high: $43 \%$ of the injured victims died. 
NBS has interpreted these data as indicating that the control of ignition in upholstered furniture may be one of the most effective available means of reducing injury and loss due to fire in the United States.

Recently, additional evidence for the need for a standard has come to light with analysis of the Fire Incident Data Organization, maintained by the National Fire Protection Association. According to this study, upholstered furniture is the item ignited in approximately $20 \%$ of U.S. fire deaths.

For reference purposes, a brief description of the national Household Fire Survey and of FF iCTS is presented in the Appendix. A preprint of "Fire Death Scenarios and Fire Safety Planning," which discusses the FIDO study, is also included.

III. The Recommended Proposed Standard

Provisions of Standard

The accident data indicates that the primary flammability problem with upholstered furniture is ignition by cigarettes and smoldering combustion. The proposed standard includes a cigarette ignition test; and is intended to reduce, to a very low level, the quantity of new furniture manufactured which would ignite from a cigarette and continue to smolder.

The proposed standard requires that furniture constructions, be tested in mockup form prior to manufacture and at 3 or 6 month intervals thereafter, depending on materials control. Because of component interaction, e.g., cover and backup, testing the construction is required to predict the performance of the product. To minimize cost, a fabric classification test is also included in the proposed standard. This test reduces the number of mockup tests which must be performed. All fabrics must be tested and classified, generally by the fabric supplier. Mockup tests are required of the combinations of a fabric from the class to be used with each interior construction to be used in the production furniture. Differences in the shape or size of furniture do not require separate muckup testing.

\section{Means for Compliance}

From NBS research the following generalizations can be inade regarding constructions and materials:

1. Class A fabrics can usually be used over any i.tterior construction.

2. C1 :ss B fabrics can usually be used over untreated polyurethane foam, untreated polyester batting, and untreated down; and over untreated cotton batting if one of the above materials is used as a thermal barrier between the fabric and the cotton batting. Class $B$ fabrics can also be used directly over currently available treated cotton batting. 
3. Class C fabrics require better thermal sarriers than Class $B$ fabrics. Coating the fabric with a resin with a high aluminum content is effective. A needle punched nonwoven with aluminum as a barrier is effective. Class $C$ fabrics can also be used directly over currently available treated cotton batting.

4. Class D fabrics can be used over a needle punched nonwoven with aluminum as a barrier. It is difficult to design a construction using Class $D$ fabrics that gives acceptable comfort and aesthetics with the above exception.

IV. Specific Comments on the Bureau of Domestic Commerce Impact Report

The following comments are based on NBS experience with the test method and with fire retardant fabrics.

1. Fabric Upgrading $B D C$ estimated a $\$ 291 M$ cost increase to upgrade fabrics. Class A fabrics require no upgrading and Class B fabrics probably require no upgrading. If a màket shift occurs, which is likely, from Classes C and D fabrics toward Classes $A$ and $B$, actual fabric cost may decrease in conjunction with the increase in safety because fabrics that currently fall in Class $A$ and $B$ are often cheaper than current Class C and D fabrics. Chemical treatments for fabrics are normally about 40 cents/yard of fabric, maximum.

Fabric Cents/yd. Yds. in

$\frac{\text { Class }}{\mathrm{A}} \frac{\text { Cost Increase }}{0} \frac{\text { Use }}{17.5 \mathrm{M}}$

$\begin{array}{rrr}\text { B } & 0 & 87.5 \mathrm{M} \\ \mathrm{C} & 40 & 70.0 \mathrm{M} \\ \mathrm{D} & 40 & 175.0 \mathrm{M}\end{array}$

\begin{tabular}{cc}
\multicolumn{2}{c}{ Upgrading Costs } \\
NBS Estimate & BDC Estimate \\
\hline 0 & 1.4 \\
0 & 13.1 \\
28 & 79.1 \\
70 & $\frac{197.7}{9291.3 \mathrm{M}}$
\end{tabular}

2. Fabric Test Cost BDC Estimated \$278M to test fabrics. The BDC estimate is not broken down, therefore it is not possible to verify their figures. For a "ballpark" estimate, assume 50 fabric manufactures $x$ 15,000 fabric styles each $\mathrm{x} \$ 15$ per test equals $\$ 11.25 \mathrm{M}$.

3. Cotton Batting BDC Estimated $\$ 82 M$ to upgrade or find substitutes for cotton batting. Cotton batting can be treated so that the mockup test can be passed rith Classes $A, B$, and $C$ fabrics. Since a large portion of the cotton batting is used in furniture locations not subject to test, less than half the cotton would require treatment at about 20 cents $/$ pound. $80 \mathrm{M}$ 1bs. $\times 20$ cents $=\$ 16 \mathrm{M}$. 
4. Polyester Fiberfill BDC Estimated $\$ 6 M$ to upgrade polyester fiberfill. NBS tests indicate that polyester fiberfill requires no upgrading, therefore no increase in cost.

5. Welt Cord BDC Estimated $\$ 1.3 M$ to upgrade welt cord. The mattress industry has forced the welt cord manufacturers to cope with this problem. This estimate should be reduced by at least half. NBS estimate $\$ 0.6 \mathrm{M}$.

6. Polyurethane Foam BDC Estimated $\$ 127 M$ to upgrade polyurethane foam. NBS tests indicate that polyurethane foams require no u.grading, therefore no increase in cost.

It appears that BDC may have confused the California furniture flammability requirements with the NBS recommended proposed standard. Some polyurethane foams require fire retardants to meet the California requirements. In fact,.. cost increases for fire retarded foam to meet the California requirements are about $13 \%$ instead of the BDC estimate of $36 \%$.

7. Muslin BDC Estimated $\$ 3 M$ to upgrade muslin. NBS tests indicate that muslin has little effect on mockup test results and requires no upgrading, therefore no increase in cost.

8. Down BDC Estimated $\$ 50 \mathrm{~K}$ to upgrade down. NBS tests indicate that down requires no upgrading, therefore no increase in cost.

9. Mockup Testing BDC Estimated $\$ 285 \mathrm{M}$ for mockup testing. A fabric from the fabric class to be used in the production furniture must be tested with each interior construction. If the fabric and interior construction passes the mockup test, that interior construction can be combined with any fabric from the class tested in production furniture without further testing. Class D fabrics will probably all be upgraded to a higher class or replaced with higher class fabrics leaving three fabric classes to test. Eew companies would have as many as ten interior constructions. Testing is required quarterly. 3 Classes $\times 10$ int. const. $x \$ 50$ per test $\times 4$ quarters $=\$ 7000 /$ year per furniture manufacturer.

Using the BDC industry information, 12 companies make up $6.3 \%$ of the total industry volume; $12 \times 7000 \div 0.063=\$ 1.33 M$ total industry cost.

Cost Summary

The following summarizes the cost estimates based on NBS expertise. These estimates are about $12 \%$ of the BDC estimates. They assume the most expensive case, no change in fabric mix and an upgrading of the Class D fabric now being used. A product switch to the safer Class A and Class $B$ fabric would reduce the impact cost even more than the NBS estimate shown here. 
BDC Estimate

(Millions \$)

Fabric Upgrading

Fabric Testing

Cotton Batting

Polyester Fiberfill

Welt Cord

Polyurethane

Muslin

Down

Mock-up Testing

TOTAL
291.3

278.0

82.0

6.0

1.3

127.0

3.0

.05

285.0

$1,073.65$
NBS Estimate

(Millions \$)

98.0

11.25

16.0

0

0.6

0

0

0

1.33

127.18 


\section{APPENDIX}

\section{A. National Household Fire Survey}

This survey was sponsored jointly by NBS and CPSC and was conducted by the Bureau of the Census. The following outlines the findings on upholstered furniture from the survey.

- Over 33,856 households were surveyed.

- of these households, 2,463 reported having had a fire during the pre'ious twelve months. (Projected to national figures, this represents an annual total of 5.6 million fires in the United States.)

- The number of fires in which fabric items were first to ignite is estimated to be 628,000 .

- Upholstered furniture accounted for 198,000 or $31 \%$ of the first to ignite items. ( $\pm 35,000$ are the $95 \%$ coufidence limits for this estimate.)

- In 90\% (178,000) of the upholstered furniture fire incidents, cigarettes, cigars and pipes were the ignition source.

\section{Flammable Fabrics Accident Case and Testing System (FFACTS)}

FFACTS was developed by NBS in response to the DOC responsibility for determining the need for standards under the FFA and to characterize accident scenarios. The following outlines the upholstered furniture information from FFACTS.

\section{Al1 Upholstered Furniture Cases}

- Data are derived from the 3,347 fabric fire incidents currently in the data base.

- The total number of cases in which upholstered furniture was involved (not necessarily first to ignite) is 305.

- Of the 305 cases, 186 (61\%) involved personal injury.

- In 287 of the 305 cases, fatality information is available: 93 of the 287 (32\%) cases had fatalities.

\section{Ist to Ignite Upholstered Furniture Cases}

- Upholstered furniture was the first item ignited in 209 (69\%) of the 305 upholstery involved cases. 
- The ignition source is known for 198 of the 209 cases:

Cigarettes, cigars, pipes and unknown smoking materials were the ignition source in 166 of the 198 cases in which upholstery was first to ignite, that is, in $84 \%$ of the cases.

- The injury disposition of the victims in the 209 fires was:

Died

Hospitalized

Treated \& Released

First Aid

Unknown Injury

Total Injured
49

31

21

8

5

114

In 95 cases, there were no injuries.

- Fatality information was available in 199 of the 209 cases. (The final status of 10 of the hospitalized victims was unknown.) Thus there were 49 deaths out of 199 , or $25 \%$ of the cases in which it was known whether or not the victim died. This compares to about a $20 \%$ fatality rate for first to ignite sleepwear fires.

- The ratio of deaths to injuries is $49 / 114$ which equals 0.43 .

- Injuries occurred in 55\% (114 out of 209) of the cases. 
NBS.114A (REV. 7.73)

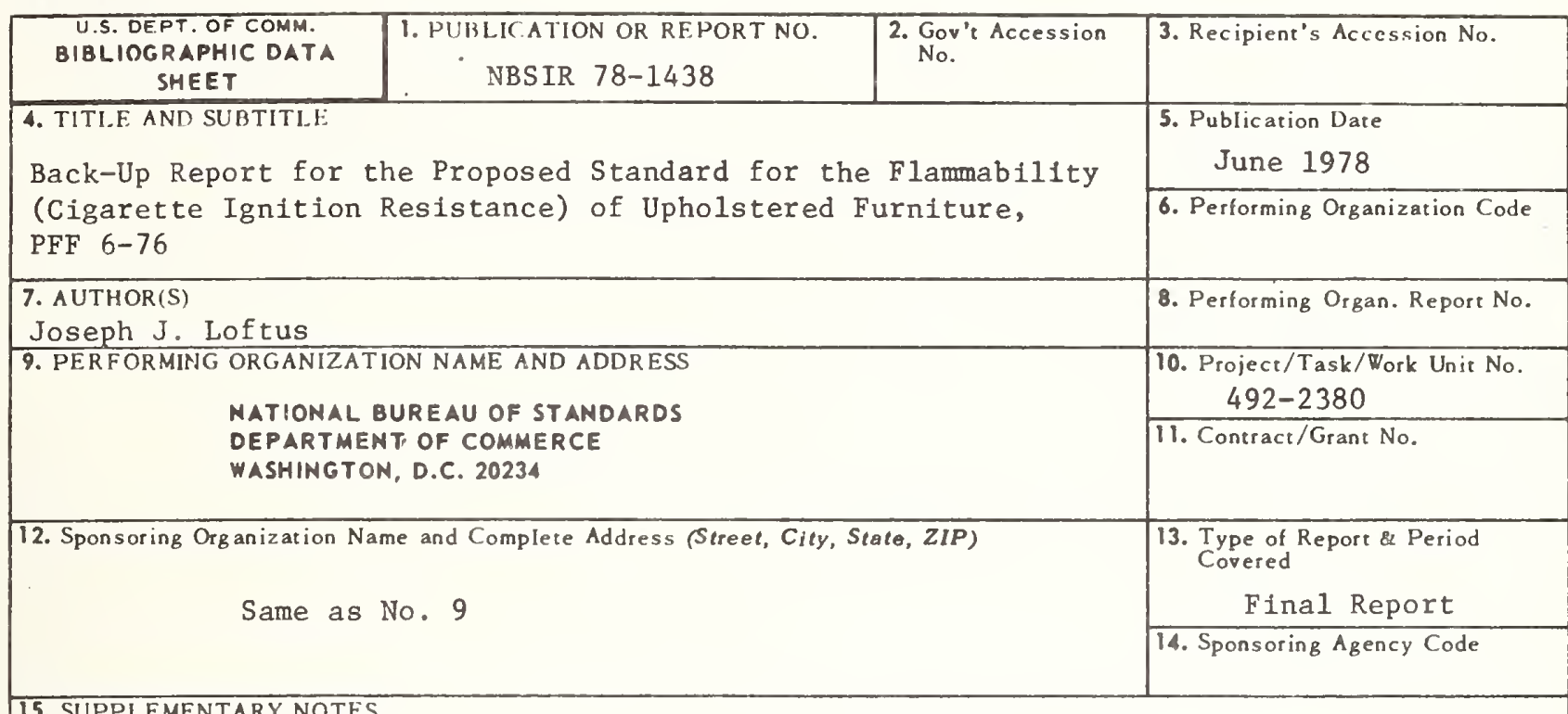

\section{SUPPLEMENTARY NOTES}

16. ABSTRACT (A 200-word or less factual summary of most significant infomation. If document includes a significant bibliography or literature survey, mention it here.)

This report brings together data, information, and reports generated by the Center for Fire Research (CFR) at the National Bureau of Standards (NBS) and by others during four years of work on the development of the test method. All of this information was used in the preparation of a recommended Proposed Standard for the Flammability (Cigarette Ignition Resistance) of Upholstered Furniture, PFF 6-76.

17. KEY WORDS (six to twelve entries; alphabetical order; capitalize only the first letter of the first key word unless a proper name; separated by semicolons) Cigarette ignition; fabric classification; mock-up furniture samples; smoldering; upholstered furniture; upholstery fabrics.

18. AVAILABILITY Unlimited

$\square$ For Official Distribution. Do Not Release to NTIS

$[$ Order From Sup. of Doc., U.S. Government Printing Office Washington, D.C. 20402, SD Cat. No.Cl3

y Order From National Technical Information Service (NTIS) Springfield, Virginia 22151

\begin{tabular}{|l|c|}
$\begin{array}{l}\text { 19. SECURITY CLASS } \\
\text { (THIS REPURT) }\end{array}$ & 21. NO. OF PAGES \\
UNCLASSIFIED & 239 \\
\hline $\begin{array}{c}\text { 20. SECURITY CLASS } \\
\text { (THIS PAGE) }\end{array}$ & 22. Price \\
UNCLASSIFIED & $\$ 9.50$ \\
\hline
\end{tabular}


t

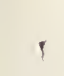

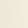


